\title{
Cutting Knowledge: The Pathologization of Self-Injury in Correctional Discourse
}

\author{
by \\ Cristine Raquel Rotenberg
}

A thesis submitted to the Faculty of Graduate and Postdoctoral Affairs in partial fulfillment of the requirements for the degree of

Master of Arts

in

Sociology

Carleton University

Ottawa, Ontario

(C) 2014

Cristine Raquel Rotenberg 


\begin{abstract}
This thesis critically examines correctional discourse on prisoner self-injury produced by the Correctional Service of Canada's (CSC) Research Branch (RB) between 1990 and 2012.

Since 2010, the RB has published over 700 pages worth of research on prisoner selfinjury. This new wave of research is identified in this thesis as a significant growth in correctional knowledge on self-injury. Self-injury in correctional environments has been a topic of much debate in recent years, where academics and governments alike have assessed the ability of the prison to adequately manage and treat self-injuring prisoners. Stepping back from these debates of the punitive versus therapeutic capabilities of the prison (Hannah-Moffat, 2001; Kendall, 1994; Kilty, 2006, 2008b), this thesis examines what knowledges on prisoner self-injury are produced in correctional discourse and how these knowledges both enable and constrain understandings of self-injury in the prisoner population.

Through a discourse analysis, this thesis identifies the discursive shifts in correctional knowledges on self-injury. Grounded in the extant clinical and correctional discourse that has historically constructed self-injury as practiced by manipulative, violent or suicidal prisoners, the new surge of research demonstrates a shift to predominately pathological explanations that aim to reduce the deviant behaviour to the manifestation of a mental illness. This domination of the 'psy-sciences' as 'intellectual technologies' (Rose, 1990, 1996b) in turn both demotes and bars sociological or otherwise non-psy understandings of self-injury. It is suggested that political accountabilities further shape the output of research. This is demonstrated in how the characterization of prisoners as pathologically inclined to self-injure lends to the CSC's displacement of responsibility for self-injury from the prison to prisoners' mental illness. I suggest that women prisoners are increasingly pathologized for their self-injurious behaviours in relation to men when the historical medicalization of women's madness (Ussher, 1991, 2011) is considered.

This thesis contributes to critical debates on whether quantitative versus qualitative methods should be problematized as contributing to the production of knowledge. It is argued that it is not the research methodology that should be problematized, but rather the ideological platform from which the discourse originates. It is suggested that regardless of methodological approach, the RB's conceptualization of prisoners who engage in selfinjury was pre-determined by their ideological alignment with the psy-sciences. The implications of the recent shift in correctional discourse with respect to the responsibilization of prisoners for their mental illness(es) are also explored.
\end{abstract}

Key words: self-injury, prison, correctional discourse, psy-sciences, knowledge, pathologization, mental illness, responsibilization 


\section{Acknowledgements}

The completion of this thesis would have not been possible without the support and patience of a few individuals.

I would like to thank my supervisor, Dr. Aaron Doyle, for supporting me throughout this research process. I thank you for encouraging me to enroll in a graduate program in the first place, as without this push I'm not sure I would have thought I was capable. Eventually I rid myself of what you term 'imposter syndrome' and was able to pull through with confidence. Thank you immensely for all your time and patience.

Thank you to Dr. Jennifer Kilty for taking the time to not only carefully examine my thesis drafts but also for the time you invested in me throughout the journey to this point. You have always been so engaged in and passionate about a number of topics we share a mutual interest in. Your enthusiasm to see me move forward and grow as a critical thinker played a big part in me achieving this academic (and personal) accomplishment.

To Dr. Evelyn Maeder, I thank you for giving this thesis a good third read, but more importantly, I am grateful for how you have helped me grow over the years. It is because of you that I have a better-rounded view of 'psy': your relentless reminders that I specify what branch of psy I am targeting have undoubtedly made this thesis stronger.

Benjamin, you have seen me through this challenging time and never ceased to offer your support, be it listening to me ramble on about feminism (sorry), accepting my hours at a time of emotional absence while I was ravenously typing away, or even proof-reading most of my chapters. You have challenged me to be a more critical thinker, and even though neither of us enjoys being 'wrong', I believe our debates have served us both well and inevitably improved my understanding of critical theory.

I thank my colleagues from work (you know who you are) for reasons outside of the traditional co-worker exchange dynamic. Our conversations about how it works on the inside are invaluable to me, and I truly do appreciate your frank and honest accounts of the current state of corrections, its history, faults, as well as benefits. It is because of you that I am better informed to undertake such research. You have opened up my eyes to how not everything is as horrid as it is made out to be and how the reality is truly quite complicated and challenging. This has undoubtedly enhanced my integrity and credibility to write critically about something that I have experienced to a degree on both ends.

Thank you to Jenny, although you did not per se help me write this thesis (and will likely never read this), you have always been a great sister, and I appreciate you for that. Sometimes life gets in the way, but in the end we both know we will always have our sister to call.

Finally, I am grateful for the support of the Social Sciences and Humanities Research Council in awarding me with a Joseph-Armand Bombardier Canada Graduate Scholarship. 
I am covered in skin

No one gets to come in

Pull me out from inside

I am folded and unfolded and unfolding

- Colorblind, Counting Crows 


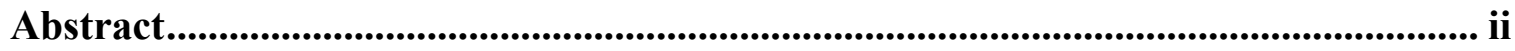

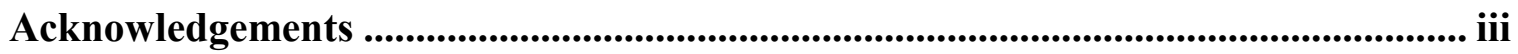

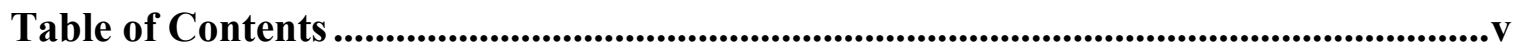

List of Acronyms ...................................................................................................... vii

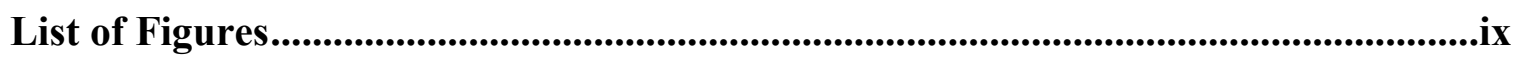

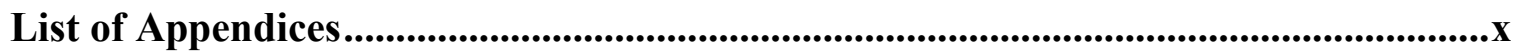

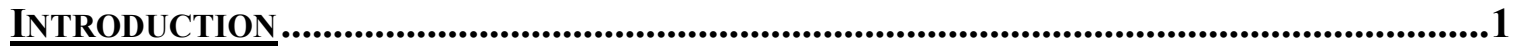

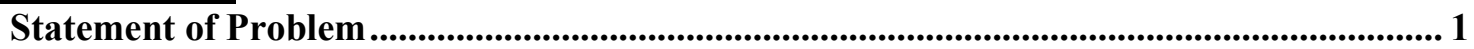

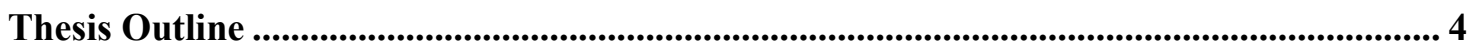

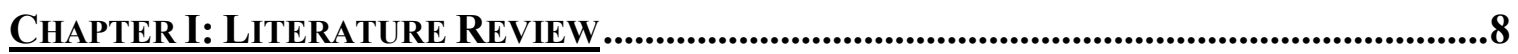

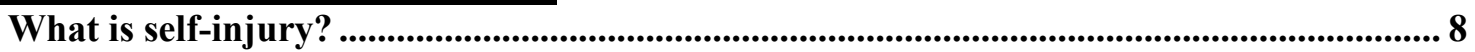

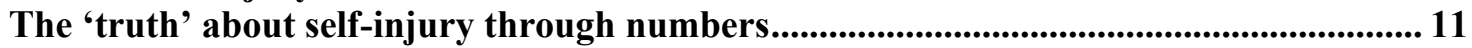

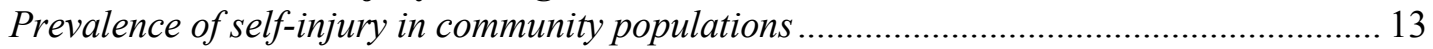

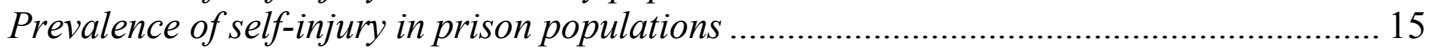

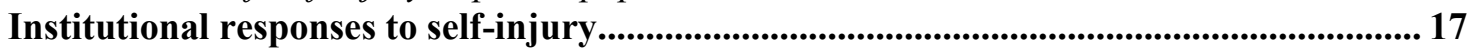

Reporting on self-injury in Canadian federal prisons................................................................ 19

A short history of the shifts in clinical discourse on self-injury .......................................... 23

Shifts in correctional discourse on self-injury................................................................................. 27

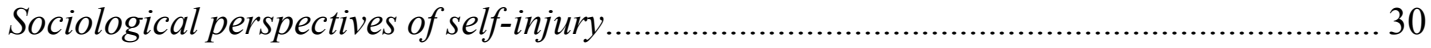

The prison as a contributing factor to self-injury .................................................................. 31

Towards a theoretical framework ................................................................................................... 32

CHAPTER II: THEORETICAL FRAMEWORK ….............................................................334

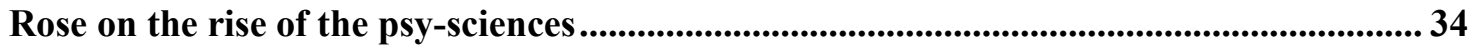

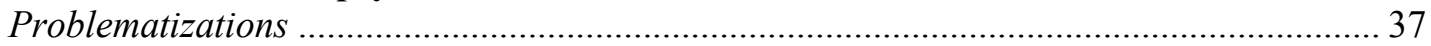

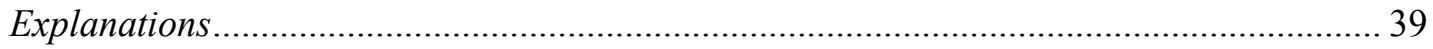

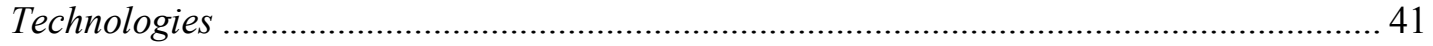

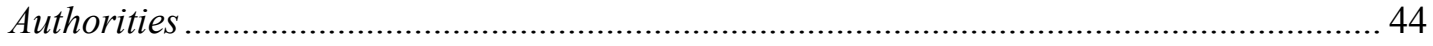

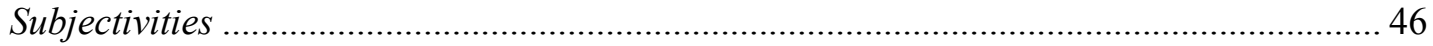

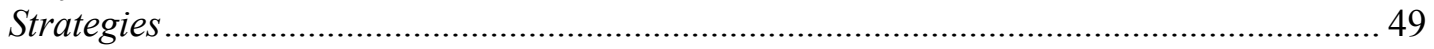

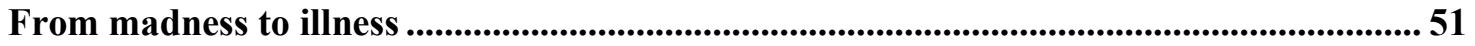

Taming women's madness: The intersection of gender and psy ......................................52

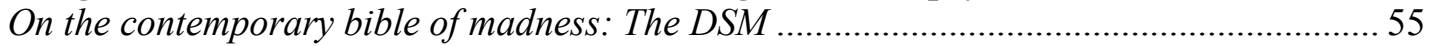

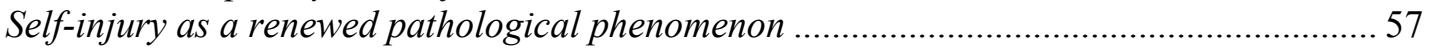

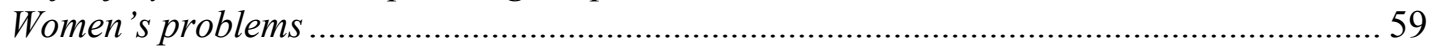

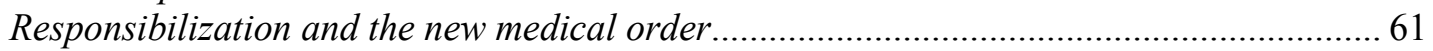

Psychologization in and of penality .................................................................................................6 63

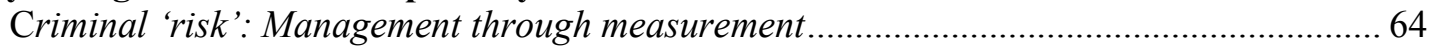

The criminalized woman: The intersection of penality and gender....................................6 68

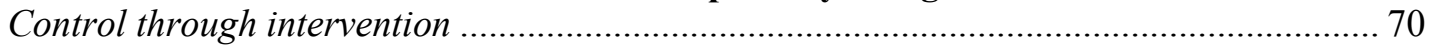

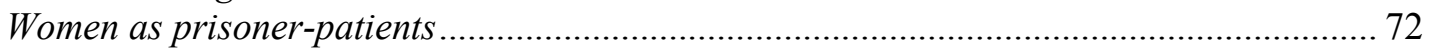


CHAPTER III: METHODS......................................................................................................74

Defining 'correctional discourse' ................................................................................................ 74

Towards a research object .................................................................................................................. 77

The 'Research Branch': A correctional laboratory ……………………………………..... 78

Research Questions ............................................................................................................... 82

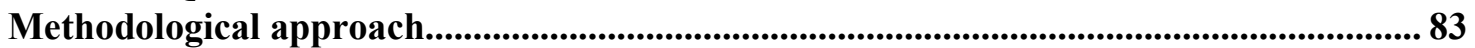

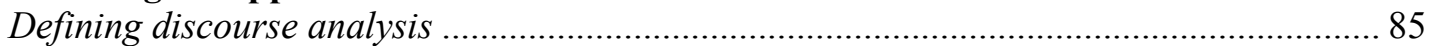

Variations and limitations of discourse analysis .............................................................. 93

Empirical Framework ...............................................................................................94

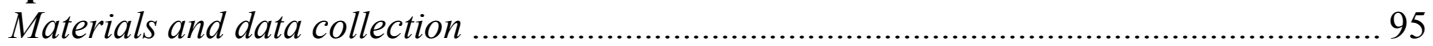

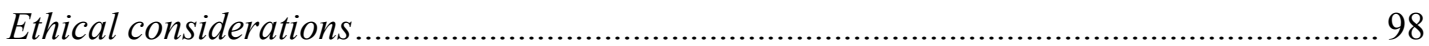

Contribution to the literature, claims to originality and validity ......................................... 99

CHAPTER IV: RESULTS ...................................................................................................101

Report no. 1: "Report on Self-Injurious Behaviour in the Kingston Prison for Women" (1990)...... 102 Report no. 2: "Women Offenders who Engage in Self-harm: A Comparative Investigation" (2002) 108

Cluster no. 1: Research undertaken to determine what is currently known about self-injury

(i.e., best practices) in the literature (post-2010). 114

Cluster no. 2: Research intended to improve understandings for why men prisoners engage in self-injury and/or the characteristics of men who self-injure (post-2010) 123 Cluster no. 3: Research intended to improve understandings for why women prisoners engage in self-injury and/or the characteristics of women who self-injure (post-2010) ..... 133 Cluster no. 4: Research intended to improve understandings for why prisoners engage in self-injury generally and/or the characteristics of prisoners who self-injure (post-2010) .. 146

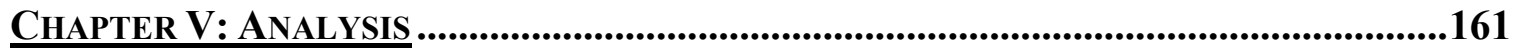

Significance ................................................................................................................................. 161

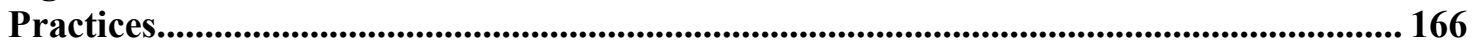

Identities ......................................................................................................................... 172

Politics................................................................................................................................... 176

Relationships ............................................................................................................................ 181

Connections............................................................................................................................ 185

Language type and sign systems................................................................................................. 186

ChAPTER VI: CONCLUSION ...............................................................................188

Prioritizing psy: The domination of psy-knowledges .............................................................. 189

Responsibilizing irresponsibility .................................................................................. 192

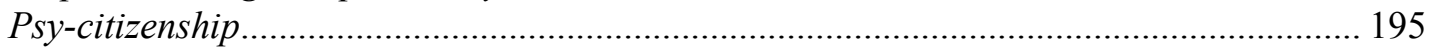

On the production of knowledge: The problem with internally commissioned research .. 197

Barred from the brigade: The demotion of sociological knowledges................................... 198

Quantitative versus qualitative: Is it really all in the methods? .............................................. 203

Tracing the wave................................................................................................................. 208

Final cuts and concluding thoughts ..................................................................................... 210

References.......................................................................................................................215

Appendix A ..........................................................................................................271

Appendix B ........................................................................................................................273 


\section{List of Acronyms}

$\begin{array}{ll}\text { APA } & \text { American Psychiatric Association } \\ \text { ATIP } & \text { Access to Information and Privacy } \\ \text { BPAQ-SF } & \text { Short Form Buss-Perry Aggression Questionnaire } \\ \text { BSI } & \text { Brief Symptom Inventory } \\ \text { CAEFS } & \text { Canadian Association of Elizabeth Fry Societies } \\ \text { CCRA } & \text { Corrections and Conditional Release Act } \\ \text { CD } & \text { Commissioner's Directive } \\ \text { CMHI } & \text { Community Mental Health Initiative } \\ \text { CoMHISS } & \text { Computerized Mental Health Intake Screening System } \\ \text { COPE } & \text { Brief Coping Orientation for Problem Experiences } \\ \text { CRS } & \text { Custody Rating Scale } \\ \text { CSC } & \text { Correctional Service of Canada } \\ \text { CTQ } & \text { Childhood Trauma Questionnaire } \\ \text { CX } & \text { Correctional Officer } \\ \text { DBT } & \text { Dialectical Behavioural Therapy } \\ \text { DFIA } & \text { Dynamic Factor Identification and Analysis } \\ \text { DHS } & \text { Depression, Hopelessness and Suicide screening form } \\ \text { DSM-III } & \text { Diagnostic and Statistical Manual of mental disorders, } 3^{\text {rd }} \text { edition } \\ \text { DSM-IV-TR } & \text { Diagnostic and Statistical Manual of mental disorders, } 4^{\text {th }} \text { edition } \\ \text { DSM-V } & \text { Text Revision } \\ \text { IMHI } & \text { Diagnostic and Statistical Manual of mental disorders, } 5^{\text {th }} \text { edition } \\ \text { NHQ } & \text { Institutional Mental Health Initiative } \\ \text { NSSI } & \text { National Headquarters } \\ \text { OCI } & \text { Non-Suicidal Self-Injury } \\ \text { OMS } & \text { Office of the Correctional Investigator } \\ \text { OSIBI } & \text { Offender Management System } \\ \text { P4W } & \text { Offender Self-Injurious Behaviour Inventory } \\ \text { PBC } & \text { Prison for Women (Kingston) } \\ \text { PMDD } & \text { Parole Board of Canada } \\ \text { PMS } & \text { Premenstrual Dysphoric Disorder } \\ \text { Premenstrual Syndrome } \\ \text { DS }\end{array}$




$\begin{array}{ll}\text { RB } & \text { Research Branch } \\ \text { RPC } & \text { Regional Psychiatric Centre } \\ \text { RPD } & \text { Reintegration Programs Division } \\ \text { RSPMC } & \text { Regional Suicide/Self-Injury Prevention Management Committee(s) } \\ \text { RTC } & \text { Regional Treatment Centre } \\ \text { SCID I/II } & \text { Structured Clinical Interview for DSM disorders (Axis I and Axis II) } \\ \text { SIB } & \text { Self-Injurious Behaviour } \\ \text { SIR-R1 } & \text { Statistical Information on Recidivism - Revised 1 } \\ \text { SITREP } & \text { Situation Report } \\ \text { UQO } & \text { University of Quebec en Outaouais }\end{array}$




\section{List of Figures}

Figure 1. Number of major research reports on self-injury published by the CSC ..........97

Figure 2. Diagram depicting the RB's production of knowledge .................................207 


\section{List of Appendices}

Appendix A: Email exchange: status of textual material as public knowledge..............271

Appendix B: Comprehensive roll-up of textual material...........................................273 


\section{$\underline{\text { INTRODUCTION }}$}

... knowledge is not made for understanding; it is made for cutting. (Foucault, 1984a, p. 88)

I'm Maggy and I started to cut my body 5 years ago. I go to casualty and get hauled onto the psychiatric bandwagon. I am then given a nice little 'label'. The current label is Schizophrenia. That's how the professionals see me. I'm a self-destructive Schizophrenic. But how do I see myself? (Pembroke, 1994, p. 13)

Like tears from our eyes, the body can cry blood (McLane, 1996). Why an individual would deliberately tear his or her own flesh or break his or her bones may always be somewhat of a mystery to others. The act of harming ourselves is in contradiction to everything we are told (by some) about our nature; that is, that we are filled with the innate desire to survive (Adler, 1927; Hobbes, 1651 as cited in Martinich \& Battiste, 2011). Not only does self-injury challenge this idea of self-survival, it evokes confusion, discomfort and intense anxiety in those who bear witness (Adler \& Adler, 2005; Law, Rostill-Brookes, \& Goodman, 2009). If the thought of someone handling a steel industrial razor (the kind made for reloadable exacto knives) and proceeding to cut the soft warm flesh that lines his or her inner arm until the blood pools in circles on the cold bathroom tiles makes you cringe in discomfort, you are not alone.

\section{Statement of Problem}

In 2013, the Office of the Correctional Investigator (OCI), the ombudsman for federal prisoners in Canada, reported that the number of self-injurious incidents in federal penitentiaries had more than tripled over the last five years (OCI, 2013c). Statistics of this

sort caused somewhat of an uprising in the news (e.g., CBC News, 2013; Harris, 2012, 
2013; Kilty, 2013), where media discourse in addition to correctional discourse ${ }^{1}$ and critical criminological discourse considered the issues correctional management faces with prisoners who engage in self-injury. This recent attention has for the most part arrived further to the political aftermath of the self-inflicted death of prisoner and teenager Ashley Smith at Grand Valley Institution for Women in 2007. Ashley is reported to have endured a considerable amount of suffering while in prison, including being subjected to forced psychotropic injections and permanent segregation status in response to her self-injurious behaviours for the better part of a two year period (see LeBlanc, 2012; LeBlanc \& Kilty, 2012; OCI, 2008a). The inquest ruled her death a homicide in late 2013, and while no criminal responsibility was laid on the Correctional Service of Canada (CSC), Smith's family is expected to pursue criminal charges against senior executive CSC staff independently of the inquest (Kaszor, 2013; Mulholland, 2013). Since Ashley's death, the CSC has been under fire for the 'inhumane' practices they use in managing self-injuring prisoners (see OCI, 2010a, 2011, 2012a, 2013a, 2013b, 2013c; Zinger, 2012a). While the question of correctional responses to prisoner self-injury (including segregation, physical restraints, and/or forced psychotropic injections) is an important one, this thesis does not attempt to discern the most effective or ineffective management practices to handle self-injury, nor does it examine the (mis)treatment of Ashley Smith². Rather, this thesis takes a step back from the

\footnotetext{
1 'Correctional discourse' is defined as texts and communicable messages that are mostly produced by official governing bodies that participate in the administration of corrections and/or the management of the prison. This excludes critical criminological/sociological scholarship. See chapter III (methodology) for a full definition (p. 74).

${ }^{2}$ Ashley Smith's case has been the object of analysis for a growing number of research papers, projects, forums, and notably graduate level theses (e.g., Campbell, 2012; Coyle, 2013; Ferrari, 2011; LeBlanc, 2012; LeBlanc \& Kilty, 2012; Ring, 2013; Wasserman, 2013), and as such critical accounts of her narrative have reached a saturation point in academia.
} 
discussions that are currently taking place in the media, academia, and correctional discourse $^{3}$ in order to explore the production of knowledge on self-injury in correctional discourse.

A few years after Ashley's death, the CSC's internal Research Branch (RB) published twelve lengthy research reports on prisoner self-injury by both men and women. Prior to 2010, the CSC had only published two research reports on self-injury (1990 and 2002 respectively). This thesis embarks on a critical discourse analysis to examine this new wave of correctional texts that attempts to understand prisoner selfinjury. This thesis is critical in the sense that the methodology accounts for the shifts and surges in discourse and questions their political underpinnings, and theoretical insofar as epistemological tools are utilized to challenge the proposed correctional understandings of self-injury.

When large politically charged organizations, such as the CSC, publish information about the subjectivities of prisoners, this knowledge is absorbed by the public and external stakeholders in lieu of any (public and transcendent) voices that echo to the contrary. One key component that enables the CSC to discursively embed such knowledges is its relationship with and adherence to the principles of psychological knowledges (to be understood as the 'psy-sciences'). That is, knowledges about human (ab)normality and pathology in broader society and how they are applied in correctional discourse in order to attribute prisoner (mis)behaviour to mental illness. This thesis interrogates the psy-knowledges both absorbed and produced by correctional discourse

\footnotetext{
${ }^{3}$ One needs to look no further than typing 'self-injury' and 'prison' into an Internet or academic article search engine to find recent debates about the (mis)treatment and (mis)management of self-injuring prisoners (e.g., Bersot \& Arrigo, 2010; Desjardins, 2013; Lanes, 2009b; OCI, 2013a, 2013b; Perkel, 2013a).
} 
on prisoner self-injury and examines the process by which knowledge is cut (defined at the outset by an ideological platform), carved (shaped by political and methodological filters), and consequently produced, insofar as it participates in the construction of human (prisoner) subjectivities.

This thesis resonates with Jennifer M. Kilty's $(2006,2008 b)$ commentary on the mistreatment and institutional misclassification of women prisoners who engage in selfinjury insofar as self-injury is problematically understood by correctional discourse as a risk to the security of the institution. However, I deviate from Kilty's findings as I suggest that discourse published since 2010 has evidenced a new underlying theme, where previous salient understandings of prisoner self-injury as a 'security risk' have been replaced with its interpretation as evidence of 'mental disorder'. This is not to suggest that self-injury amongst prisoners is no longer considered a security risk in correctional discourse; indeed, this principle remains. Nonetheless, the previously dominating languages of 'risk', 'security' and/or 'threat' have been softened in recent texts produced by the CSC, and in their place has grown a new dominant theme, this time on how self-injurious behaviour is explained as the byproduct of mental illness.

\section{Thesis Outline}

In chapter I, I provide a background on the dominant understandings of selfinjury. I discuss how self-injury is called by different names, how it is counted and quantified in different ways, and how it is measured and assessed in different populations. I present these 'truths' about self-injury as understood by the discourses that have adopted self-injury as a popular object of inquiry, namely clinical and 
forensic/correctional discourses. To do so, I review terminology used in the literature and discuss estimates of prevalence rates in community populations as reported in clinical research as well as in the prison population. I highlight debates on how self-injury is reported within corrections in order to expose some of the issues of data integrity that exist in this kind of reporting, as often quantitatively legitimized figures are taken for granted. A summary of the current institutional responses to self-injury in Canada is then presented. Next I provide readers with a brief history of the shifts that have taken place in clinical psychological discourse on self-injury in order to ground the transformations that have equally taken place in correctional discourse. Critical criminological contributions to the literature on the prison as a contributor to self-injury are also discussed.

Chapter II reviews the theoretical frameworks that guide this thesis through to its critical analysis. I begin with a discussion of Nikolas Rose's (1990, 1996b) accounts of the 'psy-sciences' and provide an overview of six theoretical tools that Rose uses to understand and problematize psy-knowledges. Next, a section on gender unfolds, in which I rely on Jane Ussher's (1991, 2011) conceptualizations of the psy-sciences and how they interact with gender. Ussher's critiques of psy-knowledges serve to relay a critical feminist reading of the historical medicalization of women's madness. I engage in a critical discussion of the Diagnostic and Statistical Manual of Mental Disorders (DSMV, formerly DSM-IV-TR) and consider how self-injury has found a new home within this 'psy bible' (Kutchins \& Kirk, 1997). A discussion on responsibilization ensues, where I explain how psy-knowledges contribute to the medicalization of (women's) feelings and behaviours. Finally, I present a critical discussion of the blurring of the psy-sciences and the correctional system as a segue to a discussion of the prison and knowledges in and of 
penality. 'Risk-logic', 'control through intervention', and 'women as prisoner-patients' are critically assessed as concepts that are inherently linked to dominating psychological ideologies. How gender amplifies the effect of certain penal practices is discussed.

My methodological approach is presented in chapter III, preceded by a history of the creation and roles of the RB as a department within the CSC in order to pave the way to my research object. Research questions are presented and the key components of a discourse analysis are defined and given an overview in accordance with James Paul Gee's (2011a, 2011b) frameworks for doing discourse analysis. I present my empirical framework, consider some ethical obstacles, and explain how this thesis contributes to the critical literature on self-injury in correctional discourse.

Results are presented in chapter IV, where the textual material of the discourse analysis is organized first in chronological order and then in 'clusters' of research texts by theme. Under each results theme I organize my deconstruction of the texts in accordance with Gee's (2011a, 2011b) seven building blocks of discourse analysis: significance, practices, identities, politics, relationships, connections, and language type and sign systems.

A critical analysis of the data is undertaken in chapter $\mathrm{V}$, which builds on the results chapter insofar as I tie in links to key theoretical frameworks including Rose (1990, 1996b) and Ussher's (1991, 2011) conceptualizations of the psy-sciences. I also use this chapter to identify any shifts in discourse that have taken place in the textual material over time. Results of the discourse analysis are linked to concepts and processes that are evidenced elsewhere within the CSC to invite a critical discussion on how 
political filters such as inter-departmental relationships and bureaucratic accountabilities shape the output of research.

In chapter VI, I broaden the scope of my analysis and discuss in a more general sense how the psy-sciences have proliferated mainstream thought. I touch again on responsibilization discourse in the prison and amongst those diagnosed with 'mental illnesses' in order to hash out the complexities of the modernized 'mental health awareness' doctrines and what this implies for prisoners who self-injure or who are diagnosed as 'mentally ill'. I consider what is problematic about the production of internally commissioned research and of knowledges tailored to fit the needs of governing bodies. I conclude by offering a debate on qualitative versus quantitative methods and consider how, despite much of what critical scholarship suggests, positivist methods are not the lone culprits in the production and dissemination of dominating knowledges; rather, I argue that it is the ideological platform from which this body of research originates that should be problematized. 


\section{CHAPTER I: LITERATURE REVIEW}

\section{What is self-injury?}

Self-injury is frequently misunderstood, in part because of the tendency in clinical psychological bodies of literature to use the term interchangeably with other terminology that describes similar but very different behaviours. These include: 'parasuicide', 'wristcutting', '(deliberate) self-harm', 'non-suicidal self-injury' ('NSSI') ${ }^{4}$, 'self-injurious behaviours', 'simulated suicide', and 'self-mutilation'. Some terminology overlaps; for example, 'parasuicide' was historically used to describe acts that resulted from failed suicide attempts, a definition that means that it is easily mistaken for simulated suicide and other broader terms like self-harm. The conflation of suicidal behaviours (i.e., harm with the end goal of self-imposed death, even if no death occurred) with non-suicidal behaviours (i.e., harm with no intent to die) has also been a problematic hurdle throughout clinical literature that seeks to explain the behaviour (e.g., De Leo, Burgis, Bertolote, Kerkhof, \& Bille-Brahe, 2006; Nock, 2010; for critical accounts of, see Chandler, Myers, \& Platt, 2011).

Throughout the early to mid-1900s, psychiatrists and psychologists problematized suicidal behaviours, first with the belief that any suicidal behaviours ought to be explained by impulse-control or behavioural disorders (e.g., Dabrowski, 1937; Keniston, 1913), and later by considering the deliberate harming of one's own body as an indicator of the intent to die (e.g., Menninger, 1935, 1938; Wilson, 1942). Eventually, a distinction between suicide and self-injury was established, and terms like 'wrist-cutting syndrome'

\footnotetext{
${ }^{4}$ Non-Suicidal Self-Injury (NSSI) is the term that the CSC has predominately adopted in the last decade or so to differentiate between self-injury with suicidal tendencies and self-injury without suicidal intent. It is inferred that this terminology is based on the American Psychiatric Association's (APA) decision to begin characterizing the behaviour as 'NSSI' (see APA, 2010, 2013a).
} 
surfaced to describe a behaviour that, at the time, was considered to be predominately practiced by women as a form of maladaptive ritualistic behaviour (Rosen \& Thomas, 1984; Rosenthal, Rinzler, Wallsh, \& Klauser, 1972). Although it is not clear who coined the term, 'self-mutilation' was used towards the end of the twentieth century to describe the deliberate destruction of one's own body tissue (Ross \& McKay, 1979; Ross, McKay, Palmer, \& Kenny, 1978). In the early 1990s, 'self-mutilation' became a widely popular area of study. Psychiatrist Arthur Favazza notably contributed a great deal to the literature; clinical and psychiatric bodies of literature cite his works to this day. Favazza (1998) described self-mutilation as the "deliberate, direct destruction or alteration of body tissue without conscious suicidal intent" (p. 260). Critical scholarship has brought to light that 'self-mutilation' stems from the Latin word 'mutilis', suggesting that the term implies "to maim, cut off a limb, create a dysfunction or to make imperfect through excision" (Pitts, 1999, p. 293). Thus Pitts $(1998,1999)$ argues that using the term selfmutilation suggests that the behaviour is an impulsive and irrational act (as would be evidenced by works such as Favazza, 1992; Favazza \& Conterio, 1988, 1989; Suyemoto, 1998; Walsh \& Rosen, 1988). Indeed, using this kind of terminology to represent a subjective behaviour (insofar as there are diverse reasons why individuals engage in it) can be misleading (Adler \& Adler, 2005; Kilty, 2008b); thus 'self-mutilation' eventually dropped out of the literature as the most prevalent descriptor at some point in the late 1990s.

'Self-harm' eventually replaced 'self-mutilation'; however, it too presented its own descriptive challenges. Self-harm is typically understood as an umbrella term for self-destructive behaviours that are not socially sanctioned, such as substance abuse, 
disordered eating, engaging in risky (sexual) behaviour, or deliberate harm to one's own body (Fillmore \& Dell, 2000; Kilty, 2008b). Adorning the body with ink tattoos or piercings - although by definition the deliberate destruction or perforation of the skin - is not considered self-harm, given that these forms of behaviour are generally socially acceptable (instead they are referred to as body modification practices). Scarification is a relatively new body modification practice that emerged out of a long history of use in primitive cultures (Farber, 2002), which involves the cutting or slicing of surface skin to leave behind an aesthetic image or message in the form of a permanent scar. Scarification and body branding without the use of tattoo ink were at one point socially problematized (Featherstone, 1999), but recently have more or less moved into the mainstream and are considered by some subcultures as socially acceptable forms of body modification alongside tattooing (Straker, 2006). Thus the main difference between acts of self-harm (like disordered eating or drug abuse) and socially sanctioned practices of body modification (like tattooing or scarification) is that self-harm is often an unplanned (re)action not done primarily for artistically aesthetic purposes, whereas body modification involves planning and preparation (such as ensuring availability of equipment and taking sterilization measures, mapping out a plan of the modification, etc.), and is primarily carried out for aesthetic purposes.

Unlike self-harm, 'self-injury' limits the scope to behaviours that are directly and physically injurious to the body's exterior. Self-injury cannot be defined in the same manner as body modification as having a principal purpose given that there are diverse reasons why people engage in self-injury, most which cannot be explained in one simple sentence. The most widely accepted definition of self-injury is as follows: 
The deliberate, self-inflicted destruction of body tissue resulting in immediate damage, without suicidal intent and for purposes not socially sanctioned. As such, this behaviour is distinguished from: suicidal behaviours involving an intent to die, drug overdoses, and other forms of self-injurious behaviours, including culturally-sanctioned behaviours performed for display or aesthetic purposes; repetitive, stereotypical forms found among individuals with developmental disorders and cognitive disabilities, and severe forms (e.g., self-immolation and auto-castration) found among individuals with psychosis.

(International Society for the Study of Self-Injury, 2007, n.p.)

In other words, 'self-injury' is typically considered to describe behaviours like cutting the skin, scratching, burning, picking open existing wounds, or banging one's body parts (Claes \& Vandereycken, 2007). Tying ligatures around one's body parts is also recognized as self-injury, though it is not often explored in clinical literature on community populations; rather, it is most often found in research that concerns forensic populations given the availability of fabrics to create ligatures and the unavailability of sharp objects (e.g., Borrill, Snow, Medlicott, Teers, \& Paton, 2005; Power, 2011; Smith \& Kaminski, 2011).

\section{The 'truth' about self-injury through numbers}

The use of statistics and numerical values is generally understood as having shaped the character and classification of social facts. One early and fitting example of this is Durkheim's (1897) use of suicide statistics to draw conclusions about the suicide rate as if they encapsulated the truth and scope of suicide in society (see Pickering \& Walford, 2000). The nineteenth century saw quantitative and probabilistic modes of thought emerge as legitimate ways of understanding the social (Hacking, 1990, 1991). Statistics became increasingly attractive in public life as they were able provide an air of scientific objectivity (Porter, 1995), and thus began to play a key role in governing 
insofar that statistics determine both who holds power and which social facts are made calculable for the purpose of governing (Rose, 1991, 1999). Aside from the dearth of sociological literature exploring the application of statistics in governing, Rose (1991, 1999) discusses how numbers "map the boundaries and the internal characteristics of the spaces of population" $(1999$, p. 197) insofar that they render human qualities calculable and operable where statistics contribute to the formulation and justification for intervention. I propose that with respect to self-injury, determining its prevalence, incidence, or otherwise numerical qualities in a given population (e.g., the community, adolescents, clinical patients said to possess a mental disorder, criminal populations) has two goals: 1) to assess the extent of the behaviour on behalf of the researchers in order to inform whether intervention is necessary, and if so, the most effective ways to intervene; and 2) to provide both researchers and the general population with 'hard facts' on what proportion of a given population engages in self-injury, the most frequent chosen methods of self-injury, the most common reasons why people do it, and so on.

Statistics on self-injury, or more broadly, mental disorder, provide a sense of quantitative legitimacy that generally appears to satisfy both researchers and the public with what they interpret as a meaningful assessment of the scope of a given behaviour. Identifying prevalence of mental illness contributes to the current 'culture of diagnosis' insofar that counting and marking bodies with labels of mental disorder and abnormality cater to a social market that thrives on the excess of explanation (Robertson \& Walter, 2013). In the interest of providing readers with a background in what clinical and forensic psychology research has to report about the scope of self-injury, I present prevalence rates as per this discourse. I do not suggest that statistical renderings of self-injury are 
unhelpful or not useful; indeed social science depends as much on systematic, numerical social observation as it does theoretical analysis (Curtis, 2001), and so statistical accounts of self-injury are important in informing and transforming knowledge about self-injury in productive ways. Nevertheless, it is important to be cognizant of how easily we may become lost in the quantitative 'truths' of numerical values. Statistics are a product of the positivist and quantitative paradigm and can be both shining and blinding. By this I mean that 'hard facts' communicated through quantitative languages are generally alluring and desired by most for their accessible presentation and ease of digestibility of social facts and phenomena, yet they can blind us to a myriad of life experiences, contextual considerations, and even methodological caveats. An exploration of the current 'culture of diagnosis' is introduced in the theoretical framework chapter, and a discussion of quantitative methodologies and positivist modes of thought takes place throughout the analysis and conclusion sections of this thesis. For now, the different 'truths' about the prevalence of self-injury in psychological discourses are presented.

\section{Prevalence of self-injury in community populations}

As reported in clinical psychological discourse, the best estimate of the prevalence of self-injury in the general population sits at around 4\% (Briere \& Gil, 1998; Klonsky, Oltmanns, \& Turkheimer, 2003; Ryan, Heath, Fischer, \& Young, 2008), although this proportion is said to be steadily increasing (Miller, 2008). Self-injury is said to occur at increased rates in adolescent populations, where between $8.1 \%$ and $13.2 \%$ prevalence rates have been reported internationally (De Leo \& Heller, 2004; Fekete, Voros, \& Osvath, 2004; Groholt, Ekeberg, Wichstrom, \& Haldorsen, 2000; Hawton, 
Rodham, Evans, \& Weatherall, 2002), and between 11\% and 38\% reported in North American research that studied high school populations and university student samples (Favazza, DeRosear, \& Conterio, 1989; Goldstien, Flett, Wekerle, \& Wall, 2009; Gratz, 2001; Heath, Toste, Nedecheva, \& Charlebois, 2008; Laye-Gindhu \& Schonert-Reichl, 2005; Nixon, Cloutier, \& Jansson, 2008; Ross \& Heath, 2002; Whitlock, Eckenrode, \& Silverman, 2006). Self-injury is reportedly most prevalent in clinical populations who are under psychiatric care or who are otherwise hospitalized for mental instability, where the prevalence is reported to range from $30 \%$ in mental health patients to $80 \%$ in patients with 'borderline personality disorder' (Gratz \& Gunderson, 2006).

When it comes to gender, clinical research is divided. A considerable number of studies have reported higher percentages of women engaging in self-injury than men (Brakoulias, Ryan, \& Byth, 2006; De Leo \& Heller, 2004; Hawton et al., 2003; Hawton, Fagg, Simkin, Bale, \& Bond, 2000; Laye-Gindhu \& Schonert-Reichl, 2005; Ross \& Heath, 2002; Zetterqvist, Lundh, Dahlström, \& Svedin, 2013). On the other hand, some research has demonstrated no difference between the prevalence of self-injury in women over men (Gratz, Conrad, \& Roemer, 2002; Holly, 2007; Jacobson, Muehlenkamp, Miller, \& Turner, 2008; Klonsky et al., 2003; Muehlenkamp \& Gutierrez, 2004). This discrepancy found between such a large body of research may be attributed at least in part to definitional differences used by researchers, the tendency of women to more willingly disclose information about themselves, and a potentially higher female participation rate in psychology-based research studies (Holly, 2007). However, women's self-injury is often associated with broader self-harming behaviours, such as disordered eating. Women diagnosed with an eating disorder are reported to have increased self- 
injury rates than those without an eating disorder, given that studies report that between $32 \%$ to $65 \%$ of women with eating disorders admit to engaging in self-injury at some point in their lives (Claes, Vandereycken, \& Vertommen, 2005; Solano, FernandezAranda, Aiken, López, \& Vallejo, 2005).

\section{Prevalence of self-injury in prison populations}

It is generally accepted in clinical and forensic literature that lifetime prevalence rates of self-injury in prison populations is much higher than rates found within community populations; however, there exists debate on whether self-injurious behaviours should be calculated as the prevalence occurring while incarcerated or the prevalence of self-injury at any point in a prisoner's life. Prevalence rates of selfinjurious behaviour occurring while incarcerated in the general population of correctional institutions are reported as ranging between $1 \%$ and 5\% (Fotiadou, Livaditis, Manou, Kaniotou, \& Xenitidis, 2006; Maden, Chamberlain, \& Gunn, 2000; Smith \& Kaminski, 2010; Toch, 1975; Western Australia Department of Justice, 2002), although lifetime prevalence rates for self-injury range from $15 \%$ to $38 \%$ in incarcerated populations (Fotiadou et al., 2006; Maden et al., 2000; Power, Brown, \& Usher, 2013b; Smith \& Kaminski, 2011). Results in this area of research tend to be inconsistent. For example, early studies found that the incidence of self-injury in prisons was no higher than $3.8 \%$ (Sloane, 1973; Toch, 1975), while more recent research has found rates as high as $52.9 \%$ among prisoners in the United Kingdom (Gray et al., 2003), and 59\% for women in a Canadian federal prison (Heney, 1990). Sampling size and methodology inevitably drive 
up or down prevalence rates, and as such it is difficult to discern exactly how much of the prison population engages (or has engaged) in self-injury.

Unlike with community populations, forensic/correctional bodies of literature have generally reached a consensus that self-injury amongst women prisoners is much more prevalent than in men. Studies on men prisoners have found lifetime prevalence rates of self-injury ranging between $6 \%$ and $17 \%$ (Maden et al., 2000; Shea, 1993). On average, forensic studies report that women prisoners are three and a half times more likely to engage in self-injury than men; prevalence rates between $23 \%$ and $59 \%$ have been reported (Borrill et al., 2003; Gray et al., 2003; Heney, 1990; Howard League, 1999; McDonagh, Noël, \& Wichmann, 2002). One study in the United Kingdom suggests that incarcerated women may be as much as five and a half times more likely to engage in self-injury than men prisoners while incarcerated, with $23 \%$ of women in custody for at least two years reporting that they engaged in self-injury at some point during their sentence (Howard League, 1999). Similarly, Borrill and colleagues (2003) conducted a widespread survey across ten prisons in England and concluded that $32 \%$ of women prisoners had self-injured during their prison sentence compared to $17 \%$ of men. In Canada, recent correctional research has reported that lifetime prevalence rates of selfinjury are high for women prisoners (ranging between 24\% and 38\%), although incidence rates are reportedly low while incarcerated (3.8\%) (Power et al., 2013b). Comparable prevalence studies have not yet been conducted on the Canadian male prisoner population. 


\section{Institutional responses to self-injury}

When a self-injurious incident occurs in a Canadian federal prison, the CSC's policy procedures dictate that after a mental assessment is conducted on the prisoner who has self-injured, they are to be placed in isolation for suicide watch (CSC, 2013k, CD 843). This is primarily done for security reasons, where suicide watch is intended to help "ensure the safety of inmates who are self-injurious or suicidal [...] in a safe and secure environment" (CSC, 2013k, CD 843, p. 1). The CSC's (2010c) 'mental health strategy', stipulates that "individuals at risk for suicide or self-injurious behaviours are monitored according to their level of risk" (p. 14), which reifies the principle of monitoring in the case of prisoners who self-injure even in correctional 'mental health' discourse as opposed to security/safety discourse. In some serious cases of repetitive self-injury, the prisoner may be transferred to a Regional Psychiatric Centre (RPC) or Regional Treatment Centre (RTC) for more specialized care, facilities of which are required by the Corrections and Conditional Release Act (CCRA) to act as both federal prison and hospital $^{5}$ (CCRA, 1992, s. 86; CSC, 2013k, CD 843).

Authorized force can be used against prisoners who are considered repeat selfharmers or those who threaten to self-injure or commit suicide. Use of force ${ }^{6}$ measures supported in CSC policy include applying restraint equipment, such as the Pinel or the

\footnotetext{
5 The CSC operates three RTC's including the Shepody Healing Centre for men (Dorchester, New Brunswick), the Regional Mental Health Centre for men (Sainte-Anne-des-Plaines, Quebec), the RTC within Pacific Institution (Abbotsford, British Columbia), and one RPC which holds both men and women prisoners (Saskatoon, Saskatchewan). The Ontario RTC for men closed in September of 2013 along with Kingston Penitentiary (CSC, 2013m).

${ }^{6}$ A use of force is defined as using one or more of the following measures: "a. non-routine use of restraint equipment, b. physical handling/control, c. display and/or use of inflammatory or chemical agents, d. use of batons or other intermediary weapons, e. display and/or use of firearms, f. deployment of the Emergency Response Team, in conjunction with at least one of the use of force measures identified above" (CSC, 2013c, CD 567-1, p. 14).
} 
Pro-straint chair (CSC, 2013d, CD 567-3, 2013i, CD 800-2, 2013k, CD 843; OCI, 2012a, $2013 b, 2013 c)$, and/or the use of inflammatory or chemical spray agents (e.g. Oleoresin capsicum [pepper] spray) in order to stop or prevent self-injury and/or to gain compliance from the prisoner (CSC, 2013e, CD 567-4; OCI, 2012a, 2013b, 2013c). The CSC's approach to managing self-injury has been repeatedly critized by the OCI (2009a, 2010a, 2011, 2012a, 2013b, 2013c) for a lack of effective, responsive, and coherent approach. The OCI writes:

The Service's approach to self-injury has been defined as much by promise and pilots as by plans and priorities. It includes seemingly endless revisions to policy, action plans and strategies on a national basis. The activities and research associated with this overall effort, while necessary and important, remain a 'work in progress.' (2011, p. 19)

The Office has documented a series of concerns [...] over-reliance on use of force and control measures, such as physical restraints, and restrictions on movement and association to manage self-injurious offenders. (2013a, p. 17)

Notwithstanding the elusiveness of a concrete effective plan to deal with prisoners who self-injure and the over-reliance on controlling responses as remarked by the OCI (2011, 2013a), all uses of force by correctional staff are required by policy to be reported as a security incident (CSC, 2013f, CD 568-1). Incidents of self-injury, given their interpretation in correctional policy as a security incident (CSC, 2013k, CD 843), are also required to be reported by staff. However, the ambiguousness of interpreting self-injury as a suicide attempt and vice versa paired with data capturing complications presents a challenge for correctional officials. 


\section{Reporting on self-injury in Canadian federal prisons}

Research that involves prisoners living in Canadian prisons is generally conducted by correctional staff (i.e., an employee of the Canadian federal government) or by an individual or an organization contracted by the government to undertake the research project. As independent academic researchers such as Kilty (2008b) and Martel (2004) discuss with respect to self-injury and administrative segregation respectively, there exist bureaucratic challenges in gaining access to the federal prison population to conduct research on politically sensitive topics (see also Piché, 2011; Yeager, 2008). That being said, the following is a review of how the CSC currently reports on self-injury inside their prisons.

At present, the CSC tends to report inconsistently on self-injurious behaviour that occurs within their institutions. Some data acquired by the media through Access to Information and Privacy (ATIP) requests and provided by the CSC presents the raw number of self-injury incidents (CBC News, 2012), while other data provided by the CSC to the OCI (2012a, 2013b) offers a count of prisoners involved in self-injurious incidents. These are two distinctly different ways of assessing the extent to which self-injury occurs in Canadian prisons.

One way that the CSC captures prevalence data on self-injury relies on the identification of prisoners with 'alerts', 'needs' or 'flags' populated by the CSC's internal electronic Offender Management System (OMS) (CSC, 2011b). In the OMS, case management staff can check and un-check alerts, needs, or flags on each prisoner's file as they arise, whether at intake or at any point in the prisoner's sentence (CSC, 2011b). For example, some alerts include 'COMMUNITY CONCERN,' having 'PREDATORY 
BEHVIOUR, or there being 'STAFF SAFETY CONSIDERATIONS' (CSC, 2011b). An example of a need is having a 'COMMUNICATION DISABILITY', while a flag includes items such as 'RESTRAINING ORDERS' (CSC, 2011b). As of 2011, two 'alerts' related to self-injury are available to onsite staff with which to identify prisoners with "CURRENT RISK SUICIDE/SELF INJ." and/or "SUICIDE/SELF INJURY HISTORY" (CSC, 2011b, p. 2). Using the checkbox system introduces limitations where alerts, needs, or flags may be outdated (i.e., items checked are static until unchecked by facility staff). Being identified as at 'current risk' for self-injury at one point in a prisoner's sentence may not accurately reflect this 'risk' later on. Further, this method does not capture the total number of self-injurious incidents given that alerts are strictly prisoner-based, where no matter how many times a prisoner self-injures, his or her alert for self-injury is only checked once (Gordon, 2010).

To capture incident-based self-injury, data is collected in two ways. The CSC requires in policy that site staff report varying levels of institutional security incidents, which includes reporting "self-inflicted injuries" within three working days to the Security Operations Branch at Regional Headquarters and National Headquarters (NHQ) (CSC, 2013f, CD 568-1). All self-injurious incidents are then entered into the OMS and linked to the involved prisoner's file (CSC, 2013f, CD 568-1). Given the blurred definitional boundaries of self-injury and the ability for such an incident to be captured under other existing institutional security incident categories available for selection by site staff (e.g., 'non-serious bodily injuries', 'incident involving serious bodily injury', 'attempted suicide', 'overdose interrupted', ‘medical emergencies', or 'minor disruption'; 
CSC, 2013f, CD 568-1, Annex C, D, E), there is a high possibility of incident mislabelling (Gordon, 2010; Power, Usher, Sapers, \& Beaudette, 2012).

The second method by which self-injury incidents are captured is through daily security briefings known as Situation Incident reports (SITREP's), which are qualitatively-based reports written by security personnel for any and all security-related incidents (CSC, 2013f, CD 568-1). This presents a challenge for the CSC given that an incident of self-injury may be difficult to identify or infer from qualitative accounts of possibly unrelated security incidents, which can include disciplinary incidents, cell extractions, or assaults on staff or other prisoners (Gordon, 2010). Moreover, this approach to coding qualitative information likely requires time and resources.

Given the conflation of self-injurious behaviour and suicide in the CSC's checkbox alert system (CSC, 2011b), issues of security incident categorical overlapping (Gordon, 2010; Power, Usher, Sapers, \& Beaudette, 2012), and the subjective staff interpretations of prisoner intent required to classify SITREP's as involving a selfinjurious incident (Gordon, 2010; Power, Gordon, Sapers, \& Beaudette, 2012), it is inferred that data limitations exist in the CSC's ability to report on self-injury incidents. This is important for readers to acknowledge given the overconfidence that the media and the OCI tend to exude when sharing statistics on the number of self-injurious incidents and the number of prisoners who engage in the behaviour (e.g., CBC News, 2012; Harris, 2012, 2013; OCI, 2012a, 2013b, 2013c); it also forces us to consider the problematic ways in which statistics are employed to construct theoretical truths. While those doing research on the topic are inclined to accept statistics on self-injury in prison where they 
are offered, we should be wary of the possibility that such reporting structures can be theoretically, methodologically and/or conceptually flawed.

Notwithstanding the possible reporting limitations, what follows are prevalence and incidence statistics on self-injury as reported by the CSC. In a study conducted by the CSC using the 'alerts' method to identify self-injury, McDonagh, Noël, and Wichmann (2002) report that of the 74 federally sentenced Canadian women who participated in the study, $25 \%$ were considered a 'current risk' for self-injury. Since then, a different methodology has been undertaken within the CSC, namely the use of SITREP's to extract qualitative self-injury incident-based information (see Gordon, 2010; Power, Gordon, Sapers, \& Beaudette, 2012). In 2006, 274 self-injury incidents were recorded as SITREP's in the OMS, compared to 957 incidents in 2011, representing an increase of approximately 250\% (OCI, 2012a). To put Canada's self-injury incident numbers in perspective, the federally incarcerated population increased by $12.2 \%$ during the same time period, from mid-2006 (12,671) to mid-2011 (14,221) (Public Safety, 2012). According to England and Wales' prison records of self-injury, the total number of selfinjurious incidents increased by only $5.3 \%$ across the same timeframe (Ministry of Justice [UK], 2013), while the prison population increased by 11\% (Berman \& Dar, $2013)^{7}$. In 2006, Canadian federal women prisoners reportedly accounted for $8.5 \%$ of all self-injury incidents, a proportion that increased to 33\% by 2011 (CBC News, 2012). Women have generally accounted for $4 \%$ to $5 \%$ of the total federally incarcerated population in the last few years (CSC, 2010a). Aboriginal prisoners are reported to

\footnotetext{
${ }^{7}$ Note, however, that there may be differences in data collection methodologies between the United Kingdom's prison system and the CSC's self-injury incident reporting tools.
} 
account for $45 \%$ of all self-injury incidents (CBC News, 2012), yet they represent $22 \%$ of the federally incarcerated population (OCI, 2013c). In sum, incidents of self-injury in Canadian federal prisons are reported to have more than tripled in the past five years, where both women and Aboriginal prisoners are noted as being overrepresented in these incidents (OCI, 2013c).

\section{A short history of the shifts in clinical discourse on self-injury}

Much like geological tectonic plates that shift and re-adjust in accordance with their surroundings, understandings of self-injury have shifted and adjusted over time. First, I overview the broader shifts in clinical discourse on self-injury not particular to the prison, and then I address similar shifts found in correctional discourse specifically.

The majority of early research on self-injury conducted on community populations contended that self-injury was a product of insanity (Dabrowski, 1937; Keniston, 1913) or a suicide attempt (Menninger, 1935, 1938; Wilson, 1942; Zuk, 1960). Prefaced by lingering discourse on women and hysteria (see King, 1993; Micale, 1990), some research suggested that attempted suicide and self-injury were positively correlated with a woman's menstrual cycle (Tonks, Rack, \& Rose, 1968). Even as recently as the 1990s, Favazza (1996) suggested that the lack of control a woman has over her body (i.e., menstruation, changes in puberty, sharing her body during pregnancy) contributes to a woman's inclination to self-injure.

Shaw's (2002) critical sociological piece identifies four kinds of shifts in clinical self-injury discourse between the early 1900 s and today. First, she points to the changing degrees of clinical interest in self-injury, where interest in the issue comes in waves and 
then drops out of the literature until some new theorization of the behaviour surfaces. For example, in the early 1990s, Shaw (2002) identifies a surge in clinical literature that sought to determine the neurobiological roots of self-injury where self-injury served some physiological purpose making it difficult to quit as if it were a physiological addiction (e.g., Haines, Williams, Brain, \& Wilson, 1995; Simeon et al., 1992). Second, Shaw (2002) demonstrates how understandings of self-injury shifted from disturbing/mad to episodic/repetitive, and then from manipulative/attention-seeking to pathological. Shaw (2002) explains that treatment approaches also changed over time, for example from psychotherapy to psychiatric medications and cognitive behavioural therapies rooted in behavioural psychology. Lastly, Shaw (2002) explores the changing landscape of how women who self-injure are perceived: from young, innocent and privileged women to disturbed women who are seen as young, poor, and desperate for attention.

Pathological understandings of self-injury have withstood the majority of these shifts in clinical discourse as they are routinely considered to be an underlying factor of self-injurious behaviour. The greatest example of the pathologization of self-injury is in the debates amongst the psy-disciplines surrounding the inclusion of 'NSSI' in the DSMV (APA, 2013a). In the previous version of the DSM (IV-TR) (APA, 2000), self-injury was not recognized as an independent disorder. It was instead considered a symptom of or co-morbid with other disorders, including (but not limited to): 'borderline personality disorder', eating disorders, substance abuse, 'histrionic personality disorder', 'antisocial personality disorder', 'post-traumatic stress disorder', and 'dissociative identity disorder' (Adler \& Adler, 2007; APA, 2000; Brown, Comtois, \& Linehan, 2002; Claes et al., 2005; Davis \& Karvinen, 2002; Goldstein, Flett, Wekerle, \& Wall, 2009; Ryan et al., 2008; 
Warm, Murray, \& Fox, 2003). Deliberations for the inclusion of self-injury as an independent disorder in the next DSM followed. These debates centred on whether selfinjury should be characterized as a mood disorder or as a behaviour disorder (Shaffer \& Jacobson, 2009), and whether 'NSSI' should be included in the DSM-V so it may legitimize the diagnosis and allow research to begin accrediting targeted research and interventions (Bain \& Fedynich, 2011; Eisenkraft, 2006; Plener \& Fegert, 2012). Supporters argued that the inclusion of 'NSSI' in the DSM-V would help clinical practitioners better distinguish between individuals who self-injured but did not meet the criteria for 'borderline personality disorder' and those who $\operatorname{did}^{8}$ (Klonsky et al., 2003; Wilkinson \& Goodyer, 2011). Some clinical practitioners have argued that it is problematic that patients who self-injure cannot always satisfy the criteria for a diagnosis of 'personality disorder' and are left diagnosis-free ${ }^{9}$ (Arensman \& Keeley, 2012; Bain \& Fedynich, 2011; Kaputsa, 2012). Other clinical opinions maintained that more research was required to empirically validate NSSI prior to its inclusion in the DSM-V (De Leo, 2011; Mullins-Sweatt, Lengel, \& Grant, 2012; Selby, Bender, Gordon, Nock, \& Joiner, 2011), while others stood firmly against its inclusion in the DSM-V (e.g., Arensman \& Keeley, 2012; Kapur, Cooper, O’Connor, \& Hawton, 2013):

A patient receiving an NSSI diagnosis may conceal fluid suicidal intent which, by being labelled as NSSI, may increase the risk that suicidality may go undetected and consequently also increase the risk of not receiving the appropriate clinical attention which prevents low suicidal intent

\footnotetext{
8 A diagnosis of 'borderline personality disorder' requires that an individual exhibit "significant impairments in personality functioning", including impairments in identity, self-direction, empathy, intimacy, and "pathological personality traits" characterized by manipulativeness, deceitfulness, callousness, hostility, irresponsibility, impulsivity, risk taking, and self-harming or suicidal behaviour (APA, 2012; 2013a).

This camp founds their arguments on early literature that revealed that the most commonly diagnosed disorder as a result of self-injury symptomatology is 'borderline personality disorder' (e.g., Leibenluft, Gardner, \& Cowdry, 1987; Walsh \& Rosen, 1988).
} 
developing into moderate or high suicidal intent. The assumption that all episodes labelled as NSSI are not suicidal behaviours cannot be tested at the epidemiological level. [...] Given the association between NSSI and suicide attempts described above, this could prevent the identification of a significant group of people who are at risk for further suicide attempts and who could benefit from targeted interventions. (Arensman \& Keeley, 2012, p. 9)

In other words, those against the inclusion of 'NSSI' in the DSM-V were of the opinion that 'NSSI' would prevent the diagnosis of other pathologies. Given the intra-disciplinary disagreements, the DSM-V underwent numerous revisions but was eventually published with 'NSSI' as a new independent disorder in May of 2013 (APA, 2013a). The APA's rationale for the inclusion of 'NSSI' stated that self-injury previously had a limited and inappropriate representation in the DSM-IV-TR (APA, 2010). And so, today, psy-experts have a choice on differential diagnoses - they are free to diagnose a patient with 'borderline personality disorder', or solely with 'NSSI', or both.

With respect to gender, women in general have been historically clinically interpreted as inclined to internalize their negative affect, whereas men are generally understood as externalizing negative emotions through demonstrations of aggression or violence (Crick \& Zahn-Waxler, 2003; Leadbeater, Blatt, \& Quinlan, 1995). This lends to the interpretation of self-injury in women as an internalization of emotional pain (LayeGindhu \& Schonert-Reichl, 2005), whereas men's self-injury is somewhat lost in this binary way of understanding gender performativity given that it is often mistaken for acts of acceptable aggression that is public and/or violent (Babiker \& Arnold, 1997; Taylor, 2003) or for accidental injuries (Frost, 1995). Some self-injury committed by men is thus arguably regarded as socially acceptable demonstrations of masculinity (e.g., punching a wall or other object to the point where the body bleeds, head-bashing, or implicating 
oneself in a physical fight with the intent of being harmed), and as such it is left out of much of the extant psy-literature on self-injury (Rotenberg, forthcoming). Though this is an idea that requires empirical development, I suggest that these gender binaries seen in historical and current psy-discourse serve to minimize self-injurious behaviour in men while women's self-injury is maximized through readily available pathological explanations for women's distress ${ }^{10}$.

\section{Shifts in correctional discourse on self-injury}

In the same way that clinical literature saw its share of shifts in understandings and conceptualizations of self-injury, so did correctional literature. After the radical views of early research fell out of the literature - some of which, for example, went so far as to attribute self-injury in prisoners to 'heterosexual inadequacies' (Claghorn \& Beto, 1967) - a dominant theme in correctional discourse evolved: self-injury in prisoner populations was a product of manipulative and/or attention-seeking behaviour (e.g., Franklin, 1988; Haycock, 1989; Martinez, 1980; Ross et al., 1978; Wicks, 1974). The behaviour was understood as a manipulative gesture largely because prisoners were perceived as hungry for attention or desiring rewards or privileges from institutional staff (Dear, Thomson, \& Hills, 2000; Hayes, 1993; Hillbrand, 1993; Martinez, 1980; Ross et al., 1978; Wicks, 1974). As with community populations, self-injurious incidents in prison were dichotomously understood as either 'genuine' (having an intent to actually die) or 'non-genuine' (superficially harming the body for attention with no intent to die) (see Kenning et al., 2010; Short et al., 2009). Prisoners were perceived as malingering by

\footnotetext{
${ }^{10}$ I elaborate on the pathologization of women's distress in chapter II (see p. 52).
} 
engaging in self-injurious behaviour while threatening serious self-harm or suicide (Fagan, Cox, Helfand, \& Aufderheide, 2010). The APA (2013a) recognizes malingering not as a mental illness but as a focus of clinical attention, characterized as the intentional production of false or exaggerated psychological or physical symptoms motivated by external incentives. The tendency to reduce the behaviour to a serious/not serious binary resulted in the conflation of self-injurious behaviours and suicide, as self-injury continued to be seen as either a passive suicide attempt or as a suicide attempt faked for attention (see CSC, 1981; McAllister, 2003). At the same time, research on self-injury in carceral settings generally came to the conclusion that self-injury was positively correlated with insanity, violence, and recidivism (Blanchette \& Motiuk, 1995; Bonta, Pang, \& WallaceCapretta, 1995; Rettinger, 1998). It was suggested that self-injuring prisoners were a violent subculture incapable of treatment, and a threat to the safety of themselves and others (Hillbrand, Krystal, Sharpe, \& Foster, 1994).

New research eventually emerged that differentiated between self-injury as a suicide attempt and self-injury independent of the intent to die (Fagan et al., 2010; Fulwiler, Forbes, Santangelo, \& Folstein, 1997), but the understanding that prisoners selfinjured to reap institutional rewards or otherwise seek attention remained. Correctional bodies consequently tended to specifically perceive women who engaged in self-injury as unfeminine, misbehaved, manipulative, dangerous, unruly, and a threat to public safety. As such women who self-injured were labeled as deviant and dangerous 'cutters' who were redefined as risks to the security of the institution (see Kilty, 2006, 2008b).

The manipulation model was eventually met with heavy criticism for its failure to consider self-injury as an honest cry for help or as a sign of emotional distress or despair, 
especially with respect to women prisoners, whose self-injury was never considered to be an act of institutional resistance or an assertion of agency (Fillmore \& Dell, 2000, 2005; Frigon, 2001; Holley \& Arboleda-Florez, 1998; Kilty, 2006, 2008b; Liebling, 1995). Soon after, a new object of inquiry emerged ${ }^{11}$, where prison research began to explore the extent to which institutional staff perceived self-injury as manipulative or attentionseeking. This research determined that correctional staff attitudes towards prisoners who engage in self-injury are generally negative and lacking in empathy (DeHart, Smith, \& Kaminski, 2009; Kenning et al., 2010; Marzano, Ciclitira, \& Adler, 2012; Short et al., 2009; Smith \& Kaminski, 2011). Prison staff are reportedly more likely to harbour resentment and feelings of anger towards prisoners whose self-injury is perceived as 'non-genuine' (Short et al., 2009). Female correctional staff are reportedly slightly more empathetic and tolerant of self-harming inmates than their male counterparts, and are consequently more likely to demonstrate understanding and compassion towards selfharming prisoners whereas male guards are more likely to respond with punitive actions (Ireland \& Quinn, 2007). It is suggested that the combination of a lack of training paired with the intersectional effect of criminalization and prejudice against those who selfinjure may influence staff members negative stigma against self-harming prisoners (Kenning et al., 2010; Thomas, Leaf, Kazmierczack, \& Stone, 2006).

In recent years mental disorder has become an increasingly ubiquitous explanation for self-injury in correctional discourse. Clinical/forensic studies conducted in the last decade on prisoner populations have routinely attributed self-injury to mental

\footnotetext{
${ }^{11}$ Though some correctional discourse on self-injury as a manipulative act has lingered in the past decade or so (e.g., Dear et al., 2000; Jeglic, Vanderhoff, \& Donovick, 2005).
} 
disorder(s), including psychotic, mood, or personality disorders (Dixon-Gordon, Harrison, \& Roesch, 2012; Fotiadou et al., 2006; Lanes, 2009a; Marzano, Fazel, Rivlin, \& Hawton, 2010; Palmer \& Connelly, 2005; Senior et al., 2007; Völlm \& Dolan, 2009). Given that international correctional discourse has been simultaneously examining the heightened (and some argue increasing) prevalence of mental disorder in prisoner populations in relation to community populations (e.g., Brandt, 2012; Butler, Allnutt, Cain, Owens, \& Muller, 2005; Fazel \& Danesh, 2002; Fazel \& Seewald, 2012; Ogloff, Davis, Rivers, \& Ross, 2007; Simpson, McMaster, \& Cohen, 2013; Sirdifield, Gojkovic, Brooker, \& Ferriter, 2009), conclusions of this nature are not surprising.

\section{Sociological perspectives of self-injury}

While most forensic literature posits that self-injury is largely a product of mental disorder, critical criminological literature explains that self-injury is not a simple plea for attention, but instead should be understood as occurring for a myriad of reasons. Grounding their theorizations in critical feminist literature on self-injury as an act of resistance (e.g., Coy, 2009; Inckle 2007; Pitts, 1998, 1999), self-injury has been theorized as a means to resist the lonely and oppressive environment of the prison (Bailey, 2009; Frigon, 2001; Groves, 2004; Kilty, 2008b; Rhodes, 1998) and as a response to histories of trauma, abuse, victimization, and/or criminalization (Fillmore \& Dell, 2000, 2005). Selfinjury has also been theorized in contemporary sociological literature as a gesture or 'body-as-text' in the sense that it embodies testimony relayed through the body (Cresswell, 2005; Hewitt, 1997; Kilby, 2001; Lingel, 2008), as performativity of the body (Jaworski, 2003), as an assertion of agency (Coy, 2009; Kilby, 2001; Medina, 2011; Pitts, 1998), and as a reflexive practice of embodiment whereby self-injury is seen as quite 
literally engaging with the self through the skin (McLane, 1996; for reflexive practices more generally, see Adkins, 2002; Cronin, 2000). Rhodes (1998) applies this idea to prisoners whereby self-cutting represents the self-reflexive aim of quite literally opening up one's skin to the panoptical gaze as an extreme offering of visibility. These kinds of interpretations of self-injurious behaviour exemplify the diversity of understandings present in the literature. This thesis will show that correctional discourse is absent of such understandings, and instead relies on narrow pathological rationalizations for why prisoner self-injury occurs.

\section{The prison as a contributing factor to self-injury}

The prison as a contained, restrictive, and emotionally and socially limiting environment is argued to exacerbate self-harming behaviours through the very experience of being incarcerated (Biggam \& Power, 1999; Holley \& Arboleda-Florez, 1988). When prisons become overcrowded, they are said to increase tension, volatility and unrest in the prison population (Haney, 2006c, 2012; OCI, 2012a, 2013c), consequentially raising the rate of suicide and self-injury (Sharkey, 2010). It is thus of concern that the rate of double-bunking in Canadian prisons rose twofold (from 12\% to 21\%) in the last ten years and that self-injury incidents are reported to have increased threefold since 2008 (OCI, 2013c).

The segregation (i.e., solitary confinement) of prisoners has been theorized as 'a prison within a prison' (Rivera, 2010; Sykes, 1958a) and as such has been widely discussed for its negative effects on prisoner 'mental health' and its disregard for basic human rights (Cohen, 2008; O'Keefe, 2008; Shalev, 2011; Smith, 2006). The same 
arguments are applied to 'supermax' prisons, which are common in American correctional systems but are comparable to maximum security cells in Canada where prisoners generally do not leave their cell for more than one hour per day (Arrigo \& Bullock, 2008; Haney, 2006a; Pizarro \& Stenius, 2004; Rivera, 2010; Shalev, 2011). A substantial body of correctional and critical literature supports the notion that subjecting prisoners who engage in self-injury to segregation of any form and/or physical restraints will not deter self-injury, but will instead exacerbate future acts of self-injury by reinforcing feelings of hopelessness (Arrigo \& Bullock, 2008; Dear, 2006; Great Britain Parliament, 2004; Kilty, 2008b; Lord, 2008; Morin, 1999; Royal College of Psychiatrists, 2010; Toch, 2008). Not surprisingly, self-injury amongst prisoners occurs most frequently after placement in segregation (Liebling, 1994; Ross et al., 1978) and prisoners who self-injure are doubly likely to be housed in long-term segregation (Lanes, 2009b, 2011). Recently the OCI (2012a) concluded that close to one-third of reported self-injury incidents occur in segregation units. As such, the present (and expected) influx of people into Canada's penitentiaries (see Cook \& Roesch, 2012) paired with the subjection of self-injuring prisoners to solitary confinement is of concern when considering the possibility of reinforcing self-injury.

\section{Towards a theoretical framework}

The prison is a breeding ground for the production of knowledge about self-injury (Groves, 2004). If we look to how community-based research on self-injury (particularly about adolescent girls) has come in waves (Shaw, 2002), we see how the same effect occurs in correctional research. Arriving in waves, self-injury as an object of study 
attracts widespread attention for a given amount of time by clinical bodies, only to drop back out of the spotlight again until the behaviour can be re-theorized in some new way (Shaw, 2002). Recent critical accounts of clinical literature on self-injury have pointed to the growing reliance on psychology and psychiatry to understand individuals who selfinjure (Brickman, 2004; Chandler et al., 2011; Johnstone, 1997; Kokaliari \& Berzoff, 2008; McAndrew \& Warne, 2005). Paired with the growing reliance on psychological and psychiatric ways of understanding and treating prisoners (Kilty, 2012), correctional discourse is susceptible to the same techniques of medicalizing deviant behaviour. In the chapter that follows, I lay out theoretical tools that better assist us in understanding the proliferation of clinical psychological and psychiatric discourse and how they reign as dominating knowledges in greater society. 


\section{CHAPTER II: THEORETICAL FRAMEWORK}

We have tied ourselves 'voluntarily' to the knowledges that [psy] experts profess, and to their promises to assist us in the personal quests for happiness that we 'freely' undertake. (Rose, 1996b, p. 77)

In this chapter I present a sociological critique of what Nikolas Rose (1990, 1996b) terms the 'psy-sciences'. I then consider how gender impacts the production and application of psychological knowledge by relying on Jane Ussher's (1991, 2010, 2011) theoretical interpretations of the medicalization of women's madness. I then introduce the prison as a site of psychological knowledge and consider how psy-knowledges are amplified in and through penality. This discussion draws on actuarial risk logic as an example of Rose's conceptualization of the assessment tool as a regulation strategy. I consider how 'risk' is applied to women prisoners specifically and discuss how the intersection of the psy-sciences and penality produces regimes of control through intervention and institutionalizes women as both prisoner and patient.

\section{Rose on the rise of the psy-sciences}

Rose broadly defines the psy-sciences as disciplines that have the prefix 'psy', such as psychology, psychiatry, psychopharmacology, and psychoanalysis, among others. Rose has contributed a great deal to critical literature on this topic, by pointing out the influence the psy-sciences have over human behaviour and how people perceive themselves, and how they shape us through what he terms a 'current genealogy of the self'. Rose is considered a Foucauldian scholar insofar that much of his theoretical approaches to and characterizations of madness, abnormality and responsibilization build on Michel Foucault's ideas (e.g., Foucault, 1977, 1980a, 1988a, 1988b, 2003, 2006a, 
2006b). Rose characterizes his analysis as an exploratory examination rather than a simple criticism of the psy-sciences per se. In what he terms a 'critical history', Rose (1990) sets out to explain the current state of the psy-sciences and the burdens, limits, nature, and powers of influence they have over society and how they dominate, disturb and 'fragment' the self by imposing certain restrictions and baselines for how we should see ourselves, and how to determine truth(s), reality(ies), and knowledge(s). Rose (1990) posits that 'veridical discourses', namely positivist knowledges and expertises of truth, play a key role in rationalities of government, spaces and subjects. The psy-sciences subscribe to the positivist commitment to scientific objectivity and are generally welcomed because they offer 'corrective promises' (Rose, 1996b). Rose encourages readers to 'think against the present' by taking what is currently understood as 'truth' and thinking 'against' it in order to unveil the underlying discursive powers of the psysciences and how they infiltrate our every day decision-making and thought processes.

At the outset of this research the social scope covered by the psy-sciences must be carefully laid out. Rose's conceptualization of the psy-sciences is rather broad. His critiques range from problematizations of the psychology of the workplace where the expertise of management aims to produce productive workers (Rose, 1990) to accounts of in-vitro fertilization and biomarkers that lend to the managing of genetic risks (Rose, 2005, 2007b; Singh \& Rose, 2009). This range includes problematizations of social psychology (Rose, 2008a) to problematizations of the growing reliance on biological technologies or neuroscience as a way of understanding human subjectivities (AbiRached \& Rose, 2010; Rose, 2001, 2003, 2007a, 2007b, 2007c, 2008b, 2010, 2013). This 
thesis focuses on the specific critiques that Rose $(1990,1992,1996 \mathrm{~b}, 2006)$ puts forth with respect to clinical and/or abnormal psychology and psychiatry.

Clinical psychology is understood by the American Psychological Association as incorporating,

... science, theory, and practice to understand, predict, and alleviate maladjustment, disability, and discomfort as well as to promote human adaptation, adjustment, and personal development. (n.d., para. 1)

Clinical psychology is often confused with, or substituted for, abnormal psychology or psychiatry, which is defined as an "area of psychological investigation concerned with understanding the nature of individual pathologies of mind, mood, and behaviour" (Gerrig \& Zimbardo, 2002, as cited in American Psychological Association, 2013, para. 2). A key component that is constitutive of clinical/abnormal psychology/psychiatry is the practice of diagnosing mental disorders as defined by the DSM in a clinical, laboratory, institutional, hospital, or physical locale that otherwise involves the spaces in which 'mental health professionals' operate. Further, clinical/abnormal psychology/psychiatry is characterized as intervening with individuals in very specific ways. These include, predominantly, the administration of pharmaceutical medications and the provision of intervention programmes or therapies that adhere to one of the core tenets of psychology (such as the psychodynamic approach, the cognitive behavioural perspective, and the behavioural approach). I adopt Rose's term the 'psy-sciences' to encapsulate the very specific disciplines of and knowledges produced by clinical/abnormal psychology and psychiatry. At no point should readers interpret the critiques of the psy-sciences woven throughout this thesis as directed at broader psychological disciplines such as social psychology. 
In his book Governing the Soul: The Shaping of the Private Self, Rose (1990) establishes six tools in which to conduct a genealogy of the psy-sciences, all of which he applies in his later book, Inventing Our Selves: Psychology, Power and Personhood (1996b). They are: 1) problematizations; 2) explanations; 3) technologies; 4) authorities; 5) subjectivities; and 6) strategies. Rose utilizes these tools as guidelines that introduce questions of theoretical examination rather than as formalized methodological tools. These tools will serve as the framework to organize Rose's conceptualizations of the psysciences. I weave in other pertinent literature that compliments his theorizations where applicable.

\section{Problematizations}

Early on, Rose (1985) posited that normality emerged out of a concern with everyday types of conduct, thought, and expression deemed troublesome or dangerous to others or oneself. Language was, and continues to be, used to articulate abnormality and its characteristics, from psychiatric diagnoses to problematizing conduct in the courtroom, the workplace, the prison, and the school. Language, then, mobilized the establishment of dichotomies based on interpretations of abnormality/normality and entrenched them in social discourse. After all, language is the medium used to identify and describe what abnormality or normality is, and the differences between them. Rose (1996b) points to psychology in the nineteenth century as having "invented the normal individual" (p. 17), wherein 'normality' is met with its opposite, and thus the binary oppositions that surround madness are born. Psychology and psychiatry rely on binary characterizations of abnormality/normality and human subjectivities: normal/abnormal, 
health/sickness, sane/insane, disorder/order, depression/mania, introvert/extrovert, bipolar/unipolar, and so on. Dichotomized characterizations of people are 'psychologized': they are simultaneously rendered both troubling and intelligible (Rose, 1990, 1996b). Put another way, human behaviour can be simultaneously identified as undesirable or problematic and examined to the point where we now know more about that behaviour. Through these problematizations, the psy-sciences propose a method of appropriate conduct by suggesting that by sticking to the 'normal' end of the normal/abnormal binary, one reaps the benefits of autonomy and self-actualization ${ }^{12}$.

Psy-knowledge about normal behaviour often emerges in sites where problems take place: the schoolyard and childhood maladjustment, the prison and criminality, Aboriginal reserves and racial degeneration, and so on (Rose, 1990). Similarly, it emerges when psy-experts point to key (dys)functional elements in a patient's life, such as relationships with friends, family and others, which Rose (1990) terms the 'neuroticization of social intercourse'. The psy-sciences take hold of particular spaces to designate the subjects and sources of the abnormality or dysfunction and scrutinize, study, and problematize these subjects and sources. Although Rose did not specifically use the term 'culture of diagnosis', his theorizations align with the idea that the psysciences have infiltrated daily life to the point where psychological understandings of human behaviour have become part of most western cultures. Problematizations of human behaviour evolve in an attempt to reform or cure behavioural abnormalities, wherein the psy-sciences prescribe ways for us to conduct ourselves in certain spaces

\footnotetext{
${ }^{12}$ The notion of attaining self-actualization and autonomic benefits will be explored further under the fifth of Rose's genealogical tools, subjectivities (see p. 46).
} 
and/or with others. In order to do so, problematic human behaviours must be adequately explained, proven, calculated, and accepted as truth.

\section{Explanations}

'Explanations' seek to prove certain truths in order to validate or invalidate hypotheses. Rose draws largely from Foucault's (1972a, 1972b, 1978, 1980a) work on the idea of a 'regime of truth' to problematize the power/knowledge relationship inherent in the psy-sciences and how truth is constructed. Battles over truth are enacted within the psy-disciplines through the undertaking of experiments, analyses, and the extraction of truths from living subjects or social phenomena. Certain beliefs are restricted from entry into the arena of truth if not found to be methodologically or conceptually sound in accordance with the dominant principles of thought at the time (Rose, 1990, 1996b). These 'truth battles' result in declarations of certain facts/truths over others in scholarly journals, governmental research rationales, poster presentations, conferences, and other forms of information dissemination. Rose (1996b) posits that,

... truth entails an exercise in alliances and persuasion both within and without the bounds of any disciplinary regime, in which process an audience for truth can be identified and enrolled. (p. 55)

In this vein, truth regimes are fed to and digested by hungry audiences who crave explanations about human characteristics in order to be satisfied that they might now know themselves.

Mechanisms that construct truth in the psy-sciences include practices like experimental or differential research methods, factorial designs, meta-analyses, testing hypotheses, and collapsing and coding human behaviour. Experts seek to 'prove' truths 
through establishing criteria of demonstration, domains of evidence, language systems that classify truths (rhetorics, metaphors, analogies, logics), and calculable formulas that render facts (in)visible, (in)valid, (un)reliable, and so forth (Rose, 1990, 1996b). Rose $(1990,1996 b)$ provides examples of spaces in which explanations for truth are sought in psy-settings: intelligence tests in the war era, occupational psychological assessments in places of work, childhood development tests as required by schools, emotional intelligence tests at the hand of relationship counsellors, and criminal risk assessments in prisons. The idea of setting up domains of evidence in which to code or collapse truths about human behaviour and human subjectivity has been more recently theorized in accounts of penality and immigration practices. For example, Aas (2006) explains how the body has become a site of identification through biometric tools like identification cards and DNA databases which seek to 'code' the body and its identity into a password for access or denial. Such red-light/green-light analogies are applied to, for example, 'crimmigrants' who are deemed unsafe for entry, citizenship, or access to certain spaces or privileges in light of identity codes that have connected them to criminal others in some way (Aas, 2011). Identities thus lose their 'narrative' and are made amenable to data collection by compressing, indexing, and stacking one's personal information to fit the parameters of a database (Aas, 2004). Psychological studies follow the same parameters of subject coding that Aas describes by classifying minds along the abnormal/normal binary. The discovery of 'truth' in the form of treatments and interventions for mental disorder is supported by 'evidence-based' means of producing and reporting data on mental health. The qualities of subject/patients must first be rendered extractable, quantifiable, or otherwise operationalized for data collection in 
order for larger-scale truths about disorder, treatment and the like to be extrapolated to the societal level.

Rose's (1990, 1996b) critique of explanations can be linked to those of Aas $(2004,2006,2011)$ insofar that Rose touches on statistics as an instrument of the psysciences that mobilizes theory and produces psychological phenomena. The use of various statistical techniques during the experimentation and information extraction stages are 'processes of inscription' and a way of 'condensing the empirical' (Rose, 1996b), much like Aas' ideas on the transformation from narrative to compressed database. Rose (1996b) posits that statistics are reshaped until they foster a 'materialization of the theoretical', after which point they serve as evidence in support of the broader theory hypothesized as part of the experiment. This aligns with Aas' argument on how the identities of subjects are transformed into 'informationality' in order to fit the parameters of the database, in other words, extracting the narrative and collapsing certain indicators or concluding results from various assessment tools. In summary, Rose's conceptualization of the element of 'explanation' can be understood in tandem with the shift toward 'informationality' as suggested by Aas. But how exactly are judgments and ideas for reformation assembled? Rose's technologies account for the methods that are undertaken in order to reach an explanation.

\section{Technologies}

Technologies refer to how the judgment of truth is assembled, namely, through varying sorts of examinations, tests, assessments and so on. Technologies consist of "any 
assembly structured by a practical rationality governed by a more or less conscious goal" (Rose, 1996b, p. 26), in which case human technologies are:

Hybrid assemblages of knowledges, instruments, persons, systems of judgment, buildings and spaces, underpinned at the programmatic level by certain presuppositions and objectives about human beings. (Rose, 1996b, p. 26).

There are three main forms of technologies that Rose $(1990,1996 \mathrm{~b})$ uses to characterize the psy-sciences. They are: 1) technologies of assembly which can include the school, the prison, the asylum as spaces that put forth conscious goals, 2) mobile technologies that are not stuck to given spaces, such as pastoral relations (see also Hannah-Moffat, 2001), and 3) human technologies, where the promise of personhood is offered through responsible self-governance. Human technologies differ from mobile technologies because they are in a sense stuck to personhood insofar that they characterize outcomes of human conduct such as reform, efficiency, education, cure, and virtue. Rose (1996b) argues that the most important factor of the technologies of the psy-sciences is that the psy-sciences, unlike some older professions, do not have a particular space attached to its truths (such as the court and judgment, the church and redemption, or the hospital and diagnosing and curing). The psy-sciences, on the other hand, produce mobile knowledges that do not originate out of a particular space. They are prolific, fluid, infective, and seep their way into almost all other static institutional spaces (Rose, 1996b).

Rose (1990, 1996b) describes how the 'techne of psychology' overarches technologies insofar as the techne represents how human beings are understood and assembled by technologies which lend to the kind of knowledge required to produce subjectivities. The techne of psychology would thus include the accumulation of spaces 
where psy-experts operate, the different relations between bodies of authority and other authorities, and between bodies of authority and their subjects. However, within certain spaces where psy-expertise is in whole or in part the basis for the space's existence (e.g., psychiatric hospitals, a psychologist/psychiatrist/therapist/social worker's office, the prison), tension cannot exist solely based on the legitimacy of psy-knowledge, given that it contributed to the inception of the space in the first place. Part of the techne of psychology is its 'free' cost, that is, its ability to lend itself to anyone who desires to adopt its knowledge.

Psychology and psychiatry are technological in that they use their own languages to render things thinkable, orderable, classifiable, fragmented, relational, and so forth. For instance, the idea of 'co-morbid disorders' is a linguistic technology of the psysciences that implies the existence of innate ties between two behaviours or traits of addiction. Further, psy-language has become a valuable and indispensible asset to other professions, where its language serves to bridge understandings and provide translatability between politicians, lawyers, professionals, businessmen, managers, clinical criminologists, and so on. Language is a technology because it functions as 'intellectual machinery' (Rose, 1996b, p. 54) that seeks to describe the world and its subjects in structured ways. Tactics of intellectual machinery amount to what Rose dubs 'intellectual technologies'. The psy-sciences are intellectual technologies rather than simply technologies because they operate at the interpretive level and influence how we understand human behaviour. They have evolved into 'practical rationalities' insofar that they have become embedded in the everyday or common sense knowledge of what norms should be followed and what strategies, technologies and devices should be utilized to 
reform human conduct. Psy has taken the shape of various programmes that hold the promise of correction and reform in accordance with the common expectation of an appropriately self-governing subject.

\section{Authorities}

'Authorities' refer to who is expert and what the relations are between authorities and their subjects. This includes professional groups or what Rose (1996b) refers to as the 'new authorities': clinical, educational, and industrial psychologists, psychiatrists, psychotherapists, pharmacists, social workers, cognitive behavioural program facilitators, therapists, and any professional position which directs an individuals' striving for autonomy in the direction of the most 'appropriate' and 'productive' fashions. These 'new authorities' actively claim social power and status as a result of their possession of psy-knowledges. Rose (1996b) explains how authorities are heterogeneous and dispersed around the globe with an underlying unity of power. An individual who visits his or her therapist does not simply trust the advice or guidance of his or her therapist because he or she sees the therapist as a purveyor of power, but rather because he or she is cognizant of a greater technology of power at work. The system of knowledge of the psy-sciences is so deeply embedded into our social world that the therapist serves as a medium who channels this knowledge to the individual. Experts are, by definition, servants to dominating ideologies: they do not think for themselves, rather, they apply knowledge to the problems defined by the dominating ideology (Žižek, 2013, as cited in The Guardian, 2013). In essence, expert authorities serve as open channels that allow psy-knowledge to flow into our social world, operating under the greater authority of the psy-sciences. 
Authority is granted to individuals and groups who dominate existing institutions by applying psy-knowledge. For instance, the teacher in the school, the correctional officer or program facilitator in the prison, the manager in the workplace, the nurse in the psychiatric ward, the commander in the army, and the expert witness in the courtroom. These roles possess authority in their own right within their professions: the child learns from the teacher, the prisoner must follow orders from the correctional officer or 'demonstrate' skills learned in programming, the worker must deliver to the taste of his or her manager, the psychiatric patient must take all medications as prescribed by his or her mental health professionals, the recruit must follow the commander's orders, and the juror must trust the expert witness. This logic is not solely explained as the dissemination of truth via authority, but as a project that seeks to improve the capacity of individuals to exercise authority over themselves - how can the prisoner, the student, the worker or the patient best please their respective authorities? By regulating their own conduct wherein,

... the exercise of authority, here, becomes a therapeutic matter: the most powerful way of acting upon the actions of others is to change the ways in which they will govern themselves. (Rose 1996b, p. 64)

Authorities are dependent on the techne of psychology in part due to the 'free' cost of psy-knowledge, that is, its ability to lend itself to anyone who desires to adopt its knowledge (Rose, 1990, 1996b). Because it is readily available, it is easily adopted as a 'legitimate' method of research, analysis or thought process by various social authorities. Psy is also easy to adopt because it promises a 'simplification' of human behaviour. For instance, the DSM codifies all 'known' mental disorders into a master list and offers diagnosable criteria in a simple, calculable fashion. This tool is often referred to as the 'psychologist's bible' (Kutchins \& Kirk, 1997) because it involves truth claims about 
mental disorder and offers simple mechanisms of diagnosis for practitioners. The authority held by psychologists, psychiatrists and the like grants them permission, whether indirectly or directly, to participate in the fabrication of contemporary social reality. Diagnoses handed down by psy-experts can be seen as discursive constructions created by processes of expert definition (Fee, 2000; Kirk \& Kutchins, 1992; Littlewood \& Lipsedge, 1982; Sedgewick, 1987; Ussher, 1991). The increasing accumulation of authority amongst the psy-sciences results in the decontexualization of social problems, wherein social problems are fragmented, individualized, interpreted, and treated though medicine (Conrad, 1992; 2005; Rose, 2007a).

\section{Subjectivities}

What is the ontology of a human subject? In what ways do we exist, have a soul, a spirit, a consciousness? What is the epistemology of truth? How do we know what we know - through observation, confession, or trust? Rose (1990, 1996b) asks these questions in establishing the concept of subjectivity. The subjectivities of human beings, according to Rose $(1990,1996 \mathrm{~b}, 1998,2000 \mathrm{a}, 2000 \mathrm{~b})$, are characteristics that are operated upon by greater governing regimes that seek to mould, position, prevent, test, and characterize people. This should be understood in relation to vocabularies and other explanatory systems that contribute to the 'social construction of subjectivity' (Rose, 1996b). Rose's four aforementioned theoretical tools used to trace the discursive powers of the psy-sciences are applied to human subjectivity: to problematize it, to explain its ins and outs, to put technologies to work to inform and shape it, and to place authorities in positions of relational power to it. Inherent in the subjectification of individual citizens is 
the need to encourage them to be free and autonomous individuals, where the role of the state in the government of its citizens is reduced and replaced with a sense of selfresponsibility. This rationality demands that citizens learn new techniques of understanding, practicing and engaging in self-reform/governance (Rose, 1990, 1996b).

Governmental regimes endorse self-responsibilizing management strategies in what Rose $(1990,1996 a)$ terms 'advanced liberal democracies', where organizations base their central tasks on the management of subjectivity. Relationships between expertise and politics are enhanced, social technologies experience a new 'pluralization', and the subject of government is newly specified, reorienting responsibility and the notion of freedom and autonomy onto active, individual, enterprising citizens (Rose, 1996a).

The concept of 'responsibilization' (i.e., the displacement of responsibility from and by the state to other institutions and/or to its subjects) is discussed at length in contemporary critical criminological scholarship. For instance, critical feminist scholarship explains how women prisoners are systematically molded into 'respectable ladies' through cognitive behavioural therapy based correctional programming (Carlen \& Worrall, 2004; Kendall, 2002; Kilty, 2012; Pollack, 2005, 2006) and more generally through reform ideals that target the 'criminogenic needs' of the 'woman offender' (Hannah-Moffat, 1999, 2000, 2001, 2004a, 2004c, 2006, 2009; Shaw \& Hannah-Moffat, 2004). These mechanisms call on the subject to be held accountable for past harms and thus responsible for their futures as law-abiding, productive citizens. O’Malley (1996, 2009) proposes the idea of 'prudentialism', a practice of removing the regulation of the individual through collective/state risk management and displacing the responsibility onto the individual in order to let them manage their own risk, which, in the case of 
prisoners, also forces them to become knowledgeable about crime prevention and risk. Such measures of self-responsibilization are a product of having been rendered a subject. Governments operate upon the subjectivities of its citizens by imposing techniques of self-regulation to most efficiently govern the population. Such techniques are not passively imposed; they draw the autonomous subject into active self-regulation that is maintained by the subject through the fear of being reprimanded for unsuitable behaviour (Rose, 1996a, 1996b).

The psy-sciences serve to set a benchmark, a baseline, or a norm for human conduct and to identify deviations from that norm that require reformation. Rose (1996b) explains how governmental rationalities operate upon human subjectivity by advancing and solidifying ideas of psychological appropriateness. Psy discourses remind us to 'look inwards' and reflect on whether or not we are governing ourselves appropriately, meaning that psy as a governmental rationality works to instill 'technologies of the self' in its subjects. Foucault $(1986,1988 b)$ first posited that 'self-steering mechanisms' enable individuals to experience, understand, judge and conduct themselves. These ideas were further advanced by Miller and Rose (1990) and Rose (1996b). Self-steering mechanisms take hold in three ways: 1) they require us to relate to ourselves epistemologically (how do we know ourselves?); 2) despotically (how can we master ourselves?); and 3) productively (how can we best care for ourselves?). The psy-sciences allow us to know, master and care for ourselves through the various technologies they offer for us to take part in. To know oneself may be to self-monitor one's emotions, to 
master oneself may be to self-responsibilize and attain self-actualization ${ }^{13}$, and to care for oneself may be to seek intervention and treatment from psy-experts to ensure normal functioning. Society largely accepts the notion that we are to live our lives in psychological terms, be it development, adjustment, fulfillment, relationships, or selfactualization. We do not only accept psy understandings about ourselves because this knowledge is passed down through channels of authority and diagnosis, but also because we fear being stigmatized as mad if we do not take strides in managing our madness ${ }^{14}$ (Foucault, 1977). The psy-sciences set up 'mirror traps' that are designed to reflect notions of madness back onto the subject (Foucault, 2006b). In this vein the psy-sciences reverse the onus of care onto the individual, where "through self-inspection, selfproblematization, self-monitoring, and confession, we evaluate ourselves according to the criteria provided for us by others" (Rose, 1990, p. 11). To do so, governmental rationalities enact various strategies, a concept Rose uses to characterize the tactics of action and regulation.

\section{Strategies}

'Strategies' explain the ways in which the psy-sciences engage in calculated decisions. For example, in the form of policy mandates which seek to minimize or maximize a behavioural trait or syndrome or re-organize ideas about human behaviour in a way that legitimates and supports the continued proliferation of the psy-sciences. One example of such a strategy is 'governing at a distance' (Rose, 1990), where government

\footnotetext{
13 'Self-actualization' was famously introduced as a tenet of humanistic psychology by Abraham Maslow (1943) who described it as the high-level need or desire to reach one's potential: "What a man can be, he must be [...] the desire to become more and more what one is, to become everything that one is capable of becoming" (p. 383, original emphasis).

${ }^{14}$ The irony in this sentiment is intended as per Foucault (1977).
} 
bodies instill techniques of self-governance in individuals so that they may reduce state responsibility. The psy-sciences govern-at-a-distance insofar as they establish a gap between the legal and penal powers of the state and the everyday activities of individuals. A hands-off approach to government is evident, wherein the majority of individuals follow the rules of the state within the parameters laid out to them (e.g., criminal and civil laws, movement rules in buildings and institutions, criteria required to be a part of a given profession, etc.). Through the dance of governing-at-a-distance, it must be understood that the expertise of the techne of psychology is not grounded in political thought or rationality, but in the claim to truth based on a particular stream of knowledge. Governmental rationalities put this knowledge in motion to establish criteria by which to structure and govern our lives.

More broadly, strategies of regulation come in various forms, by which governments and the psy-disciplines can control and regulate society, for example, through ensuring disease/disorder prevention or degeneration. This can include techniques of classification and assignment according to an analytical grid, given that the characterization of human behaviour serves as a tool for authorities to generate strategies of regulation. Rose $(1990,1996 \mathrm{~b})$ speaks of two such features of government that are present in the psy-sciences. First, that government depends on knowledge to operate through the production, circulation and reification of truths that justify the governance of certain objects/subjects in the first place. Second, the classification of phenomena is mobilized through various transcription measures, such as recording a birth, a death, an illness, an intelligence quotient score, and so forth. Thus government depends on the knowledge of certain truths about the psy-sciences, for example, the verity of 'clinical 
depression', in conjunction with tools that were developed to test for 'clinical depression', such as the Beck Depression Inventory (Beck, Steer, \& Garbin, 1988; Beck, Ward, Mendelson, Mock, \& Erbaugh, 1961) or the Center for Epidemiological Studies Depression Scale (Eaton, Muntaner, Smith, Tien, \& Ybarra, 2004; Radloff, 1977). Rose (1996b) argues that the expanding army of assessment tools, clinical classifications, statistical publications and intervention therapies in the psy-sciences are strategies that have made human subjects governable.

\section{From madness to illness}

How exactly it is that 'madness' transformed into what we recognize today as mental 'illness'? Foucault (1988a) contends that towards the beginning of the nineteenth century, understandings of madness shifted from focusing on the movement of spirits through the space of the body (e.g., the womb and hysteria) to focusing on moral judgments with respect to the sensibility or the emotional state of the patient (e.g., a patient's emotional affective state). Foucault (2006a) writes:

There is no common language: or rather, it no longer exists; the constitution of madness as mental illness, at the end of the eighteenth century, bears witness to a rupture in a dialogue, gives the separation as already enacted, and expels from the memory all those imperfect words, of no fixed syntax, spoken falteringly, in which the exchange between madness and reason was carried out. (p. xxviii)

Psychiatry became a medicine to locate the organic origins of madness, refining the nomenclature for madness by fleshing out a flurry of different types of disorders (Foucault, 2006a, 2006b). One key difference that marks the shift to illness was that things located exterior to the body of the patient were now considered to influence the state of the mind. After a long history of madness, abnormality was now being 
conceptualized as a disease of the mind, as something that could be met with psychiatric intervention. Rose $(1990,1996 \mathrm{~b}, 2000 \mathrm{~b})$ argues that the notion of taking action upon patients marks the shift from madness to illness, where psy-experts gleaned the authority to dictate, define, and prescribe remedies to cure or alleviate diseases of the mind. With this shift came the power to identify, label and prescribe the specific conditions of mental illnesses (Penfold \& Walker, 1984). Now, psy-practitioners had "found the power to unravel insanity", where the "patient would accept this self-surrender to a doctor both divine and satanic" (Foucault 1984c, p. 163). As Foucault (2006b) once said, "our science enables us to call your madness illness" (p. 345). Women are increasingly subjected to classification under the psy-systems given that psychiatric knowledges serve to continually suppress women to a subjugated position in society (Ussher, 1991, 2011). Critical feminist literature argues that psy-knowledges fail to consider the impact that past social traumas have had on women's distress (Pollack, 2006; Ussher, 2011).

\section{Taming women's madness: The intersection of gender and psy}

Within a positivist paradigm, madness is construed as an individual problem - a disorder affecting an individual woman, on whom biological, psychological or social factors impact in order to produce symptomatology. (Ussher, 2011, p. 51)

Rose (1996b) considers the idea of the self to be 'culturally relativized' and fractured by circuits of power maintained and complicated by differences across various characteristics - namely gender, race, and class - which are revealed "not as our inner truth but as our last illusion" (p. 5). Other than noting that gender is constitutive of subjectivity, Rose did not write at length about the implications the proliferation of psy has had on gender. Jane Ussher draws on Rose and Foucault as well as other feminist 
scholars such as Simone de Beauvoir, Judith Butler, Phyllis Chesler, Elaine Showalter, and Susan Bordo to do just that. Ussher's texts provide a detailed analysis of the intersection of gender and psychology - where women are considered to be increasingly subjected to hyper-pathologization. Ussher (2011) contends that madness is a discursive construction, and that labeled as mad, women are "subjected to misdiagnosis and mistreatment by experts whose own pecuniary interests can be questioned, as can their use (or abuse) or power" (p. 1). This perspective is not intended to deny the reality of distress that women may experience, but rather to elucidate how reasonable responses to distress are minimized and pathological underpinnings of such distress are maximized by the psy-disciplines. Ussher (2011) adopts what she terms a 'critical realist materialdiscursive-intrapsychic model' to study gender and psychology in order to "acknowledge the reality of women's distress, while at the same time rejecting the medicalized positioning of this distress as a sign of pathology within" (p. 65). She borrows from Rose and Foucault to shape her epistemological framework, problematizing the (ab)normal and questioning how power is (ab)used in the dissemination of psy-knowledges.

Ussher (2011) maps out the historical pathologization of women, linked back to the seventeenth century where women's (mis)behaviour was considered a product of hysteria. Prior to the dawn of modern medicine, psy-perspectives on women and madness were rooted in ancient Hippocratic texts, which documented the pathological and foreign nature of a woman's body (Micale, 1990). The term 'hysteria' shares linguistic roots with the Greek word 'hystera,' signifying the womb or uterus (Merriam-Webster, 2013). Psyprominent figures (namely physicians and those involved in psychoanalysis) contended that a woman's diagnosis of hysteria was a product of her uterus dislodging from its 
normal position and wandering about the body (King, 1993). While this pseudo-science has long since been abandoned, hysteria has remained both gendered and embedded in understandings of femininity. Szasz's (1961) radical perspective of 'the myth of mental illness' suggests that diagnoses of hysteria were purposely made in poor faith because the diagnosis doubled as a constant reassurance to eventually reveal key underlying psychochemical/biological origins and differences between men and women that do not exist. The 'Hippocratic tradition' of diagnosing women with varying disorders of the mind that are said to be revealed by chemical imbalances of the brain is maintained through much of the biomedical and bio-psychiatric approaches to women's mental health today (Showalter, 1985; Ussher, 2011).

In contemporary clinical and psychological literature, women continue to be routinely pathologized for their distress in relation to men. In 2013, Freeman and Freeman (2013a) released a book based on analyses of twelve large-scale international epidemiological studies on mental disorder that date back to the 1990s. They conclude that women are $40 \%$ more likely than men to develop a mental illness (Freeman \& Freeman, 2013a). Freeman and Freeman's conclusions were generally met with praise and were heavily publicized in mainstream media, in psychological online newspapers, and in larger reputable news journals such as Time magazine (e.g., Ball, 2013; Brady, 2013; Freeman \& Freeman, 2013b, 2013c; Leighton, 2013; Mientka, 2013). Indeed some feminist groups took issue with this finding with one news media site stating: "women definitely less sane than men, claim men" (Ryan, 2013). The take away point here is that the historical association of women with 'madness' and other related characteristics (e.g., hysteria, irrationality, emotion, foolishness, promiscuity, immorality) set the course for 
establishing causal, pathological explanations for women's 'misbehaviours' and deviance throughout the centuries to follow (Ussher, 1991, 2011, 2013a).

\section{On the contemporary bible of madness: The DSM}

Psychiatric diagnosis is a professional reification about human misery, not a fact. (Ussher, 2011, p. 50)

Throughout Ussher's work, the DSM is conceptualized as having set a framework for representations of madness, defining the boundaries of what it means to be 'disordered' in addition to constructing,

... the subject position 'mad women', legitimizing the right of particular experts to speak about and treat her condition, and defining which particular 'truths' are accepted as explanations for her disordered state. (Ussher, 2011, p. 4-5)

Ussher's argument holds that the DSM is not an objective science or a practice of medicine, but rather a technology that serves to construct and reify women's problems while companies with financial interests profit from the proposed 'cures'. Ussher lays out her argument by providing examples of how certain criteria for mental disorders are written in a way that innately encompasses the essentialized behaviour of women in general. 'Histrionic personality disorder', for example, a recognized personality disorder in the DSM-V, is said to be a derivative of hysteria after being renamed in 1980 with the publishing of the DSM-III to escape the negative connotation of ancient Hippocratic beliefs (Ussher, 2011, 2013a). 'Borderline personality disorder' is one of the most widely critiqued disorders for its essentialization of the dramatic/emotional woman (Bjorklund, 2006; Shaw \& Proctor, 2005). It is also seen as a medicalized reincarnation of hysteria, first recognized officially in the DSM-III (APA, 1980; Friedel, 2004), however it differs slightly from 'histrionic personality disorder' in that women are now not only mad, they 
are also angry (hence the inclusion of criteria denoting recklessness, affective instability, identity disturbance and intense anger) and therefore dangerous (Jimenez, 1997; Ussher, 2011, 2013a).

During consultations for the anticipated DSM-V, psy-experts debated renaming 'borderline personality disorder' as some derivative of 'emotional dysregulation disorder' (Howell \& Blizard, 2009; Kalapatapu, Patil, \& Goodman, 2010), which would appear to link the diagnosed individual with defecits in adaptive emotional management capacities. Some psy-experts wrote at length about why 'borderline personality disorder' should be retained in the DSM-V regardless of its name after the field had been hit with recent critiques of how the disorder is a caricature of essentialized femininity (Paris, Silk, Gunderson, Links, \& Zanarini, 2009; Tyrer, 2009; Yeoman, Levy, \& Clarkin, 2009). Indeed, 'borderline personality disorder' is diagnosed between three and seven times more frequently in women than in men (Becker, 2000; Bjorklund, 2006; Hartung \& Widiger, 1998; Widiger \& Weissman, 1991).

Beyond personality disorders, Ussher (2011) explores other areas of mental deficit that are generally understood as a problem associated with being a woman. Depression and the clinical classifications that come with it have been conceptualized in critical feminist literature as a woman's diagnosis as they are diagnosed nearly three times more often in women than in men (Bebbington, 1996; Ussher, 2010, 2011). Further, to treat their depression, women are twice as likely as men to be prescribed psychotropic medication (Ashton, 1997; Currie, 2005; Hamilton, Grant, \& Jensvold, 1996). Premenstrual Syndrome (PMS) and Premenstrual Dysphoric Disorder (PMDD) are uniquely women's disorders, and up until the DSM-IV-TR (APA, 2001), both PMS 
and PMDD were captured under 'depressive disorder not otherwise specified', meaning that they were not, in and of themselves, mood or behaviour disorders. With the publication of the DSM-V (APA, 2013a), PMDD is now recognized as a specific subset of depressive disorders and has moved to the main body of the text from 'depressive disorder not otherwise specified' (APA, 2013a, 2013b). Ussher (2011, 2013a) argues how given ascriptions like these, femininity itself has been pathologized in the DSM.

\section{Self-injury as a renewed pathological phenomenon}

Consider how self-injury has recently received a warm formal welcome into the DSM-V (APA, 2013a). This inclusion attests to the expanding net of pathologized deviant behaviours commissioned by the psy-sciences and specifically for those that are discursively linked to women. As psy-literature has come to the conclusion that selfinjury is a maladaptive and therefore abnormal behaviour (Claes \& Vandereycken, 2007; Haines \& Williams, 1997; Haines et al., 1995; Klonsky, 2007; Laye-Gindu \& SchonertReichl, 2005), it has also severed understandings of self-injury as adaptive, for example, as an act of rational agency, resistance, or reflexive embodiment. While there is some debate, women are typically suggested as being more likely to engage in self-injury (Laye-Gindhu \& Schonert-Reichl, 2005; Ross \& Heath, 2002), which discursively renders it a woman's problem (Brickman, 2004; Chandler et al., 2011; Shaw, 2002; Taylor, 2003). Further, one self-injury typology model proposed and supported by the psy-sciences asserts that self-injury is a means to acquire attention from or manipulate 
others $^{15}$, where yet again the essentialization of the desperate and calculating woman emerges. Known as the 'interpersonal influence' model of self-injury, it was originally proposed to capture individuals who were perceived as harming themselves for attention from others through dramatic displays of attempted suicide (Favazza \& Conterio, 1989; Lloyd-Richardson, Perrine, Dierker, \& Kelley, 2007; Podovall, 1969; Ross \& McKay, 1979; Walsh \& Rosen, 1988). This type of ideology is bridged to common understandings of hysteria, where it was suggested that hysterical women had agendas of their own designed to induce certain feelings, persuade, coerce, or promote action in others (Langer, 1942).

Self-injury is thought by some to have biological origins, wherein sufferers are plagued by neurophysiological deficits and engage in self-injury as a mechanism of selfstimulation to appease their increased need for neurophysiological activity (Cullen, Westlund, LaRiviere, Klimes-Dougan, 2013; Russ, Roth, Kakuma, Harrison, \& Hull, 1994; Andover, Schatten, Crossman, \& Donovick, 2011; Haines et al., 1995). To aid in the legitimization of such claims, in May 2013, the DSM-V introduced self-injury as a unique and independent disorder (APA, 2013a). In anticipation of this inclusion, psypractioners were eager to try out the new disorder category and assess which populations are more likely to fall under the forthcoming 'NSSI' disorder (e.g., In-Albon, Ruf \& Schmid, 2013; Odelius \& Ramklint, 2013; Zetterqvist et al., 2013). This new diagnostic

\footnotetext{
${ }^{15}$ Although there are mixed and varying models, a large portion of psy-literature contends that self-injury can be explained by at least one of seven typologies. The vast majority of the literature endorses the 'affect regulation' model which suggests that self-injury is a strategy or coping mechanism that alleviates negative emotions or affective arousal (e.g., Claes et al., 2007; Klonsky \& Muehlenkamp, 2007; Linehan, 1993; Nixon, Cloutier, \& Aggarwal, 2002; Nock \& Prinstein, 2004; Rodham, Hawton, \& Evans, 2004). Endorsement of the remaining six models varies according to the population of study. They include: antidissociation, anti-suicide, interpersonal boundaries, interpersonal influence (i.e., manipulation), selfpunishment, and sensation seeking (see Klonsky, 2007).
} 
criterion is sociologically problematic insofar as it reduces self-injury to a methodical behaviour, rendering the lives of patients dysfunctional ${ }^{16}$. Designating self-injury as a new mental disorder does not 'give light' to this behaviour but instead reconstructs it as inherently pathological by ruling in and simultaneously ruling out certain behaviours required to accept or reject the diagnosis. Foucault (1980a) acknowledges this process of exclusion as one of the main functions of power through systems of discourse. The inclusion of NSSI disorder in the DSM-V thus further empowers the psy-disciplines to determine who warrants this diagnosis and who does not based on the subjective interpretation of human thoughts, feelings, and behaviours. Moreover, NSSI as a mental diagnosis represents the crux of how the psy-disciplines fail to understand self-injury in any meaningful sociological context that recognizes the subjective and fluid nature of human behaviour as it exists across various cultures and across history (Adler \& Adler, 2007; Brown, 2009; Kilty, 2008b). Shaw (2002) explains how psy-practitioners come close to drawing meaningful conclusions about the multitude of motivations and/or sociological precipitators for self-injury, before returning to characterizing the behaviour as pathological.

\section{Women's problems}

Given the extant psy-literature in which self-injury, 'borderline personality disorder', 'histrionic personality disorder', depression, PMS and PMDD (evidently), are

\footnotetext{
${ }^{16}$ A diagnosis of Non-Suicidal Self-Injury disorder requires that the individual has "in the last year [...] on 5 or more days, engaged in intentional self-inflicted damage to the surface of his or her body [...] for purposes not socially sanctioned," and that the self-injury must be associated with at least two of the indicated patterns of thoughts or behaviours, including "depression, anxiety, anger [...] a period of preoccupation with the intended behaviour $[\ldots]$ the urge to engage in self-injury [...] clinically significant distress or impairment," and/or engagement in self-injury for "relief from a negative feeling/cognitive state $[\ldots]$ or induction of a positive feeling state" (APA, 2010, n.p.).
} 
rendered women's problems, this discourse marks women with varying labels to classify their madness. Ussher (2011) explains how "madness is a gendered experience, with 'symptoms' judged differently in women and men, and certain diagnostic categories more likely to be applied to women" (p. 12). This becomes problematic now that the definition of mental disorder has changed to: "behavioural or psychological syndrome or pattern that occurs in an individual that reflects an underlying psychobiological dysfunction" (APA, 2011, para 1., emphasis added; see also Stein et al., 2010; Kendler, 2010; Sue, Sue, Sue, \& Sue, 2011). The new 'developmental' biologically-informed direction of the DSM-V reifies the organic inherency of abnormal behaviours. While some psy-literature has criticized the reductionist and deterministic focus on biological underpinnings of mental disorder in the DSM-V (Ghaemi, 2013; Hyman, 2007; Lane, 2013), this approach ensures that stereotypical women's disorders are now considered to be a product of women's faulty biology. This creates more opportunities to classify women's madness with a diagnostic label: when a woman self-injures repeatedly it is because she has a 'physiological need' for self-stimulation, when she has mood swings it is because of the imbalance of chemicals in her brain, when she is emotionally unstable, irrational and impulsive, her behaviour is explained by her personality disorder, and when she has mood swings and marked irritability prior to her biologically induced menstrual cycle she has PMS or PMDD.

The new DSM-V is a hyper-pathologization tool that enables psy-practitioners to widen the net of diagnosis, to identify deficiencies in individuals, and to discern appropriate interventions and psy-therapies. While some diagnoses are inherently gendered and primarily affect women, men are not exempt and are also more heavily 
subjected to the psychological gaze than ever before. However, given the historical hyper-pathologization of women in particular, the new DSM creates increased opportunities for the pathologization of women's (mis)behaviours (Ussher, 2013b).

\section{Responsibilization and the new medical order}

Governmentality theory explains the formation of the moral, mundane, and abiding ideal female citizen who governs her own behaviours according to neoliberal notions of responsibilization and personal accountability (Brown, 2005). Women are likewise expected to take care of their bodies and conform to ideals of Westernized beauty (Nguyen, 2011), and act 'ladylike' or otherwise remain subdued and docile. For instance, Ussher (2011) argues that women patients are more likely than men patients to accept and internalize a diagnosis handed down to them by a psy-practitioner or to selfdiagnose. Thus, the diagnosis of any of the aforementioned disorders is often the point where a woman accepts her 'fate' as mentally disordered. The over-medicalization of women's misery is exacerbated by their subject position under psy's gaze (Ussher, 2010, 2011).

Using PMS or PMDD syndromes as an example, Ussher problematizes the medicalization of women's menstruation. She argues that this pathologization of women's biology leads to a self-silencing process wherein women experience increased self-surveillance, guilt, shame and body-blaming in the attempt to dispel society's presumptions that women are unruly during menstruation (Ussher, 2004, 2006, 2008). This coerced self-policing plays a central role in women's continued subjectification (Ussher, 2004). The practices of self-policing and self-silencing are effective modes of 
'responsibilization', where women are held responsible for their defective minds and bodies and expected to seek treatment to remedy these defects.

Diagnostic categories are used to characterize women's distress, to identify women's pathologies, and to propose interventions. This practice can be theorized in tandem with Rose's methods, wherein women's behaviours are problematized (hysterical, dramatic or emotional behaviour as abnormal behaviour), explained (rooted in the biology of being a woman), tested through technologies (reified by analyses that support ongoing truth claims), proclaimed by bodies of authority (the DSM and the psyexperts who carry out these diagnoses), rendered into subjectivities (women are unique subjects with specific characteristics that are operated upon by greater governments), and met with strategies (where therapies, medications, and self-responsibilization discourse are tailored to women).

A woman's technologies of the self are determined by a set of cultural standards that operate as distinctly gendered norms that dictate the appropriate performance of femininity: sexual identity, how to carry one's body, ways of grooming, beauty, marking, framing or displaying the body (e.g., Bordo, 1993; Butler, 1990; Nguyen, 2011). Sociocultural explanations for women's distress are ignored, excluded, or rendered null; instead, the 'problem' is located squarely within the woman herself. Disorder is then constructed as a disease of the mind wherein women's lived experiences are translated into pathological ailments. Feminist critical realism recognizes the materiality of psychological experiences, but considers that such materiality is mediated by culture, language and politics (Bhaskar, 1989). With the rising pathologization in western culture (Rose, 1990, 1996b) and the pathologization of 'everyday life' (Burr \& Butt, 2000; 
Ussher, 2011), there is no space better than the prison to examine the proliferation of pathologization discourses (Rose, 1996b).

\section{Psychologization in and of penality}

The territorial boundaries between correctional systems and the psy-sciences are blurred (Arrigo, 2002; Kendall, 2000; Pollack, 2005). The blurring of these systems of thought explains how their ideological goals overlap in intimate ways. Goals of control, discipline, punishment, and reform are conflated with goals of intervention, correction, rehabilitation, and treatment. Power relations are central to the penal system in the same ways that they are in the greater psy-sciences, where both psy-staff and correctional officials (which includes psy-staff as well) govern through knowledge (Rose, 1990, 1996b). Foucault $(1977,1980$ b, 1991) clarifies the relationship between the psy-sciences and the prison by explaining how the medical system has historically served as an auxiliary to the penal system. This does not preclude there being tension in these systems; indeed there has always been tension between the psychiatric/health care component of the prison and the prison as a correctional, disciplinary society (Foucault, 1977; Groves, 2004). Prisons cannot limit themselves to discourses produced exclusively on prisonhood. In order to "assure the permanence and functioning of the institution," the collaborative application of distinct bodies of discourse that feed the prisons' goals and practices are required (Foucault, 1980b, p. 38). The penal system thus relies equally on psytechnologies as it does on penal-technologies to operate efficiently and effectively. Both discourses take on the 'facilitation of rehabilitation' objective, which confounds their ideological objectives in the modern prison system (Timmermans \& Gabe, 2002), given 
that while one goal of the correctional system in Canada may be to 'rehabilitate and reintegrate' (CSC, 2008), the prison is also a space of incapacitation, discipline, and punishment (O’Malley, 1999).

This is not to suggest that the pursuit of improving the experiences of prisoners through mental health intervention should be dismissed; rather, it is an analysis of how within correctional discourse, the production of specific knowledges on the behaviours of prisoners has increasingly relied on psychological understandings. Penality, as a space of discipline and punishment, is psychologized insofar that its technologies absorb psy methods of classifying criminal behaviour from already established psy-technologies (i.e., the clinical, hospital, and medical systems that operate independently of the prison). At the same time, penality also opens up a space in which the psy-sciences psychologize those who occupy that space.

\section{Criminal 'risk': Management through measurement}

The prison becomes a site of discipline when criminality or otherwise deviant behaviour can be measured, evaluated, and acted upon. This is often recognized in government colloquial language as 'risk management'. A primary example of this is the criminal risk and criminogenic need assessments administered when a federal prisoner is admitted into custody in Canada. Such assessment tools are based on various static and dynamic criteria, results of which are made to fit aggregated datasets that ultimately produce a number that translates into a trichotomous rating of high/moderate/low risk and high/medium/low need (CSC, 2012a, CD 705-6, 2013h, CD 705-7; see also HannahMoffat, 2004a, 2009). Actuarial risk logic has proliferated the penal system in recent 
years and is argued to have replaced most or all elements of social and individualized ways of understanding people in conflict with the law (Feeley \& Simon, 1992; Kemshall, 2003; O’Malley, 1996; Walklate \& Mythen, 2011). This turns towards 'actuarial justice' was encouraged by the desire for increasingly 'efficient' means by which to classify prisoners and make 'empirically validated' and informed correctional decisions that relate to 'public safety' (Feeley \& Simon, 1992, 1994; O’Malley, 1996; Simon, 1988). Castel's (1991) piece on the shift from dangerousness to risk considers how 'mental medicine' has given way to a new direction in risk assessment where it is no longer about the immediate harms caused by an individual but rather about predicting the potential for future dangerousness. O'Malley $(1996,2009)$ argues that the practice of risk management is the result of the political state in which the prison is aligned with, namely neo-liberalism and neo-conservatism ${ }^{17}$.

Actuarial risk tools have become increasingly saturated in Canadian penality, in part due to the push to increase 'offender accountability', which is part and parcel to the measurement of criminal risk. This idea that offenders need to be held more responsible for their crime(s) was highlighted in a lengthy 2007 report authored by an independent review panel appointed by the Minister of Public Safety. The report writes that "the offender must seize opportunities offered to change - to pick up the tools of rehabilitation and use them" (CSC Review Panel, 2007, p. vii). In 2008, the CSC established a 'Transformation Team' that led the CSC through its 'Transformation Agenda' geared towards implementing the majority of the CSC Review Panel's (2007) recommendations

17 O'Malley $(1996,1999,2009)$ suggests that the increasingly volatile direction of the crime and punishment agenda is due to the tension of neo-conservative and neo-liberal rationalities. 
in order to "enhance public safety for Canadians" (CSC, 2012g, para. 1) $)^{18}$. This shift in ideology was later legitimated by changes in federal legislation that sought to get 'tough on crime' in part by 'increasing offender accountability' (Bill C-10, 2012; Bill C-37, 2013; Public Safety Canada, 2013). This change resulted in a renewed commitment by the CSC to "take proactive action to mitigate potential risks to ensure delivery of core business that contributes to public safety" (CSC, 2013o, p. 10), wherein the CSC considers itself to be

... strengthening the inmate discipline process and adding more structure to the institutional routine to ensure offenders fully use their time to address factors that lead to their incarceration. (CSC, 2012g, para. 5)

The 'increasing offender accountability' agenda is conducive to the risk management practices operating within the CSC as it seeks to measure and evaluate the individual responsible for the crime(s) while simultanousely emphasizing personal accountability for one's criminal history.

Actuarial tools used (and mostly developed) by the CSC include, but are not limited to: the Statistical Information on Recidivism Scale (SIR-R1) which assesses the risk of recidivism in non-Aboriginal men; the Custody Rating Scale (CRS) which assesses institutional security risk and penitentiary classification level for all prisoners and recidivism risk for Aboriginal and non-Aboriginal women prisoners; the Dynamic Factor Identification and Analysis (DFIA) which assesses criminogenic needs; the Static Factors Assessment Report which assesses fixed risks at intake; a Reintegration Potential

\footnotetext{
${ }^{18}$ Jackson and Stewart (2009) offer a critique of the CSC Review Panel's (2007) recommendations and deny that things like 'increased offender accountability' will contribute to public safety in any way. The authors write: "the Panel's analysis reveals such fundamental misunderstandings and misinterpretation of the Canadian correctional context that both its observations and recommendations are indelibly flawed" (Jackson \& Stewart, 2009, p. ix-x).
} 
assessment tool; the Offender Accountability rating scheme; Offender Motivation rating; Offender Engagement rating; psychological risk assessments; and a flurry of other assessments that are subscales of existing tools, such as the Institutional Adjustment rating, Escape Risk rating, Security Risk rating, and the Public Safety Risk rating (CSC, 2012a, CD 705-6, 2013h, CD 705-7).

The outcomes of these assessments have implications for prisoners across the entire carceral continuum, from intake to community supervision. For example, once assigned an institutional security level as per the CRS, prisoners involved in institutional incidents may be re-assessed to increase their security level and be issued a transfer warrant to a higher security level prison (CSC, 2013h, CD 705-7). When up for parole, the prisoner's CRS level and other assessment outputs generated by tools such as the Reintegration Potential assessment tool or the Public Safety risk scale influence the Parole Board of Canada's (PBC) decision on whether or not to grant discretionary release (PBC, 2013; Stys, Dunbar, Axford, \& Grant, 2012). The existence of these tools and their enshrinement in correctional policy demonstrates the penal system's commitment and indebtedness to actuarial risk logic. Through the measurement of risk, these tools ultimately serve as a predictive risk management strategy that legitimizes intervention through pre-emptive action (Rose, 2000a, 2000b, 2005), namely, the mere confining of prisoners in custody for fear that they will recidivate ${ }^{19}$. As Zinger (2004) notes, actuarial risk assessment in the context of the Canadian criminal justice system has resulted in the

\footnotetext{
${ }^{19}$ This is not to suggest that 'public safety' is the paramount reason for why individuals who commit crime are sentenced to prison. Indeed the desire to punish with sentences 'proportional' to the crime committed plays a large role in sentencing (von Hirsch, 1990). Emotional justifications for punishment are similarly argued to play into sentencing as if the suffering of a perpetrator in prison will 'do justice' for suffering experienced by victims (Christie, 2010; Murphy, 2004; Pratt, 2000).
} 
corporatization of determining criminal risk, that is, the turning of criminal risk tools into a big business.

\section{The criminalized woman: The intersection of penality and gender}

Correctional discourse has long claimed that there are 'gender-responsive' services and programs available that serve to empower women prisoners to become responsible and productive law-abiding citizens (CSC, 2010a; Blanchette, 2002; Fortin, 2004; Verbrugge \& Blanchette, 2002). However, feminist criminologists question the CSC's definition of 'empowerment' and whether the prison environment can offer rehabilitation at all (Hannah-Moffat, 1995, 1999, 2001, 2004b; Hayman, 2006; Kendall, 1994, 2000). Risk-logic has become a topic of much debate where critical scholarship argues that risk-based actuarial tools are gendered insofar as they continue to evoke male normative standards, stereotypical constructions of femininity and criminality, and fail to consider women's lived experiences as linked to their criminalization (Hannah-Moffat, 2004a, 2004c, 2006, 2009; Hannah-Moffat \& O’Malley, 2007; Hannah-Moffat \& Shaw, 2001). Moreover, actuarial risk tools are argued to hybridize risk and need where women are not seen as having needs that come without risks (Hannah-Moffat, 2004a; Maurutto \& Hannah-Moffat, 2006).

The neoliberal shift from punitive to 'correctional' is arguably harder on women prisoners who are increasingly held responsible for their criminality and rehabilitation (Hannah-Moffat, 2000; Heeren, 2010; Shantz, Kilty, \& Frigon, 2009). The 'increasing offender accountability' proponent of Bill C-10 aims to enhance penal practices that hold prisoners increasingly accountable for their past offences and to make increased efforts to 
redeem themselves for their actions (see Public Safety Canada, 2013). While it is too soon to see the effects this law has on women prisoners specifically, its emphasis on 'offender accountability' demonstrates how correctional discourse increasingly responsibilizes women prisoners for their past experiences, brushes with the law, and for simply being 'at-risk'. Moreover, such neoliberal ideologies of responsibilization are argued to problematically assume that "'good" choices are equally available to all people" (Pollack, 2000a, p. 73).

Correctional techniques of responsibilization paired with the increased reliance on psy-discourse in penality offers ways to classify and treat women's criminality, all the while holding women increasingly accountable for their criminal histories. Women prisoners are particularly vulnerable to pathologization and responsibilization in the pursuit of normative femininity and gender conformity (Carlen, 2012; Hannah-Moffat \& Shaw, 2001), and where women's over-medicalization is largely unchallenged (Conrad, 1992, 2005; Ussher, 2011). This layering of different points of social vulnerability is further complicated where racially marginalized women are concerned, particularly Aboriginal women prisoners, who are reported to have higher rates of mental illness diagnoses (Balfour, 2000; Faith, 1993; Wesley, 2012), to be more likely than nonAboriginal women to be prescribed medication in prison (Langner, Barton, McDonough, Noël, \& Bouchard, 2002), and to be more likely to have substance-related problems (Dell \& Boe, 2000; Dowden \& Blanchette, 1999; MacSwain \& Cheverie, 2012; Moore \& Trevethan, 2002; Mullins \& MacDonald, 2012). The intersection of gender, Aboriginal heritage, and criminality is argued to result in the construction of the 'expected 
Aboriginal woman drug offender' (Dell \& Kilty, 2012) and the layering of social vulnerabilities is said to invite increased psychological diagnoses (Kilty, 2012).

\section{Control through intervention}

Correctional and mental health programs designed to address women's criminality and mental instability have been critically assessed as essentialized representations of femininity that are coercive in nature (Hannah-Moffat, 1995, 2004b). Programs are 'voluntary' by definition (CSC, 2011c, CD 726-1) yet women who refuse to participate are penalized for failing to follow their correctional plan, consequences of which can result in the revocation of privileges or contribute negatively to their parole review (Cabana, Wilton, \& Stewart, 2011; Hannah-Moffat, 2000; Hannah-Moffat \& Shaw, 2001). Similar to how predictive risk management strategies permit pre-emptive action upon populations (Rose, 2000a, 2000b), the practice of labelling women prisoners as in need of program intervention for structural reasons they cannot alter gives way to mandated interventions. This bears the question whether the prisoners were truly devoid of decision-making abilities (as cognitive behavioural based therapies imply), or whether correctional regimes construct them as such to exercise an additional layer of control that is, beyond the explicit disciplinary control of spatially confining their bodies in a prison. Manufacturing cognitive-based reasons to take action upon a prisoner serves as an example of how the mind has become the new object of discipline (Foucault, 1977).

Dialectical Behavioural Therapy (DBT) is one of the programs offered to federally sentenced women who have "emotional difficulties and behaviours [that] are very problematic and resistant to change, particularly those with patterns of persistent 
self-destructive and/or suicidal behaviour" (Warner, 1998, Chapter V, para. 1). While DBT referral criteria requires that candidates exhibit symptoms of or be diagnosed with 'borderline personality disorder', the program is generally offered to women who show signs of self-injury ${ }^{20}$ (Laishes, 2002). Contrary to how the CSC presents the program, DBT has been criticized as individualizing women's crimes by failing to consider social contributors to criminality and by pathologizing women's behaviours and feelings, all the while simultaneously placing the blame squarely on the shoulders of the women for 'failing' at living a crime-free life (Canadian Association of Elizabeth Fry Societies [CAEFS], 2005; Kendall, 2000). DBT and other cognitive behavioural therapy programs (including non-mental health centered 'correctional' programs) are argued to fail at addressing the prison environment itself and how it may contribute to and exacerbate emotional instability or distress (Kendall, 2000, 2002; Pollack, 2005). Kendall (2000, 2002) posits that such programs exclude the incorporation of systemic issues as valid risk factors for criminality, thereby promoting a process of 'othering' criminalized women. In turn, this 'othering' encourages moral indifference, dehumanizes women prisoners, legitimizes the revocation of their rights as free citizens, and holds them responsible for their own historical oppression (Kemshall, 2002; Kendall, 2000, 2002; Pollack, 2005, 2006). By not acknowledging how class, gender, race, histories of trauma or abuse and other vulnerabilities come into play in the commission of criminal acts, these programs individualize women's crimes and place the burden of responsibility squarely on their

\footnotetext{
${ }^{20}$ Note that DBT is not offered to men prisoners in Canadian federal prisons, though in 2009 the CSC funded a lone-standing 'complex needs unit' designed to treat men prisoners with serious cases of selfinjury (CSC, 2011j) which began operating by late 2010 (OCI, 2013c). In March of 2013 this unit closed as it was reported that the specialized treatment centre had a high staff turnover rate and was not yielding significant results in reducing self-injury (Stone, 2013). No equivalent initiative for federal women prisoners was established.
} 
shoulders (Balfour, 2000; Hannah-Moffat, 2004c; Kendall, 2002). Despite this camp of criticism, the CSC has prided itself on offering mental health programs for women, including DBT and Psychosocial Rehabilitation (Blanchette, Flight, Verbrugge, Gobeil, \& Taylor, 2011; Laishes, 2002; McDonagh, Taylor, \& Blanchette, 2002; Sly \& Taylor, 2003, 2005), in addition to correctional programs that are designed to address women's criminogenic needs such as substance abuse and violence prevention (Booth, 2012; CSC, 2012c; Fortin, 2004; Grant, Furlong, Hume, White, \& Doherty, 2008; Matheson, Doherty, \& Grant, 2009).

\section{Women as prisoner-patients}

As Carlen (1986) points out, psy-practices within the prison have been "refashioned as one more weapon in the prison's never-ending quest for ideological justification of its power to punish" (p. 266). The intellectual technologies of the psysciences that dictate how women prisoners should be examined and acted upon are not rooted in objectivity or scientific truths as promised. These ways of thinking hail from social and political processes and quests for power (Kemshall, 2002; Kendall, 2000; Rose, 1998). The correctional system privileges a medical formulation that constructs abnormal behaviours as pathological (Kendall, 2000; Pollack, 2005); to respond to these gender-specific pathologies, the psy-sciences promise solutions to social problems in objective and neutral ways. Pollack (2012) comments on the practice of 'scientific spectatorship' with respect to dominant 'evidence-based' ideologies. She argues that discourses embedded with scientific psy-gazes, 
... shield from view the individual, collective, and social pains of imprisonment ${ }^{21}$, preoccupied instead with transforming, controlling, predicting and reconstructing the criminal subject, while simultaneously refusing to see her. (Pollack, 2012, p. 8)

The very nature of being in prison is a call for psy-expert intervention, evaluation, and monitoring for abnormalities of the mind. If we accept that the prison environment exacerbates the symptoms of mental disorder through increased feelings of women's distress (e.g., Carlen \& Worrall, 2004; Hannah-Moffat, 2001; Kilty, 2012), it is no wonder that women prisoners are met with intervention and are in turn painted as one of the most high-risk groups for mental instability. If psy-experts were to assess every person in mainstream society for presence of mental illness, how many more would be labelled disordered? For most of us, attending a psy-expert's office for diagnosis is a choice - something women prisoners do not have. Indeed "the capacity to create a therapeutic prison environment, conducive to healing, is antithetical to the purposes of the corrections system" (Peters, 2003, p.5). In fact, the CSC has been characterized as being stuck between the opposing entities of the prison and the hospital (OCI, 2011, 2012a, 2013c). As a result of this hybridization of penality and mental health care, correctional discourse and the penal practices they represent actively institutionalize women as both prisoner and patient.

\footnotetext{
${ }^{21}$ The 'pains of imprisonment' is a prominent theory in critical criminology, wherein Sykes' (1958b) first posited that individuals who are held in the 'society of captives' are faced with painful experiences of being deprived of liberty, goods and services, relationships, and autonomy. Crewe (2011) and Haney (2006b) offer a contemporary review of the pains of imprisonment, while others have applied the theory to selfinjury wherein the behaviour is theorized as a resistance strategy, particularly for women offenders, as a natural response to the oppressive prison environment (Fillmore \& Dell, 2005; Frigon, 2001; Kilty, 2006, 2008a) and as an attempt to resist alienation (Robert, Frigon, \& Belzile, 2007), and similarly with respect to suicide attempts (Liebling, 1994, 1995).
} 


\section{CHAPTER III: METHODS}

To know a particular social language is either to be able to 'do' a particular identity or to be able to recognize such an identity. (Gee, 2011b, p. 156)

\section{Defining 'correctional discourse'}

Discourses, more generally speaking, have been subject to much definitional debate (e.g., Foucault, 1972a, 1972b; Purvis \& Hunt, 1993). My methodological approach accepts that discourse and ideology are two separate yet overlapping terms, and that ideology supports discourse rather than opposes it (Purvis \& Hunt, 1993). Discourse, then, provides a vehicle in which ideological modes of thought are communicated, serving to engage with social relations as a way to organize thinking, understanding, and experiencing (Purvis \& Hunt, 1993). In more pragmatic terms, ideology is accepted in this thesis as being a system of ideas (e.g., the belief that criminals should be punished and that we need to get 'tough on crime'; see Hogeveen, 2005; Mallea, 2010), while discourse is the vehicle in which these ideas are communicated through language, text and other transmissible modes of communication (e.g., the passing of the Safe Streets and Communities Act [Bill C-10, 2012], or other bills and policies that seek to increase offender accountability’ [Bill C-37, 2013; CSC, 2012g; Public Safety Canada, 2013]).

Correctional discourse thus consists of modes of communication that originate from a correctional-oriented ideological base. I define this as all research, publications, texts, and other communications put forth by representatives and officials who work within (or in collaboration with) the criminal justice system, and that seek to (whether explicitly or implicitly) communicate an ideological basis that supports the prison. That is, that the prison is generally accepted as a valid and/or effective means of punishing 
and/or 'rehabilitating offenders'. This includes what some have termed 'administrative criminology' or 'managerialist criminology' (see Pavlich, 2000; Valverde, 2008; Walklate, 2007; Young, 1986), whose central concerns are managing the problem of crime through the development and utilization of actuarial and other risk-management tools.

Individuals who participate in the production of correctional discourse thus largely consist of government officials, executives, and in-house researchers who study and publish texts related to incarceration and community corrections, but may also include external contract employees and academic scholars who are working in collaboration with such officials. Topics may range from preventative policing to recidivism and release outcome management, so long as the nature of the content touches on the prison or the idea of correcting or rehabilitating individuals who have committed a criminal offence. One of the best examples of correctional discourse in Canada would be the breadth of research that Don Andrews, James Bonta, and Paul Gendreau, among others, have contributed, most notably with respect to the development of actuarial criminal risk tools (e.g., Andrews, 2001; Andrews \& Bonta, 1995, 2010; Andrews, Bonta, \& Wormith, 2004, 2006; Andrews, Zinger, Hoge, Bonta, Gendreau, \& Cullen, 1990; Bonta \& Andrews, 2003, 2007). Similarly, Kelley Blanchette and Kelly Taylor make up some of the key researchers who produce correctional discourse about women prisoners (e.g., Blanchette, 2001, 2002; Blanchette \& Brown, 2006; Blanchette \& Taylor, 2004, 2005, 2009; Blanchette et al., 2011; Taylor \& Blanchette, 2009).

Any piece of text related to crime or criminal justice (e.g., research, policy, departmental or organizational report) published by a department who is in some way 
recognized as directing or influencing the criminal justice system and who touches upon the prison and/or its corrective capacities is also understood as an example of correctional discourse. Generally, this concerns official bodies of literature promulgated by or under provincial or federal governments. This would include any text published by the CSC, the PBC, the Ministry of Public Safety Canada, the $\mathrm{OCI}^{22}$, the Royal Canadian Mounted Police, Statistics Canada, the Department of Justice, Canada Border Security Agency, or the Parliament of Canada. One may ask how Statistics Canada, for example, produces correctional discourse given their self-stated neutral stance on external governmental policies and practices (Statistics Canada, 2013). Because they report on statistics related to the correctional system (e.g., police reported crime statistics and the compilation of prison population data), they ultimately contribute to correctional discourse.

What is not considered correctional discourse? It is not critical criminology, which is primarily concerned with analyzing power relations, social injustices, and the criminalization of individuals, groups, or acts (Doyle \& Moore, 2011). Critical criminology may be considered as the opposing force to administrative or managerialist criminology as it generally seeks to challenge correctional discourse, but it also engages in a reflexive interrogation by actively challenging its own exclusions, omissions and limitations (Barak, Leighton, \& Flavin, 2010; Doyle \& Moore, 2011). This thesis adopts a critical criminological perspective insofar that the theoretical frameworks and epistemological challenges applied to the textual material or to correctional discourse more generally problematize the ideological bases that produce correctional discourse.

\footnotetext{
${ }^{22}$ Although the OCI acts as an ombudsman for federal prisoners and is generally critical of certain correctional practices, the organization ultimately reports to the Minister of Public Safety and is run and governed as all other federal public service offices are.
} 
Before moving on, it is important that we acknowledge that correctional discourse is not a 'bad' thing or an 'evil' entity in some way. Correctional discourse is an essential component of the criminal justice system; without it the justice system would simply not exist. Correctional discourse should be better understood as a body of knowledge that, for the most part, holds political and policy implications, as it can be a vehicle that drives systemic change when permitted by the political climate. Even when no change is caused directly by correctional discourse, it builds up a body of knowledge that is absorbed by individuals and groups who operate within and outside of the justice system (i.e., academics, activists, the media). The potential for change through discourse is neither necessarily negative nor positive, as it will always depend on the evaluator or the audience to decide what kind of impact discourse has had. However, the potential for knowledge absorption or transmission is positive in the sense that whether correctional discourse is accepted or dismissed, we are bound to interpret it in some way which contributes to the development and advancement of correctional knowledge and critique.

\section{Towards a research object}

As the official governing body of federal corrections in Canada, the CSC is responsible for the care and custody of prisoners sentenced to a two or more year term in a federal prison. In addition to being responsible for the management of prisoners throughout their incarceration and community supervision, the CSC researches, creates, implements and promotes a number of organizational initiatives that are focused on pursuing their mandate; that is, the assisted reintegration of offenders into society (CSC, 2008). The common means of measuring such success involves evaluation, namely the 
internal auditing of interventions using largely quantitative methodologies where treatment groups are compared to control groups and conclusions about effectiveness and efficiency are drawn. For example, the CSC determines whether Aboriginal prisoners who resided in a 'healing lodge' were more likely to be granted a discretionary release than those who did not (CSC, 2011d; Trevethan, Crutcher, Moore, \& Mileto, 2007), whether prisoners who participated in their in-house CORCAN employment program were more likely to attain employment in the community than those who did not (Nolan, 2012), and whether those who participated in a cognitive-behavioural-based correctional program were less likely to return to custody than those who did not (CSC, 2009b, 2010b; Usher \& Stewart, 2011). Research like this is conducted at all stages of intervention implementation, whether on a pilot initiative that is slated to expand nationally, or on already established programs and initiatives. Much of this research is concentrated in one department within the CSC known as the Research Branch (RB). The RB's core research topics include, broadly, research on Aboriginal prisoners, women prisoners, correctional operations, community corrections, correctional programs and interventions, substance abuse, offender profile and forecasting, and health and mental health issues (CSC, 2013p, 2013q).

\section{The 'Research Branch': A correctional laboratory}

Texts and knowledge produced by the RB form a large portion of what I have termed correctional discourse, specifically in contemporary Canadian criminology. The $\mathrm{RB}$ is best understood as the 'knowledge production' centre of CSC-specific correctional discourse as opposed to the more strategic or legislative flavoured variants of correctional 
discourse such as departmental performance reports or organizational policies. The RB's self-stated mission is to:

Make direct links between research findings and implications for our institutions, community sites and the public. [...] help(s) offenders work towards successful reintegration and assist(s) staff in identifying effective strategies to work safely and efficiently. (CSC, 2013p, para. 1)

The RB was born out of a need to provide comprehensive results on organizational initiatives and was previously a fragmented group of people working on various correctional research projects for the CSC (CSC, 1989). In the late 1980s it solidified its shape and structure within the organization as a place of empirical validation for existing initiatives:

The CSC can now begin to address research concerns in a more concerted and directed fashion, more closely tied with the development of our corporate objectives and policies. [...] A greater sense of ownership of research activities should result, generalizing in time to a greater readiness to apply the findings of research. (CSC, 1989, para. 10)

Internally commissioned research invites obvious concerns of objectivity and impartiality. The issue of experimenter bias was not explicitly addressed in the original RB documents that detailed its establishment, nor has it been a topic they have reflexively addressed in recent publications. External contractors are not deemed useful for their impartiality as a result of their lack of stake in the outcome of the project, rather, they are deemed useful for alleviating the internal workload. In doing so, employees working for the $\mathrm{RB}$ are positioned as key to meeting and maintaining the needs of the CSC:

Although contracting out can be useful, particularly for large data collection efforts, research staff are essential to give continuity to the process, to make the most effective use of existing information that can potentially feed into research analysis, to develop mutually supporting 
relationships with operational managers, and to learn how to integrate and communicate research findings so as to be most useful and appealing. (CSC, 1989, para. 18)

Today, the RB, located at the CSC's $\mathrm{NHQ}^{23}$, is the crux of all correctional research and is a well-respected department within the CSC and in international correctional discourse more broadly. This includes throughout Europe (World Congress on Probation, 2013), the United Kingdom (Jolliffe \& Farrington, 2007; Ministry of Justice [UK], 2011; Sapouna, Bisset, \& Conlong, 2011), and the United States (Camp, 2004; Gaes, Flanagan, Motiuk, \& Stewart, 1998; Latessa, 2004). The international recognition of research published by the RB or by staff affiliated with the CSC demonstrates how Canadian correctional discourse influences international correctional policy, practices, and, notably, 'best practices' for correctional programming.

Given the RB's international reputation and its privileged positioning within the $\mathrm{CSC}$ both to conduct research on and to access the correctional environment, the RB may be theorized as a 'correctional laboratory' that contributes to the production of correctional knowledge. In this laboratory researchers are privy to an endless supply of research subjects and opportunities. Given that the RB's role is to conduct research (CSC, 1989, 2004, CD 009), prison capacities are analyzed and projected, practices are accredited and evaluated, corporate strategies are validated through the appraisal of performance indicators, and the subjectivities of prisoners are placed into dichotomous experimental and control groups in order to arrive at some 'empirically validated' understanding of which individuals are more likely to do (or not do) certain behaviours

\footnotetext{
${ }^{23}$ The CSC's NHQ is the central decision-making hub and is responsible for writing policies, publishing research, streamlining and implementing practices, and all other things required of the center of command that dictates how the regional institutions and operational and corporate departments will operate (CSC, 2013o).
} 
when compared to other prisoners with varying characteristics, or lack of characteristics, and so on.

The RB's laboratory may also be theoretically interpreted as being 'black-boxed' insofar that the truths it produces are generally accepted and/or unquestioned by external international correctional discourse because of the CSC's reputation for correctional expertise $^{24}$. This is evidenced in the international praise the RB and their research have received with respect to 'best practices' for correctional interventions (e.g., Camp, 2004; Ministry of Justice [UK], 2011; World Congress on Probation, 2013), where the RB's 'evidence-based' findings have generally gone unchallenged. In fact, much of the discourse that has sought to directly engage with and challenge truths hailing from the $\mathrm{RB}$ or otherwise from within the CSC is located outside of correctional discourse and within critical criminological literature. For example, Webster and Doob (2004a, 2004b) engaged first hand with the RB when they challenged the CSC's use of the CRS with women prisoners (for the CSC's response, see Blanchette \& Motiuk, 2004), while Hannah-Moffat (2009) challenged Smith, Cullen and Latessa's (2009) and Taylor and Blanchette's (2009) views on the use of the Level of Service Inventory-Revised tool with women prisoners (see also Morash, 2009). These kinds of inter-disciplinary debates are indeed important in terms of considering all sides of an issue, however after time passes and the debate fizzles out, the RB returns to their laboratory and churns out the research they sought to produce in the first place (e.g., Blanchette \& Taylor, 2005; Gobeil, 2007;

\footnotetext{
${ }^{24}$ This idea of the laboratory and 'black-boxing' is inspired by Latour's (1987; Latour \& Woolgar, 1979) conceptualization of the laboratory as a workplace that produces and thus constructs hard facts. While Latour was generally concerned with more traditional scientific disciplines, contemporary scholars like Haggerty (2001) have applied Latour's theories to the production of truths by social science disciplines, such as crime statistics.
} 
Thompson, McConnell, \& Paquin-Marseille, 2011 on the security reclassification scale for women; Barnum \& Gobeil, 2012 for the use of the CRS with women).

One research subject that has recently been a hot topic in corrections, and, as such, an area of inquiry that has kept the correctional laboratory invested and engaged, is that of prisoner self-injury. After the death of Ashley Smith in 2007, media attention and stakeholders put pressure on the CSC to address the issue of self-injury amongst prisoners $^{25}$. Shortly after this an abundance of research on self-injury authored by the RB surfaced. Methodologically speaking, it is necessary to note that prior to Smith's death, there were two research articles published by the RB on prisoner self-injury. Today, fourteen extensive reports on prisoner self-injury published by the RB exist. This surge in research reports published by the RB is a cause for inquiry. Why now, and what is this new research saying about self-injury that may not have been said before?

\section{Research Questions}

1. What does the new surge of CSC research say about prisoner self-injury?

a. How is prisoner self-injury explained? What are the conclusions surrounding the functions of self-injury for prisoners?

b. Are the research reports and their conclusions gendered? If so, in what ways?

\footnotetext{
${ }^{25}$ See, for example, repeated requests made by the OCI that call on the CSC to produce an 'inventory of best practices' for self-injury (OCI, 2009a), establish a "consistent framework for recording and reporting attempted suicides, self-inflicted injuries and overdoses" (OCI, 2008b, p. 32), and to produce "clinical research' that would support a 'proven treatment program/plan' for self-injuring prisoners (OCI, 2010a, 2011), in addition to external organizations that called for reform of the treatment of individuals with selfinjury and mental health concerns in prison (CAEFS, 2009; Ombudsman and Child and Youth Advocate, 2008; Prison Justice, 2008), and media reports that generally played off the OCI's harsh criticism of the lack of adequate services for self-harming women in prison (CBC News, 2009; Silliker, 2009; Zlomislic, 2010).
} 
c. How does the research approach the 'best practices' in the assessment and intervention of self-injury? What is not addressed?

d. What reasons could explain the sudden surge of production of research on prisoner self-injury? What reasons may be excluded from the RB's selfstated rationale for this research?

2. Has the tone of research shifted over time within CSC publications? If so, in what ways?

a. Does this shift affect the power relations between the institution and its prisoners? If so, how?

b. Does this shift benefit the institution in some way?

c. What does this shift in self-injury discourse imply politically for the CSC?

\section{Methodological approach}

To answer these questions, a qualitative method of analysis was undertaken to deconstruct the CSC's publications on prisoner self-injury. Given that I examined texts distanced by a lengthy time period (one of the reports dates back to 1990), discourse analysis allowed me to study the core messages and meanings while elucidating the shifts in stance on the issue (if any) between texts written twenty years apart. Moreover, discourse analysis allowed me to unpack the political messages behind the research while simultaneously using sociological interpretations to draw out the social languages used and to unveil what messages they seek to convey. Social languages are understood as analogous to discourse to the extent that they characterize a given discourse by making up the language bits, connotations, tones, and messages relayed (Gee, 2011a, 2011b). In 
this sense, the phrasing and language used in a given discourse enacts specific social languages, which are associated with a particular social identity (Gee, 2011a, 2011b).

Discourses exist in many forms, including speech, posturing, dressing, feeling, acting, interacting, writing and texts. To synthesize my project, I rely heavily on James Paul Gee's work (2011a, 2011b), which focuses mostly on discourses as language-in-use, namely in speech or in text. His theorization of the latter, language-in-text(s) is the focus of this methods chapter. Gee is known mostly for the approachability and accessibility of his methods and the analytic tools he uses to deconstruct texts or language (Burns, 2013; Lewis, 2011). Gee (2011a) generally accepts that discourse itself is an interpretation and that a discourse analysis is thus an "interpretation of an interpretation" (p. 122). Gee's approach is more accessible than other complex or layered forms of text analysis, such as Luhmann's (1993) second-order observation or what is recognized as a 'Foucauldian discourse analysis' (e.g., Kendall \& Wickhham, 1999). Although, it is important to note that Gee's perspective on truth and discourse aligns with how Foucault described discourses as a product of the power/knowledge relationship, where power is constituted through accepted bodies of knowledge, science, and 'truth':

Truth is a thing of this world: it is produced only by virtue of multiple forms of constraint. And it induces regular effects of power. Each society has its regime of truth, its "general politics" of truth: that is, the types of discourse which it accepts and makes function as true; the mechanisms and instances which enable one to distinguish true and false statements, the means by which each is sanctioned; the techniques and procedures accorded value in the acquisition of truth; the status of those who are charged with saying what counts as true. (Foucault, 1980c, p. 131)

Foucault views knowledge not simply as a vehicle for understanding, but as the adoption of fragmented pieces of ideologies (Foucault, 1984a). It is not possible to absorb 
knowledges in their entirety, rather, in using knowledge we are inevitably 'cutting it up'; we create (new) meaning out of the bits we have cut and spliced into our own thought (Foucault, 1984a; Osberg, 2010). Gee's discourse analysis methods draw from the same epistemological underpinnings as Foucault insofar as truths are perceived as constructed in part by discourses and the social institutions that uphold them, and that knowledges are seen as socially constructed and maintained (Gee, 2011a). Throughout the next section, I describe Gee's interpretation of discourse analysis and outline his method.

\section{Defining discourse analysis}

Discourse analysis involves both method and theory, as a sensible method requires a theory of the analytic domain (Gee, 2011a). Discourse analysis elucidates problems and controversies in the world, whether about how social goods are distributed or the degree to which certain populations benefit from or are impaired by policies, practices and so on (Gee, 2011a). It is inevitably subjective and does not consist of an algorithm or query that extracts automated or computable results, methods which have come to be known as positivist; instead discourse analysis adopts and adapts pre-existing tools of social inquiry and pairs them with various strategies for implementing them. Termed a 'community of practice', those who engage in this kind of research together form the baseline for the use of discourse analysis tools, while contributing to the development of what discourse analysis actually means (Gee, 2011a). Research groups, then, have a certain amount of freedom in adapting the tools of discourse analysis to fit their research projects. A researcher must adapt the method accordingly to his or her domain; namely, the general topic at hand and its socio-political context. 
It is important to distinguish between a 'discourse analysis' and a 'critical discourse analysis'. A discourse analysis sans 'critical' - also known as a descriptive discourse analysis - does not consider the social contexts or political climate that bore the analytic material. In this way, the approach of descriptive discourse analysis is seen as evading social and political responsibility (Gee, 2011a). However, Gee (2011a) posits that all discourse analysis must be critical because language is political. This logic aligns with other key beliefs on the politicization of the social world, for example in feminist studies where the primary view is that 'the personal is political' (Hanisch, 2000). If "the theory of language [...] has meaning only in and through social practices" (Gee, 2011a, p. 12, original emphasis), by default then, any analysis of language (at least by a researcher in sociology) must consider politics. Given this logic, this project will not be critical to the extent that particular grammar, syntax, semantics, or linguistic utterances are analyzed (as is done in traditional critical discourse analysis or in functional linguistic analysis; Newmeyer, 1998; van Dijk, 2009; Wodak \& Meyer, 2009), but rather in the sense that there is an assumed connection between the texts as a whole and a particular socio-political stance.

Gee (2011a, 2011b) differentiates between two types of discourses, one being discourse with a lowercase "d", signifying language-in-use that does not have greater societal implications, such as short conversations or stories. The second type of discourse, which is the main point of study here, is uppercase "D" discourses, which always involve language in addition to the societal considerations and implications that come with it. Big "D" discourses involve the recognition of discourses as particular bodies of identity/identities, which are seen as engaged in a particular type of activity or 
practice. This thesis examines big " $\mathrm{D}$ " discourse, but for the sake of general flow and sound grammatical structure, I will herein refer to big "D" discourse simply as 'discourse'.

Gee (2011a, 2011b) identifies seven distinct elements used to facilitate discourse analysis. These include: significance, practices, identities, politics, relationships, connections, and language type and sign systems. These seven building blocks of discourse analysis allow researchers to disaggregate components of the material and characterize each category independently to draw out the fundamental themes in the discourse(s) of study. Each building block is associated with a particular question in order to assist the researcher in answering how their textual material uses (or does not use) particular elements of discourse to position themselves as truth or align themselves with a particular political/social stance. In applying these questions to my own research project, I review Gee's seven building blocks of discourse analysis and apply them to broader criminal justice, corrections and/or psy-based contexts to set the stage for synthesizing the textual data in the forthcoming results chapter.

1. Significance: Where language renders ideas significant or lessens significance, it acts as a signal to readers on how to view or determine the relevance and weight of an argument. For example, some psychological texts emphasize and propagate the validity and truths of mental disorders as biologically determined (see, for example, Charney \& Nestler, 2011; Kupfer, Frank, \& Phillips, 2012; Nestler \& Hyman, 2010). In doing so these texts lessen the significance of the nature versus nurture debate by focusing on biological determinacy. The recent passing of 'tough on crime' legislation 
(i.e., omnibus Bill C-10) also serves as an example, where its discourse (prior to and after royal assent) renders significant things like the danger of criminal others, achieving 'truth in sentencing', and retribution for victims through increased 'offender accountability' (Hogeveen, 2005; Mallea, 2010; Moore, Burton, \& Hannah-Moffat, 2003). Texts can equally render significant ideological suppositions about research methodologies and what constitutes valid or sound research.

Discourse analysis questions: How are the RB's texts being used to make certain things significant or not and in what ways?

2. Practices: If we accept that a practice is a "socially recognized and institutionally or culturally supported endeavor that usually involves sequencing or combining actions in certain specified ways" (Gee, 2011a, p. 17), then texts are used as recognition points in engaging in a certain sort of practice or activity. The pro-mental health awareness movement serves as an example. Various organizations including governments promote being sensitive to the needs of those with mental illness by advertising policies or awareness campaigns that support the care of, or at least recognition of, mental illness (see, for example, Government of Canada, 2006; Public Health Agency of Canada, 2012). Practices and texts exist in a recursive relationship, where texts would have no meaning without practices, and where practices rely on texts to be enacted. This chicken and egg argument is resolved by accepting, as Gee (2011a) puts it, that texts/language and practices "'boot strap' each other into existence in a reciprocal process through time" (p. 18). Certainly practices can evolve and transform, but their corresponding texts transform simultaneously. 
Discourse analysis question: What practice(s) is/are the RB's texts enacting and encouraging others to recognize?

3. Identities: Texts and language participate in the construction of a social identity or identities. Language is used in specific ways to attribute or impose a certain identity onto others. Such is the case with psychological texts (e.g., the DSM) that construct human beings as (ab)normal and bearing pathological identities. Gee uses the term 'situated identities' which is understood as analogous to one's social position and subjectivity, the latter of which Rose $(1990,1996 \mathrm{~b})$ uses to characterize human identities. Gee does not necessarily use the term identity to signify that the identity is fixed over time; indeed, he acknowledges that identity, like subjectivity, is fluid.

Discourse analysis questions: What identity or identities are the RB's texts attributing to others (e.g., readers, governments, prisoners, patients) and how are these identities constructed?

4. Politics: Texts and language are used to convey a perspective on politics. For example, when correctional officials speaking on behalf of the CSC suggest that there are no viable alternatives to segregating the mentally ill (at least financially), as an organization they are situating themselves as less responsible and less culpable for the effects of punishment that result from segregating the mentally $\mathrm{ill}^{26}$. How things are phrased allows for the positioning of guilt, blame, and legal responsibility. The

\footnotetext{
${ }^{26}$ In October of 2013 during the Ashley Smith inquest, the Commissioner of the CSC told jurors to be realistic when proposing suggestions to manage mentally disordered prisoners: "there is no free pocket money that we can go to implement some of those things," he stated, adding that segregation can sometimes be the only "safe place" for the mentally ill (Perkel, 2013b). Such statements exemplify how an organization like the CSC can position itself as less responsible for Ashley's outcome by evoking a particular political stance on the issues at hand.
} 
displacement of responsibility from a social institution onto a population or an external organization is also an act that is inherently political. Such (in)actions are committed for political reasons and hold political implications.

Discourse analysis questions: What political perspective(s) are the RB's texts communicating? How do these texts evade or welcome responsibility, and for what purpose?

5. Relationships: Texts signal what sort of relationship they have with their readers, government organizations, political platforms, social institutions, and other bodies of research or literature. Discourses thus use the content of their texts to establish or maintain social relationships (or lack of). For example, the RB, as a branch of the CSC, publishes research on behalf of and ultimately for the CSC. This is indicative of a close internal relationship between the knowledge producer and the political platform and correctional philosophies of the current governing body. Notwithstanding that discourse from within government can indeed run against the dominant governmental ideological values of that time (e.g., see the Canadian Bar Association's [2011], the Justice of Children and Youth's [2011], and the Canadian Psychological Association's [2012] submissions on Bill-C10), this is less so the case within smaller organizations where different branches exist within one entity such as the CSC. More generally speaking, internally commissioned research tends to speak with one voice and a voice that supports the corresponding political climate and policy practices of that time (Gee, 2011a). Similarly, texts can demonstrate and maintain the 
lack of social relationship with external bodies of discourse by dismissing them or being absent of their discussion.

Discourse analysis questions: What sort of relationship(s) do the RB's texts have with other bodies of research, organizations, or social bodies? How do these texts maintain these (present or absent) relationships?

6. Connections: Texts and language are used to render things connected (or not) and relevant (or not) to other things. Language and texts are also used to break or mitigate these connections and relevancies. I have chosen to focus this building block of discourse analysis on the (dis)connection to other bodies of literature as a more indepth extension of the 'relationships' building block. For example, psy-texts largely attribute patient behavioural improvement to psychiatric drugs and/or exposure to cognitive behavioural therapies, thereby connecting the successful outcome with the intervention strategies offered by the psy-disciplines. Conversely, psy-literature may break connections with sociological understandings and interpretations of behaviour by excluding or dismissing such knowledge. In a more applied sense, discerning (dis)connections in textual material can also include the analysis of bodies of literature that are referenced (or not) in the text's bibliography.

Discourse analysis question: How do the RB's texts connect or disconnect to other discourses and disciplines, rendering certain things relevant or irrelevant?

7. Language type and sign systems: Multiple types of languages exist within discourses. This includes different types of language origin, whether French or English, technical 
vs. non-technical language, or juridical language vs. lay person language. This would also include using language rich in psy-references to describe personality (e.g., from the DSM) versus everyday language about how people behave. If one's textual material consists of empirical research, the choice of methodology undertaken is also indicative of the language used. For instance, quantitative research yields a specific positivist-oriented language that strives to present 'empirically validated' results as 'hard facts'. Sign systems, on the other hand, use systems that are not language (e.g., equations, graphs, images, tables) to portray information or a position on information. Knowledge claims are more often made through these systems than one might think; for example, recent news reports determined that the crime rate decreased over the last 40 years by referencing Statistics Canada's illustrated line graphs (e.g., Mahoney, 2013; The Canadian Press, 2013). Languages and their accompanying sign systems also privilege certain modes of thought above others. For example, the Criminal Code of Canada privileges juridical language and thus those who are proficient in legal logic to understand the meanings and nuances within the text.

Discourse analysis question: How do the RB's texts privilege or disprivilege (or delegitimize) specific languages or sign systems that proclaim to possess certain knowledges? Which types of language, sign systems, and knowledges are privileged and why?

These seven building tasks are integrally linked and are often supported by the same phrases and excerpts of textual material (Gee, 2011a). For example, a socially situated identity borrows from practices, and practices are mobilized through specific language 
types and sign systems. As such, overlap between Gee's seven building blocks of discourse analysis is inevitable. To move forward with Gee's discourse analysis requires engaging these seven building blocks to ask how language and text are used in the production of correctional discourse on self-injury.

\section{Variations and limitations of discourse analysis}

Discourses can become increasingly complicated once they are dissected and characterized into layers of discourse. Discourses may be better understood in some cases as 'hybrid discourses' formed from two previously distinct ideological identities. For example, as Foucault (1977, 1980a, 1980b) posited, the medical system has always served as an auxiliary to the penal system, so what we recognize today as 'forensic psychology' or 'forensic psychiatry' is actually a product of two separate discourses that have become hybridized: psy and corrections (yet they are distinct because at least one psy - can exist without the other). Similar to hybrid discourses, discourses can also have multiple identities, where two or more situated identities (from different originating discourses) come together as one discourse, but may not necessarily have contributed in equal denominations (Gee, 2011a). For example, where sections of the Criminal Code of Canada weave in references to mental disorder and the lack of mens rea or criminal responsibility, the text remains predominantly jurilingual in tone and focus but borrows language from the psy-sciences.

Discourse analysis can be construed as unscientific because the research may be seen as biased in favour of the researcher's specific political interests or social passions (Baker, 1999; Gee, 2011a). Discourse analysis, among other qualitative research 
methods, is routinely criticized for being unable to reproduce the same results in two different readings by two different researchers, thus rendering it subjective and unreliable. It is generally accepted that social science research is value-laden, but objectivity and valid empirical knowledge are still attainable and desirable (Hawkesworth, 2006). This thesis accepts that all knowledge is subjective, ideological, and that one cannot reconcile or adjudicate between two distinct epistemological and methodological perspectives. Researchers cannot simply rid themselves of their experiences, and thus knowledge production always reflects subjective biases (Bernard, 2013; Hawkesworth, 2006). Ultimately, it is not possible for researchers using qualitative methods to be completely objective. It is therefore important to remain open to finding evidence that challenges one's favoured views. The production of knowledge is not reserved for certain disciplines or individuals, it stems from multiple sources in multiple forms and as such must be recognized as 'going both ways'. This point suggests that I am not only interpreting knowledges produced by corrections, but also that I am producing a body of interpretive knowledge as the author of this thesis.

\section{Empirical Framework}

Using discourse analysis, this thesis aims to locate and deconstruct discourses on self-injury advanced by the RB of the CSC. In order to answer my research questions, I identify the textual materials selected for discourse analysis and consider some ethical obstacles. 


\section{Materials and data collection}

All textual material was identified by locating research reports, summaries or literature reviews from the CSC's public website ${ }^{27}$. Eventually it became clear that the $\mathrm{RB}$ was, for the most part, the only division within the CSC that was responsible for this genre of reporting. Research was selected by searching for any document that bears in its title the word 'self-injury', 'self-harm', or 'self-mutilation'. Other reports or documents whose main objects of inquiry were not self-injury but who did address it (e.g., reports on segregation) were not considered in data collection in order to narrow the scope and restrict the data to reports whose main research questions were concerned with prisoner self-injury. At first the idea was to only include research papers published by the RB, but this would have excluded Heney's (1990) key paper on self-injury amongst women prisoners at the Kingston Prison for Women (P4W). Heney's (1990) report was not technically written under the umbrella of the RB as she was contracted externally, but was submitted to and published by the CSC. It is likewise important to note that the RB was not fully established at the time of Heney's report; it had just finished developing its role statement and national research plan (CSC, 1989). Heney's report marks the first ever article published by the CSC that was specifically concerned with prisoner selfinjury, and given the date it appeared, it was important to include this report in order to map out the emergence of the institutional interest in self-injurious behaviour. For simplicity's sake, all references to the material collected for analysis including Heney's (1990) report will be referred to as the 'RB's reports'.

\footnotetext{
${ }^{27}$ Note that over thirty years ago, the Bureau of Management Consulting Supply and Services Canada (1981) was contracted by the CSC to conduct a literature review of self-injurious and suicidal behaviour within the prison environment. This report is excluded from the textual material because it is neither referenced nor available on the CSC's website.
} 
Selecting only reports published by the RB was done to narrow the scope of correctional discourse and to allow for statements about the political affinities that the texts have to the CSC. As per my definition of correctional discourse, I am not cataloguing all reports on self-injury within correctional discourse, but am instead selecting a key collection of texts that represent the CSC's view of self-injury in Canadian federal prisons. Indeed there are other sources of correctional discourse on selfinjury in Canada and internationally. In fact the very authors who are credited with publishing the textual material I have selected simultaneously published their research findings in academic journals or as doctoral theses (these include: Heney, 1996; Power, 2011; Power et al., 2013a, 2013b ${ }^{28}$; Power \& Smith, forthcoming). Other more recent sources of correctional discourse on self-injury have been briefly reviewed in the first chapter, namely research originating from the United Kingdom (e.g., Kenning et al., 2010; Marzano et al., 2010, 2012; Short et al., 2010), the United States (e.g., DeHart et al., 2009; Fagan et al., 2010; Lanes, 2009a, 2009b, 2011; Smith \& Kaminski, 2011), Australia (e.g., Dear, 2006; Dear et al., 2000) and from Canada but outside of the selected textual material (e.g., Blanchette \& Motiuk, 1995; Bonta et al., 1995; OCI, 20131, 2013b; McDonagh, Noël, \& Wichmann, 2002).

At the time of the initial search for textual materials, only seven reports were available in their entirety for download from the RB's website. I contacted the RB to acquire all remaining reports in full whose summaries were online. All content, once

\footnotetext{
${ }^{28}$ For curiosity's sake I reviewed these articles and dissertations and concluded that they came to the same conclusions as is evidenced in their CSC-version texts, albeit some of the language used differed as in CSC-published research authors are limited to using politically neutral language (e.g., the use of the word 'prisoner' or 'prison' was used liberally in the academic pieces but never in the CSC-published versions, with the exception of Heney's [1990] text).
} 
officially referenced on the public website, was publically accessible and as such no ATIP requests were required to gather the material. I verified this with staff from the RB who confirmed in writing that although not technically on the public website in full, all research reports I would be referencing were considered public knowledge (Appendix A). In total, the textual material consists of fourteen reports on prisoner self-injury (797 pages) and fifteen one-page research briefs, summaries or emerging results on self-injury published by the CSC's RB, altogether totaling 812 pages. See Appendix B for comprehensive details of textual material.

- Heney, 1990

- Wichmann, Serin, \& Abracen, 2002

- Gordon, 2010

- $\quad$ Power \& Brown, 2010

- Usher, Power, \& Wilton, 2010

- $\quad$ Power \& Riley, 2010
- Power \& Usher, 2010, 2011a, 2011b, 2011c, 2011d

- Power, Beaudette, \& Usher, 2012

- Power, Gordon, Sapers, \& Beaudette, 2012

- Power, Usher, \& Beaudette, 2012

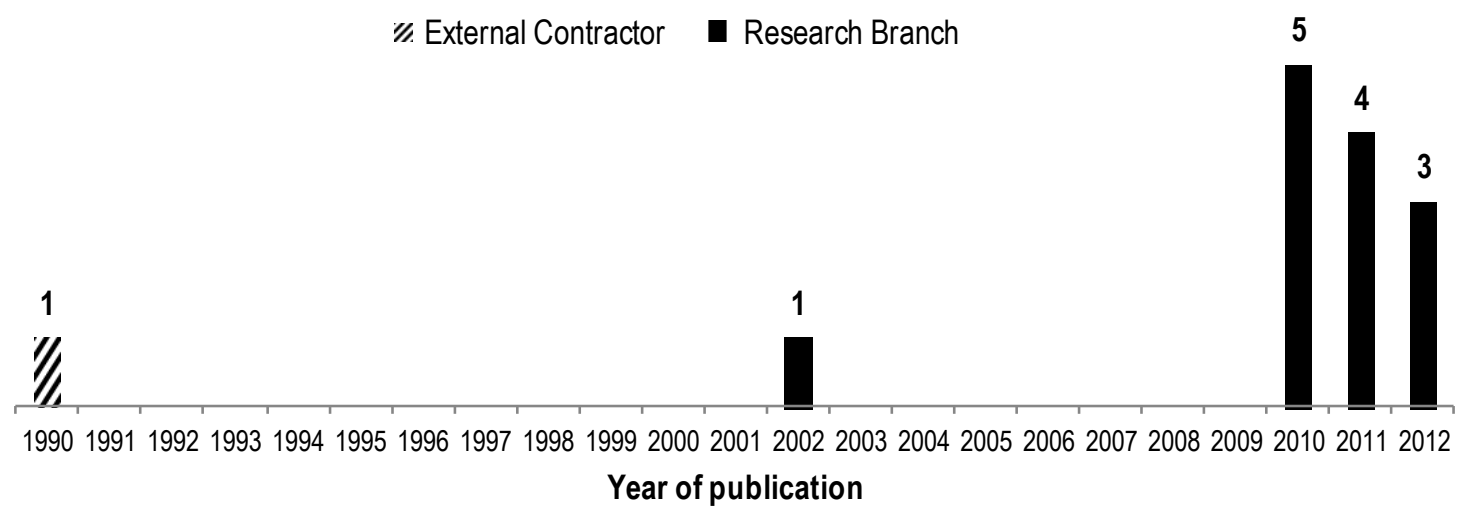

Figure 1. Number of major research reports on self-injury published by the CSC

I documented each report by title, number of pages, and general topic covered (e.g., men prisoners, women prisoners, intervention practices). I carefully read through each text, 
highlighting themes and identifying uses of social languages, adherence to practices, and areas where the research welcomed or closed off particular knowledges.

\section{Ethical considerations}

Given that a researcher doing discourse analysis must always situate herself in the material and assess her ability to understand relevant social languages (Gee, 2011a), I must disclose my experience working in corrections. This includes over two years working for the CSC. Due to employer privacy issues I am not able to disclose where and in what capacity. Important to note, however, is that I have never worked for the RB in any capacity and thus am not speaking in conflict to my object of inquiry, meaning at no point did I contribute to the production of the textual material analyzed in this thesis.

Negotiating through the dissonance I experienced with respect to my academic identity as a critical scholar and my workplace identity as a public servant proved challenging. This thesis is a product of my best attempt at satisfying the requirements of both identities; that is, engaging in rigourous scholarly analytical work while satisfying the obligations of my employment contract as required by the $\mathrm{CSC}^{29}$. Readers should also know that this requirement has prevented me from discussing operations or practices that are not already or have not yet been made public knowledge directly by the CSC or through alternative mediums such as ATIP requests. The CSC's employee directives evidently limit my ability to be openly reflexive throughout this research process. This is not to suggest that I did not engage in a reflexive assessment of the tension I experienced both working for and, in a sense, 'against' corrections, indeed this caused me to question

\footnotetext{
${ }^{29}$ Policy on standards of conduct for employees of the CSC states that "employees must not be critical of policy or operations in front of offenders or the public; to do so is to encourage a lack of respect for the Correctional Service of Canada and its staff" (as cited in Brisson, 2011, p. 17).
} 
my own role as both critical researcher and correctional discourse accomplice. Nevertheless, this nature of discussion is absent from this thesis in order to maintain my commitment to my employer's requirements of ethical conduct. At this point it is equally important to emphasize the fact that this thesis does not aim to criticize the RB or its methodologies in and of themselves, but rather to examine the emergence and production of particular knowledges within correctional discourse. Finally, it goes without saying that this thesis does not reflect the views or policies of the CSC nor should it be construed as such.

Contribution to the literature, claims to originality and validity

This is a unique discourse analysis given that no one, to my knowledge, has critically reviewed the surge of research on self-injury published by the CSC in recent years. Indeed the 1990 and the 2002 study have been mentioned in critical appraisals of self-injury research put forth by the CSC (e.g., Hannah-Moffat, 2006; Kilty, 2006, 2008b, 2011, 2012), but the emergence of the twelve new reports beginning in 2010 since is significant in terms of the generation of a wave of (potentially new) discourse on selfinjury. This thesis will contribute to the existing literature by examining how the new wave of correctional discourse on self-injury has shifted in Canada and by offering an updated critical reading of this discourse. This thesis will also contribute to greater debates about the increasing reliance of psy-technologies in the prison, as it will be demonstrated that this is precisely the case with correctional discourse on prisoner selfinjury. I stress again that discourse analysis is not a means to uncovering or debunking $\operatorname{truth}(\mathrm{s})$; it is an interpretation of an interpretation (Gee, 2011a). It is not about 
determining what is true, but about how a discourse (in this case, produced in the form of textual material) has come to be accepted as true. Being cognizant of this fact is of the utmost importance when conducting critical work like this, so as not to get lost in the idea that one truth trumps another. 


\section{CHAPTER IV: RESULTS}

But they seldom, if ever, asked questions concerning the relations between the object of psychological knowledge - the mental life of the human individual, subjectivity - and psychological knowledge itself. (Rose, 1996b, p. 49)

The results of the discourse analysis are presented in a question-answer style in satisfying Gee's (2011a, 2011b) seven building blocks of discourse analysis. Readers will notice that some overlap between the seven building blocks of discourse analysis is inevitable. For instance, some of what the texts render significant is also an admission of political responsibility (or lack of). The goal of this chapter is to present the results of what the texts contain while saving critical engagement with theory for the forthcoming analysis chapter.

Results are organized first by chronological order of the research produced by the RB (1990, 2002), and then for all post-2010 research, by goal/direction of the research according to the title or executive summary of the article. With respect to the post-2010 $\mathrm{RB}$ reports, four clusters were evident through the self-stated rationales for the initiation of the research: 1) research undertaken to determine what is currently known about selfinjury (i.e., best practices) in the literature (2 reports); 2) research intended to improve understandings for why men prisoners engage in self-injury and/or the characteristics of men who self-injure (3 reports); 3) research intended to improve understandings for why women prisoners engage in self-injury and/or the characteristics of women who selfinjure (4 reports); and 4) research intended to improve understandings about why prisoners engage in self-injury generally and/or the characteristics of prisoners who selfinjure (3 reports). When referencing the one-page summaries that are associated with the 
full length reports I include the year followed by the month (e.g., Power, 2010, July) as a simple indicator to differentiate the two types of texts. Note that the author(s) of the onepage summary documents are not necessarily the same sequence of authors who composed the full-length report. Additionally, these distinct RB summaries are only available for post-2010 RB reports, and one summary reviewed did not have a corresponding full-length report (Power \& Usher, 2010, October).

\section{Report no. 1: “Report on Self-Injurious Behaviour in the Kingston Prison for Women" (1990)}

At the outset it must be noted that of the fourteen RB reports, Heney's (1990) is the only one that was authored by an external contract employee. For this reason alone it is anticipated that the key messages elucidated by the discourse analysis will be different in tone and message than those authored by the RB. The self-stated goal of Heney's report is to determine the extent of the issue of self-injurious behaviour in the P4W and to provide recommendations to address these issues. Heney employed a mixed-methods approach (mostly qualitative) consisting of interviews with 45 women prisoners and 41 correctional offers among other CSC staff. Some quantitative analyses were conducted to determine the proportion of women prisoners who self-injured on a regular basis, although no formal quantitative statistics methodologies (e.g., tests of statistical significance or control and experimental groups) were utilized. All of Heney's respondents resided or worked in the P4W between 1989 and 1990.

\section{Significance.}

Heney (1990) characterizes self-injury as an adaptive behaviour in the sense that it serves a functional purpose for the women: "It should be kept in mind that self-injury is 
not a problem in and of itself, but rather, is a symptom or outward expression of more fundamental issues" (p. 16). This logic is evident throughout Heney's text as she discusses the self-stated themes of the text, namely: determining correctional responses to self-injury, methods to reduce self-injury, and suicide identification strategies. Her findings render childhood abuse and victimization as experienced by the women significant in precipitating self-injury. Although she attributes self-injury to traumatic social experiences, Heney (1990) calls for psychological intervention and 'mental health professionals' to intervene with and treat self-injuring women prisoners:

It is further recommended that a woman who self-injures be brought to health care services where either a psychiatrist, psychologist, nurse (if properly trained in these issues), or physician (if properly trained in these issues) can assess whether the woman is best served by remaining out of the general population. (p. 14-15)

Given that any policy which will impact on all prisoners may have repercussions in terms of mental health issues, prior to the implementation of such a policy input should be solicited from psychology, health care services, and psychiatry. (p. 20-21)

Here we see how the significance of psy-intervention is underscored as the best intervention for self-injurious behaviour. Readers are signaled to accept that while social explanations for self-injury are rendered most significant, psychological interventions are held up as the most meaningful intervention approach.

Practices.

Prior to making recommendations for practices she deemed necessary to implement, Heney spoke of existing practices and explained how the current security measures of the prison took precedence over existing rehabilitation practices. Heney proceeds to recommend an operational framework that supports rehabilitation, while 
encouraging readers (and the CSC) to recognize that the current practices were not conducive to alleviating the issue of women prisoner self-injury. For example, Heney (1990) writes:

In the midst of our discussion, a CX [correctional officer] staff person knocked on the door to announce that the 4:00 count was going on and the prisoner had to immediately return to her cell. I believed that this woman needed to finish her conversation with me but the rules of the institution took precedence. That night, the prisoner in question slashed. I am confident that this slashing could have been avoided had there been some forum to circumvent established count protocol, thus, allowing the counselling session to continue. (p. 23)

At the same time Heney (1990) affirms that it is not the staff or the security personnel who are a detriment to the women's healing or rehabilitation, but rather it is the policies and protocols in place that the staff are expected to follow that are problematic: "To place staff in a position where they must accept responsibility for breaking protocol is unreasonable and places an unfair burden on the CX staff' (p. 23-24). ${ }^{30}$

Noting that the services available to the women prisoner population at the $\mathrm{P} 4 \mathrm{~W}$ were insufficient, Heney calls for increased mental health-oriented practices. This includes: qualified female counselors, 24-hour mental-health resource availability, instituting a Childhood Sexual Assault Survival Group, and having a native counsellor with an understanding of issues unique to the Aboriginal culture ${ }^{31}$. In an attempt to

\footnotetext{
${ }^{30}$ Interestingly this sentiment resurfaced in recent media accounts of the Ashley Smith inquest, where instead of holding front-line prison staff accountable for Ashley's death - as was originally done by the CSC who either fired or suspended the staff who were present for her death (Union of Canadian Correctional Officers, 2008b) - Ashley's family and legal counsel have turned their attention to senior correctional officials who handed down orders to correctional staff to not enter her cell as she suffocated from self-asphyxiation (Kaszor, 2013; Mullholland, 2013).

${ }^{31}$ Heney (1990) uses the term 'native' to characterize Aboriginal peoples. The shift from the term 'Indian' to 'native' to 'Aboriginal' first occurred in 1982 with the promulgation of the Constitution Act which recognized 'Aboriginal peoples' and their three distinct sub-heritages (Indian [later recognized as First Nations], Inuit, and Métis) (Hayman, 2006). However, the adoption of the term 'Aboriginal' within CSC discourse did not occur until the mid 1990s.
} 
respond to these recommendations, Heney proposed a framework for a 'support/crisis programme' that would address the need for crisis intervention in the prison setting. This would mean a program for:

Individuals who are in emotional distress not only acknowledge that emotional distress can result in an inability to work but provide a means of support while the individual concentrates on emotional issues. (Heney, 1990, p. 21)

Heney presented a selection process for staff, training modules, implementation strategies, and information on how to provide on-going support. The underlying message in her text with respect to practices is the desire to have the CSC recognize the gaps in their current practices and to accept and endorse her recommended strategies of reform.

\section{Identities.}

Heney's report constructs self-injuring women as trying to exercise control in the only way they know they can in an otherwise powerless situation. This may be critically interpreted as the construction of self-injuring women prisoners as passive victims given that her use of language significantly attributes self-injury with being the victim of childhood (sexual) abuse. Conversely, Heney allows for several honest accounts of the women's experiences in prison to come through by demonstrating compassion for the lived realities of the women she interviewed. For example:

Despite the fact that prisoners were not questioned directly on the appropriateness of segregation in response to self-injury, 39 of the 44 prisoners interviewed spontaneously addressed this issue. Of these prisoners, 97\% (38) argued that segregation is an inappropriate response to self-injury. [...] The fact that so many prisoners discussed segregation in the absence of direct questioning indicates the extent of the distress over the existing protocol. Although the transfer to segregation is for monitoring as opposed to punitive purposes, experientially it is perceived by the women as punishment. (Heney, 1990, p. 12) 
This contributes to her overarching positioning of women prisoners as institutionally mistreated and in need of meaningful rehabilitation-based intervention.

\section{Politics.}

Evident throughout the report is the fact that Heney only uses the term 'prisoner' rather than the common identifiers 'inmate' or 'offender' that are seen in modern correctional discourse. Given this specific choice in language, Heney takes on a political stance that is not in the primary interest of corrections; by using the term 'prisoner', Heney distances herself from in-house correctional discourse and signals to readers that she acknowledges that these women are in fact imprisoned against their will.

Heney positions the genesis of self-injury amongst prisoners on the prison itself, denoting that it as an environment that encourages the behaviour as a result of the overarching concern on security. Her political stance is also evidenced through a number of organizational recommendations that are phrased in such a way that lays legal responsibility on the CSC. She makes suggestions to rectify certain issues, including that "the situation must move from the security domain to that of psychology/health care services" (p. 14), and that,

... it is important in times of emotional distress that the women have someone with whom they can talk. [...] Given that the nursing staff are often a prisoner's first contact after a self-injury, the nurses should be provided training in appropriate intervention. (Heney, 1990, p. 15)

Heney lays responsibility on the CSC for failing to provide appropriate interventions and services for self-injuring women prisoners. Politically, her recommendations assert a stance in favour of structurally improving the lives of women prisoners rather than those that are more in the best interests of corrections. 


\section{Relationships.}

The text and language reveal that Heney was not speaking from the point of view of the organization, but rather as a voice on behalf of the prisoners and what she recommended to best address the situation. For example, Heney (1990) states more than once that the CSC has its objectives backwards or otherwise fails to take action: "Prison personnel have taken a reactive rather than a proactive stance toward self-injurious behaviour" (p. 16), and,

... many of the recommendations made in this report are the ones that have been voiced by the two prison psychologists and health care services staff for quite some time. The fact that these voices have not been heard or acted upon, reflects the historic trend towards a reactive rather than a proactive stance to mental health issues. (p. 35)

Moreover, Heney (1990) discusses how staff contribute to the negative environment that fuels self-injurious behaviour: "The security staff themselves recognize that some staff members act in an inappropriate manner," (p. 19) and that "policy changes, the attitudes of certain CX staff, and mass punishment were most often cited as the reasons for the tension [that caused self-injury]" (p. 10). This narrative reveals that Heney's relationship with the CSC does not command her to write a report that pleases the organization insofar that she produces findings that match the CSC's organizational needs. Instead, Heney's text does not attempt to establish or maintain a social relationship with the CSC, but rather highlights that the current regimes of practice are in dire need of change in order to see a reduction in self-injurious behaviour amongst women prisoners and make strides towards better treatment of women prisoners generally. 


\section{Connections.}

Heney's report does not make any direct connections to any particular bodies of knowledge given the report did not include a comprehensive evaluation of the extant literature (only four references were cited).

Language type and sign systems.

Heney's report privileges both a sensitive-feminist genre of language in addition to psy-language that supports psy-intervention. However, the latter language does not dominate the text; instead, the predominant type of language communicates the unfortunate state of women and self-injury in prison through sharing the voices of the women themselves. Heney (1990) speaks of systemic change, of rehabilitation and of reintegration:

In the absence of systematic change, these women, upon completion of their sentence, will go out into the world doubly victimized. It is unreasonable to expect that after such an experience they can reach their full potential as citizens. (p. 36)

Despite the often false pretenses in which rehabilitation discourses are used (see Moore \& Hannah-Moffat, 2005 for how the 'liberal veil' is enacted in correctional discourse), this does not appear to be the intent in this report.

\section{Report no. 2: "Women Offenders who Engage in Self-harm: A Comparative Investigation" (2002)}

Wichmann, Serin and Abracen's (2002) report marks the first empirical report on self-injury in the federal prison population that was written and published by the RB. A quantitative approach compared a sample of 78 incarcerated women prisoners who 
engaged in self-injury to a matched group of 77 women who did not ${ }^{32}$. Functional analyses and tests of statistical significance were conducted on a number of profile characteristic indicators, including suicide history, criminal history, risk, need, mental health adjustment, and institutional adjustment. The goal was to produce descriptive statistics on the self-injuring group and how they differ from the women who did not selfinjure and it was noted that the report was brief (26 pages) and that future research would be required to provide a more comprehensive analysis.

\section{Significance.}

Wichmann and colleagues' report attributes a history of suicidal behaviour to a greater likelihood of self-injuring. It is often unclear whether their results represent women who had engaged in self-injury, attempted suicide, or both. A transformation in language takes place mid-way through the report, where a narrative that speaks solely of suicidal behaviours as a collective umbrella category evolves after having left self-injury behind in the results section. The significance of 'self-harm' (the term chosen by the authors) as a distinct behaviour for women prisoners is minimized, while the notion of women with 'suicidal tendencies' is made most significant, becoming the take-away point in the discussion section.

The report links misbehaviour and violent tendencies to self-injurious behaviour. It is reported that women who self-injure are more likely than those who do not to have more extensive and violent criminal histories, problems with institutional adjustment,

\footnotetext{
${ }^{32}$ Although not specified in the report's methodology section, it is important to note that the sample of women would no longer include women incarcerated at the P4W. Five women's institutions and one Healing Lodge were opened further to the closure of P4W in 2000 (see CSC, 2000, 2013m), and as such it should be deduced that the results from this study are based on women residing in one or more of these newly built institutions.
} 
segregation placements, disciplinary problems, involvements in a disturbance, histories of substance abuse, reclassifications to a higher security level, greater overall risk and need levels, escape-related behaviours, and a greater likelihood of returning to custody. They conclude:

While coping deficits may be related to the expression of suicidal behaviour in these women offenders, their violent behaviour was not exclusively self-directed. That is, for these women offenders, there was considerable evidence of violence against other inmates and staff. (Wichmann et al., 2002, p. 14)

In light of these conclusions, the text renders significant that self-injuring women prisoners are misbehaved and violent.

\section{Practices.}

This report does not directly address, endorse, evaluate or propose any institutional or operational practices with respect to interventions for treating self-injury. The report's objective is factual and statistical with little explanation of the implications of the results. Interestingly, the report acknowledges Heney's (1990) position that selfinjurious behaviour must be redefined as a mental health issue as opposed to a security issue:

Heney (1990) views self-injurious behaviour as a coping strategy to deal with past abuse, and a means of gaining control over the woman's environment. To support her position, Heney considered case studies, noting that there appeared to be outbreaks of self-injurious behaviours, often in response to heightened levels of stress in the prison environment. (Wichmann et al., 2002, p. 3)

Despite citing Heney's perspective, the issue of treatment versus security is never addressed at any point in the analysis, which found that a number of security-oriented responses were being used against women who engaged in self-injury. Given the absence 
of engagement with institutional or operational practices, this text does not call on readers to recognize the current state of practices. However, in attempting to be neutral and omitting a discussion of policies and practices, this report does not consider in what capacity they may be problematic or harmful.

\section{Identities.}

The findings reported suggest that women who engage in self-injury should be construed as an 'at-risk' group. Women who self-injure are constructed in a detached and negative light, where riskiness is attributed to the group of women self-injurers which thereby suggests to readers that this is part of the identity of women prisoners who engage in self-injury:

Women who engaged in self-harm were more likely to be rated as high in overall static risk and less likely to be rated low than women who did not [...] When overall needs level was examined, this pattern was repeated, with equally significant results. (Wichmann et al., 2002, p. 10)

Women prisoners who engage in self-injury are characterized as at-risk of self-injuring ${ }^{33}$, committing suicide, and higher in criminal risk (i.e., static risk to recidivate). These conclusions suggest that women prisoners who engage in self-injury are constructed as deviant, suicidal, and a threat to public safety.

Politics.

The report does not comment on the hardships that women endure while in prison, or how resorting to self-injury may be a sign of personal distress as experienced in a prison environment. Instead, the women are treated as units of analysis, and the language

\footnotetext{
${ }^{33}$ The tautological nature of this finding is not addressed in the report.
} 
used is concrete, cold, detached, and factual. Data is presented with little discussion short of risk-based logic. The discussion is removed from the issue at hand:

Second, for those women offenders who exhibited suicidal behaviour, there were a host of adjustment difficulties that were also prevalent. These difficulties were not apparent in a matched group of women offenders. (Wichmann et al., 2002, p. 14)

This kind of utterance renders any guilt, blame or responsibility for self-injury on the part of the institution moot by failing to consider causal factors for self-injury that exist outside of the individual woman. By evading a discussion of social and environmental causes, this text enacts a political stance that detaches the CSC from moral and legal responsibility for prisoner self-injury. There was only once instance in the text that touched on the possibility of the institutional environment having an impact on selfinjurious behaviour:

These factors [substance abuse, anxiety, depressive disorders] in addition to characteristics of the prison environment, may increase the likelihood of self-harm occurring. (Wichmann et al., 2002, p. 1)

This sentence is noted at the outset in the introduction of the report; however, this idea drops out of the text as no follow-up attempt to answer this question is made.

\section{Relationships.}

The title page itself, as with all reports analyzed in this thesis with the exception of Heney's, is an indicator of the relationship the text has with the CSC as the governing body of federal prisons in Canada ${ }^{34}$. Neutral language similarly denotes this relationship. For example:

Further research regarding additional components of the process model is

\footnotetext{
${ }^{34}$ All title pages are prefaced with the "Correctional Service of Canada" and "Research Branch" corporate brand identifiers.
} 
warranted to gain a full appreciation of the role of suicidal behaviour in women offenders. Nonetheless, this research is an important contribution in that it utilized objective data and incorporated a matched comparison group of women offenders. (Wichmann et al., 2002, p. 14)

By using neutral and organizationally appropriate language, the text upholds and maintains a bureaucratic relationship of departmental accountability between the RB and the CSC.

\section{Connections.}

The texts are limited in scope with respect to what kinds of bodies of knowledge they borrow from. At first glance, over two thirds of references in the bibliography are of the CSC's RB or their own in-house journal, 'Forum on Corrections Research',35, or otherwise authored by an individual who was associated with the CSC in 2002 (e.g., Blanchette, Grant, Motiuk, Brown, Serin, and so on). Although the reference list is rather brief (less than two pages), it demonstrates a reliance on a few key correctional texts that lend to the specific type of knowledge the text is producing. Non-psy understandings of self-injury and critical considerations of the carceral environment are excluded, signaling a rupture between the text and external critical discourses.

\section{Language type and sign systems.}

The report privileges positivist methodology and related ideology; readers are required to have some degree of knowledge of concepts like covariates and measures of statistical significance. If they do not, however, the report's brief conclusions summarize the findings for laypersons, translating quantitative methodological language into soundbite statements about women prisoners and self-injury. Either way, positivist quantitative

\footnotetext{
35 'Forum on Corrections Research' was an online journal prepared, edited, and published by the RB between 1989 and 2007. It was composed mostly of research conducted by employees of the CSC, however some academic and international researchers were invited to submit articles.
} 
modes of thought are privileged while qualitative understandings and sociological considerations are excluded.

Cluster no. 1: Research undertaken to determine what is currently known about selfinjury (i.e., best practices) in the literature (post-2010)

This cluster consists of secondary research undertaken by the RB to examine what is currently known about self-injury in prison as per the extant literature. This cluster is separated from the following three post-2010 clusters because it does not conduct any primary research on prisoners (i.e., no experimental or differential design methodologies). The reports in this cluster consist of two full publications (Power \& Brown, 2010; Usher, Power, \& Wilton, 2010) in addition to their corresponding one-page 'research at a glance' summaries (Power, 2010, February; Power, 2010, March), and an additional stand-alone one-page 'research review' that is not linked to a larger report (Power \& Usher, 2010, October).

Significance.

Many of the conclusions drawn from the literature reviews consist of critiques on the lack of adequate empirically validated classification systems of self-injurious behaviour in correctional populations: "research has yet to determine the process by which NSSI [non-suicidal self-injury] is initiated and maintained" (Power, 2010, February, p. 1). This type of nuance, woven through all texts in this cluster, seeks to render significant the idea that there currently exists no appropriate and accurate means of classifying (and thus understanding) self-injuring prisoners. It is unclear, however, whether the RB is specifically seeking to understand the characteristics of prisoners who engage in self-injury in order to best identify those at risk, or to understand the reasons 
why prisoners engage in self-injury in order to strategize solutions to prevent and manage this behaviour. The primary goal appears somewhat lost, although answers to each of these questions are addressed at various points throughout the reports.

The texts signal location within positivist paradigm that is only satisfied by specific quantitative methodologies that garner 'validation' and 'reliability'. For example, the $\mathrm{RB}$ emphasizes its position on the value of empirically validated results:

The majority of the published literature is composed of anecdotes and personal experiences of mental health care providers. [...] empirical studies are required to determine if approaches work and, if so, for which groups. (Usher et al., 2010, p. 10)

No adequate SIB [self-injurious behaviour] classification system has been developed [...] An empirically-derived classification system that accounts for the unique environment of a correctional facility could help increase understanding of the [self-injurious] behaviour and target treatment to the particular needs of at risk individuals (Power, 2010, February, p. 1)

Although the method [analyzing archival prisoner information] shows promise, it still needs to be tested prospectively on other populations to determine its utility in predicting future SIB. (Usher et al., 2010, p. 12).

By reiterating the fact that the extant literature has not been able to produce a reliable typology or self-injury risk-prediction tool for self-injuring prisoners, the RB's texts underscore the idea that a specific quantitatively evaluated and approved tool should be developed and then used to assess this population.

\section{Practices.}

The texts acknowledge that suicide and self-injury are two distinct behaviours:

In order to effectively treat and manage both of these behaviours, they should not be grouped together. Rather, their different characteristics, motivations and purposes suggest that different approaches may be needed. (Power \& Usher, 2010, October, p. 1) 
In doing so, the RB notes the need for two different management strategies. With respect to prisoners who self-injure, Usher and colleagues (2010) note that "segregation should be used with caution and only when absolutely required to preserve the offender's safety" (p. 26). The controversial treatment of segregating self-injuring prisoners is reviewed to a greater extent in Usher and colleagues' (2010) text, suggestions of which are followed by this:

Research has not yet explored whether some of the factors that increase feelings of isolation while the offender is residing in a segregation cell can be reduced by increasing in-person staff contact and support services during their stay in segregation. Methods of mediating the negative emotions that often accompany placement in segregation, such as increased staff contact, should be explored. (p. 26)

Power and Brown's (2010) text allude to the current segregation practices in place and further suggest that they are warranted in some cases:

The current priority at the CSC in responding to SIB is to decrease the severity of damage that an individual inflicts on him or herself, and thus the offenders' negative perceptions of these kinds of interventions must be balanced with the priority of offender safety. (p. 33)

These kinds of sentiments suggest a reaffirmation of the importance of security despite acknowledging the potential harm that the segregation of prisoners who engage in selfinjury may cause. In this way, the CSC's current practices are upheld: "CSC has implemented a number of policies and initiatives that are in-line with evidence based practices for the treatment and prevention of self-injury" (Power, 2010, March, p. 1). Usher and colleagues' (2010) suggestion that segregation be used only when absolutely necessary does not challenge the CSC's existing practices that are founded in policy, where: "Should the inmate be deemed high risk, he or she can be placed on suicide watch 
(i.e., placed in a closely monitored segregation cell) [...or] restraints applied" (Usher et al., 2010, p. 33-34). One important piece of text touches on the prioritization of security:

While some critics have stated that SIB in women offenders is disproportionately viewed as a security threat, rather than a mental health issue (Kilty, 2006), research to date does not support this view. (Usher et al., 2010, p. 27)

Here we see an explicit dismissal of external research that challenges the CSC's practices. Interestingly and ironically, the text makes a statement that suggests feelings of isolation could be reduced while in segregation despite having dismissed the possible effects of segregation on self-injury given the lack of empirically validated research:

CSC should also explore methods of reducing feelings of isolation when offenders who engage in SIB require segregation to determine if frequency of the behaviour can be decreased while providing the safety of segregation. (Usher et al., 2010, p. 36)

Existing practices like correctional and mental health programming (e.g., DBT and cognitive behavioural therapy) are described in the reports as 'cognitive restructuring' and 'therapeutic intervention'. These interventions are said to provide prisoners with effective coping skills. To this end the RB concludes that these programs are effective in reducing the incidence of self-injury: "This finding points to the importance of working collaboratively with the individual to teach them effective coping skills" (Usher et al., 2010, p. 23), and that, "for the most part, the current SIB strategy is consistent with recommended practices" (Usher et al., 2010, p. 35).

\section{Identities.}

Given that the texts' goals were not to engage in primary research on the characteristics of prisoners on self-injury, the texts do not participate in the first-hand construction of prisoner identity. 
Politics.

The most prominent topic discussed within the texts that is indicative of a political stance is whether or not incarceration influences self-injurious behaviour. Evidently this question is politically charged insofar that if the CSC were to accept that the prison environment encourages or perpetuates self-injurious behaviour then it would call its own existence into question. The RB's texts evidence a kind of dance around these questions:

Some authors have suggested that the correctional environment and the way in which SIB is handled within correctional institutions is a direct cause of NSSI (Kilty, 2006; Thomas, Leaf, Kazmierczak, \& Stone, 2006). [...] It is unclear whether incarceration causes NSSI or incarcerated individuals are more likely than non-incarcerated individuals to have a history of NSSI prior to entering the correctional system. Given that it is impossible to randomly assign individuals to a correctional institution, causal statements about the effects of institutionalization on NSSI cannot be made. (Power \& Brown, 2010, p. 30)

This excerpt demonstrates an evasion of responsibility for prisoner self-injury insofar that it suggests researchers cannot draw empirically validated conclusions about the effect of incarceration on prisoner self-injury. This kind of phrasing satisfies the interests of the CSC whose proclaimed political mandates are to assist in the rehabilitation and reintegration of offenders (CSC, 2008) by suggesting that the relationship between selfinjury and incarceration is unclear and unknown.

The texts also discuss why the motives behind prisoner self-injury are important to elucidate in future research:

Yet the motivation for self-injury may be a critical factor for understanding the behaviour so that the individual can be successfully treated and his or her risk for the repeating the behaviour reduced. (Power \& Brown, 2010, p. 22) 
Although this phrase taken alone appears to speak to the desire to improve the lives of those who engage in self-injury (by suggesting the goal is to reduce it), when linked to other risk-based statements made in the same text, it becomes increasingly apparent that the risk of self-injury is linked to institutional and operational setbacks. These include: self-injurious behaviour being "the single best predictor of eventual suicide" (Power \& Brown, 2010, p. 21), associated with “increased risk to assault treatment staff” (Power \& Brown, 2010, p. 1), a precursor for use-of-force paperwork after staff members "use restraints in order to reduce the risk of self-injury" (Power \& Brown, 2010, p. 33), an indicator of multiple subsequent self-injurious incidents to come ${ }^{36}$ (Usher et al., 2010), and more generally, how self-injury poses "a threat to the mental health and physical safety of offenders and staff alike" (Power \& Brown, 2010, p. 34). The texts are woven with risk-logic wherein correctional risk assessment is no longer solely about determining prisoner risk/need levels, but about predicting and managing the risk of self-injury:

Frontline staff, health care workers, and mental health professionals must regularly assess whether an offender is at risk of SIB and, if so, they need to develop a strategy to determine how to react to this risk. (Usher et al., 2010, p. 10)

Furthermore, with respect to the increased sensitivity required in future risk assessment tools that would be used to predict self-injurious behaviour ${ }^{37}$, the authors write:

Specificity should be considered in so far as an instrument that has a low specificity screens in too many people who are not at risk for SIB, thus wasting resources. (Usher et al., 2010, p. 11)

\footnotetext{
${ }^{36}$ The tautological nature of this finding is not addressed in the report.

37 The authors argue that self-injury risk prediction tools should ideally be high in sensitivity (i.e., they would detect most people who self-injure), and high in specificity (i.e., they would exclude those who will not self-injure). Additionally, the authors state that a tool higher in sensitivity is more important than having high specificity, as it is better to identify those at risk of self-injury than overrepresenting those who will not self-injure (Usher et al., 2010).
} 
In considering utterances to this effect in tandem with the more general attempts to evade responsibility for the prison environment potentially exacerbating self-injurious behaviour, the political base on which this research rests is clear: the positioning of legal responsibility for prisoner self-injury is displaced from the correctional body to the individual prisoner.

\section{Relationships.}

The texts accumulate knowledge on behalf of and for the benefit of the CSC. The stage is then set for the RB's future research agenda (clusters 2, 3, and 4):

The Research Branch at the CSC is currently conducting national studies on NSSI in men and women offenders that endeavour to address these current gaps in knowledge and will inform treatment and policy of NSSI in the future. (Power \& Brown, 2010, p. 34)

By calling for research that only the $\mathrm{RB}$ is privy to answer, the texts highlight a privileged relationship between the $\mathrm{RB}$ and the $\mathrm{CSC}$ and ask readers to recognize the RB's knowledge, expertise and authority to research and draw conclusions about selfinjury amongst prison populations. Statements about filling research gaps and producing results maintain this social relationship by guaranteeing corporate results for the governing body through the continuous supply of research. This relationship is maintained, evidently, through the organizational structure that created the RB in the first place (CSC, 1989).

\section{Connections.}

The texts evidence a disconnect to the extant literature on self-injury, particularly that which exists outside of the psy-disciplines. Although they do acknowledge that some critical literature exists (e.g., Kilty, 2006; Thomas et al., 2006), for the most part the ideas 
offered by such authors are dismissed or framed as inconclusive anecdotal research. Other than brief mentions of such literature, the texts are absent of critical feminist/gender literature, social constructivist scholarship, sociological texts, and texts on the performative nature of body practices, among others that theorize self-injury in various ways. This leaves the reader uninformed about the broader debates and ways of interpreting self-injurious behaviour. Moreover, the texts devalue non-positivist research. For example, in response to Heney's (1990) research that attributes outbreaks of selfinjury to institutional tension, Power and Brown (2010) write: "These outbreaks were not confirmed quantitatively" (p. 25). Further, in addressing Fillmore and Dell's (2000) study that examined self-harm amongst federally sentenced women in the Prairie region, one text states:

Data for this study were multi-sourced and entirely qualitative $[\ldots]$ the broad definition of self-harm and the qualitative nature of the data highlight a need for further quantitative research to augment these findings. (Power \& Brown, 2010, p. 11-12)

Moreover, in response to Fillmore and Dell's (2005) follow-up study in which institutional service providers were interviewed and had indicated a perceived $20 \%$ increase in women's self-harm over a five year period, Power and Brown (2010) state "there is no verifiable data to back-up this claim" (p. 12).

The significant amount of attention paid to producing a self-injury typology and/or self-injury risk-prediction tool further demonstrates the texts' absence of critical sociological knowledges, in which rigid classification grids of this sort are usually not encouraged. The reliance on positivist and psy-knowledges thus tautologically supports the exclusion of critical/sociological knowledes on self-injury because critical sociology 
is deemed not useful in deriving social phenomena into classification typologies as it is seen as lacking in empirical significance. According to the RB, any research that does not adhere to a positivist quantitative methodology lacks scientific rigour, credibility and validity. By ignoring or suggesting that external bodies of literature are inconclusive renders their relevancy moot while amplifiying the relevancy of the predominantly psychological literatures chosen for inclusion.

\section{Language type and sign systems.}

The specific language used, that of the psy-sciences, privileges discourses that locate the aetiology of self-injury in the individual. For example, positivist and/or psylanguage is apparent in almost every sentence: "A wide variety of motivations for engaging in SIB have been proposed, although few have been empirically validated" (Power \& Brown, 2010, p.iii), and,

... it is most likely that those who engage in SIB are a heterogeneous group. An empirically derived typology could help organize this diversity into a system that can better inform risk assessment and treatment of these individuals. (Power \& Brown, 2010, p. 31)

$\ldots$ if it is found that an offender has any current or previous history of $\mathrm{SIB}$, he or she is referred for a comprehensive psychological assessment, where a more in-depth review of the offender's mental health will be conducted. (Usher et al., 2010, p. 33)

To further dismantle the 'myth' of incarceration as exacerbating self-injury, Power and Brown (2010) employ psy-languages to offer a commentary on how, in reports reviewed in their literature review: "The authors found that SIB was related to neurotic and personality disorders and cannot simply be explained by environmental stress" (p. 31). This statement is dismissive of the extant research on self-injury, where no research has 
explicitly suggested that environmental factors alone offer a simple explanation for selfinjury. This is but one example of how psy-knowledge structures the report and goes unquestioned and unchallenged. By using this genre of language, the RB's texts privilege a language that is central to the psy-sciences and thus delegitimizes languages whose main objects of inquiry are social rather than psychological.

\section{Cluster no. 2: Research intended to improve understandings for why men prisoners engage in self-injury and/or the characteristics of men who self-injure (post-2010)}

This cluster consists of primary differential research undertaken by the RB to determine the motivations, emotions, and precipitating events related to self-injury in men prisoners. This research is offered to help fill the gap in the literature given that recent research by the CSC focused on women prisoners:

Recent research has contributed to the understanding of SIB in women offenders (Power \& Usher, 2010, 2011b, 2001c [sic]), but research on male offenders is still lacking. (Power, Usher, \& Beaudette, 2012, p. 1)

This cluster includes three full publications (Power, Beaudette, \& Usher, 2012; Power \& Usher, 2011b; Power, Usher, \& Beaudette, 2012) in addition to their corresponding onepage 'research at a glance' summaries (Power, 2010, May; Power, 2011, August; Power, 2012b, November), and one 'emerging research results' page of text (Power \& Usher, 2011, July).

The same group of self-injuring men prisoners act as participants in all three reports (104 men who were recruited from eleven medium and maximum security federal 
institutions ${ }^{38}$ ). Two reports employed a quantitative approach where these 104 men were compared to a group of matched controls $(n=95)$ that had no known history of selfinjury. One of the quantitative reports sought to determine the reasons why men prisoners engaged in self-injury. A semi-structured interview, a series of questionnaires, and a clinical interview to assess presence of psychological disorders were administered. Correlations between self-injury groups and factors thought to be associated with selfinjury were examined, including mental illness, impulsivity, aggression, and childhood trauma. The other quantitative report conducted an archival analysis of historical selfinjury incidents in order to determine temporal patterns, age of onset, method of selfinjury, and body parts self-injured, among other descriptive variables that have operational implications. This text did not provide an analysis of the characteristics of the kind of individual that engages in self-injury, but rather of the situational circumstances. The third study employed a qualitative approach and interviewed the 104 men who had a history of self-injury (using the same semi-structured interview utilized in the quantitative study). Interviews were recorded on a digital recorder, transcribed using NVivo 7, and analyzed using content analysis at the discretion of the primary researchers.

\section{Significance.}

Given the varying methodological approaches of the reports, at first glance the reports convey two different messages that are rendered significant about why men prisoners self-injure: the qualitative report emphasizes 'coping' as the primary function

\footnotetext{
38 Men prisoners residing in the CSC's RTC's or RPC were excluded from all three men's studies. Prisoners with the most severe cases of self-injury are generally transferred to one of the CSC's RTC's/RPC (OCI, 2013a), and as such it is significant to note that these studies exclude this population. Power and Usher (2011b) mention that this population "will be addressed in a forthcoming report" (p. iii). No such report has been published as of January, 2014.
} 
of self-injury, whereas the quantitative report that sought to determine reasons for selfinjury points to mental disorder as the overarching precipitator of self-injury. After a second closer read, it becomes increasingly apparent that the term 'coping' or 'coping mechanism' as used in the qualitative report is understood as a technique that alleviates negative affect (i.e., negative emotions) that one cannot control, thus rendering it a constituent of mental illness (e.g., linked through and to depression, where one is mentally incapable of regulating emotions). As a result, the two texts that sought to determine motivations for self-injury cite mental disorder (whether implicitly of explicitly) as the reason why men prisoners self-injure:

Individuals who experience high levels of emotional dysregulation and lack more adaptive coping strategies to deal with their emotions may use NSSI as a method of effectively, if maladaptively, regulating their emotions. (Power, Beaudette, \& Usher, 2012, p. 3)

It was found that participants in the NSSI group were significantly more likely to meet the criteria for any disorder, particularly substance abuse, major depressive disorder, posttraumatic stress disorder, and borderline personality disorder. Those with a history of NSSI were also more likely to meet the criteria for antisocial personality disorder and panic disorder. (Power \& Usher, 2011b, p. 26)

The quantitative text on motivations for self-injury also identifies correlates of self-injury that are not mental disorders (but that are common symptoms of various diagnosable mental illnesses), including hostility, impulsivity, aggression, and childhood abuse. Yet these non-pathological correlates are rendered intrinsically linked to pathology by being framed as precursors to mental disorder through what is termed a 'path analysis ${ }^{39}$ :

\footnotetext{
${ }^{39}$ Path analysis is a widely practiced technique in quantitative research where variables are modeled as being correlated through indirect and direct relationships. In other words, in a path analysis with more than one variable, where the first variable may not be directly related to an outcome, a second variable is posited as a potential link between the first variable and the outcome (Webley \& Lea, 1997, as cited by Power \& Usher, 2011b).
} 
A [path] analysis of the proposed origins of NSSI revealed that offenders with a history of NSSI were significantly more likely to have experienced all forms of childhood abuse, including sexual abuse. These offenders are in turn more likely to experience depression, substance abuse, and borderline personality disorder, all of which increase likelihood of engaging in NSSI. (Power \& Usher, 2011b, p. iii)

This text employs path analysis to test the relationship between childhood sexual abuse and self-injury, namely the 'childhood sexual abuse model'. The text concludes that childhood abuse predicts self-injury where mental disorder is present. By suggesting that social traumas are a 'pathway' to mental disorder, which then leads to self-injury, the text denies the ability for social traumas to lead directly to self-injury. This is not to suggest that the authors did not consider this, albeit in the 'path analysis' section they did explore the link between childhood abuse and self-injury irrespective of mental illness. However, this idea was diluted by the dominating links drawn to self-injury via mental disorder. What is made most significant is that self-injury is ultimately a product of mental disorder, irrespective of how that mental illness may have manifested.

Evidence of mental disorder in participants was confirmed by making use of psychological report data, extracted from the CSC's OMS, and paired with new data generated by psychometric tools designed to scan for the possibility of mental illnesses, namely the Structured Clinical Interview for DSM-IV Axis I and Axis II disorders (SCID-I and SCID-II ${ }^{40}$ ), among other assessment tools ${ }^{41}$. The use of these sorts of tests in

\footnotetext{
40 The SCID-I/II tool is cited as the 'gold standard' for uncovering psychiatric diagnoses. According to the SCID-I/II's website, the tool offers a "semi-structured interview for making the major DSM-IV Axis I/II diagnoses" (Biometrics Research Department, n.d.). The SCID-I/II provides clinicians or researchers with a list of structured questions to ask a patient, where the administrator then assigns a number based on the perceived intensity of the patient experiencing a given characteristic or symptom. Throughout the test, there are prompts for administrators: 'if no go to obsessive compulsive disorder' or 'if yes go to past manic episode'.

${ }^{41}$ These include: the Short Form Buss-Perry Aggression Questionnaire (BPAQ-SF) which assesses extent of physical/verbal aggression, anger and hostility; the Depression, Hopelessness and Suicide (DHS)
} 
characterizing the subjectivities of prisoners amplifies the significance of clinical/abnormal psychology in explaining deviant prisoner behaviour.

Practices.

Although the texts did not set out to evaluate the effectiveness of mental health or correctional programs, the qualitative text explains how participants expressed using certain coping strategies learned through programming to help prevent them from selfinjuring. A leap in logic is made where programs are credited for having taught prisoners these skills despite any statement to that effect made by participants:

Several participants expressed using methods of coping with NSSI that are currently taught in CSC programs, although none of the men specifically described how they obtained these specific skills. Even though the men did not spontaneously acknowledge programming as the source of their effective coping skills, it is likely that the methods being used were obtained through therapy and programming and that these skills were successful in diminishing NSSI. (Power, Beaudette, \& Usher, 2012, p. 34)

This statement offers support for the current practices even if no support was warranted, thereby 'boot-strapping' the current programming practices into existence.

Risk-logic is notably evident in one of the quantitative texts. The text extends a platform on which it may stand in the future to develop risk-assessment tools:

Further research could contribute to the effective management of NSSI in correctional settings through the development of an empirically-based risk tool to assess the risk for NSSI or a suicide attempt during their sentence. (Power \& Usher, 2011b, p. iii)

screening form designed to assess risk of suicide in prisoners; the Brief Coping Orientation for Problem Experiences (COPE) inventory which assesses adaptive and maladaptive coping strategies; the Childhood Trauma Questionnaire (CTQ) which attributes scores to histories of abuse and neglect; the Brief Symptom Inventory (BSI) which asks participants to rate nine dimensions of psychological distress on a Likert scale; the Dynamic Factor Identification and Analysis (DFIA) assessment to identify impulsivity (same tool used to determine criminogenic needs upon intake); and the Offender Self-Injurious Behaviour Inventory (OSIBI), which was originally developed by the RB to assess self-reported reasons and aetiology of selfinjury (Power \& Usher, 2011b). 
The significant relationships found here should be used to inform future research on the development of a tool to predict NSSI. (Power \& Usher, 2011b, p. 41)

Much like the texts in the previous cluster, this power of suggestion opens up a space in which future knowledges may be received. The RB hints at the future practice of predicting self-injury with actuarial assessment tools but first suggests it needs to develop, validate, and implement such a tool in order to meet their own 'empiricallybased and validated' standards. Through this communication, readers are asked to recognize the importance of such a tool, and thus the practice associated with the use of this tool.

\section{Identities.}

Men are first and foremost constructed as being inclined to self-injure as a result of mental disorder, and as such as possessing pathological identities. A secondary explanation for self-injury is offered, wherein the men's identities are constructed in accordance with cultural stereotypes of the impulsive, delinquent man. Men prisoners who self-injure are reportedly more likely to be housed in maximum security facilities than those who do not (Power, Usher, \& Beaudette, 2012) and are said to self-injure out of anger and impulsivity (Power \& Usher, 2011b). Under the coded theme 'hurt self instead of others', the qualitative text describes prisoners who, quite literally, hurt themselves as opposed to physically harming another person around them:

By internalizing their emotions, they felt that they could avoid institutional charges or sanctions such as being placed in segregation for harming offenders or staff. (Power, Beaudette, \& Usher, 2012, p. 12)

This qualifier assumes that the action of 'hurting' is only associated with the physical act of harm and injury of another individual. Contrary to this, much of the extant research on 
self-injury posits that the 'hurt self instead of others' theme is understood in a broader sense as when individuals self-injure in order to negate their (potentially impulsive) desires to let someone down emotionally, get angry at someone, or otherwise present unbecoming emotions to another person (Briere \& Gil, 1998; Brown, 2009). This idea of 'hurting' someone else is interpreted by the RB only in terms of externalized violence, thus constructing self-injuring men prisoners as violent.

\section{Politics.}

A particularly political perspective is evident throughout the qualitative text, where the report presents a very different take on the theme 'institutional influence' than readers might expect. At first read, this category appears to represent men who are influenced by the institution to engage in self-injury, partly given the summary that reads:

Coping was the most common reason cited by the men with almost $60 \%$ of participants reported using NSSI as a method of coping with negative emotions or to moderate their mood in some way. The second most common reason was institutional influence, which involved using NSSI instrumentally while incarcerated to exert control or obtain external rewards. Among men who initiated NSSI in a CSC institution, institutional influence was the most common motivation. (Power, 2012, May, p. 1, emphasis added)

However, this idea of exerting control in resisting the institution is never recalled. Instead, 'institutional influence' is defined as "a method of exerting interpersonal influence specifically on institutional staff or other offenders to gain an external reward that was desirable to the participant" (Power, Beaudette, \& Usher, 2012, p. 10). At one point the term is substituted for 'institutional manipulation' (p. 9). There appears to be a disconnect between how participants' responses are interpreted, and what men prisoners 
may actually mean when making statements that allude to prison resistance. For example, the following quotes made by prisoners are cited:

P017: I felt that was my only way to lash out and get out of [institution name] hoping they would send me to RPC1...It just felt like that was pretty extreme. And that was the first time I actually went through with something like that. But...I felt I had no other alternative. (Power, Beaudette, \& Usher, 2012, p. 10)

P148: Uhm, I felt like why should I even bother living if I have to, if I'm going to get thrown in prison for the rest of my life so. Despondent and didn't really care. (Power, Beaudette, \& Usher, 2012, p. 19)

These statements were coded as 'institutional influence' and 'hopeless' respectively, yet it may be argued that they demonstrate how the lack of viable options in an isolative prison environment can lead to a drastic act of resistance in response to an uninhabitable situation. Presenting responses of prisoner resistance would run in contradiction to the politics of the institution. It appears that the narratives offered by men prisoners are filtered and fed through a coding system with selective definitional outputs, ultimately erring on the side of political caution: what interpretation would bring about the lowest threat to the political sanctity of the CSC? This results in the excusal of the CSC from moral, legal, or political responsibility for the hardships that men prisoners endure while in prison.

One of the quantitative texts concludes that the 'correctional environment' appears to affect men who engage in self-injury because they have increased opportunities for institutional manipulation:

Additionally, only $7 \%$ of women first self-injured while in a CSC institution, compared to $42 \%$ of men. These gender differences are again consistent with the increased use of self-injury for reasons of interpersonal influence among men and that the correctional environment has a greater 
impact on self-injury in men than women. (Power, Usher, \& Beaudette, 2012, p. 30)

The extent to which the prison environment can affect self-injury is reduced to the idea that it alters men's personalities, and thus self-injury is attributed to the person and not the prison. Power, Usher and Beaudette (2012) also explain how there is no known influence of the prison environment on self-injury given lack of research on the subject:

In their sample of 1,741 male prisoners, the authors [Maden, Chamberlain, \& Gunn, 2000] found that SIB was related to neurotic and personality disorders (which are more prevalent in offender populations) and could not simply be explained by environmental stress or social influence. The lack of conclusive research in this area points to an important gap in the literature. It is not yet known the extent to which social environment influences initiation or maintenance of SIB. (p. 3)

\section{Relationships.}

Cluster no. 2 reports begin to answer the research questions posed in cluster no. 1 texts. This is indicative of a close relationship with the governing institution, where the $\mathrm{RB}$ essentially has free reign to collect information on prisoners in the interests of correctional social experiments used by and for the CSC. So long as the research supports the RB's role to develop and uphold the corporate objectives and policies (CSC, 1989, 2004, CD 009), then the RB satisfies the CSC's organizational needs. The 'emerging research results' men's study is a prime example of how the RB calls upon itself for future research production:

Men who self-injure have more complex mental health issues that should be considered in efforts to treat and prevent this behaviour. More research into the motivations for self-injuring among federally sentenced men is required. This research is ongoing at the Research Branch. (Power \& Usher, 2011b, July, p. 1)

This reveals the self-perpetuating relationship between the CSC and RB, where the RB is meeting the CSC's needs simply by publishing more research on prisoner self-injury. 
Indeed evidence of this relationship is expected given the RB's self-stated role to conduct research for the CSC (CSC, 2004, CD 009), but it is nevertheless important to note that there is clear evidence of this relationship throughout the texts.

\section{Connections.}

The men's self-injury texts do not review the extant literature on self-injury that exists outside of the psy-paradigm. There is no connection made to literature on selfinjury and gender, nor is there any meaningful reflection on how gender as a social construct may lend to understandings of self-injury despite the fact that one text endorsed some masculine stereotypes. Of all post-2010 RB research, this cluster is the most removed from discourse that sits outside of the corrections or psy literature. This is likely because the reports focused on men prisoners and much of the critical literature (e.g., Kilty, 2006) concerns women prisoners.

\section{Language type and sign systems.}

The quantitative texts are predominately based in psy-language whereas the qualitative text has a medley of social-psychological and psy-languages. The quantitative text that sought to determine the profile of the self-injuring prisoner explains how clinical interviews as per the SCID-I and the SCID-II were used to detect mental disorders that may have slipped past prior psychological assessments administered at intake. By offering up this kind of language to the reader, the text privileges psychological modes of thought, promoting and disseminating psy-knowledges in today's culture of diagnosis ${ }^{42}$ :

\footnotetext{
${ }^{42}$ For example, Power and Usher (2011b) nonchalantly indicate that as per the SCID-I/II, $99.0 \%$ of the men's self-injury group met the criteria for any mental disorder, versus $87.4 \%$ of the men's non-self-injury group. This fails to question the evident excess of diagnosis; not only is there a marginal difference between the two groups, but how is it possible that nearly only 1 in 10 men prisoners do not meet the criteria for a mental disorder?
} 
Posttraumatic stress disorder, borderline personality disorder, antisocial personality disorder, and substance abuse disorders were found to be more common in the NSSI group as measured by the SCID, which conflicts somewhat with results from the semi-structured interview. This may be due to the fact that the SCID measures any past or current depressive symptoms, while the interview was intended to capture historic diagnoses, or it could be explain [sic] by the fact that though the men were exhibiting symptoms of a psychological disorder but had never been formally diagnosed. (Power \& Usher, 2011b, p. 26)

Conversely, in the qualitative report, dissonance is evidenced between the socialpsychology language (e.g., speaking of relief or regret as emotions that follow a selfinjurious episode), and psy-medical languages (e.g., where 'coping' mechanisms and emotional dysregulation topics are concerned). Neither language is distinctly privileged given that the other competes with its authority to reign as the ideological truth. This is not to suggest that two languages cannot co-exist; rather it means that the qualitative text does not privilege one language over the other. Nevertheless, the text maintains a particular demeanour that abides by the common correctional approach to distance research from the isolating and dehumanizing experiences of the prisoners.

Cluster no. 3: Research intended to improve understandings for why women prisoners engage in self-injury and/or the characteristics of women who self-injure (post-2010)

This cluster consists of primary differential research undertaken by the RB to determine the motivations, emotions, and precipitating events related to self-injury in women prisoners. The reports in this cluster consist of four full publications (Power \& Usher, 2010, 2011a, 2011c, 2011d), four corresponding one-page 'research summaries' (Power, 2010b, July; Power, 2011, August; Usher, 2011, August; Usher \& Power, 2011, August), and one page of 'emerging research results' (Power, 2010a, July). 
The same sample group of 150 women prisoners who were recruited between July and October of 2009 from each of the six federal women's institutions ${ }^{43}$ act as participants in three of the four reports, $38 \%(n=57)$ of whom self-reported engaging in self-injury. Two of these three reports employ a quantitative approach where the 57 women are compared to a group of matched controls $(n=93)$ that had no known history of self-injury. A series of questionnaires and a clinical interview designed to assess presence of psychological disorders were administered. Correlations between both groups and factors thought to be associated with self-injury were assessed using quantitative analyses. Variables include mental illness, relationship to past suicide attempts, impulsivity, aggression, and childhood trauma. The third report, which is qualitative in nature, is based on semi-structured interviews with 56 of the 57 women in the originally identified pool of self-injurers. Interviews were recorded on a digital recorder, then transcribed using NVivo 7, and analyzed using content analysis at the discretion of the primary researchers.

The last report presents an archival analysis of 400 randomly selected women who were incarcerated between April 1, 2008 and March 31, 2009, of which 23.4\% (n = 95) were identified as having a history of self-injury and $46.3 \%(\mathrm{n}=185)$ as having either a self-injurious incident or a suicide attempt in their past. Quantitative analytical techniques were used to differentiate between those who engaged in self-injury and those who did not on a number of factors, including history of abuse, criminal history, mental illness, depression, suicidal ideation, and substance abuse. Both inferential and

\footnotetext{
${ }^{43}$ These include: Nova Institution (Truro, Nova Scotia), Joliette Institution (Joliette, Quebec), Grand Valley Institution (Kitchener, Ontario), Fraser Valley Institution (Abbotsford, British Columbia), Edmonton Institution for Women (Edmonton, Alberta), Okimaw Ohci Healing Lodge (Maple Creek, Saskatchewan), and the RTC in the Prairies (Saskatoon, Saskatchewan) (CSC, 2013m).
} 
descriptive statistics pertaining to the self-injury group were included, such as prevalence $^{44}$, incidence, type and bodily location of self-injury, spatial location where self-injury occurred, temporal patterns, and self-reported reasons for self-injury.

Significance.

The texts render the idea that that self-injury in women prisoners is largely attributable to mental disorder as the most significant. The language used and the conclusions drawn in this cluster of research point to the significance of mental disorder as the root cause for self-injury. Much like the men's studies, similar psychometric tests were applied, including the SCID-I and SCID-II among other assessment tools ${ }^{45}$. The conclusions are more of the same:

Participants who had a history of NSSI scored significantly higher on measures of impulsivity, depression, hostility, sexual abuse, and aggression. Participants in the NSSI group were also significantly more likely to meet the criteria for Obsessive-Compulsive Disorder and Borderline Personality Disorder. (Power, 2011, June, p. 1)

Women with a history of SIB were more likely to have been previously diagnosed with a psychological disorder, including bipolar, mood disorders, psychotic disorders, substance use disorder, anxiety disorders, and personality disorders. The files of these women were more likely to have evidence of a history of depression, hopelessness, suicidal ideation, and substance abuse. (Power \& Usher, 2011d, p. iii)

Participants in the NSSI group were significantly more likely to meet the criteria for obsessive-compulsive disorder (21\% vs. 5\%), major depressive disorder (68\% vs. $45 \%$ ), borderline personality disorder (51\% vs. $22 \%$ ), and any disorder (excluding alcohol and substance use disorders at $91 \%$ vs. 67\%). (Power \& Usher, 2011c, p. 23-24)

\footnotetext{
${ }^{44}$ A contradiction is seen in Power and Usher's (2011d) report, where despite stating that "the sample was randomly selected proportionate to the incarcerated population in each region", (p. iii) and that "the research sample is representative of the total women offender population in custody" (p. 6), the report states "this sample was not randomized, however, and conclusions about prevalence of NSSI could not be reached" (p. 5).

${ }_{45}$ These include: the BPAQ-SF; the Barratt Impulsiveness Scale Version 11 which measurers impulsivity on three subscales; the DHS; the Brief COPE; the CTQ; the Paulhus Deception Scale which accounts for participants responding in socially desirable ways; the OSIBI, and the DFIA.
} 
The idea that self-injury could be influenced solely by social experiences is dispelled when the texts propose that childhood abuse, for example, leads to mental disorder, which in turn causes self-injurious behaviour. This 'pathway' logic is the same as seen in the men's texts:

The Childhood Abuse Model proposes that the experience of childhood sexual abuse leads to psychological disorders such as eating disorders, depression, PTSD [post-traumatic stress disorder], and borderline personality disorder, which in turn, lead to NSSI. (Power \& Usher, 2011c, p. 28)

All four RB texts in this cluster point either explicitly or implicitly to mental disorder as a correlative of women who self-injure. They do so explicitly, by claiming that women who self-injure are plagued by a flurry of Axis I and Axis II disorders (Power \& Usher, 2011a, 2011d), and implicitly, by suggesting that they engage in maladaptive coping methods as a result of their inability to successfully manage or regulate emotions (Power \& Usher, 2010, 2011c). This connection is fused in part through the fact that the key criterion for various mental disorders consists of the inability to regulate emotions or 'emotional dysregulation" ${ }^{46}$. As a result, the texts signal to readers that women prisoners who engage in self-injury are pathologically inclined to do so because they are unable to effectively regulate their emotions.

\section{Practices.}

While none of the studies sought to determine the effectiveness of programming on self-injurious behaviour specifically, each text offered commentary on how adaptive

\footnotetext{
${ }^{46}$ For example, 'borderline personality disorder' can be diagnosed when an individual meets the following criteria: "instability in goals, aspirations, values, or career plans [...] intense, unstable, and conflicted close relationships [...] unstable emotional experiences and frequent mood changes [...] feeling fearful, apprehensive, or threatened by uncertainty", while 'disruptive mood dysregulation disorder' as a new addition in the DSM-V is used to characterize one facet of bipolar disorder (APA, 2012, 2013a).
} 
coping skills are taught to women in programming, which in turn may help reduce selfinjurious behaviour:

Alternative strategies for coping have been learned by many women with histories of NSSI, often through institutional programming such as DBT. The results suggest that women offenders at risk for self-injury could benefit from exposure to training on alternative coping strategies. These strategies are consistent with current correctional program content so could be incorporated into existing core interventions. (Power, 2010, July, p. 1)

There are other possible explanations for this decrease in [self-injurious] behaviour, including: 1) federally sentenced women within CSC have access to a wide range of supportive programs and interventions in which women may learn alternatives to NSSI. (Power \& Usher, 2011a, p. 25)

Through these texts the CSC's programs are credited for playing a hand in preemptively reducing self-injury even though some of these programs were not specifically designed to do so. This kind of praise is not uncommon in more general correctional discourse, which tends to amplify the 'reintegrative and rehabilitative' aspects of correctional programs despite the fact that the realities of program participants may not match up to this idealized vision (see, for example, DeVellis, 2012; Kendall, 2000; Moore \& HannahMoffat, 2005). The RB concludes that women who self-injure would be better served by extending referral criteria of mental health programming to include those who do not necessarily meet the diagnosis of borderline personality disorder:

Correctional planning may be well served by offering offenders training in coping strategies as an alternative to NSSI in a wider range of programs, and not limiting access to these intervention strategies to women with Borderline Personality Disorders who qualify for the DBT program. (Power \& Usher, 2010, p. 32)

Prediction of self-injury risk is as evident throughout the women's reports as it is in the men's texts. The RB's findings serve to answer the CSC's questions: can self- 
injury in prisoners be predicted? The RB is of the opinion that yes, with more rigorous and empirically validated studies, it may be both possible and recommended to adopt this practice:

Longitudinal research would be required to determine how and why NSSI is initiated and maintained over time. Future studies could contribute to the management of NSSI in correctional settings through the development of an empirically-based risk tool that could be used in correctional settings to assess the likelihood that an individual will engage in NSSI or a suicide attempt during their sentence. (Power \& Usher, 2011c, p. iii)

Part of the RB's methodology involved the creation of the Offender Self-Injurious Behaviour Inventory (OSIBI) assessment tool ${ }^{47}$, which demonstrates both the implementation and reification of psychometric assessment practices.

\section{Identities.}

The texts construct the identities of self-injuring women prisoners by conceptualizing, amalgamating, and deriving their experiences from a number of response schemas, quantitatively and qualitatively. Women prisoners who self-injure are constructed as plagued with mental illnesses and as lacking the ability to appropriately manage their emotions. A secondary underlying construction suggests that women prisoners who engage in self-injury are high-need, impulsive, depressed, hostile, abused, but also dangerous, angry, and risky. The authors write:

Participants who had a history of NSSI scored significantly higher on measures of attentional impulsiveness, non-planning impulsiveness, and overall impulsiveness, depression, hostility, sexual abuse, and verbal and overall aggression. Women with a history of NSSI also scored higher on hopelessness, anger, hostility, physical aggression, emotional abuse, and substance use as a method of coping. (Power \& Usher, 2011c, p. 21)

\footnotetext{
${ }^{47}$ The OSIBI is an 8-page self-report participant questionnaire with 74 yes/no variation questions, 15 Likert scale questions and 2 multiple-choice questions. The OSIBI is said to gather information on "motivations for NSSI, onset of NSSI, and the effects of incarceration” (Power \& Usher, 2011c, p. 14).
} 
Women with a history of SIB were significantly more likely to have shorter sentences ${ }^{48}$, have higher risk and higher need, be higher security, and have a major admitting offence of homicide or assault compared to those without a history of SIB. (Power \& Usher, 2011d, p. 15)

Interestingly, self-injury is not considered wholly attributable to women who engage in the behaviour for manipulative or instrumental reasons. This marks a distinct shift in the literature from previous understandings:

It is interesting to note that the next four most common motivations [after affect regulation] listed were "to get support or attention from staff", "for external rewards", "to get moved out of my cell or unit", and "for excitement/boredom", all of which imply an element of manipulation. [...] While some women do engage in NSSI for external rewards, it is important to remember that this is not the primary reason for this behaviour and most women do not self-injure due to this motivation. (Power \& Usher, 2011d, p. 35)

Furthermore, the texts note the distinction between self-injurious behaviour and suicidal tendencies. This too marks a shift in the literature from previous understandings that tended to conflate the two behaviours:

Though many of them [women offenders] had engaged in both behaviours [suicide and self-injury], they could clearly articulate the differences in their intent and, often, their method of injury. This distinction between the two behaviours allowed for ease of categorization into study groups and further reinforced the finding that these behaviours are different phenomena. (Power \& Usher, 2011c, p. 36)

These distinctions serve to refine the construction of women prisoners as, for the most part, pathologically inclined to self-injure by suggesting that self-injury is more often a byproduct of mental illness than of manipulative intent, and that self-injury as a

\footnotetext{
${ }^{48}$ This contradiction between women who are more likely to be of higher risk, need and security level, yet have shorter sentences should be noted. Generally speaking, sentences imposed by the courts reflect the severity of the crime and crime type. If women who self-injure are serving shorter sentences than women without a history of self-injury yet are still more likely to be in higher security, this suggests a disjuncture between the severity of the original sentence and how prisoner staff (whether during intake or later on in the prisoner's sentence) perceive the women as more unruly or otherwise a threat to the safety and security of the prison. This was not addressed in the texts.
} 
phenomenon distinct from suicide is attributable to mental instability. The understanding that women who self-injure are high risk and high need and potentially a threat to the security of the institution remains apparent in the texts:

Risk of SIB would influence security classification and thus offenders with these behaviours would logically be classified at high security levels where they would be supervised more closely. (Power \& Usher, 2011d, p. 33)

However emphasis on the security and safety of the institution is a less prominent construction in the texts when we consider the primary constructions of women who selfinjure as harbouring mental illnesses.

Politics.

Further to the understanding that self-injuring women prisoners are plagued by mental illness, the RB draws an additional conclusion that is inherently political: selfinjury in women prisoners is largely a behaviour learned and practiced prior to being admitted to the prison:

Of the women with a history of NSSI $(n=57), 93 \%$ first initiated the behaviour prior to admission to CSC, and $40 \%$ reported at least one incident of NSSI while incarcerated. [...] Rates of NSSI and suicide attempts are already high in this population prior to incarceration. (Usher, 2011, August, p. 1)

While $40 \%$ of women with a history of NSSI reported engaging in NSSI while at CSC, the vast majority of those women first initiated the behaviour in the community. [...] As such, there appears to be little support for the theory that incarceration increases NSSI, nor is there support for a contagion effect. [...] Based on the results of this study, few women initiate NSSI after incarceration and incarceration does not appear to increase the frequency of NSSI in those with a prior history of the behaviour. (Power \& Usher, 2011a, p. 23-24)

These statements serve to divert the attention from self-injury as a problem exacerbated by the prison to the women whose abnormal personalities are suggested to have been 
formed prior to being admitted to prison. Based on the finding that only $7 \%(n=4)$ of women reported that their first self-injurious incident occurred in a CSC institution, the $\mathrm{RB}$ concludes that self-injury is not a product of the prison, but rather of the person. This may be interpreted as reflecting a political perspective that attempts to excuse the prison from causing or contributing to self-injury. In this sense responsibility is evaded, and the positioning of blame for self-injury is redirected to the women prisoners, who are constructed as having brought the problem in with them.

Much like the men's study equivalent, the qualitative women's study utilized a specific coding scheme when categorizing respondent's self-stated motivations for engaging in self-injurious behaviour. For example, the report codes the following participant's response under 'anxiety and fear' as opposed to 'being in prison':

P095: I was scared coming [in]. I mean I am a first time federal sentence woman. It is not something, I don't have a big, long criminal history. It is not something I wouldn't do the rest of my life, it is just something terrible happened, a tragedy in my life, and I am here dealing with it. And the chances of me reoffending are next to nil. (Power \& Usher, 2010, p. 15)

Here the text comes close to capturing experiences of the 'pains of imprisonment' but then reclassifies the woman's message as demonstrative of 'anxiety and fear'. Some participant responses are captured under various other themes as opposed to 'being in prison', which suggests that endorsements for prison-related stressors as motivation for self-injury may have been diluted.

Despite this, the qualitative study evidences a solid effort with respect to preserving a narrative of women's experiences in prison. Indeed the report does acknowledge that some (even if few were coded as such) women endorsed 'being in prison' as a motivation for their self-injury. The fact that the RB undertook a qualitative 
approach to understanding women prisoner's self-injury at all is surprising given the usual quantitatively-driven approach of the RB. At the outset the qualitative text makes a point to heighten awareness of women's experiences:

The present study examined the NSSI through semi-structured interviews with incarcerated women offenders in order to tap into the subjective experiences of the women. (Power \& Usher, 2010, p. 2)

Despite this, the text treads carefully in order to maintain alignment with the RB's political obligations. That is, being required to refrain from unveiling any real harm on the part of the institution, while at the same time providing a narrative that portrays the lived experiences of women in prison. It is suggested that this balancing act ultimately yields a disjuncture between the one qualitative and the three quantitative texts, the latter of which appear to erase the idea that the prison environment could influence self-injury at all:

The Incarceration Model proposes that the experience of being incarcerated leads to NSSI through inability to cope with the stressors of incarceration and the impact of viewing other offenders self-injure while incarcerated $[\ldots]$ very few women reported that their NSSI was influenced by seeing others self-injure or being incarcerated and no significant relationship was found between coping and NSSI. (Power \& Usher, 2011c, p. 32)

As per the 'incarceration model', superficial elements that come hand-in-hand with being imprisoned are posited as the causal link between environment and self-injury outcome. This limits understandings about self-injury to the idea that: a) incarcerated women can accumulate ineffective coping skills, or b) that women may self-injure because they saw another women prisoner do it (also known as the 'self-harm contagion'49). In two of the

\footnotetext{
${ }^{49}$ A significant body of research has explored how exposure to others who self-injure may actually cause or increase the likelihood of self-injury (Derouin \& Bravender, 2004; Hodgson, 2004; Rosen \& Walsh, 1989; Taiminen, Kallio-Soulainen, Nokso-Koivisto, Kaljonen, \& Helenius, 1998; Walsh \& Rosen, 1985). This
} 
four women's studies, the reports acknowledge some of the critical literature that pointed to the prison as having an exacerbatory effect on self-injury:

Some authors have suggested that the correctional environment and the way in which SIB is handled within correctional institutions is a direct cause of NSSI (Kilty, 2006; Thomas, Leaf, Kazmierczak, \& Stone, 2006). [...] The limited research and the conflicting findings in the research that does exist, highlight an important gap in the literature: the identification of pathways which individuals follow resulting in NSSI and the effect (if any) of the correctional environment on these pathways. Based on the research conducted to date, the precise relationship between incarceration and NSSI is not yet known. (Power \& Usher, 2011a, p. 3)

Similarly, while the effect of institutionalization on NSSI has been widely discussed in the literature (e.g., Fillmore \& Dell, 2000; Franklin, 1988; Kilty, 2006; Thomas, Leaf, Kazmierczak, \& Stone, 2006), we found little evidence to suggest that institutionalisation played a principal role in triggering NSSI for federally sentenced women. In fact, most women discussed self-injuring outside of the institutions rather than inside. (Power \& Usher, 2010, p. 29)

The fact that most women began self-injuring prior to entering the prison does not mean that incarceration does not exacerbate or reinforce self-injury. This leap in logic demonstrates how the RB produces knowledge to fit the parameters of the desired outcome, that is, to circumvent the link between prisoner self-injury and prison environment. The dismissal of research that contradicts the findings of "no significant relationship' for the incarceration model further evidences the political position of the CSC. By not mentioning what negative effects the prison environment can have on women, the texts evade responsibility for this possibility.

Finally, on the issue of segregation and self-injury, an omission is apparent in Power and Usher's (2011d) archival study. In the Appendix, the 'location of incident in 2003; Lohner \& Konrad, 2007), although it is generally not considered a predominant theory with which to understand why self-injury occurs. 
institution' is noted as a variable that includes 'segregation', 'cell (general population)', 'treatment centre', 'mental health unit', 'cell (protective custody)' and 'administrative segregation' (p. 55). The report does not present nor discuss the results of each of these location categories; instead the authors only review the security level classification.

\section{Relationships.}

As seen in the case of the men's self-injury studies, the RB signals their commitment to the CSC through choice of neutral and organizationally appropriate language. On a more micro scale, the hierarchical relationship between the interviewers (employees of the RB) and the participants (women prisoners) in the qualitative study may affect the outcome of the interview as well as how the results are interpreted and presented. The text does not wholly address this issue and falls short of reflexively considering the effect the authors' position of authority has on the responses of the women, or how their position lends to their characterization of the women's identities. This potential for bias is addressed in one sentence:

In order to reduce the possibility of bias, methods of improving the validity and reliability of self-report data that are supported in the literature were implemented, including the use of female interviewers, reducing the power differential through appropriate dress and demeanour and ensuring a large sample size. (Power \& Usher, 2011a, p. 25)

These efforts do not address the most obvious power differential of prisoner versus prison staff. Assuming participants were advised that the interviewers were employees of the CSC (notably from NHQ, which holds its own attached cultural tags ${ }^{50}$ ), it is possible that

\footnotetext{
${ }^{50}$ In my experience at the CSC, NHQ staff are often viewed by employees working in (or offenders residing at) regional sites as 'know-it-all's' who sit in the comfort of their cubicles making decisions about what will happen on an institutional level, despite potentially never having stepped foot in an institution. It is possible that if respondents were aware that NHQ staff would be interviewing them, they may have been somewhat hesitant to speak openly.
} 
participant responses were not unconditionally open and honest. Had a neutral party such as an independent researcher who was not affiliated with the very organization that was confining these women - interviewed participants it is possible that the responses and the interpretations of those responses would have been different.

\section{Connections.}

An interesting disconnect is evidenced within the texts of this cluster: the qualitative report in part acknowledges the prison as being a source of negative influence on self-injury, yet the quantitative reports deny this idea with the noted absence of evidence for the 'incarceration model'. This is likely an unintentional disjuncture on the part of the authors, but it demonstrates a lack of regularity among this cluster of reports. Such a dissonance may also be indicative of the balancing act the RB must undertake to satisfy both the pursuit of objective research yet respect the political infrastructure of the CSC.

The texts are absent of discourses that are not predominantly psy-oriented. Although the RB does cite some scholarship that has pointed to the failures of the penal system with respect to the treatment of self-injuring prisoners (as reviewed under politics, e.g., Fillmore \& Dell, 2000; Kilty, 2006; Thomas et al., 2006), there is little evidence of meaningful engagement with these texts. When they are acknowledged, they are for the most part dismissed for being unable to draw a causal link between self-injury and incarceration. Instead the notion that "it is not known whether incarceration in-and-ofitself increases the risk for NSSI" (Power \& Usher, 2011a, p. 4) or that "incarceration was not found to have a significant effect on NSSI" (Power \& Usher, 2011c, p. iii) took priority over the messages suggested by the critical bodies of literature. This difference in 
view suggests a fracture between research grounded in the psy-sciences, which the RB relied on to support explanations for women's self-injury (i.e., mental disorder and affect regulation) and sociological knowledges that offer alternative explanations for why women prisoners may engage in self-injury (e.g., resistance or as an expression of agency. See Fillmore \& Dell, 2000, 2005; Frigon, 2001; Holley \& Arboleda-Florez, 1998; Kilty, 2006, 2008b; Liebling, 1995).

Language type and sign systems.

Psy-language dominates the texts. Part of the methodology consisted of making use of clinical interviews to diagnose psychiatric disorders, namely the SCID-I and the SCID-II. By offering this kind of language to the reader, the texts privilege clinical/abnormal psychological modes of thought and promote and disseminate psyknowledges in today's culture of diagnosis ${ }^{51}$. Conversely, these four texts suggest the disprivileging of languages that hail from sociological discourse or critical criminological understandings of human behaviour given that little to no attention was paid to alternative explanations for women's self-injury in prison outside of those proposed by the psysciences.

Cluster no. 4: Research intended to improve understandings for why prisoners engage in self-injury generally and/or the characteristics of prisoners who self-injure (post2010)

This cluster consists of three primary differential research studies undertaken by the RB whose objectives do not explicitly fit the preceding clusters (Gordon, 2010;

\footnotetext{
${ }^{51}$ Power and Usher (2011c) nonchalantly indicate that in using the SCID-I/II tools, $98.2 \%$ of the women's self-injury group met the criteria for any mental disorder, versus $94.6 \%$ of the non-self-injury group. This fails to question the evident excess of diagnosis; not only is that a marginal difference between the two groups, but how is it possible that nearly only 1 in 20 women prisoners do not meet the criteria for a mental disorder?
} 
Power \& Riley, 2010; Power, Gordon, Sapers, \& Beaudette, 2012). A common theme that ties the reports together is the highlighting of the differences between self-injurious behaviour and suicide. Corresponding one-page summaries are included for each report (Gordon, 2010, December; Power, 2010, May; Power, 2012a, November).

In all cases the research was initiated to investigate the extent of self-injury in federally sentenced prisoners in order to better inform treatment, prevention and management. Gordon (2010) examines 1,230 self-injury incidents (involving 573 prisoners) reported in the OMS and in institutional SITREP's between April 1, 2006 and September 30, 2008. Self-injurious incident reports were coded on a number of variables, including type and severity of self-injury, how the incident was discovered, and what action was taken immediately after the incident. A quantitative approach determined the statistical significance of self-injurious incident outcomes. Gordon (2010) also addresses the methodological limitations of the CSC's data capturing systems (i.e., OMS, SITREP's), arguing that relying solely on data from the OMS to generate self-injury incident numbers may actually underestimate incidence ${ }^{52}$. As such, Gordon (2010) calls for the implementation of a new "efficient, reliable and effective self-injury tracking system" (p. 33) after concluding that the current reporting frameworks are inadequate. This conclusion separates his study from the rest of the post-2010 RB reports. Power, Gordon, Sapers, and Beaudette (2012) state that their research goal is to replicate Gordon's (2010) study but extend the time frame of analysis from October 1, 2008 to

\footnotetext{
${ }^{52}$ Note that all other RB studies with the exception of Power, Gordon, Sapers and Beaudette's (2012) relied solely on data from the OMS to identify self-injury incidents.
} 
March 31, 2011 in order to determine whether or not Gordon's (2010) initial findings remain valid.

Power and Riley (2010) conducted an archival review of 20 prisoners who were involved in self-injury incidents and 66 cases of prisoners who committed suicide. All prisoners were the subjects of national incident investigations ${ }^{53}$ between April 1, 2003 and March 31, 2008. The objective of this study was to review both self-injury and suicide incidents and as such yields different findings and conclusions than reports solely on self-injury. The authors note that because of a small sample size $(n=86)$, the study relies mostly on quantitative descriptive statistics to characterize prisoners who engage in self-injury or those who committed suicide; variables of analysis include gender, ethnicity, relationship status, offence type, sentence length, risk, need, mental illness, type of self-injury/suicide, time of day/week/month when incident occurred, location where the incident occurred, and precipitating events or risk factors that occurred prior to the incident.

Significance.

The understanding that self-injury in prisoners should not be confounded with suicidal ideation was rendered equally significant in all three reports, as such these behaviours are best studied independently:

\footnotetext{
53 The Incident Investigations Branch of the CSC is mandated to review all cases of an offender who dies while under the CSC's custody or who suffers serious bodily injury, as per s. 19 of the CCRA (1992). Serious bodily injury is defined as: "Any injury as determined by Health Services personnel as having the potential to endanger life, or which results in permanent physical impairment, significant disfigurement or protracted loss of normal functioning" (CSC, 2013f, CD 568-1, Annex B, p. 15).
} 
The current analysis found that 20 of the $26(77 \%)$ inmates who died [of suicide] had no previous documented self-injury incidents throughout their incarceration. (Gordon, 2010, p. 20)

The results indicate that offenders in the suicide group were more likely to have cause [sic] someone serious harm or death, while the offenders in the SIB group had a greater proportion of offenders who had inflicted "no damage" to others. (Power \& Riley, 2010, p. 23)

The reports differ on the measurement of prisoner characteristics. While Power and Riley's (2010) report tested for the presence of mental disorder in both the self-injury and the suicide group, the other two studies do not address any specific individual characteristics as precipitating self-injury given that their research goals were to investigate the nature and outcome of self-injury incidents. On mental illness, Power and Riley (2010) write:

A significantly greater percentage of offenders in the self-injury group had two or more psychological disorders compared to the suicide group, $2(1, \mathrm{~N}$ $=30)=4.71, p<.05$. The frequency of specific disorders is presented in Table 8. The category of Mood Disorders includes Major Depression, Bipolar, Manic Episodes, and Dysthymia. (p. 17)

Offenders in the SIB group are significantly more likely to have concurrent psychological disorders than those in the suicide group. This finding suggests that the SIB group may have different and more significant mental health needs. Concurrent disorders may present unique challenges for mental health providers. (p. 26)

These types of conclusions render most significant the fact that self-injurious behaviour is a product of (sometimes multiple) mental disorder(s).

In Gordon's (2010) report, the idea rendered most significant, aside from the idea that self-injury should not be conflated with suicide, is that women prisoners are more likely to engage in self-injury (and more frequently) than are men prisoners. Gordon (2010) also highlights that there are a number of methodological limitations in using the 
OMS to report on the prevalence of self-injurious incidents (six full pages were dedicated to a discussion solely on this), and that there was a "sharp increase in the number of offenders in CSC involved in self injury during the last 6 month period of the study ${ }^{54,}$ ( $p$. 12). Power, Gordon, Sapers and Beaudette (2012) suggest that the spike in self-injurious incidents in the beginning and towards the middle of the period of study (October 1, 2008 to March 2010) is mostly attributed to a small group of women:

A relatively small group of women (14\%) who engaged in repeated selfinjury during the study period accounted for the majority of incidents (79\%) and two women in particular accounted for $49 \%$ of the incidents, suggesting that a few extreme cases explain a sizeable amount of the variance in the results for women. (p. 25)

Power, Gordon, Sapers and Beaudette (2012) also note that contrary to Gordon's (2010) findings, incident data revealed that self-injurious incidents actually "rose for the first 42 months studies and plateaued for the final 18 months" (p. 25), and that, ... while the number of incidents increased from the first six months to the last six months of the study period, the number of incidents was relatively stable - and even decreased slightly - over the last 18 months of the study. (p. 25)

Power, Gordon, Sapers and Beaudette (2012) do not voice the same concerns as Gordon (2010) with respect to the limitations of the OMS or the SITREP data capturing methods.

\section{Practices.}

${ }^{54}$ This would have been after Ashley Smith's death in October of 2007, where the last 6 months of the period of study Gordon is referring to ranges from April 1, 2008 to September 30, 2008. 
All three reports present results that unintentionally question the appropriateness of security classification systems. Self-injurious incidents are reported as being more likely to occur in higher security level institutions ${ }^{55}$. For example, Gordon (2010) writes:

Post-hoc analyses showed that while treatment centres, maximum/multilevel security institutions and women's facilities did not differ statistically from each other in terms of the number of self-injury incidents; all three experienced significantly more incidents than did medium or minimumsecurity facilities. Indeed several of the minimums did not have a single incident during the study period. (p. 10)

While Power, Gordon, Sapers and Beaudette do not discuss the distribution of self-injury incidents by institutional security level, the table of results presented for men prisoners demonstrates that the majority $(41.8 \%)$ of incidents occurred at a maximum or multilevel institution, followed by an RTC (30.6\%). As Gordon (2010) notes, it is unlikely that prisoners who engage in self-injury would be held in a minimum security in the first place given their association with high risk and increased institutional incidents (as suggested by Power \& Usher, 2010, 2011a, 2011b, 2011c, 2011d; Power, Usher, \& Beaudette, 2012; Wichmann et al., 2002). RB reports thus acknowledge that not only are prisoners in higher security level facilities more likely to engage in self-injury, but that self-injury is more likely to occur in higher security level facilities. Gordon (2010) ponders:

It is also not clear why so many self-injuring offenders are classified as maximum security. Certainly, repeated self-injury suggests the need for more stringent controls offered in maximum security institutions. It remains to be seen whether other aspects of these offenders' behaviour (e.g., violence toward others, high risk and high needs profiles) also warrant that classification. (p. 23)

\footnotetext{
${ }^{55}$ This finding varies slightly for Power and Riley (2010). Given that their sample consisted of both women and men prisoners, many of the incidents occurred in multi-level institutions. Because all women's penitentiaries are multi-level, it is inferred that this factor drove up this proportion. Security levels were not broken down for each gender.
} 
This excerpt may be interpreted as coming close to addressing the key issue at hand (i.e., that the placement of prisoners who self-injure in higher level security facilities may be problematic), but the author appears to pivot away from this possibility towards politically appropriate rationales that help explain the risk factors self-injurious prisoners present. This in turn represents a disjuncture between research results and practices, where the text has yet to draw meaningful conclusions from the implications of the overrepresentation of prisoners who engage in self-injury in high security facilities. Given this absence of meaningful engagement with and/or challenging of this paradox, it is suggested that the RB's texts ultimately accept correctional practices as they are.

The reports are similarly distanced from a meaningful discussion of the segregation of prisoners who self-injure. Gordon (2010) notes that if the degree of injury is not serious enough to warrant a trip to a hospital, then the individual will most likely be sent to segregation:

The offender was also sent to a community hospital in $31 \%$ of cases [after self-injury], typically, according to the situation report, as a precautionary measure. Forty-one percent of offenders were confined to an observation cell or segregation ${ }^{56}$ following the incident, and $13 \%$ were sent to a treatment centre, typically after returning from outside hospital. Only 7\% of cases noted the use of restraint equipment. (p. 18, emphasis added)

Power, Gordon, Sapers and Beaudette (2012) report that "more than half of the [selfinjury] incidents by women occurred in isolation or segregation cells" (p. 21), while Power and Riley (2010) present a similar finding:

\footnotetext{
${ }^{56}$ An 'observation cell' is the linguistic term used in the CD Management of Self-Injurious and Suicidal Behaviour (CSC, 2013k, CD 843) as an appropriate response to managing the risk of self-injurious or suicidal prisoners. This term is contrasted with 'administrative segregation' (CSC, 2007, CD 709), which responds to all other behaviours warranting (in)voluntary segregation. Observation cells are located within administrative segregation units (Rivera, 2010) and have been theorized as essentially being the same in physical structure despite enacting two very different rationales from opposing policy backbones (Rotenberg, 2012a, 2012b).
} 
Self-injury is more likely to take place in segregation relative to other areas in the institutions. This increased proportion of incidents occurring in segregation may reflect CSC policy around the handling of these incidents by staff in the institutions, as the offenders who are at imminent risk for self-injuring are placed in segregation appropriately so they can be monitored. (p. 24)

Although each report inadvertently suggests a potential link between self-injury and segregation, none of the texts address the implications of placing a prisoner who has selfinjured in solitary confinement, a practice which involves remaining alone in a small confined cell for 23 hours a day (CSC, 2007, CD 709). As a result of this absence, it may be suggested that the texts support and reify the practice of segregating prisoners who engage in self-injury by commenting on how it is necessary for monitoring/safety and security purposes.

\section{Identities.}

The texts were mostly concerned with assessing the precipitating events that led to self-injury rather that the detailed characterization of the type of individual who engages in self-injury. Nevertheless two of the reports suggest that self-injury is more likely to occur at the hand women and/or of Aboriginal prisoners. Gordon (2010) notes “while $19.7 \%$ of CSC's incarcerated population self-identify as Aboriginal, $25.3 \%$ of the offenders who self-injured were of Aboriginal ancestry" (p. 9), while Power, Gordon, Sapers and Beaudette (2012) note that "Aboriginal women accounted for $21 \%$ of the total 2,102 incidents, which is considerably more than the $1 \%$ of the offenders in CSC's population that is comprised of Aboriginal women" (p. 26). Power and Riley's (2010) report did not come to any conclusive findings about the gender or ethnic identity of 
prisoners who engage in self-injury largely because it was not within the scope of the study's goal.

Considered collectively, the three texts in this cluster are not as forthright in projecting a particular identity of prisoners who engage in self-injury in comparison to the other RB texts. If we consider these three texts alongside other RB research, they do however contribute to the broader construction of the self-injuring prisoner as higher risk (hence being more likely to be in a higher security level institution) and as either cognitively inept in coping skills or mentally disordered (hence accounting for most serious cases of repetitive self-injury incidents, or being more likely to have co-occurring psychological disorders).

Politics.

Two reports clearly express that self-injury is most likely to occur in segregation, while the third text, Gordon (2010), notes that self-injury is most often responded to with subsequent segregation so long as the seriousness of the incident does not escalate to the point of requiring medical intervention. These findings are political insofar that they might pique the interest of various external stakeholders who may seek to challenge the CSC on these continued practices (e.g., the OCI, the CAEFS, John Howard Society, and so on). Gordon (2010) briefly acknowledges the idea that an isolating prison environment could exacerbate or at least not be conducive to treating self-injury:

One could argue that the increased confinement and reduced social contact of a maximum security environment is not well suited to offenders who are displaying self-injurious behaviour (Konrad et al., 2007). In fact, the close confinement (including frequent segregation status) that many selfinjuring offenders experience may actually increase the likelihood of further self-injury (Dear, 2006). (p. 23) 
Despite what appears as a stride towards critically questioning the issue at hand, political obligations appear to stand in the way of what would be a paradigm shift in correctional discourse. The text reverts back to blaming the unknown for the environmental conditions that may cause or influence self-injury as opposed to engaging with discourse that problematizes the segregation of prisoners who engage in self-injury:

It is also possible that there may be more tension in institutions and more vulnerable offenders may be self-injuring to either cope with the stress or seek to escape it. Such a dynamic has been described in the literature (Dear, 2006), but it is not clear what the source of such systemic tension might be. Unfortunately, the present study does not have data that speak to these or other possible reasons for the increased rates of self-injury. (Gordon, 2010, p. 25)

Power and Riley's (2010) text offers more of the same:

The risk factors and precipitating events identified for the in custody group include: deterioration in mental health as evidenced my [sic] mood and behaviour; residing in segregation; an increase in stress (due to a variety of factors, including interpersonal difficulties, pending charges, financial difficulties); change in location, including being transferred to a new institution, transferred to a new unit of the same institution, or readmitted to an institution from the community; the loss of an intimate relationship; substance use; the revocation or denial of parole (including offenders recently readmitted to an institution due to a new charge or breech of parole); and the death of a loved one. (p. 14)

'Deterioration in mental health' or 'increase in stress' is not linked to residing in segregation, nor are these qualities linked to more general negative institutional experiences such as denial of parole or the challenges of being transferred or released with little to no support systems. The failure to acknowledge the link between conditions of confinement and self-injury permits the (re)positioning of responsibility for self-injury onto the individual prisoner. 
Lastly, one omission is important to note. While Power, Gordon, Sapers and Beaudette (2012) assure readers that "efforts were made to replicate the previous methodology of Gordon (2010) as accurately as possible" (p. 28), upon a review of each variable included in both reports, one variable is absent from Power and colleagues' text that was originally included in Gordon's study: the 'action taken' after the self-injury incident occurred ${ }^{57}$. Power and colleagues offer no explanation as to why this variable was not analyzed. It is possible that given the unbecoming results that this variable yielded for Gordon's (2010) study (the majority of prisoners who were not sent to a hospital were placed in segregation), this variable was excluded in the replication study. It is also possible that there were methodological limitations in reporting on this information, though because the authors do not address this omission, the rationale for this omission is inconclusive but remains questionable.

\section{Relationships.}

All three texts, as with all other recent RB texts reviewed thus far, employ neutral, bureaucratic and organizationally appropriate language that meets and supports the departmental accountabilities of both the RB and the CSC. One notable difference, however, is that Gordon's text is more mental-health oriented than all other RB texts reviewed in this thesis. This is to be expected given the author's affiliation with the Health Services department of the $\mathrm{CSC}^{58}$. The author compliments the CSC's health care

\footnotetext{
57 In Gordon's (2010) study, under the 'action taken' variable, coding descriptions include 'transport to outside hospital', 'placement in an observation cell', 'application of restraints', 'admission to an RTC', 'referral to a psychologist (or other mental health staff)', and 'return to the offender's cell' (p. 7).

${ }^{58}$ Arthur Gordon is noted as affiliated with Health Services as opposed to the RB. It would appear that the $\mathrm{RB}$ worked in collaboration with Gordon to produce this report, as it was ultimately published under the RB's collection of reports. It is also worth noting that this report was originally authored in 2009, just prior to the surge in RB reports on self-injury (Power and Riley [2010] cite Gordon's report as an unpublished
} 
practices, nuances of which are not otherwise evident in the RB's texts. This elevated positioning of 'Health Services' serves to strengthen the relationship between the text and the CSC:

Recently, significant gains have been made in strengthening the continuum of mental health care for offenders through the implementation of a more comprehensive mental health screening process, building the capacity in regular institutions to respond to mental health needs, and improving mental health training for mental health and correctional staff working in both the institutions and the community. Despite these gains, improving the management and treatment of offenders who engage in selfinjurious behaviour (SIB) continues to be a challenge that CSC is committed to addressing. (Gordon, 2010, p. 1)

This prioritization of 'Health Services' is also apparent in Power, Gordon, Sapers and

Beaudette's (2012) study, which notes:

On April 1st, 2010, the Mental Health Branch at CSC established Regional Suicide/Self-Injury Prevention Management Committees [RSPMC]. These committees were created to support institutions in providing care to offenders who engage in severe and/or repetitive SIB while incarcerated. In the months following the establishment of these committees, the frequency of SIB stabilized after a consistent upward trend over the months studied. While it is impossible to determine the influence of the committees on the frequency of SIB, the presence of these committees may have contributed to this change in the trend. (Power, Gordon, Sapers, \& Beaudette, 2012, p. 25)

The latter excerpt suggests that the stabilizing trend is in part a positive result of recently implemented self-injury prevention and 'management committees' 59 . This further demonstrates the relationship between the RB and the CSC as the texts imply that the

report completed in 2009), but for unknown reasons the RB eventually published Gordon's piece publically in December of 2010.

59 The text does not elaborate on the role of these committees, but CD 843 (CSC, 2013k) remarks that facility staff are to refer self-injury cases to the RSPMC after continuous 24 hour use of restraint equipment (s. 53). The CSC's 'National Strategy' for self-injuring prisoners describes the RSPMC as "meet[ing] monthly to monitor incidents of self-injurious behaviour within institutions, placing particular focus on repeat self-injurious behaviour. Committees will work with institutional staff to provide support and assist them in implementing an interdisciplinary team approach to managing offenders who self-injure. Committees will also work with institutional staff to improve our interventions with these offenders by revising and enhancing interdisciplinary management plans" (CSC, 2011j, p. 6). 
recent practices implemented by the CSC are producing positive results. Two of the three reports evidence the routine trend of citing intra-organization research:

Unfortunately, there is relatively little research on self-injury adult prison populations (Power \& Brown, 2010) but CSC researchers have several relevant studies underway. (Gordon, 2010, p. 26)

Research results on when SIB occurs among federal offenders in Canada have been mixed, with some evidence of increased SIB in the evenings and during the winter months among a primarily male sample (Power \& Riley, 2010), and other evidence suggesting that no temporal patterns exist (Power \& Usher, in press d; Power, Usher, \& Beaudette, in press). (Power, Gordon, Sapers, \& Beaudette, 2012, p. 28)

It is pieces of text like these that signal the positioning of the RB as subject matter expert on the topic of self-injury in Canadian federal corrections.

\section{Connections.}

There is a lack of connection between the three texts and any discourses other than correctional discourse. While Gordon (2010) does cite some literature that examines the negative effects of segregation (e.g., Dear, 2006; Konrad et al., 2007), this research remains situated within correctional discourse, albeit outside of Canadian sources. In fact, in this cluster there were no references to critical, sociological, or otherwise external but applicable literature on prisoner self-injury that could have lent to the understanding of self-injury as distinct from suicide, or that offered insight on the negative effects of segregation for prisoners who self-injure. Overall, this cluster of texts is distanced from literature that would complicate the CSC's practices of using maximum security and segregation placements to manage prisoners who engage in self-injury.

Of note is the absence of comparison of results reported by Power, Gordon, Sapers and Beaudette (2012) with respect to the stabilization of self-injury incidents 
towards the end of the study period to the OCI's (2012a, 2013b) documented concerns about the rather rapidly increasing rate of self-injury in the prisoner population, particularly among Aboriginal women. Granted that the OCI's (2013b) report on selfinjury was released after Power and colleagues' (2012) report, the OCI (2012a) reported that as of fiscal year 2010-2011, self-injury incidents had more than doubled since five years prior. Statements to this effect challenge recent results reported by Power, Gordon, Sapers and Beaudette (2012), contradictions of which are not addressed.

Language type and sign systems.

The use of psy-languages is evident throughout all three reports, though to a lesser extent in Gordon's (2010) text, which was more concerned with 'mental health awareness'. Yet even through this focus on 'mental health', the same messages of mental illness are communicated: individuals require intervention from the psy-sciences in order to better themselves as humans and attain normal levels of functioning. Two of the texts credit a new 'mental health screening system' developed by the CSC that is designed to detect the presence of mental disorder and history of mental disorder upon intake into a correctional institution:

The Computerized Mental Health Intake Screening System (CoMHISS) ${ }^{60}$ has recently been implemented nationally. The CoMHISS is designed to identify offenders with mental health issues early in their sentences so that they can be promptly referred for mental health services. (Power \& Riley, 2010, p. 27)

\footnotetext{
${ }^{60}$ The CoMHISS was developed in 2007 by CSC staff. The development project received $\$ 21.5$ million over a two year period as a part of the Institutional Mental Health Initiative (IMHI), with full implementation beginning in 2010 (CSC, 2012f). The tool was piloted and subsequently validated on a national level by the RB (Archambault, Stewart, Wilton, \& Cousineau, 2010; Stewart et al., 2010; Stewart \& Wilton, 2011; Wilton, 2010).
} 
This cluster of texts largely employs psy-languages and privileges psy-understandings of prisoner self-injury. Moreover, new assessment tools are introduced which ultimately exemplifies the texts' reliance on positivist methodologies by which to screen and locate mental illness(es) in prisoners.

This concludes the deconstruction of the fourteen RB texts. In the chapter that follows, I widen the scope of analysis from discourse analysis by report/cluster to critical interpretation of the body of texts in their entirety and consider how theoretical frameworks presented in previous chapters help us to better understand the discursive messages behind the textual material. 


\section{CHAPTER V: ANALYSIS}

Nothing could be more false than the myth of madness as an illness that is unaware of itself as such ... the way in which a subject accepts or rejects his illness, the way he interprets it and gives signification to its absurd forms, constitutes one of the essential dilemmas of the illness. (Foucault, 1987, p. 46-47)

This chapter revisits Gee's (2011a, 2011b) seven building blocks of discourse analysis and analyzes the collective body of RB texts reviewed in this thesis. I identify any discursive shifts in the literature between one generation of texts and another with respect to significance, practices, identities, politics, relationships, connections, and language type and sign systems. I use the theoretical constructs and frameworks outlined in the literature review and theory chapters to analyse the RB's textual material.

\section{Significance}

Texts render ideas significant or lessen their significance through language (Gee, 2011a, 2011b). Heney's (1990) text is an outlier among the fourteen texts that renders significant quite different and at times opposing ideas to those found in the other thirteen texts. To Heney, women principally self-injure as a result of past social experiences, specifically sexual abuse endured during childhood ${ }^{61}$. While this finding is replicated in three of the four post-2010 RB clusters, it is not presented as a significant message. Additionally, Heney (1990) suggests that self-injury should not be seen as a problematic behaviour in and of itself, but rather as "a symptom or outward expression of more fundamental issues" (p. 16), whereas the remainder of the RB reports express the

\footnotetext{
${ }^{61}$ Heney's findings are synonymous with a large body of literature that posits that self-injury and other self-destructive behaviours are the result of having experienced trauma in one's life, including physical abuse, sexual abuse, emotional abuse, or having witnessed violence or other traumatic events (e.g., Boudewyn \& Liem, 1995; Coy, 2009; Favazza, 1998; Green, 1978; van der Kolk, 1996).
} 
contrary: "NSSI can unquestionably be considered a maladaptive method of coping with stressors" (Power \& Usher, 2010, p. 2).

It is important to identify which discourses on self-injury were produced by an external researcher, such as Heney, who was contracted by the CSC, in order to better contextualize the discursive shifts evidenced in the RB's texts. Heney's (1990) understanding of self-injury as an unfortunate result of abuse does not reflect the dominant themes in correctional discourse at that time. Rather, Wichmann and colleagues' (2002) text is more representative of the dominant correctional ideology, wherein the underlying message communicated was that women who self-injure are dangerous, unpredictable, and thus a security risk to the institution not only for their selfinjurious behaviours but also for the characteristics associated with self-injury, such as violent tendencies, higher risk/need, increased disciplinary problems, segregation placements, and reclassifications to a higher security level (e.g., Blanchette \& Motiuk, 1995; Bonta et al., 1995; Dear et al., 2000; Hillbrand et al., 1994; Rettinger, 1998).

The shift from Wichmann and colleagues' (2002) text to the post-2010 RB texts marks a distinguishable transformation in the literature. Self-injury is newly depicted as a behaviour that is clearly distinct from suicidal tendencies and manipulative motivations for self-injury have for the most part disappeared as a significant interpretation of the behaviour. Psychological understandings are newly relied upon to explain the causal factors for both men's and women's self-injurious behaviour, reducing it to a mental illness with diagnoses such as 'borderline personality disorder', 'histrionic personality disorder,' 'depressive disorder', 'anti social personality disorder', and so on. If not explained by a particular disorder, self-injury is attributed to deficits in adaptive coping 
skills that denote a deficiency on the part of the prisoners' emotional regulation capacities. I suggest that this latter attribution is indirectly yet inherently linked to mental illness insofar that psy-practitioners tend to rely on language like 'emotional dysregulation,' 'inability to manage emotions' or deeming behaviours as 'maladaptive' in diagnosing some mental disorders ${ }^{62}$. As such, whether the text explicitly states a formal disorder as per the DSM or cites some rendition of the inability to manage or cope appropriately with one's emotions, these ascriptions demonstrate how psy-technologies are at work within the prison and are used to problematize and explain human behaviours that are interpreted as problematic in the contexts in which they occur (Rose, 1990, 1996b). The RB's post-2010 texts evidence a 'psychologization' of human characteristics, where self-injury is rendered both troubling (insofar that it is identified as a problem) and intelligible (where now the RB knows more about this problem). Prisoner's behavioural characteristics are reduced to simple yet causal explanations where self-destructive behaviours are explained to be indicative of a mental disorder. Through the deployment of the psy-sciences as intellectual technologies (Miller \& Rose, 1990; Rose, 1996b), the RB's texts participate in a 'truth battle' by making claims about self-injury and mental illness.

The RB's quest for 'truth' is supported by the 'empirically validated' and 'evidence-based' means of producing and reporting data on prisoner behaviours and illnesses. Human behavioural and personality characteristics and qualities are rendered

\footnotetext{
${ }^{62}$ For example, such is the case for diagnosing 'borderline personality disorder': "unstable emotional experiences and frequent mood changes", which was notably proposed for renaming to "emotional dysregulation disorder' in the DSM-V (Howell \& Blizard, 2009; Kalapatapu, et al., 2010), and the inclusion of 'disruptive mood dysregulation disorder' to characterize one facet of bipolar disorder (APA, 2012, 2013a).
} 
extractable, quantifiable, and operationalizable in order to facilitate data collection and corporate reporting. The use of the SCID-I/II tool serves as an example of the reliance on psy-technologies to support the production and reification of psy-knowledges (Rose, 1996b). Further, the use of yes/no questionnaires and tick-boxes within the RB's studies (e.g., the OSIBI) assumes that symptoms can be categorized and classified in a dichotomous manner as either being present or not. As such a prisoner's account of their emotions and experiences are likely to be excluded from such a rigid classification grid (Ussher, 2011).

While some non-psy explanations for self-injury are cited infrequently (as seen in the qualitative studies; e.g., institutional or interpersonal manipulation, to see blood or feel pain, or as a result of being in prison; Power \& Usher, 2010; Power, Beaudette, \& Usher, 2012), the majority of rationales for why self-injury occurs are rooted in clinical/abnormal psychology/psychiatry. This tendency to pathologically ascribe prisoners who self-injure ignores other interpretations of the behaviour offered by critical criminological or sociological discourses, in which self-injury has been theorized as an act of resistance (Coy, 2009; Inckle 2007; Pitts, 1998) to resist the lonely and oppressive environment of the prison (Bailey, 2009; Frigon, 2001; Groves, 2004; Kilty, 2008b; Rhodes, 1998), as a response to histories of trauma, abuse, victimization, and/or criminalization (Fillmore \& Dell, 2000, 2005), as a performative or communicative act (Cresswell, 2005; Hewitt, 1997; Kilby, 2001; Jaworski, 2003; Lingel, 2008), as an assertion of agency (Coy, 2009; Kilby, 2001; Medina, 2011; Pitts, 1998), or as a reflexive practice of embodiment (McLane, 1996; Rhodes, 1998). This failure to engage with discourses outside of psy to interpret self-injury is indicative of the 'truth battles' the 
RB's text present insofar that psy-understandings of prisoner behaviour are positioned as true and unchallenged. Now that 'non suicidal self-injury' has been given its own canonical category in the DSM-V (APA, 2013a), the RB is retroactively legitimized in using pathological ascriptions to describe self-injury. Given that 'NSSI' was only made an official disorder in 2013, the RB's reports would not have had the 'NSSI' diagnosis with which to label prisoners. However, there is evidence of the CSC waiting for the arrival of the new DSM-V; during a meeting about prisoner mental health, they adopted the forthcoming DSM-V diagnostic criteria for NSSI to their own guideline material (CSC, 2010f, p. 9). As a result of the increasing desire to render significant the pathologies of prisoner behaviour, prisoners, arguably more so than everyone on the outside, live an examined life.

The psychiatrization of prisoners exemplifies how psy-discourse embarks on a "quest for a knowledge of madness that will integrate its subjects and rarify its existence" (Rose, 1992, p. 144). This knowledge of madness is realized in penal discourse, where the structured and systematic psychiatrization of subjects acts as a vehicle that gives madness reality, a space in which madness can be made to exist (Foucault, 2006b). On the other hand, madness is rarified by these same discourses that attempt to contain it, suppress it, and differentiate the findings of madness from the general or 'normal' population (Foucault, 2003, 2006b). This is evident in how the RB's texts actively construct the potential functions of self-injury for prisoners as if their abnormality is explained in part by their criminality and in part by their self-injurious tendencies. Collectively, the texts serve as evidence of how the correctional system privileges the 
psy-medical model that constructs self-injurious/abnormal behaviours as pathological (Kendall, 2000; Pollack, 2005).

\section{Practices}

Practices are institutionally supported endeavours that are 'boot strapped' into existence through a reciprocal reifying relationship with the texts and language that support them (Gee, 2011a, 2011b). While some of the texts specifically address an institutional or operational practice such as the segregation of prisoners who self-injure or the placement of prisoners who self-injure in maximum security facilities, others do not feature similar discussions. This absence arguably results in a silent nod of acceptance of the current state of operational practices. An example is the frequent use of the popular blanket statement 'safety and the security of staff and offenders' with respect to the management of self-injurious behaviours. Even when one text stipulates that "segregation should be used with caution and only when absolutely required to preserve the offender's safety" (Usher et al., 2010, p. 26), the discussion that surrounds this reroutes readers back to the necessity of practices of segregation, maximum security placements, or restraint equipment in the interests of security or for 'monitoring' purposes. For instance, rather than a discussion on why segregation may encourage self-injury, Usher and colleagues (2010) suggest that research needs to be done on how to reduce prisoners' feelings of isolation while in segregation, while Gordon (2010) reiterates that "repeated self-injury suggests the need for more stringent controls offered in maximum security institutions" (p. 23). Through these kinds of utterances the texts evade the question of whether security measures consitute punishment, whether restraint and isolation practices are harmful, 
including whether they may foster or exacerbate self-injurious behaviour. A temporal discursive shift is evident here. Heney's (1990) text explicitly points to the problematic prioritization of security over rehabilitation, noting a dire need for increased mentalhealth practices ${ }^{63}$. The other RB texts do not address the security versus rehabilitation debate in the same way, as they seldom question or challenge the practices that the texts 'boot strap' into practice.

Intervention with self-injuring prisoners is a theme across all texts insofar that they support the notion that prisoners who self-injure would benefit from psyinterventions. This belief in the necessity of action is precipitated by the psy-sciences, where a key cornerstone of the discipline is to intervene upon abnormal subjects in attempt to restore 'normality' (Rose, 1990, 1996b). Several of the RB's texts commented on how the CSC's existing cadre of correctional or mental health programs benefit women and men prisoners who engage in self-injury. Although program evaluation was not the objective of any of the studies, the message that 'programs work' is clearly discursively transmitted. This discursive self-legitimization is better understood when considering the larger body of correctional discourse on 'what works' in 'offender rehabilitation ${ }^{64}$. Cognitive behavioural programming is based on the assumption that the source of criminality sits at the centre of the prisoner's cognitive deficits (Kemshall,

\footnotetext{
${ }^{63}$ Heney's report is again largely a product of its time, given that her research was conducted in the P4W, whose history as a site of great mistreatment has gone unchallenged even in correctional discourse (Arbour, 1996; CSC, 2000; Dell et al., 2009; Pollack, 2008).

64 The 'what works' movement is characterized as a push towards identifying what correctional interventions are effective at reducing offender recidivism through the application of quantitative methodologies which determine recidivism rates for 'treatment groups' who had program exposure in comparison to prisoners who did not receive programming (e.g., Andrews, 2001; Andrews et al., 1990; Cullen \& Gendreau, 2000; Gendreau, 1996; Gendreau \& Andrews, 1990; Gendreau, Little, \& Goggin, 1996). The CSC continually supplements this movement through the 'evidence-based' accreditation and evaluation of their own correctional programs (e.g., Blanchette et al., Booth, 2012; Cortoni \& Nunes, 2008; CSC, 2009a, 2009b, 2011f; Motiuk \& Serin, 2000; Stewart, Hamilton, Wilton, Cousineau, \& Varette, 2009; Usher \& Stewart, 2011).
} 
2002; Kendall, 2002; Shaw \& Hannah-Moffat, 2004), thus encouraging the internalization of self-regulatory strategies (Pollack, 2005). This perspective limits prisoner agency insofar that some are ruled pathological sufferers wherein the CSC dictates their mental health plan and required interventions, including mandatory prescription medications, and in some cases, the involuntary admission to prison/treatment hybrid facilities such as the RTC's or the RPC (CSC, 2013j, CD 803).

The texts infer that prisoners who self-injure have deficits in coping abilities and are unable to appropriately manage their emotions. Here we see a link between clinical/correctional discourse on self-injury that posits that individuals who self-injure exhibit 'maladaptive' behaviours in the absence of adaptive coping mechanisms (e.g., Claes \& Vandereycken, 2007; Haines \& Williams, 1997; Haines et al., 1995; Kirchner, Forns, \& Mohíno, 2008; Klonsky, 2007; Laye-Gindu \& Schonert-Reichl, 2005) and correctional programming discourse that assumes that prisoners, particularly women, are lacking in cognitive decision-making skills (Kemshall, 2002; Kendall, 2002; Pollack, 2005; Shaw \& Hannah-Moffat, 2004). Constructing an individual as having inadequate coping mechanisms gives the psy-correctional apparatus reason to take action upon them. The texts specifically reference the DBT program as a viable option for the treatment of self-injuring women. The provision of 'rehabilitation programs' or 'mental health programs' for criminal offenders, specifically ones who self-injure, originally evolved out of 'behaviour modification' operant conditioning interventions based on 'token economies', where girls who demonstrated 'acceptable social behaviour' were rewarded 
while girls who did not (such as those who self-injured) were reprimanded ${ }^{65}$ (Ross \& McKay, 1976, 1979; Ross et al., 1978). Similar to behaviour modification programs, DBT aims to help patients identify problematic assumptions and behaviours and to adopt alternative strategies to successfully change or negate them (Linehan, 1993).

By producing research that supports prisoner intervention with DBT, the CSC's practices of programming for self-injuring prisoners are reinforced. This strategy of selfperpetuation illustrates how correctional technologies, much like psy-apparatuses, are "put together, effects are produced, inscribed, examined, debated, analyzed, theorized and the results used as the basis of further interventions" (Rose, 1990, p. xv). The RB's texts point to increased access to DBT programming as a future intervention strategy for women who self-injure (Power \& Usher 2010; Usher et al., 2010). Such current and future intervention strategies are, for the most part, developed and administered solely by employees of the CSC (CSC, 2011c, CD 726-1). This in turn sets the CSC up to be the sole proprietor of intervention strategies by positioning the CSC as the primary source of legitimate knowledge on self-injury in Canada's federal prisons. Research on the subjectivities of prisoners thus translates to the facilitation of intervention upon prisonerpatients deemed defective and/or 'at risk'.

Risk-logic is woven throughout the RB's texts as a constituent of operational practice. That is, the institution activates risk-logic by regularly assessing the risk of self-

\footnotetext{
${ }^{65}$ Ross and colleagues note that punishments used to modify the self-injurious behaviour of teenage girls involved the subjection to room isolation, forbidding visitors, assigning extra work, delaying their release, and/or revoking other privileges (Ross \& McKay, 1979; Ross et al., 1978), however Kilty (2011) explains how the girls were physically, emotionally and sexually abused throughout the period of study by correctional staff and Ross himself. The Government of Ontario awarded victims legal compensation for the suffering endured at the hand of correctional staff (Kaufman, 2002), but all claims against Ross were ultimately legally dismissed (Shea, 1999; Graycar \& Wangmann, 2007).
} 
injury and suicide in the name of the security of the prison (see also Kilty, 2006). These risks are jointly managed with universalized institutional risk management strategies, such as risk for criminal recidivism and risk for institutional misconduct (CSC, 2012a, CD 705-6, 2013h, CD 705-7). In 2011, the CSC requested the development of self-injury prediction/risk tools (CSC, 2011i, 2011j). This is important because it highlights the desire to 'condense the empirical' (Rose, 1996b) from experience to database (Aas, 2004), whereby the subjectivities of prisoners who self-injure are compressed into quantitative analytical grids that aim to predict what may be seen as 'operational setbacks' as exposed by this discourse analysis. As with the broad application of risk assessment tools that aim to extract indicators of dangerousness, violence, and unpredictability from prisoners, the same occurs for prisoners who engage in selfinjury $^{66}$. This gives new meaning to Rose's (2010) 'screen and intervene' conceptualization, where the desire is to identity both 'risky individuals' who already engage in self-injury, and 'individuals at risk' of engaging in self-injury in order to facilitate early intervention and to intercept institutional security incidents.

Notions of 'risk' and dangerousness are by no means new, but are evolving with a new object of inquiry wherein the specific mental profile of the self-injuring prisoner is condensed, extracted, and offered up for consumption by penal technologies. Indeed international research on 'empirically validated' actuarial tools to predict the risk of selfinjury in prisoners was already underway prior to the recent RB focus on self-injury (e.g.,

\footnotetext{
${ }^{66}$ This sentiment echoes past research that has argued that self-injury is a predictor of criminal recidivism (Blanchette \& Motiuk, 1995; Bonta et al., 1995; Rettinger, 1998), and research that has attempted to predict criminal recidivism in mentally disordered prisoner populations (e.g., Blanchette, 1996; Blanchette \& Motiuk, 1996; Bonta, Hanson, \& Law, 1998; Stewart, Wilton, \& Cousineau, 2012; Wilton \& Stewart, 2012).
} 
Cullen, 1985; Gray, Hill, Timmons, MacCulloch, \& Snowden, 2003; Humber, Hayes, Senior, Fahy, \& Shaw, 2011; Lanes, 2009a; Lohner \& Konrad, 2007; Perry \& Gilbody, 2009; Young, Justice, \& Erdberg, 2006), so it is not surprising that the CSC is expanding their repertoire of risk assessment tools. Though it is also possible that the goal of implementing such a tool would be to identify and alleviate the mental suffering of prisoners, it is equally important to note that the tool serves a dual purpose: a self-injury risk assessment and prediction tool would also mitigate corporate risks ${ }^{67}$ insofar that it has the potential to identify imminent operational setbacks in the form of prisoner selfinjury.

It is unclear whether the purpose of the proposed self-injury psychometric assessment tool developed and tested in the research studies (the OSIBI) is to predict selfinjury, or whether it has been officially implemented. Nevertheless, paired with other risk tools embedded in correctional practice including the development of a screening tool to identify prisoners 'at risk of becoming segregation candidates' (CSC, 2012b), the development of tools of this sort is demonstrative of an era rich in the desire to both detect and predict risk. The RB's texts uphold the broader institutional commitment to risk management practices through the production of knowledge that supports them.

\footnotetext{
67 'Corporate risk' is the language used by the CSC in high-level publications including the 'Report on Plans and Priorities' and the 'Departmental Performance Report' that offer a 'corporate risk profile' with organizational risks to which the CSC must offer 'key mitigation strategies'. These include, for example, the risk that the "CSC will not be able to improve correctional results for offenders with mental disorders" (CSC, 2011g, p. 14), which is considered mitigated by various corporate initiatives: "expanded the Mental Health Tracking System to the community, developed enhanced screening tools to identify offenders with mental health needs at intake ..." (CSC, 2012b, p. 10).
} 


\section{Identities}

Texts participate in the construction of identities by enacting specific languages (Gee, 2011a, 2011b). Apart from the overarching characterization of both men and women prisoners as pathologically inclined to self-injure, more subtle gendered nuances are apparent in the secondary constructions of the identity of the self-injuring prisoner. While dominant essentialized gender-specific understandings remain ${ }^{68}$, there are some exceptions and contradictions to the stereotypical gender binary. In fact, some of the post-2010 RB research explains how men are more likely to engage in self-injury for manipulative reasons than are women (Power, Gordon, Sapers, \& Beaudette, 2012; Power, Usher, \& Beaudette, 2012), which runs contrary to what we might expect given the historical construction of women prisoners who self-injure as manipulative (e.g., Ross et al., 1978; Ross \& McKay, 1979).

Though men who self-injure are constructed in the RB's texts in accordance with the essentialized depiction of hegemonic (criminal) masculinity, that is, impulsive, angry and delinquent (see Connell, 1995; Connell \& Messerschmidt, 2005), these constructions contradict clinical literature that constructs men self-harmers as feminine ${ }^{69}$. The RB's texts do not echo this message; instead they suggest that men who self-injure are hypermasculine, wherein self-injury is seen as a coping mechanism to sublimate violent

\footnotetext{
${ }^{68}$ This being that women prisoners who self-injure are high-risk, high-need, emotional and irrational. Although these identity constructions are secondary next to pathological constructions, they represent how previous research on self-injury lingers in current understandings.

${ }^{69}$ A higher proportion of LGBTQ individuals are reported to engage in self-injury than heterosexual individuals (Deliberto \& Nock, 2008; Gollust, Eisenberg, \& Golberstein, 2008; Serras, Saules, Cranford, \& Eisenberg, 2010; Skegg, Nada-Raja, Dickson, Paul, \& Williams, 2003; Whitlock et al., 2006). Self-injury thus becomes associated with homosexuality, and homosexual men are often perceived to possess feminine qualities (Cardoso, 2010; Hekma, 2007; Potgieter, 2006). The idea that women self-injure more than men in general also lends to the traditional construction of the behaviour as bound up with femininity, and thus men who self-injure are seen as feminine (Brickman, 2004).
} 
tendencies towards others onto oneself (Power, Beaudette, \& Usher, 2012), or where the motivation to self-injure is explained in part by anger and impulsivity (Power \& Usher, 2011b). The pre-imposed hyper-masculine identities fastened to the men who were interviewed potentially determined how they would be seen from the outset, as after all, these were criminalized individuals who were living in a federal penitentiary. It is perhaps because of the dissonance in reconciling dominant understandings espoused in clinical literature about self-injury as a woman's problem (Brickman, 2004; Chandler et al., 2011; Shaw, 2002; Taylor, 2003) and the pre-conceived identities of the men as delinquent and dangerous that dissuaded the RB from drawing conclusions about male prisoner self-harmers as feminine. How could these men, sitting in a cold jail room, perhaps looking unkempt, brute, and jaded, with a guard standing in the corner of the room, possibly be construed as feminine by the researchers? The layering of masculinity - where the biological element of being a man is overlaid with criminality and notions of violence and dangerousness - is suggested to have pre-defined men prisoner self-harmers in contradiction to how traditional clinical (non-forensic) discourse understands men who self-injure. This is an interesting theory that requires further exploration and empirical development that would be best suited for study under a gender-informed critical lens.

Self-injurious behaviour committed by women prisoners, on the other hand, is not overtly constructed as an essentialized representation of their gender identity ${ }^{70}$ in the RB's texts. Women are seen as weak minded and thus incapable of regulating their emotions and more concretely as mentally ill and in need of psychiatric intervention. This

\footnotetext{
${ }^{70}$ This being weak, desperate, attention-seeking and manipulative women (e.g., Dear et al., 2000; Favazza \& Conterio, 1989; Lloyd-Richardson et al., 2007; Martinez, 1980; Podovall, 1969; Ross et al., 1978; Wicks, 1974; Walsh \& Rosen, 1988; for critical accounts of, see Brickman, 2004; Chandler et al., 2011; Shaw, 2002).
} 
fact may be read as an essentialization of femininity insofar as women are far more likely to be diagnosed with a mental illness than are men (Ussher, 1991, 2010, 2011); in the prison women are twice as likely than men to be diagnosed with a mental illness at intake (Derkzen, Booth, Taylor, \& McConnell, 2012; Public Safety Canada, 2009). There are two exceptions to the heightened pathologization of women self-injurers. First, Heney's (1990) piece is distinct from the others; she argues that women who self-injure are victims of childhood (sexual) abuse. While this explanation may apply to some, it is not a comprehensive enough understanding to encompass the diverse functions of self-injury. Wichmann and colleagues' (2002) text evidences a shift from understandings of selfinjury as the product of abuse to self-injury as an indicator of dangerousness and unpredictability. Here women are constructed as operational liabilities to the safety of the institution. This understanding has been addressed in critical literature that sought to problematize the prioritization of security over women's needs (Hannah-Moffat, 2006; Kilty, 2006; Thomas et al., 2006).

With the wave of post-2010 RB research came new pathological understandings of self-injury in women prisoners. Such pathological understandings ignore socio-cultural explanations for women's distress, locating the problem solely within the individual woman (Ussher, 2011). Self-injury in men prisoners is indeed equally explained in the RB's texts as the manifestation of a mental illness and it is important that this be acknowledged. However, given the extant clinical and correctional discourses that have examined women who self-injure as a social phenomenon distinct from men (e.g., DixonGordon et al., 2012; Latzman, Gratz, Young, Heiden, Damon, \& Hight, 2010; Lohner \& Konrad, 2007; Suyemoto \& MacDonald, 1995; Taylor, 2003), it is argued that 
understandings of madness are more likely to stick to women rather than to men who hurt themselves $^{71}$. Paired with the historical clinical constructions of women who self-injure as mad, manipulative, and disordered (e.g., Ross et al., 1978; Ross \& McKay, 1979), the influence of the RB's texts in discursively theorizing women as mentally ill arguably leaves a deeper impression in the literature than do pathological understandings of men's self-injury.

There was a gap in the texts in terms of meaningful discussion on ethnicity and/or intersectionality. The overrepresentation of Aboriginal peoples (notably Aboriginal women) in prison is a longstanding issue, where as of March of 2013 they reportedly represented $22 \%$ of the federal prisoner population (OCI, 2013c), yet accounted for roughly $4 \%$ of the total Canadian population (Statistics Canada, 2011). None of the RB's texts entertained a discussion around how Aboriginal heritage or social history ${ }^{72}$ might impact motivations for self-injury. Instead, when the reports did address Aboriginal heritage they referred to difference (or lack thereof) in prevalence rates between groups ${ }^{73}$. It is also of concern that Aboriginal prisoners, notably Aboriginal women,

\footnotetext{
${ }^{71}$ This idea of how essentialized identities 'stick' to bodies is explained by Ahmed (2004), who suggests that racial stereotypes stick to certain bodies and accumulate in value, thus shaping their social understanding and restricting their social mobility.

${ }^{72}$ The CSC is mandated in policy to consider how 'Aboriginal social history' affects Aboriginal offenders at all points on the correctional process continuum. Aboriginal social history includes, among others: effects of the dislocation, dispossession, and the residential school system, lack of formal education, experience with poverty and the welfare system, family or community history of fragmentation, suicide, substance abuse, victimization, and loss of or struggle with cultural/spiritual identity (CSC, 2006, 2013g, $\mathrm{CD} 702$ ). It has been argued elsewhere that the absorption of Aboriginal healing models into correctional systems re-appropriates historical colonial harms and recodes the histories of 'Aboriginality' as targets for correctional intervention (Crete, 2013).

73 The reports found that there was no statistical significance between the proportion of Aboriginal prisoners with a history of self-injury compared to non-Aboriginal prisoners (Power \& Usher, 2011b, 2011c, Usher et al., 2010), that Aboriginal prisoners were significantly more likely to self-injure than nonAboriginal prisoners (Gordon, 2010; Power, Gordon, Sapers, \& Beaudette, 2012; Power \& Riley, 2010; Power \& Usher, 2011d; Wichmann et al., 2002), or the study design was not intended to discern differences between ethnic heritage groups (Heney, 1990; Power \& Brown, 2010; Power \& Usher, 2010, 2011a; Power, Beaudette, \& Usher, 2012; Power, Usher, \& Beaudette, 2012).
} 
disproportionately occupy segregation cells (Bottos, 2007; Martel, 1999; OCI, 2012b, 2013c; Wichmann \& Nafekh, 2001; Wichmann \& Taylor, 2004). The implications of ethnic identity, gender, and intersectionality are problematically absent in the RB's texts.

The rising number of Aboriginal women in prison who engage in self-injury has been highlighted in executive commissioned reports and consequently, in the media (see, for example, Harris, 2012, 2013; CBC News, 2012; OCI, 2012a, 2012b, 2013a, 2013b, 2013c; Zinger, 2012a, 2012b). Granted that this spike in incidents appears to have climaxed in the media by mid-2012 (after which point the RB's texts were already published), the CSC holds accountabilities in the area of Aboriginal corrections. Irrespective of operational challenges noted by stakeholders and the media, responding to the specific needs of Aboriginal prisoners is one of the CSC's main responsibilities (CSC, 2006; CSC 2013g, CD 702). As such, the exclusion of issues relating to Aboriginal prisoners (specifically the absence of discussion surrounding how cultural underpinnings and Aboriginal social history effect/interact with self-injurious behaviour) ultimately does a disservice to the CSC's own policies and to Aboriginal prisoners.

\section{Politics}

Texts are political in that they position guilt, blame, and responsibility (or lack of), where (in)actions are committed for political reasons and hold political implications (Gee, 2011a, 2011b). The RB's texts position self-injury as a risk to the security of the institution and/or as an operational setback (e.g., by noting the increased risk of assaults against correctional staff, use of restraint equipment, prisoner suicide, use-of-force, filing out SITREP's, and/or the involvement of the Incident Investigations Branch). The 
effectiveness of a correctional organization is often judged by the absence or presence of operational issues $^{74}$. The institutional setbacks of self-injury in the penitentiary identified by the RB thus suggest that the CSC may be operating poorly. Prior to Ashley Smith's death in 2007, the CSC was heavily criticized for the growing number of use of force actions taken against prisoners in general (OCI, 2006). Some have suggested that part of the reason why correctional officers were ordered not to enter Smith's cell during her last hour of life was in effort to reduce the amount of use of force paperwork the women's units had seen that year (Dalton, 2008; Union of Canadian Correctional Officers, 2008a, 2008b). This illustrates how self-injury is seen a security liability by the CSC, which is a political move to circumvent the reputation of what appears to be a failing correctional system. Since Smith's death, internal audits put forth by the CSC have noted that there is "no evidence at any of the [regional] treatment centres that self injurious/suicidal inmates were disciplined for self-injurious behaviour" (CSC, 2011a, p. 49) and that the commitment to "implement new procedures to strengthen accountability in security practices and use of force interventions" have been "assessed as fully completed" (CSC, 2012e, s. 4.3.1). When we consider the CSC's discourse on self-injury and institutional accountability, the RB's texts provide a reading of prisoner self-injury that suggests the behaviour is an institutional setback that prevents the organization from operating in the most efficient managerial capacity.

The texts demonstrate the displacement of responsibility for self-injurious incidents from the prison to the prisoner in two ways. First, by attributing the inclination

\footnotetext{
${ }^{74}$ See, for example, the OCI's annual reports (2008b, 2009a, 2010a, 2011, 2012a, 2013c) that more or less judge the CSC by its ability to effectively 'manage' their prisoner population.
} 
to self-injure to the individual prisoner who is painted as plagued with mental disorder. Second, by dismissing or failing to acknowledge the effects that the socio-political environment of the prison can have on its prisoners. The CSC validates the denouncement of the 'pains of imprisonment' as a potential cause of self-injury by claiming that there is no 'empirical support' for the incarceration theory (Power \& Brown, 2010; Power \& Usher, 2010, 2011a, 2011c; Power, Usher, \& Beaudette, 2012; Usher et al., 2012). By interpreting self-injury as rooted in mental pathology, the texts satisfy the political obligation to report a valid and recognizable 'hard fact'. This 'hard fact' is underscored as 'truth' as it is communicated through a positivist lens that projects quantitative legitimacy. Any lingering thoughts about the effect of the "incarceration model' are dropped as the focus is reoriented to the economy of disordered psychology.

An equally controversial rejection of segregation as increasing a prisoner's tendency to self-injure is seen in the texts. The texts that sought to determine the location in which self-injury occurred most frequently, unsurprisingly found that self-injury most often occurred in segregation (Power, Gordon, Sapers, \& Beaudette, 2012; Power \& Riley, 2010), and that women who self-injure are more likely to be placed in segregation during their sentence than women who do not self-injure (Gordon, 2010; Wichmann et al., 2002). Gordon (2010) found that the most common response to self-injury, if it does not warrant a trip to a hospital, is placement in segregation, while Power, Gordon, Sapers and Beaudette's (2012) replication study omits this variable. Despite some attention paid to segregation, the focus of discussions on self-injury and segregation are centred on the preservation of 'offender safety' (Power \& Brown, 2010; Usher et al., 2010) or, more specifically, on supporting the alternative practice of placing prisoners in 'observation 
cells' or under 'suicide watch' so they may be more closely monitored for their personal mental health and safety (Gordon, 2010; Power \& Brown, 2010; Power \& Riley, 2010; Usher et al., 2010). There is no consideration of how, for example, the restrictive spatialtemporal characteristics of solitary confinement impact an individual's loss of identity and sense of time and space (Martel, 2006), or how this may contribute to exacerbating self-injury. As such, the texts are politicized insofar as they employ linguistic strategies to redirect readers to the monitoring benefits of solitary confinement as opposed to, as some have argued, the dehumanizing and punitive experiences of segregation (Cohen, 2008; O’Keefe, 2008; Martel, 1999, 2001, 2006; Shalev, 2011; Smith, 2006). The irony is that although the language and justifications used are distinctly different (i.e., 'administrative segregation', 'suicide watch', or 'observation cell'), and that perhaps they are recorded as different incident types in the OMS, these spaces of solitary confinement are exactly the same in physical structure and experience (Rotenberg, 2012a, 2012b).

The RB finds that incidents of self-injury are highest in maximum security facilities for both men and women prisoners (Power, Gordon, Sapers, \& Beaudette, 2012; Power \& Usher, 2011b, 2011d; Power, Usher, \& Beaudette, 2012; Usher et al., 2012; Wichmann et al., 2002). It must be recognized that prisoners classified as maximum security live in similar conditions to those in segregation ${ }^{75}$. The "to segregate or not to segregate' debates ${ }^{76}$ tend to overlook the similarity between temporarily housing selfinjuring prisoners in segregation and housing them long-term in maximum security

\footnotetext{
${ }^{75}$ Maximum security facilities are reserved for prisoners who require the "high[est] degree of supervision and control within the penitentiary" (CSC, 2013h, CD 705-7, p. 9). Prisoners who reside in maximum security penitentiaries are generally only out of their cells for a couple of hours a day (Rivera, 2010).

${ }_{76}$ As evidenced in critical scholarship (e.g., Adams \& Ferrandino, 2008; Cohen, 2008; Kilty, 2006; Lord, 2008; Smith, 2006) and in correctional discourse (e.g., OCI, 2008a, 2012a, 2013b, 2013c; Zinger, 2012a, 2012b).
} 
prisons. Analyzing the spatial placements of self-injuring prisoners - whether in segregation or in high security level prisons - would better reflect the broader issue at hand of the securitization of prisoner self-injury. Despite reporting the overrepresentation of prisoners who engage in self-injury in maximum security level facilities, the RB's texts do not acknowledge how this may be problematic, as some have argued, in potentially exacerbating self-injury (Kilty, 2008b; Toch, 2008). Instead, when attention is given to the relationship between self-injury and being housed in maximum security it is either said to be 'logical' given the increased monitoring tools available at maximum security institutions (Power \& Usher, 2011d), or it is stipulated that there is inconclusive evidence for why self-injuring prisoners are more likely to be classified as maximum security (Gordon, 2010).

The texts dance around the very issue staring them in the face; that responding to self-injury with solitary confinement or otherwise isolative practices does not alleviate the situation, but are in fact likely to exacerbate it (Arrigo \& Bullock, 2008; Dear, 2006; Great Britain Parliament, 2004; Kilty, 2008b; Lord, 2008; Morin, 1999; Royal College of Psychiatrists, 2010; Toch, 2008). This sentiment is echoed in Heney's (1990) report, where she notes that when women prisoners are placed in segregation for their selfinjurious behaviours they perceive it as a direct punishment that is no different than the punishments imposed on those who harm others. Punishing prisoners is thus understood as contributing to one's state of distress and despair, ultimately leading to increased selfinjurious incidents (Heney, 1990).

When Heney's (1990) piece is juxtaposed to the other RB reports (2002-2012) a disjuncture becomes evident: namely with respect to the willingness to accept 
responsibility for harms caused. Not being affiliated with the CSC appears to have granted Heney some degree of freedom with which to criticize the CSC's existing practices. On the other hand, the in-house RB texts evidence the power of political affiliation to hinder reflexive analysis. I suggest this is precisely why there is no critical discussion of the controversial practice of segregating prisoners who engage in selfinjury. Such a discussion could not take place without bringing the prison system into disrepute for standing by practices that are contradictory to the CSC's mission statement of "exercising reasonable, safe, secure and humane control" (CSC, 2013b, CD 001, p. 1). As Martel (2004) writes,

Criminological 'science' is embedded in political realities that tend to steer knowledge construction away from epistemological orientations that could threaten the field's very existence and relevance to punitive contemporary policies about crime and punishment. (p. 181)

By removing themselves from the equation of responsibility, the texts evade the CSC from being held accountable for the issue of self-injury in prison. The purpose of such evasion is clear: if a discussion of the ways the prison influences self-injury were to take place, the organization would be forced to look inwards and challenge its own governance structure. The texts err on the safe side of language, are absent of critical debate, and as such steer clear of ruffling any feathers in the dominant political order.

\section{Relationships}

Texts delineate the kind of relationship different audiences (i.e., governments, politicians, professionals, or lay citizens) have with them and they create and maintain these relationships through language (Gee, 2011a, 2011b). While there are recent Canadian case examples where reports originating from government-run or funded 
organizations have opposed government initiatives (e.g., see the Canadian Bar Association's [2011], the Justice of Children and Youth's [2011], and the Canadian Psychological Association's [2012] submissions on Bill-C10), these sorts of challenges to policy and practice are made possible because of the diversity and multiplicity in ideological values and the social and physical distance they are from the political structure they are opposing. The correctional culture, however, is largely driven by the dominant political and ideological values of the time. Subsequently, opposition within the CSC does not occur in the same public and forward ways as demonstrated by the organizations that challenged Bill $\mathrm{C}-10$, because individuals, departments or sectors cannot band together to oppose executive management or new directions in correctional management that are handed down by the Minister of Public Safety. The CSC's mission and commitment states that all employees,

... use shared, reciprocal values to guide our behaviour, decision making, and discretionary judgement. These shared values are useful in day-to-day work within CSC and with all partners and stakeholders. In living these values, we demonstrate our commitment to personal and professional integrity and to working together to shape an organizational culture aligned with these same values. (CSC, 2013b, p. 2)

Furthe, the CSC's code of ethical conduct for employees stipulates that,

... employees must not be critical of policy or operations in front of offenders or the public; to do so is to encourage a lack of respect for the Correctional Service of Canada and its staff. (as cited in Brisson, 2011, p. 17)

Guidelines of this sort serve to enact a form of self-monitoring where employees are actively aware of their actions while occupying the physical spaces of 'corrections'; in this sense, moving in and across the very spaces that make up the CSC, be it a federal prison, parole office, or in the sea of cubicles at NHQ. Like many other government 
organizations, the CSC asks that employees think with one mind in order to uphold a set of pre-determined shared organizational values. The consequences of publicly questioning the CSC's rhetoric presents a blockade for employees who would be risking their job security should they oppenly oppose these 'shared values' by challenging existing policy or practices.

The results of this discourse analysis reveal that all but Heney's (1990) text holds a relationship with the CSC where the texts and the departments they represent have an organizational accountability to report to and meet the needs of the CSC. This distinction between Heney's text and the thirteen RB texts could be characterized as engagement versus detachment, where the latter texts adopt a bureaucratic and indifferent tone. The RB's inherent relationship with the CSC imposes an expectation that the texts respect and employ appropriate corporate languages, identities, and aligned ideological understandings of social phenomena. As such, bureaucratic language is used, measurable results are expected, and statements that would bring the Canadian correctional system into disrepute are generally prohibited, or at least, absent.

This relationship calls on the RB to answer the CSC's questions via in-house research. Drawing on the metaphor of the 'correctional laboratory', this proves problematic insofar that only employees or departments governed by the CSC are privy to access and research social phenomena related to federal prisoners. It is extremely rare that external evaluators have the chance to conduct research within Canada's penitentiaries; critical scholars argue that the CSC intentionally bars research that is sociological or that does not align with the positivist and pro-prison stances of the organization (Kilty, forthcoming; Piché, 2011, 2012; Martel, 2004; Yeager, 2008). Simon 
(2000) highlights the new reliance on positivist expertise, such as criminal risk prediction, and suggests that while external psychologists and researchers who share the prison's viewpoint may be granted access, the "involvement of sociologists with prisons is virtually all political risk for prison administrations" (p. 303). Since Heney's (1990) report there have been no research projects related to self-injury contracted out by the $\mathrm{CSC}^{77}$. It appears that the correctional laboratory guards its research specimens for clandestine experiments only to be conducted by authorized 'correctional scientists' who have the appropriate 'subject matter expertise' required to operate on the subjectivities of prisoners (Kilty, forthcoming).

These correctional scientists among other professionals (e.g., psychologists, program facilitators, parole offices, case management teams, etc.) make up what Rose $(1990,1996 b)$ refers to as 'heterogeneous authorities' that together channel psy-expertise. These experts do not think critically for themselves; rather, they actively apply their knowledge and engage an administrative/managerialist criminological approach to research and governance that embraces the rhetoric of correctional philosophies defined by the institution and thus the state. Experts in the correctional laboratory input, process, and observe prisoners as experimental exhibits and then forward the results to senior executives and decision-makers as 'empirically validated' truth claims. In the end, the CSC needs no other truth than truths produced by the RB as these truths are guaranteed to align with the political position of the CSC.

\footnotetext{
${ }^{77}$ Kilty (2008b) writes that despite her requests to access the federal women population, the CSC denied her access to conduct research on women prisoners and self-harm because she was not a 'registered psychologist' nor employed by the CSC. As a result she resorted to recruitng participants who had been released from prison who were living in the community.
} 


\section{Connections}

Texts employ languages that render certain ideas relevant by connecting them to other ideas, disciplines, and bodies of knowledge (Gee, 2011a, 2011b). One element of (dis)connection is the fracture between the RB's texts and bodies of literature outside of the psy-sciences, forensic psychology, and the like. All of the texts with the exception of Heney's (1990) ${ }^{78}$ make frequent links to literature rooted in psy-discourse. This includes correctional discourse (as defined in chapter III), references to methodological techniques rooted in positivism or psy-scientific research methods, and broader psy-literature that may not specifically involve forensic populations, but views self-injury in community settings through a psy-lens. Intra-organizational referencing from within the $\mathrm{RB}$ and among those who at one point in their careers were otherwise active in the publication of reports for the CSC is also seen. These connections to psy-discourse fuse a bond to psychological understandings of human behaviours and maintain this connection by using these knowledges to support specific research methods, findings, conclusions, and suggestions for future research.

When literature that falls outside of these categories is cited, it is generally done in passing or is referenced with the intent to dismiss it as not credible, invalid, subpar, exiguous, or unreliable research. This includes, for example, references to critical criminological literature that argues that segregation is a punitive response to self-injury (e.g., Fillmore \& Dell, 2000, 2005; Kilty, 2006; Thomas et al., 2006), which the RB either explicitly dismisses or relegates to a supporting role wherein quantitative analyses

\footnotetext{
${ }^{78}$ Heney's (1990) report cites the least amount of literature (only 4 sources) of all the texts, and as such the report should be excluded from this particular discussion point, as the goal of her report was not to conduct a literature review or otherwise make connections to other research/literature.
} 
would be required to uphold its validity (Power \& Brown, 2010; Power \& Usher, 2010, 2011a; Usher et al., 2010). Passive citations of feminist and other critical literature are also detected in what appears to be attempt to satisfy readers who may have questioned its absence had it been left out (e.g., Belknap, 2007 ${ }^{79}$; Groves, $2004^{80}$; Hannah-Moffat, $2006^{81}$ ). Those who are familiar with these critical works could argue that the messages are skewed or are lost in the RB's interpretation. Taken together, these characteristics exemplify a severed bond between the RB's objects of analysis and more critical analytical understandings of the very same objects of analysis (e.g., Fillmore \& Dell, 2000, 2005; Groves, 2004; Kilty, 2006, 2008b; Rhodes, 1998).

\section{Language type and sign systems}

Language and sign systems privilege and disprivilege certain modes of thought by proclaiming to possess certain knowledges (Gee, 2011a, 2011b). The privileging of psydiscourse and psy-knowledge is indicative of the RB's ideological base, that is, the acceptance that the psy-sciences adequately explain prisoner behaviour and provide remedies on how to intervene with and reduce such behaviour. This is mostly seen through the textual use of psy-language, but also through graphs, charts and diagrams. These tabular/graphic images, or 'sign systems' serve as another vehicle in which psyknowledges are privileged. They include, for example, depictions of 'path analyses' where correlations are drawn between mental disorder and behavioural output (Power \&

\footnotetext{
${ }^{79}$ Power and Usher (2011c) write: "path analysis has often been applied to examine the links between childhood and adult experiences and offending (Belknap, 2007)" (p. 16).

${ }^{80}$ Power and Brown (2010) write: "SIB within correctional institutions often leads to the progressive use of physical restraints (Groves, 2004; Metzner et al., 2007; National Institute of Corrections, 2004), a potentially problematic situation that CSC aims to minimize" (p. 1).

${ }^{81}$ Power, Gordon, Sapers and Beaudette (2012) write: "it is possible that the detection and/or recording of SIB varies between the genders in institutions, or that women are more likely to avoid detection for their SIB, as some authors have suggested (e.g., Hannah-Moffat, 2006)" (p. 3).
} 
Usher, 2011b, 2011c), and hierarchical classification models with which to determine whether an incident was self-injury or suicide-motivated (Power \& Brown, 2010). Paired with language type and style, the texts privilege a predominantly positivist approach to social science research that is rooted in psy understandings of human behaviour.

The texts demonstrate how entrenched the culture of diagnosis is within the prison. For instance, the results of the SCID-I/II found that roughly four out of five prisoners met the criteria for a mental disorder irrespective of belonging to the self-injury group (Power \& Usher, 2011b, 2011c). If abnormality is now the norm, does that not make abnormality normal? (Foucault, 2003). This paradox went unquestioned and unchallenged in the texts, within the scope of the construction of the research object (i.e., self-injuring prisoners), and within the greater scope of the use of tools like the SCID-I/II in detecting mental illness more generally. The use of language that supports tools like the SCID-I/II illustrates how the texts employ the psy-sciences as intellectual technologies (Rose, 1990, 1996b) to interpret human behaviour and to present findings as 'evidence-based' facts. This tendency to welcome psychological explanations for behaviour is not limited to the prison; rather this view of 'hard science' has become mainstream and as such the prison is but one saturated example of its dominant infiltration. I expand on the proliferation of the psy-sciences in the conclusion chapter of this thesis. 


\section{CHAPTER VI: CONCLUSION}

Prisons are notorious hotbeds of self-mutilation. One reason seems to be the high number of psychopaths (persons with a diagnosis of antisocial personality disorder) who end up in prisons. Psychopaths seem to have a heightened need for excitement, novel experiences, and stimulation. (Favazza, 1996, p. 168)

For what, precisely, is the problem? In what way is self-mutilation a problem in the prison, and for whom? (Groves, 2004, p. 51)

The RB both enables and constrains understandings of self-injury with respect to the prisoner population. This is done vis-à-vis three distinct processes: 1) by favouring and applying psy-ideologies as a means to understand self-injurious behaviour amongst prisoners, 2) by producing internally-commissioned research that is steered by political obligations and affinities, and 3) by barring sociological, critical criminological or otherwise non-psy understandings of prisoner self-injury. These techniques of enabling and restricting knowledge evoke broader questions about the domination of psyknowledges in everyday life and the role of political accountabilities and bureaucratic obligations in influencing research directions.

In this conclusion chapter I lay out a critical assessment of each of the three processes I identified as enabling and constraining understandings of prisoner self-injury. In doing so I ask readers to expand the scope of how they think about psy in order to address its discursive dominance in our lives. I explore how discourses of prisoner responsibilization are complicated once 'mental disorder' enters the equation and suggest how we may better understand how and to what degree prisoners are held responsible, if at all, for their mental illness. The political implications of internally commissioned research are considered, followed by a critical account of how the texts demonstrate a 
prohibition of sociological knowledges. I then consider whether the positivist modes of thought embedded in correctional research are to blame for this production of theoretically empty 'hard fact' knowledge on prisoner self-injury. The RB did attempt to curb criticisms from those who advance 'anti-positivist' methodology arguments, as they used a qualitative approach to supplement the quantitative research they conducted on self-injury. Is it only a question of methods used that determines whether research is critical, meaningful, or reflexive enough to satisfy sociological camps of thought? I argue that it is not the research method that matters, but rather the ideological base from which the research is grounded that determines the ouput of knowledge. I conclude this chapter by considering this debate. Avenues for future critical research are suggested throughout.

\section{Prioritizing psy: The domination of psy-knowledges}

Turning to psy-knowledge to explain human behaviour is not a new phenomenon; in fact, human behaviour has been pathologized for centuries. Foucault (1988a, 2003, 2006a, 2006b) identifies the emergence of psychiatry and psychology as new ways of understanding human behaviour during the late eighteenth century. Since then, the pathologization of deviant, strange, and undesirable behaviour has grown to the point where the lay person commonly adopts the doctrine of the psy-sciences and participates in the pathologization of everyday life (Burr \& Butt, 2000; Ussher, 2011).

Do you want to ensure that you harness the full potential of the power of your mind? Now you can with Luminosity, a program that claims it is a "personal trainer for your brain: like a personal trainer, the program knows you well enough to push you to be even better" (Lumos Labs Inc., 2013, n.p.). Have you heard that the controversial Mayor 
of Toronto, Rob Ford, admitted to smoking crack and getting drunk? He must do right by himself and seek the help of 'mental health professionals' (Global News, 2013; Goldman, 2013; Kay, 2013; Raimundo, 2013). Are you an employee of the public service who is suffering from 'depression'? Get a note from your 'mental health professional' that legitimates your diagnosis and you will get up to six months off on paid leave (Treasury Board of Canada Secretariat, 2011a, 2011b). You wouldn't be alone, everyone is doing it: last year nearly half of all federal government workers who went on leave were out of the office for 'mental health issues' (Weston, 2012). What do we think about teen girls Rehtaeh Parsons of Nova Scotia and Amanda Todd of British Columbia who took their own lives? Cyber bullying may have driven them over the edge, but apparently they both had untreated underlying mental illnesses (Deutsch, 2013; Gergin, 2013). Prisoners are cutting themselves with bathroom tile pieces or tying torn clothing around their limbs? The CSC responds by convening a panel of 'experts ${ }^{92}$ for a roundtable discussion of selfinjury while the Canadian Psychiatric Association (2013) issues statements pleading that the CSC take up their offer to help "develop effective, evidence-based management and treatment strategies for their populations" (para. 8), because, clearly, these prisoners have mental disorders.

The psy-sciences have become entrenched in how the media, pop-culture, marketing companies, government organizations, among other social bodies, explain deviant and abnormal human behaviour, participating in a culture of diagnosis. The RB is not unique in adopting a psy approach, nor is the CSC. The texts on prisoner self-injury

\footnotetext{
${ }^{82}$ This included an Executive Director of Correctional Managed Health Care centre who is also a Professor of Medicine, Psychiatry, and Nursing; a Head Professor of Forensic Psychiatry; an editor of the Journal of Personality Disorders; and a Director of an Adult Forensic Psychiatry Program who is also a Deputy Clinical Head and an Associate Professor of Psychiatry (CSC, 2013a).
} 
published by the gatekeepers of criminal/prisoner knowledge serve as but one example of how the psy-sciences are fastened to explanations of problematic human behaviour. It is precisely because self-injury in prisoners can be explained by the simple manifestation of mental disorder that researchers and the general public rest assured knowing that 'hard science' separates their behaviour from everyone else's. The psy-sciences offer a 'low epistemological profile' (Foucault, 1980c) in the sense that they are a reputable and trusted 'evidence-based' scientific mechanism through which to understand why people do the things they do.

The domination of the psy-sciences as an intellectual technology (Rose, 1990, 1996b) goes unquestioned as the RB takes on each new object of analysis, from criminality to self-injury. This trajectory of knowledge rarely stops to consider the social influences on behaviour, and when it does, it (re)characterizes lived social experiences as 'adaptive' or 'maladaptive' typologies of behaviour. This is particularly the case when the RB attributes self-injury to deficiencies in coping skills, where prisoners are thought to be unable to 'manage their emotions' in effective and productive ways. Whether explicitly calling upon mental disorder to explain the strangeness of self-injury or ruling the behaviour as reflective of deficiencies in adaptive coping mechanisms, these characterizations reduce self-injury to mental, and thus pathological, shortcomings. The RB's research question could never have truly been 'why do prisoners self-injure', but rather, what sickness of the mind causes them to self-injure. Through this pathologization, the RB severs any threads that tie the prison to responsibility for the (mis)behaviour of prisoners by deflecting liability from the prison as a socio-political environment onto the damaged mind of the prisoner, for being mentally disordered is beyond the prison's 
control. But whose control is it in, then? This requires careful consideration, as the displacement of responsibility from prison to prisoner for mental illness is not so simplistic.

Responsibilizing irresponsibility

Prison responsibilization theories have taught us that the prison projects responsibility for past criminal harms squarely onto those who are criminalized (HannahMoffat, 2000, 2001, 2004a, Kemshall, 2002, 2003; Pollack, 2000b, 2005, 2006). Can the same be said for mental disorders? While indeed it may be argued that the source of mental illness rests within the person, it also rests outside of the person. This is in part because it is not something we can tangibly test for ${ }^{83}$, and precisely because it is recognized, as if in the collective consciousness, as a 'hard fact' of life. Mental disorder is understood as a broader social problem that affects a multitude of individuals: rich or poor, man or woman, young or old, black or white, fat or thin, criminal or law-abiding. As such we must 'all work together' to alleviate the stigma attached to mental illness, to promote mental health awareness, and to empower psychiatric survivors (Cohen, 2005; Corrigan, 2004a, 2004b, 2004c; Cresswell, 2005; Crossley, 2004; Ogrodnik, 2013). As previously noted, this kind of awareness was recently promoted in public service discourse, such as in 2006 when the Government of Canada in collaboration with a number of large federal organizations released an extensive 203 page document designed to do exactly that:

\footnotetext{
${ }^{83}$ Although some neuro/bio/psycho-practitioners would argue to the contrary (e.g., Boksa, 2013; Flynn et al., 2003; Herpetz et al., 2001; Sussman et al., 2009; for critical accounts of, see Rose, 2000b, 2010; Singh \& Rose, 2009).
} 
The report helps outline what each of us can do to improve one's own mental health and the mental health of those around us. It is designed to increase public awareness of mental illness and mental health, and to help Canadians realize the great strides we are making towards the illness and Canada's new Government's commitment to mental health. (Minister's message, para. 2)

We tend to collectively take responsibility for mental disorder by acknowledging that mental illness is a societal-wide problem and that no individual should be considered personally 'responsible' for the onset of his or her mental illness. Correctional discourse does not outwardly stipulate that prisoners take sole responsibility for their mental illness(es) (as we see with traditional correctional discourse on responsibilization for criminality); rather, correctional discourse asks that prisoners accept that they have a mental illness and to be responsible by being aware of it, following the advice of mental health professionals, taking prescribed medications, accepting it as a part of their present and future make-up, and so on (see, for example, Linehan, 1993; McDonagh, Taylor, \& Blanchette, 2002; Sly \& Taylor, 2003, on DBT) .

In this sense, responsibility for one's mental illness is complicated by underlying discourses of prisoner responsibilization and mental health awareness and acceptance. First, responsibility for mental illness as originating from the prison is ruled out; mental disorder is appended to the prisoner and not the prison whereby prisoners are generally thought to be mentally ill prior to their incarceration ${ }^{84}$. Next, responsibility is transformed from being the fault of the prisoner into something that they could not have reasonably predicted or controlled. They are not considered responsible for their disease of the mind

\footnotetext{
${ }^{84}$ This is debatable given that the symptoms of mental disorder are argued to be exacerbated once in a confined, isolative environment (e.g., O’Keefe \& Schnell, 2007; Shalev, 2011), yet the onset of mental illness is generally accepted in correctional discourse as preceding the onset of criminal behaviour (Hodgins \& Cote, 1990; Ogloff, Roesch, \& Hart, 1994; Roland, Van den Bree, Ferriter, \& Taylor, 2010).
} 
insofar as they did not personally and/or intentionally cause the onset of their mental illness. Even so, prisoners must accept and take responsibility for their mental illness(es) by equipping themselves with the appropriate cognitive tools to manage their impaired minds appropriately (see, for example, DBT or Psychosocial Rehabilitation program content: McDonagh, Taylor, \& Blanchette., 2002; Sly \& Taylor, 2003, 2005; Warner, 1998). This sentiment is not unique to the prison; indeed mental health awareness campaigns are prolific and citizens are encouraged to 'beat the stigma' and be open about their diverse mental conditions (Corrigan, 2004a, 2004b, 2004c; Corrigan, Edwards, Green, Diwan, \& Penn, 2001; Corrigan, Kerr, \& Knudsen, 2005; Rusch, Angermeyer, \& Corrigan, 2005). This discourse speaks through the language of empowerment, compassionate care, human rights and inclusiveness (Menzies, 2010).

Given the pre-existing responsibilization technologies of the prison that seek to increase 'offender accountability' (CSC, 2012g; Public Safety Canada, 2013) and demand that prisoners take responsibility for their criminal histories (Hannah-Moffat, 2000, 2001, 2004a, Kemshall, 2002, 2003; Pollack, 2000b, 2005, 2006), the selfownership of mental disorder is arguably increasingly instilled in and expected from prisoners compared to the general public. As such the burden of mental illness is recognized as not originating precisely from within the prisoner or from the prison, but nevertheless it remains a quality that prisoners are responsibilized to understand, accept, and remedy. Though this idea of responsibilizing irresponsibility for mental health management was not an empirical finding identified in the RB's texts, it speaks to the broader correctional practices of mental disorder, 'rehabilitation', 'treatment', and 'offender accountability'. The complicated relationship between mental illness, penality, 
and responsibility ought to be further developed and explored in future critical criminological research.

\section{Psy-citizenship}

What do prisoners think when told (if they are told) that their self-injury is a product of an (un)treated mental illness? Six RB studies involved asking women and men prisoners to discuss their psychiatric histories in an interview setting (Power, Beaudette, \& Usher, 2012; Power \& Usher, 2010, 2011a, 2011b, 2011c; Power, Usher, \& Beaudette, 2012). The RB's texts do not consider how these kinds of questions make their subjects feel. For instance, if you tell a psy-expert that you self-injure and they ask you if you have ever been diagnosed with a mental disorder, or begin to poke and prod at what symptomatology you may be experiencing, what would you take away from this? Kilty's (2008b) research found that women prisoners in part adopted the psy-languages that were taught to them in correctional programming into their own vocabularies and identities. Adopting a pathological identity is not restricted to the prison; rather, the idea that our behaviours can be explained by inherent pathologies is something that many people willingly accept. Diagnoses in this sense can yield a sense of comfort, where patients experience relief once they are able to pinpoint exactly what disease of the mind has caused them such distress.

Scholars have explored the human desire for affiliation and identification with 'psychological identities' and suggest that some people seek and experience comfort when ascribed with a label of mental illness because it validates their emotional distress (Arrigo, 2002; Menzies, 2010). Only recently has a small body of work explored the 
notion of 'psychiatric citizenship' or 'psy-citizenship' to consider how individuals negotiate with or against ascribed psy-identities in the carceral context (Kilty, 2008a, 2008b; Rhodes, 2010). 'Psy-citizenship' is an emerging theoretical construct, but is at present underdeveloped. It can be described as the affiliation and/or identification with a psychiatric diagnosis of mental disorder(s). Claiming 'psy-citizenship' may involve the internalization or rejection of a psy-identity, and assumes a level of autonomy in terms of compliance with the corresponding psy-interventions and treatments offered to individuals by the corrective promise of the psy-sciences. Given that women prisoners (and women in general) are more likely than men to be diagnosed as mentally ill (Derkzen et al., 2012; Freeman \& Freeman, 2013; Pollack, 2005; Public Safety Canada, 2009; Ussher, 2010, 2011, 2013a, 2013b), future research may benefit from a critical feminist approach in order to examine the gendered experiences of psy-citizenship and women diagnosed as mentally disordered.

These ideas introduce critical questions on how prisoners respond when diagnosed with mental disorder: to what extent do prisoners internalize, reject and/or negotiate with the psy-identifies prescribed to them by psy-experts? There exists a gap in the literature that addresses the scope of prisoner psychiatrization and to what extent these prescribed identities are absorbed and internalized by prisoners. Kilty's (2008b) research demonstrates how women prisoners both accept and reject psychological identities, and so future research could build on this by engaging in a dialogue with prisoners to explore this idea of psy-citizenship. Given the emergence of correctional research on self-injury, it would be especially timely for research that examines how prisoners who engage in self-injury negotiate psy-citizenship. 


\section{On the production of knowledge: The problem with internally commissioned research}

The discursive production of knowledge constitutes a way to construct and reify 'truths' (Foucault, 1980a). In a practical sense, the production of knowledge about an organization conducted by that same organization might be understood as subjective or biased. Ussher (2011) explains:

The ideological stance of researchers affects the research questions they ask, the epistemological stance and methodologies they adopt, and their interpretations of the data they collect. (p. 56)

The RB's texts suggest that they carry an epistemological stance that is the product of their inherent relationship with the CSC. Bureaucratic networks such as this are precisely what hold organizations and departments back from speaking beyond the red-tape barriers that constrain their narratives. The RB could not have made suggestions or reveal findings about self-injury that would reduce or rupture the integrity of the CSC as this would have infringed upon the organization's set of 'shared values' (CSC, 2013b). As with all other products produced by the RB, the research must meet specific standards of "methodology and scientific rigour" ${ }^{85}$ (CSC, 2004, CD 009, p. 1), and must never contradict existing correctional policies or practices or otherwise bring the prison complex and its components (e.g., prison officials, governments, collaborative efforts) into disrepute. This is ensured in part by stipulating that employees "must not be [publicly] critical of policy or operations" as doing so would "encourage a lack of respect for the Correctional Service of Canada and its staff' (as cited in Brisson, 2011, p. 17). Bureaucratic affinities steer the RB to produce knowledge on self-injury that is politically

\footnotetext{
${ }^{85}$ This being rigorous, empirical research undertakings that are known to constitute positivist quantitative research (at least as dictated by the $\mathrm{RB}$ ).
} 
satisfactory, responsible and acceptable. For as the texts found that self-injury was more likely to occur among prisoners housed in maximum security (Power, Beaudette, \& Usher, 2012; Power, Gordon, Sapers, \& Beaudette, 2012; Power \& Usher, 2011d; Power, Usher, \& Beaudette, 2012) or in segregation (Power, Gordon, Sapers, \& Beaudette, 2012; Power \& Riley, 2010), how can the socio-environmental effect of the prison be denied as having an effect on prisoner self-injury? This paradox is not reconciled within the texts, as a reflexive conversation of this nature could simply not take place.

The RB's reports on self-injury make up a fraction of their annual output: according to the RB's website, in the past three years they have produced an average of 24 full-length reports and 15 short reports ${ }^{86}$ per year all related to federal corrections. This idea of the RB as 'correctional laboratory' that is privy to accessing its own populations on which to generate knowledge would make for interesting future critical scholarship that could problematize the production of internally commissioned research.

\section{Barred from the brigade: The demotion of sociological knowledges}

A hierarchy of knowledge is apparent within the RB's texts. Psy-knowledges are prioritized as the epitome of correctional knowledge while sociological and/or critical criminological knowledges are devalued, dismissed or absent from the texts. The CSC privileges quantitative methods, meta-analysis methodologies and the like while deeming sociological research "unscientific, qualitative, ungeneralisable, non-empirical, valueladen and irrational" (Kendall, 2002, p. 187). A quick perusal through the RB's bibliographies reveals a practice of incestuous citation where an overwhelming number

\footnotetext{
${ }^{86}$ Short reports include 'research snippets', 'research reviews', 'emerging research results', and 'research at a glance' publications that are typically one to two pages in length.
} 
of sources of information are drawn from previously conducted experiments within the $\mathrm{RB}$ or within the CSC. This practice positions internal, correctional, and thus psychological knowledge as superior to other knowledges.

The promotion of psy-knowledge, sustainment of organizational internal knowledge, and the demotion of sociological or critical criminological knowledges is not exclusive to the RB. This is common practice throughout the CSC, notably within the area of correctional programming. Shaw and Hannah-Moffat (2004) discuss how correctional discourse on 'what works' for offender rehabilitation engages in a circular reification of knowledge where much of the works cited are references to its own publications. What follows is a snippet of stakeholder comments and CSC responses that were assembled into a master list by the CSC's Reintegration Programs Division in November of 2011 (CSC, 2011e). Stakeholders of the CSC were asked to offer comments on the proposed revised (forthcoming) 'Program Strategy for Women Offenders ${ }^{87}$ authored by the CSC. Here are some comments made by the CAEFS and the CSC's (2011e, p. 6) response:

\begin{tabular}{|l|l|l|l|l|}
\hline Commentator & Comments by section & Recommendation & \multicolumn{1}{|c|}{ Response } & Action \\
\hline Canadian & We have been & Research external & CSC considers & \\
Association of & repeatedly assured & to CSC does not & Kelly & \\
Elizabeth Fry & that self-injury and & recognize this & Blanchette's & \\
Societies & suicide attempts are & linkage. & research as & \\
(CAEFS) & $\begin{array}{l}\text { considered and } \\
\text { criminogenic factors, } \\
\text { they are included as } \\
\text { such in the strategy. }\end{array}$ & & $\begin{array}{l}\text { meeting the } \\
\text { standards of } \\
\text { the field. }\end{array}$ & \\
& & & \\
\hline
\end{tabular}

\footnotetext{
${ }^{87}$ This is further to the earlier version (Fortin, 2004), as the women's programming model has completely changed from offering a number of varying programs (substance abuse, violence prevention, etc.) to offering a streamlined 'integrated' cadre of programs that tap into 'multiple' needs in one shot (CSC, 2012c). This in and of itself invites critical accounts and problematizations of programming regimes for women prisoners. Indeed this is an important area of inquiry for future research but is outside the scope of this thesis.
} 
This exchange suggests an overt dismissal of external ${ }^{88}$ critique that calls into question the generalizability of the CSC's in-house research. Knowledges produced by the CSC are positioned as higher order and above those external to the CSC.

To fashion a more applied example of how psy-knowledges are put on a pedestal within the correctional paradigm, I digress to an initiative I witnessed from its inception. In September of 2013, the CSC entered into an agreement with the University of Quebec en Outaouais (UQO) that would provide internships for clinical criminology students in the CSC's Reintegration Programs Division (RPD) at NHQ and in parole offices and federal institutions (CSC, 2013n, 2013q; UQO, 2013a, 2013b). The press release circulated to CSC employees quoted the Director of the RPD as saying:

This agreement not only provides career opportunities for the type of students we need, but it also allows CSC to help train a highly skilled and bilingual workforce while they are still in University. (CSC, 2013r, para. 2, emphasis added)

Clinical criminology has been characterized as a discipline that facilitates the pathological differentiation of criminal behaviour, where the goal is to recognize psychopaths, among other types of criminals, within restrictive and reductive analytical grids (Carrier, 2006). Here the CSC is choosing to employ students who are trained in 'clinical criminology' to participate in the development and administration of correctional programs in order to best suit what I suggest is the increasingly psy-reliant direction of the CSC. While it is not known whether internship or co-op positions for students from

\footnotetext{
${ }^{88}$ The CAEFS is a community-based association that works to ensure equality and fair treatment for criminalized women. It has been argued elsewhere that the differing emotive responses between the CAEFS and the CSC symbolize their vastly different ideological bases (Kilty, 2008b).
} 
non-clinical disciplines ${ }^{89}$ are being reduced, it is at least apparent that an influx of clinical criminology students are being invited into the CSC's knowledge production complex. This initiative demonstrates the demotion of sociological knowledges in favour of clinical psychological knowledge by manufacturing the future workforce based on the alignment of a university's program with the psy-sciences. As a result, sociological knowledges are ranked second-rate and are deported back to academia from whence they came.

But why would the CSC look to sociology or critical criminology literature to advance ideas about self-injury in the prisoner population, or more generally, to inform correctional policies or practices? As Simon (2000) suggests, contemporary penology is increasingly less welcoming towards sociological knowledges as its preoccupation with knowledge rests with clinical and psy-expertises that offer risk prediction, cost benefit analyses, and the like. To most correctional professionals, critical scholarship is simply not useful for advancing the administration of 'corrections' nor does it serve a purpose in enhancing the safe and secure management of the prison, and so to expect that the CSC spontaneously begin meaningfully integrating sociological knowledges into policy and practices would be haphazard and midguided. Similar to what Garland (2000) contends about the culture of 'high crime societies' wherein ideas about the fear of crime increase societal insecurity, once an ideology is established, it does not change rapidly, rather, it requires a significant shift in culture to change. The current culture of administrative/managerialist criminology in Canadian prisons determines the importance of actuarial and positivist ways of understanding criminality and to what extent

\footnotetext{
${ }^{89}$ The CSC's national capital locations (NHQ and nearby parole offices and institutions) currently recruit university students from the University of Ottawa (n.d., 2013) and Carleton University (2013), neither of which have a strong program area of focus in clinical criminology; programs offered range from critical criminology to forensic psychology.
} 
sociological knowledges are (de)valued. These ideas are likely to remain stagnant until or unless a shift in prison culture occurs that reorganizes the values and beliefs system in correctional penality.

Martel (2004) explains how criminological knowledges are 'policed' by gatekeepers who decide what to include or exclude. In 1999, Martel undertook contract research on federal women prisoners who were housed in segregation. She reports being met by the CSC with comments on how qualitative accounts of women's experiences would be subjective and would not yield credible evidence (Martel, 2004). She was instructed by the CSC of the importance of random sampling methods, representativeness to the general population, and the validity of quantitative data at different stages in her research project. Martel (2004) writes:

What this suggests is that the recommendation is based on an assumed hierarchy of paradigms where a universalistic, objectivistic and rationalistic view of social reality occupies a higher rank than alternative interpretations of social reality. What it further suggests is that this hierarchization of paradigms operates to reproduce a particular kind of order within the scientific community where the truth status of forms of knowing is chiefly measured by more traditional ideals of 'good' or 'hard' science. (p. 168)

In the next section, I argue that this 'good' or 'hard' science is too narrowly understood by critical scholarship as strictly positivist quantitative research. In the spirit of Martel's (2004) account of how knowledges are polarized into dichotomies of quantitative versus qualitative methodologies, I offer a complementary critique and consider how relegating the RB's texts to this binary is too simple of a characterization to explain how correctional knowledges are produced. 


\section{Quantitative versus qualitative: Is it really all in the methods?}

In correctional discourse, positivist thinking and rigourous 'empirically validated' research is commended for its quantitative legitimacy. This is a trend identified throughout the RB texts. Quantitative and positivist methodologies have been criticized in critical sociological/criminological scholarship for failing to consider the social realities or lived experiences of the subject(s) the research seeks to examine (e.g., Aas, 2004; Martel, 2004; Ussher, 1991, 2011; Walklate \& Mythen, 2011; Young, 2011; for more general accounts of, see Cicourel, 1964; Kitsuse \& Cicourel, 1963). For example, on the topic of medicalizing women, Ussher (2011) asserts that,

... it is arguably political or ideological to conduct research within a narrow positivist model that ignores the subjective meaning of madness and of symptomatology for women. (p. 57)

However, we must consider this kind of statement carefully. Similar to Ussher, others have suggested that the quantification of social phenomena is a technology of distance (Porter, 1995) insofar that the detachment of quantitative researchers from their objects of study serves a functional purpose: "the more that they are distanced from what they are studying, the more secure they feel" (Young, 2011, p.13). On this critique, Garland (2012) comments that he does not claim to know how quantitative researchers feel and that the practice of 'othering' the essentialized positivist researcher is hypocritical and problematic $^{90}$. Critical criminologists/sociologists sometimes resort to the routine argument of characterizing quantitative knowledges as empty positivist debris. Doyle and Moore (2011) note that it is unfair to automatically characterize quantitative research as

\footnotetext{
${ }^{90}$ Garland (2012) refers to, for example, how Young (2011) makes a parodist characterization of the quantitative researcher as a 'datasaur' who moves from database to database, "his belly huge and distended with the intricate intestine of regression analysis, he eats ravenously but rarely thinks about the actual process of statistical digestion, his tail is light and inconclusive" (Young, 2011, p. 15).
} 
"atheoretical, unreflexive, and conservative" (p. 8). In attempt to move past these dichotomous interpretations of ideological origins, some argue for a more pragmatic approach to the social sciences and encourage the use of both quantitative and qualitative methods in order to produce a well-rounded research product (Brannen, 1992, 2005; Bryman, 2006; Onwuebuzie \& Leech, 2005).

The RB could be characterized as a knowledge production assembly line, given the volume of similarly themed research they publish. Are the RB's texts an example of positivist methodologies that fail to acknowledge the subjectivities of prisoners who selfinjure? The RB undertook two qualitative studies, and as such the argument that the RB relies solely on quantitative methodologies would be incorrect and misguided. Indeed these qualitative accounts of women and men prisoners' experiences of self-injury prove to be a break in the usual positivist order of quantitative methodologies produced by the correctional laboratory. The texts appear to be a meaningful attempt to report on the narratives of prisoners who engage in self-injury as opposed to only showcasing the analytical grids, tick-boxes and correlations plotted by quantitative research, the latter of which is criticized for making lived experiences amendable to data collection by reducing the narrative of the subject to database format (Aas, 2004, 2006). However, as Martel (2004) points out, even though qualitative methods are generally demoted within the CSC in favour of quantitative ones, the CSC accepts qualitative research methods so long as they originate from within the CSC. This idea of authority and expertise through 
bureaucratic positioning is increasingly evident when we consider the RB as the official 'branch' responsible for producing research on behalf of and for the benefit of the $\mathrm{CSC}^{91}$.

What, then, can be attributed as the source of the production of the RB's knowledge on prisoner self-injury, if not mere methods? Quantitative methodologies, tests of statistical significance, or the assembly of information into databases do not act alone to 'erase' the narrative of individuals. Rather, the ideological platform ${ }^{92}$ from which the research originates determines the ideological orientation and epistemological foundation of the knowledge output. It does not matter what research method quantitative, qualitative, or mixed methods - the RB undertook, for, irrespective of methodological approach, the underlying psy-ideological platform pre-determined the research output. Regardless of method, the RB constructed men and women prisoners who self-injure as pathologically inclined to harm themselves.

This ideological platform is shaped by the constraints imposed by political obligations and accountabilities. Working on behalf of the very social institution that governs the prison inevitably influences the research craft from methods used to conclusions drawn. As such, the ideological platform intersects with political restrictions to yield research that is steered in a direction that satisfies bureaucratic obligations. Indeed, governance can be bound up with ideology insofar that ideological values

\footnotetext{
91 At one point in my position with the CSC I participated in a research project with a colleague that analyzed the specific characteristics of 'low risk' women prisoners in comparison to women with higher 'risk' levels. Our Director reviewed our report and then specifically forbid us from using the word 'research' to describe our analysis. When we asked why, we were told that the word 'research' on any formal publications are restricted for use by the RB, and that any other departments conducting research on their own must be creative and rename their research a 'project' or an 'analysis' in order to avoid compromising the organization's streamlined approach to research originating from one approved and recognized source of expertise.

92 As explained in chapter III, I accept the interpretation of ideology as a system of ideas that is supplemented by discourse rather than opposed to it (Purvis \& Hunt, 1993). In this vein I see 'ideological platforms' as the epistemological origin, or backbone, from which knowledge production is born. These platforms serve to push knowledges forward through discourse as vessel.
} 
influence governance strategies (Larner, 2000), but in the case of the RB, I argue that the ideological platform (the psy-sciences and its corrective promises) is independent of the CSC's ideologies of governance because psy-knowledge lingers in spaces that are not necessarily directly governed by official sources of government (i.e., private life) and because psy-ideology exists in spaces absent of correctional philosophy. Knowledge about human behaviour is first cut and defined at the outset by an ideological platform, next it is carved and shaped by political and methodological filters, and then it gives way to the output of knowdge that participates in the construction of human subjectivities. 


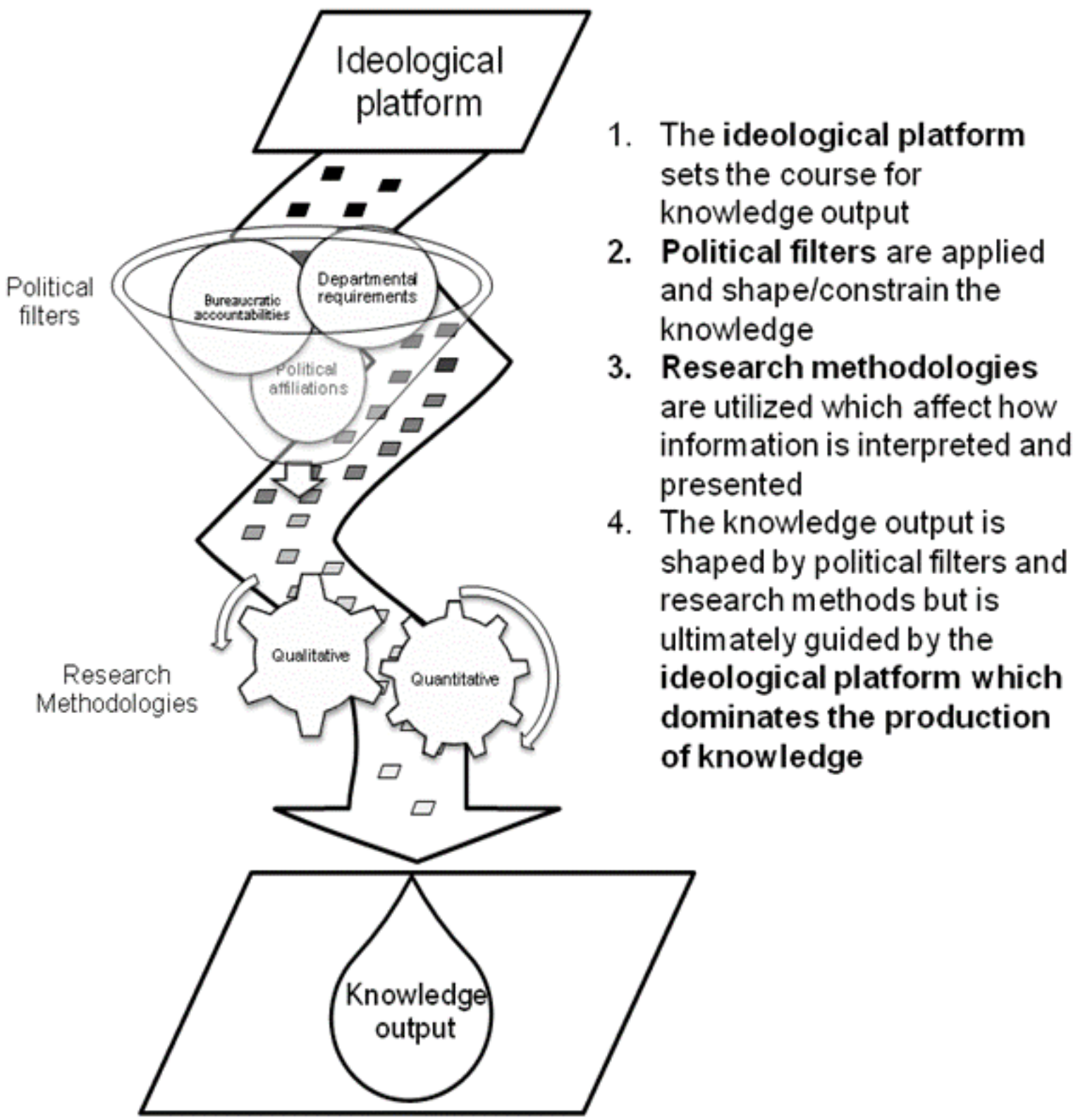

Figure 2. Diagram depicting the RB's production of knowledge 


\section{Tracing the wave}

There is one research question that has yet to be addressed: what reasons could explain the sudden surge of production of research on self-injury and what reasons may be excluded from the RB's self-stated rationale? The fact that Ashley Smith died under the CSC's direct care in 2007 is speculated to have influenced or even caused the surge in $\mathrm{RB}$ research. This is, however, never mentioned as a rationale in any of the RB's texts, nor is it in the RB's 'research plan' (CSC, 2010d), the CSC's (2011i, 2011j), 'National Strategy' or 'Action Plan' to address self-injury, the CSC's (2010e, 2011h, 2012d) official responses to the OCI's annual reports ${ }^{93}$ or in any other form of public correspondence. The OCI (2008a, 2008b, 2009a, 2009b, 2010a, 2010b, 2011, 2012a, $2013 b, 2013 c)$ refers to the Smith case frequently, however, and has repeatedly requested that the CSC produce 'clinical research' that would support a 'proven treatment program/plan' for self-injuring prisoners. Once the RB's research began pouring in, the OCI (2012a, 2013b) acknowledged that these findings have begun to 'shed light' on the issue of self-injury in prison. In essence, in recent reports the OCI $(2011,2012 \mathrm{a}, 2013 \mathrm{~b}$, 2013c) has welcomed the new breadth of clinical/forensic and 'evidence-based' research on self-injury offered by the CSC with open arms. This is precisely why, despite their pragmatic critical approach insofar that they challenge the CSC's practices, the OCI is ultimately part of what we recognize as correctional discourse that is embedded in psyideology and discourse.

\footnotetext{
${ }^{93}$ Note that for the first time since the memorandum of understanding between the CSC and the OCI in 2000, the CSC did not submit a response to the OCI's annual report for tabling at Parliament in 2013. The OCI (2013c) remarks that this suggests a deteriorating confidence in the ability for the CSC to be transparent and accountable.
} 
In early 2010 , the first few of the twelve new reports on prisoner self-injury were published. I suggest that this surge in research may have been a by-product of Ashley Smith's death. The reports serve as a corporate risk-mitigation strategy to respond to the criticism and controversy that the CSC has faced since her death. Mitigating 'corporate risk' is a common practice in correctional (and more generally, governmental) discourse (e.g., CSC, 2012b, 20131, 2013o; see also Treasury Board of Canada Secretariat, 2012). Research aimed to "increase the capacity to intervene and address preventable deaths in custody and self-harm incidents" (CSC, 2011g, p. 19) is linked to the CSC's self-stated corporate risks that the organization "will not be able to improve correctional results for offenders with mental disorders" (CSC, 2012b, p. 10) or "not be able to maintain required levels of operational safety and security" (CSC, 20131, p. 9). In accordance with the organizational practice of making efforts to mitigate corporate risks, the publication of research on self-injury serves to appease public and stakeholder criticism insofar as it shows the CSC is 'doing something' about the issue of self-injury in prison. I suggest that this production of knowledge assists the CSC in absolving themselves of responsibility or wrongdoing with respect to the treatment of self-injuring prisoners. This is more clearly seen on the issue of segregating self-injuring prisoners, where the RB texts profess that there is 'no effect of incarceration' on prisoner self-injury.

How does this discourse contribute to explaining Ashley Smith's death? By pathologizing self-injuring prisoners in correctional discourse, Smith is retroactively 
rendered devoid of personal responsibility for her actions ${ }^{94}$. As she is relinquished from responsibility for her self-harm and subsequent death, the CSC expunges itself of liability given that Smith was unable to reasonably predict or control her behaviour on account of mental disorder. With this new logic of mental health/illness responsibilization, correctional discourse indirectly suggests that if Smith's self-injury and death were beyond her control, then they were also beyond the CSC's control.

\section{Final cuts and concluding thoughts}

In 2011, Kilty pointed out and criticized the absence of correctional literature on prisoner self-injury since Heney's (1990) report: "It is as though by not speaking of it correctional officials and researchers can pretend it no longer takes place" (p. 104). The CSC's new wave of research would appear to appease this criticism, but should it? Kilty's (2011) call for documentation of self-injurious behaviours in the new federal women's prisons was evidently not made to ask corrections to characterize women (or men) prisoners as pathologically inclined to self-injure, but rather to acknowledge that it is in fact a problem. This influx of knowledge, while indeed acknowledging that selfinjury happens, ultimately serves to offload responsibility for self-injury onto prisoner mental illness in attempt to, in part, absolve the prison of responsibility. As such the post$2010 \mathrm{RB}$ research on self-injury is posited as being primarily produced in the interests of the prison rather than the prisoners who engage in the behaviour.

\footnotetext{
${ }^{94}$ Some discourse maintains that Ashley was manipulative insofar that her actions were completely rational (see Richard, 2008), however, I argue that the dominating discourses point to mental instability as what led her to self-injure and ultimately end her life. Aside from correctional discourse this is also evidenced in the media (see, for example, Blatchford, 2013; Pate, 2013; Perkel, 2013a; The Associated Press, 2012).
} 
This thesis critically examined the arrival and contents of a new wave of correctional discourse on prisoner self-injury. Using discourse analysis, this thesis exposed how a recent shift in correctional discourse has given way to a renewed reliance on psy-knowledges to explain and understand self-injury amongst the prisoner population. Irrespective of methodological approach, it was argued that the texts published by the CSC originate from a psy-oriented ideological platform, thus positioning psy-knowledges as the legitimate explanatory framework for prisoner-self-injury. The political affiliation with and accountabilities owed to the state was theorized as intersecting with this psy-knowledge trajectory to further shape the discourse output. This intersection results in the attempt to absolve the correctional system of responsibility for prisoner self-injury and displace it back onto the prisoner through complicated discourses of mental illness and responsibilization that hold individual prisoners responsible for the acceptance and appropriate management of their mental deficiencies. The barring of sociological and critical criminological knowledges was evidenced in the textual material, and as such this surge in correctional discourse on self-injury serves to both enable and constrain understandings of self-injury in penality.

There is one last thing to consider before concluding this thesis. The critique of the psy-sciences thus far has not been intended to minimize the emotional distress that prisoners, or more generally any human being, can experience. I do not suggest that there is no 'truth' to the emotional pain and suffering we may experience throughout our lives. Drawing from Ussher's $(1991,2010,2011)$ works on the medicalization of misery, I contend that psy-knowledges (re)theorize human anguish and distress into syndromes and disorders that ultimately end up navigating away from the realities of human despair. 
Similar to what Shaw (2002) contends about clinical discourse on self-injury, I argue that the RB comes close to a meaningful understanding of self-injury amongst prisoners - that is, the emotionally taxing conditions of confinement and the narratives of those who experience it - but pivots back to psy-understandings by distorting and reshaping the behaviour into something better recognized by the economy the psy-sciences. This is not to be misunderstood as an interpretation of the researchers as distancing themselves to feel some sense of security, or simply to render phenomena into quantitative variables of false precision (see Young, 2011), but rather as an ideological distancing from raw human experiences and towards nominal psychological grids of behavioural classification. Resorting to psy-knowledges is a product of how the RB's bureaucratic relationship with the CSC stands in the way of allowing the RB to draw conclusions outside that ideological and political platform.

The goal of this thesis was not to chastise the CSC for the practices they exercise with respect to self-injury, nor was it to explore alternatives. Rather, this thesis engaged in what may be understood as an art of critique insofar as it unraveled the complexities embedded in correctional discourse and attempted to understand them using critical theory. I defer to Foucault's (1991) generally pessimistic 'beyond method' idea about how critique can simply be critique:

Critique doesn't have to be the premise of a deduction which concludes: this then is what needs to be done. It should be an instrument for those who fight, those who resist and refuse what is. Its use should be in processes of conflict and confrontation, essays in refusal. It doesn't have to lay down the law for the law. It isn't a stage in a programming. It is a challenge directed to what is. (p. 84) 
Following this train of thought, readers will notice that the 'so what' question of this thesis was not to offer solutions or new corrective promises, but instead to illustrate the ways in which particular knowledges are produced and to probe ideological and epistemological questions about how we understand social and human phenomena. Indeed alternatives to managing self-injury in prison seem far-fetched given the current 'crime and punishment' agenda (see Mallea, 2010). Even the CSC has expressed doubt in their ability to treat prisoners who self-injure:

The CD [Commissioner's Directive] went for review last week and there was no consensus at EXCOM [Executive Committee] particularly on how to respond to self-injurious offenders. (CSC, 2010f, p. 2)

This is not to suggest that the management of self-injury is exclusively a question of a revised correctional approach; rather, it falls on the governing bodies, where shifts in political climate can limit or restrict the ability for existing correctional practices to change. Critical scholarship based in Canada has repeatedly called upon the CSC to remedy how self-injury is managed, including removing punitive practices such as restraints and isolation and recommending that the CSC partner with external organizations or individuals to facilitate a critical reflection that may actually yield change (e.g., Kilty, 2006; Martel, 2004; Pollack, 2005). As outlined in the CSC's (2011j) 'National Strategy' to address self-injury, the development of RSPMC's appears to be an initiative that, given the descriptions offered, does not include interdisciplinary collaboration external to the CSC. This could potentially be an avenue for positive and multidisciplinary consultation if external knowledges were included to accompany correctional ones. Given the narrow ideological scope of the correctional laboratory and its governing body, these suggestions of collaboration and permitted entry/access may be 
ideal in working towards a more inclusive body of research on epistemological questions about penality. Unfortunately, calls for collaborative action tend to hit a glass ceiling in the federal government, where open and transparent relationships are regrettably doubtful given the strict political pillars that founded and maintain the CSC. As this discourse analysis has demonstrated, if it were up to the CSC, the large social distance between correctional discourse and critical/socio/criminological scholarship would not shrink any time soon.

The privileging of psy-knowledges as evidenced in the recent surge in correctional discourse on self-injury demonstrates how knowledge about prisoner selfinjury is fragmented, cut, and carved in a way that is dictated by correctional and political philosophies. This act of carving knowledge simultaneously serves to cut out sociological and otherwise critical knowledges as if severing the undesired fat or skin of an animal. As a result of this excision of knowledge, correctional discourse arrives at a narrow understanding of prisoner self-injury. This carnage of knowledge gives way to an understanding that legitimizes correctional practices and positions correctional researchers as experts of 'hard science' who possess the authority to profess knowledge about and onto others. In doing so, these scrupulously packaged knowledges attempt to conceal the fact that the new surge in correctional discourse on self-injury suggests that the self-slashing and self-asphyxiation of prisoners is, precisely, a problem of and for the prison. 


\section{$\underline{\text { References }}$}

Aas, K.F. (2004). From narrative to database: Technological change and penal culture. Punishment \& Society, 6(4), 379-393.

Aas, K.F. (2006). 'The body does not lie': Identity, risk and trust in technoculture. Crime Media Culture, 2(2), 143-158.

Aas, K.F. (2011). 'Crimmigrant' bodies and bona fide travelers: Surveillance, citizenship and global governance. Theoretical Criminology, 15(3), 331-346.

Abi-Rached, J.M., \& Rose, N. (2010). The birth of the neuromolecular gaze. History of the Human Sciences, 23, 11-36.

Adams, K., \& Ferrandino, J. (2008). Managing mentally ill inmates in prisons. Criminal Justice and Behaviour, 35(8), 913-927.

Adkins, L. (Ed.). (2002). Reflexivity and mobility in social theory. In Revisions: Gender \& sexuality in modernity (pp. 30-56). Philadelphia, PA: Open University Press.

Adler, A. (1927). Understanding human nature. (W.B. Wolfe, Trans.). New York, NY: Greenberg Publishing.

Adler, P.A., \& Adler, P. (2005). Self-injurers as loners: The social organization of solitary deviance. Deviant Behavior, 26, 345-378.

Adler, P.A., \& Adler, P. (2007). The demedicalization of self-injury: From psychopathology to sociological deviance. Journal of Contemporary Ethnography, 36, 537-570.

Ahmed, S. (2004). The cultural politics of emotion. New York, NY: Routledge.

American Psychiatric Association. (1980). Diagnostic and statistical manual of mental disorders $\left(3^{\text {rd }}\right.$ ed.). Washington, DC: Author.

American Psychiatric Association. (2000). Diagnostic and statistical manual of mental disorders ( $4^{\text {th }}$ ed., text rev.). Washington, DC: Author.

American Psychiatric Association. (2010, March 4). DSM-5 development: Non-suicidal self injury. Retrieved from http://www.dsm5.org/ProposedRevisions/Pages/ proposedrevision. aspx?rid=443\# (note that this link was deactivated by the APA at some point in mid-2013)

American Psychiatric Association. (2011). Definition of mental disorder. Retrieved from http://www.dsm5.org/ProposedRevisions/Pages/proposedrevision.aspx?rid=465 (note that this link was deactivated by the APA at some point in mid-2013) 
American Psychiatric Association. (2012). DSM-IV and DSM-5 criteria for the personality disorders. Retrieved from http://www.psi.uba.ar/academica/ carrerasdegrado/psicologia/sitios_catedras/practicas_profesionales/610_clinica_cu adrosfront_psicosis/material/dsm.pdf

American Psychiatric Association. (2013a). Diagnostic and statistical manual of mental disorders $\left(5^{\text {th }}\right.$ ed.). Washington, DC: Author.

American Psychiatric Association. (2013b). Highlights of changes from DSM-IV-TR to $D S M-V$. Retrieved from http://www.dsm5.org/Documents/changes $\% 20$ from $\% 20 \mathrm{dsm}$-iv-tr\% $\% 20$ to $\% 20 \mathrm{dsm}-5$.pdf

American Psychological Association. (2013). Glossary of psychological terms. Retrieved from http://www.apa.org/research/action/glossary.aspx

American Psychological Association. (n.d.). About clinical psychology. Retrieved from http://www.apa.org/divisions/div12/aboutcp.html

Andover, M.S., Schatten, H.T., Crossman, D.M., \& Donovick, P.J. (2011). Neuropsychological functioning in prisoners with and without self-injurious behaviors: Implications for the criminal justice system. Criminal Justice and Behaviour, 38(11), 1103-1114.

Andrews, D.A. (2001). Principles of effective correctional programs. In L.L. Motiuk \& R.C. Serin (Eds.), Compendium 2000 on effective correctional programming (pp. 9-17). Ottawa, ON: Correctional Service of Canada.

Andrews, D.A., \& Bonta, J. (1995). The level of service inventory - Revised. Toronto, ON: Multi-Health Systems.

Andrews, D.A., \& Bonta, J. (2010). The psychology of criminal conduct (5th ed.). Newark, NJ: LexisNexis.

Andrews, D.A., Bonta, J., \& Wormith, S.J. (2006). The recent past and near future of risk and/or need assessment. Crime \& Delinquency, 52, 7-27.

Andrews, D.A., Bonta, J., \& Wormith, S.J. (2004). The Level of Service/Case Management Inventory (LS/CMI). Toronto, ON: Multi-Health Systems.

Andrews, D.A., Zinger, I., Hoge, R.D., Bonta, J., Gendreau, P., \& Cullen, F.T. (1990). Does correctional treatment work? A psychologically informed meta-analysis. Criminology, 28, 369-404.

Arbour, L. (1996). Commission of inquiry into certain events at the prison for women in Kingston. Ottawa, ON: Public Works and Government Services. 
Archambault, K., Stewart, L., Wilton, G., \& Cousineau, C. (2010). Initial results of the Computerized Mental Health Intake Screening System (CoMHISS) for federally sentenced women (R-230). Ottawa, ON: Correctional Service Canada, Research Branch.

Arensman, E., \& Keeley, H.S. (2012). Defining intent: With preparations underway for DSM-5, is there a case for a new diagnostic category of non-suicidal self-injury? Psychiatry Professional, 1, 8-9.

Arrigo, B.A. (2002). Punishing the mentally ill. Albany, NY: SUNY Press.

Arrigo, B.A., \& Bullock, J.L. (2008). The psychological effects of solitary confinement on prisoners in supermax units: Reviewing what we know and recommending what should change. International Journal of Offender Therapy and Comparative Criminology, 52(6), 622-640.

Ashton, H. (1997). Psychotropic drug prescription for women. British Journal of Psychiatry, 158(10), 30-35.

Babiker, G., \& Arnold, L. (1997). The language of injury: Comprehending selfmutilation. Leicester, UK: The British Psychological Society.

Bailey, R. (2009). Up against the wall: Bare life and resistance in Australian immigration detention. Law Critique, 20, 113-132.

Bain, S., \& Fedynich, L. (2011). Therapy on the cutting edge: Supportive perspectives of the inclusion of self-injury in the DSM-V. Retrieved from http://counselingoutfitters.com/vistas/vistas11/Article_06.pdf

Baker, T. (1999). Doing social research ( $3^{\text {rd }}$ ed). Toronto, ON: McGraw-Hill.

Balfour, G. (2000). Feminist therapy with women in prison: Working under the hegemony of correctionalism. In K. Hannah-Moffat \& M. Shaw (Eds.), An ideal prison? Critical essays on women's imprisonment in Canada (pp. 94-102). Halifax, NS: Fernwood Publishing

Balfour, G. (2012, March 27). In the absence of the rule of law: Conditions of women's imprisonment and the death of Ashley Smith. Frost Centre Brown Bag Lunch Series Seminar, Peterborough, ON: Trent University. Retrieved from http://www.trentu.ca/frostcentre/documents/110830frostreport.pdf

Ball, J. (2013, May 22). Women 40\% more likely than men to develop mental illness, study finds. The Guardian. Retrieved from http://www.theguardian.com/society/ 2013/may/22/women-men-mental-illness-study

Barak, G., Leighton, P., \& Flavin, J. (2010). Class, race, gender, and crime: The social realities of justice in America ( $3^{\text {rd }}$ ed.). Lanham, MD: Rowman \& Littlefield. 
Barnum, G., \& Gobeil, R. (2012). Revalidation of the custody rating scale for Aboriginal and non-Aboriginal women offenders (R-273). Ottawa, ON: Correctional Service of Canada, Research Branch.

Bebbington, P.E. (1996). The origins of sex differences in depressive disorder: Bridging the gap. International Review of Psychiatry, 8(4), 295-332.

Beck A.T., Steer, R.A., \& Garbin, M.G. (1988). Psychometric properties of the Beck Depression Inventory: Twenty-five years of evaluation. Clinical Psychology Review, 8, 77-100.

Beck, A.T., Ward, C.H., Mendelson, M., Mock, J., \& Erbaugh, J. (1961). An inventory for measuring depression. Archives of General Psychiatry, 4(6), 561-571.

Becker, D. (2000). When she was bad: Borderline personality disorder in a posttraumatic age. American Journal of Orthopsychiatry, 70(4), 422-432.

Belknap, J. (2007). The invisible woman: Gender, crime, and justice (3rd ed.) Belmont, CA: Thompson Wadsworth.

Berman, G., \& Dar, A. (2013). Prison population statistics. Library House of Commons, England and Wales. Retrieved from www.parliament.uk/briefingpapers/sn04334.pdf

Bernard, H.R. (2013). Social research methods ( $2^{\text {nd }}$ ed.). Thousand Oaks, CA: Sage Publications.

Bersot, H.Y., \& Arrigo, B.A. (2010). Inmate mental health, solitary confinement, and cruel and unusual punishment: An ethical and justice policy inquiry. Journal of Theoretical and Philosophical Criminology, 1, 1-82.

Bhaskar, R. (1989). Reclaiming reality: A critical introduction to contemporary philosophy. London, UK: Verso.

Biggam, F., \& Power, K. (1999). Suicidality and the state-trait debate on problem solving deficits: A re-examination with incarcerated young offenders. Archives of Suicide Research, 5, 27-42.

Bill C-10: Safe Streets and Communities Act. (2012). Royal Assent, March 13, 2012, $41^{\text {st }}$ Parliament, $1^{\text {st }}$ Session. Ottawa, ON: Minister of Justice Canada. Retrieved from http://www.parl.gc.ca/LEGISInfo/BillDetails.aspx?Language=E\&Mode=1\&billId $=5120829$

Bill C-37: Increasing Offenders' Accountability for Victims Act. (2013). Royal Assent, June 19, 2013, 41 ${ }^{\text {st }}$ Parliament, 1st Session. Ottawa, ON: Minister of Justice Canada. Retrieved from http://www.parl.gc.ca/LEGISINFO/BillDetails.aspx? Mode $=1 \&$ billId $=5507161 \&$ Language $=\mathrm{E}$ 
Biometrics Research Department (n.d.). SCID - Frequently Asked Questions. Retrieved from http://www.scid4.org/faq/scidfaq.html

Bjorklund, P. (2006). No man's land: Gender bias and social constructivism in the diagnosis of borderline personality disorder. Issues in Mental Health Nursing, 27, $3-23$.

Blanchette, K. (1996). The relationship between criminal history, mental disorder, and recidivism among federally sentenced female offenders. Carleton University. Master's thesis. Retrieved from http://curve.carleton.ca/system/files/theses/ 24431.pdf

Blanchette, K. (2001). Effective correctional practice with women offenders. In L.L. Motiuk \& R.C. Serin (Eds.), Compendium 2000 on effective correctional programming (pp. 160-173). Ottawa, ON: Correctional Service of Canada.

Blanchette, K. (2002). Classifying female offenders for effective intervention: Application of the case-based principles of risk and need. Forum on Corrections Research, 14(1), 31-35.

Blanchette, K., \& Brown, S.L. (2006). The assessment and treatment of women offenders: An integrative perspective. Chichester, England: John Wiley \& Sons.

Blanchette, K., \& Motiuk, L.L. (1995). Female offenders risk: Case management strategies approach. Unpublished paper presented at the Canadian Psychological Association Annual Convention, Charlottetown, Prince Edward Island.

Blanchette, K., \& Motiuk, L.L. (1996). Female offenders with and without major mental health problems: A comparative investigation. Forum on Corrections Research, $9(3), 1$.

Blanchette, K., \& Motiuk, L.L. (2004). Taking down the straw man: A reply to Webster and Doob. Canadian Journal of Criminal Justice, 46(5), 621-630.

Blanchette, K., \& Taylor, K. (2004). Development and validation of a Security Reclassification Scale for women. Forum on Corrections Research, 16(1), 28-30.

Blanchette, K., \& Taylor, K. (2005). Development and field-test of a gender-informed security reclassification scale for women offenders (R-167). Ottawa, ON: Correctional Service of Canada, Research Branch.

Blanchette, K., \& Taylor, K. (2009). Reintegration of female offenders: Perspectives on what works. Corrections Today, 71(6), 60-63.

Blanchette, K., Flight, J., Verbrugge, P., Gobeil, R., \& Taylor, K. (2011). Dialectical Behaviour Therapy within a women's structured living environment (R-241). Ottawa, ON: Correctional Service of Canada, Research Branch. 
Blatchford, C. (2013, September 5). Ashley Smith's mental disorder led to hellish encounters between teenager and staff. National Post. Retrieved from http:/fullcomment.nationalpost.com/2013/ 05/09/ christie-blatchford-ashleysmiths-mental-disorder-led-to-hellish-encounters-been-teenager-and-staff/

Boksa, P. (2013). A way forward for research on biomarkers for psychiatric disorders. Journal of Psychiatry and Neuroscience, 38(2), 75-77.

Bonta, J., \& Andrews, D.A. (2003). A commentary on Ward and Stewart's model of human needs. Psychology, Crime, and Law, 9, 215-218.

Bonta, J., \& Andrews, D.A. (2007). Risk-need-responsivity model for offender assessment and rehabilitation: 2007-06. Ottawa, ON: Public Safety Canada.

Bonta, J., Hanson, K., \& Law, M. (1998). The prediction of criminal and violent recidivism among mentally disordered offenders: A meta-analysis. Psychological Bulletin, 123(2), 123-142.

Bonta, J., Pang, B., \& Wallace-Capretta, S. (1995). Predictors of recidivism among incarcerated female offenders. The Prison Journal, 75(3), 277-294.

Booth, L. (2012). Effective correctional programs for women offenders (R-279). Ottawa, ON: Correctional Service of Canada, Research Branch.

Bordo, S. (1993). Unbearable weight: Feminism, western culture and the body. Berkeley, CA: University of California Press.

Borrill, J., Burnett, R., Atkins, R., Miller, S., Briggs, D., Weaver, T., \& Maden, A. (2003). Patterns of self-harm and attempted suicide among white and black/mixed race female prisoners. Criminal Behaviour and Mental Health, 13(4), 229-240.

Borrill, J., Snow, L., Medlicott, R.T., \& Paton, J. (2005). Learning from 'near misses': Interviews with women who survived an incident of severe self-harm in prison. The Howard Journal, 44, 57-69.

Bottos, S. (2007). Profile of offenders in administrative segregation: A review of the literature (B-39). Ottawa, ON: Correctional Service of Canada, Research Branch.

Boudewyn, A.C., \& Liem, J.H. (1995). Childhood sexual abuse as a precursor to depression and self-destructive behaviours in adulthood. Journal of Traumatic Stress, 8, 445-459.

Brady, T. (2013, May 23). Women suffer up to 40 per cent more mental health problems than men due to stress of juggling roles, study claims. Daily Mail UK. Retrieved from http:/www.dailymail.co.uk/news/article-2329398/Women-suffer-mentalhealth-problems-men-stress-juggling-roles-according-study.html 
Brakoulias, V., Ryan, C.B., \& Byth, K. (2006). Patients with deliberate self-harm seen by a consultation-liaison service. Australas Psychiatry, 14, 192-7.

Brandt, A.L.S. (2012). Treatment of persons with mental illness in the criminal justice system: A literature review. Journal of Offender Rehabilitation, 51(8), 541-558.

Brannen, J. (1992). Mixing methods: Qualitative and quantitative research. London, UK: Avebury.

Brannen, J. (2005). Mixing methods: The entry of qualitative and quantitative approaches into the research process. International Journal of Social Research Methodology, $8(3), 173-184$.

Brickman, B. (2004). 'Delicate' cutters: Gendered self-mutilation and attractive flesh in medical discourse. Body \& Society, 10(4), 87-111.

Briere, J., \& Gil, E. (1998). Self-mutilation in clinical and general population samples: Prevalence, correlates, and functions. American Journal of Orthopsychiatry, 64, 609-620.

Brisson, K. (2011). 'Struggling' through public safety: An examination of parole policy and practice in Canada. University of Windsor. Master's thesis. Retrieved from http://scholar.uwindsor.ca/cgi/viewcontent.cgi?article=1047\&context=etd

Brown, M.Z., Comtois, K.A., \& Linehan, M. (2002). Reasons for suicide attempts and nonsuicidal self-injury in women with borderline personality disorder. Journal of Abnormal Psychology, 111, 198-202.

Brown, T.B. (2009). Coping through cutting: A phenomenology of self-harm. Texas Tech University. Doctoral dissertation. Retrieved from https://dspace.lib.ttu.edu/etd/ bitstream/handle/2346/ETD-TTU-2009-12120/BROWNDISSERTATION.pdf? sequence $=4$

Brown, W. (Ed.). (2005). Neoliberalism and the end of liberal democracy. In Edgework: Critical essays on knowledge and politics (pp. 37-59). Princeton, NJ: Princeton University Press.

Bryman, A. (2006). Paradigm peace and the implications for quality. International Journal of Social Research Methodology, 9(2), 111-126.

Bureau of Management Consulting Supply and Services Canada. (1981). Self-inflicted injuries and suicides: A review of the related literature (3-2820). Ottawa, ON: Prepared for the Correctional Service of Canada. Published by Public Safety Canada.

Burns, A. (2013). Book review: James Paul Gee, how to do discourse analysis: A toolkit. Discourse Studies, 15(2), 247-259. 
Burr, V., \& Butt, T. (2000). Psychological distress and postmodern thought. In D. Fee (Ed.), Pathology and the postmodern: Mental illness as discourse and experience (pp. 186-206). London, UK: Sage.

Butler, J. (1990). Gender trouble. London, UK: Routledge.

Butler, T., Allnutt, S., Cain, D., Owens, D., \& Muller, C. (2005). Mental disorder in the New South Wales prisoner population. Australian and New Zealand Journal of Psychiatry, 39, 407-413.

Cabana, T., Wilton, G., \& Stewart, L. (2011). Parole review delays and cancellations and correctional programs (R-248). Ottawa, ON: Correctional Service of Canada, Research Branch.

Camp, S.D. (2004). The rewards and challenges of pursuing research in a correctional agency. Federal Bureau of Prisons. Retrieved from http:/www.bop.gov/resources/ research_projects/published_reports/prison_mgmt/camp_jcje2004.pdf

Campbell, A. (2012). A place apart: the harm of solitary confinement. University of Toronto. Master's thesis. Retrieved from https://tspace.library.utoronto.ca/handle/1807/33351

Canadian Association of Elizabeth Fry Societies. (2005, April 22). Prisons: Canada's default response to poverty, homelessness, and mental illness - especially for women. Paper presented at the 11th United Nations Congress on Criminal Justice and Crime Prevention conference, Bangkok. Retrieved from http://www.caefs.ca/wp-content/uploads/2013/04/ apri105.pdf

Canadian Association of Elizabeth Fry Societies. (2009, March 3). Correcting corrections must be a priority. Press release. Retrieved from http://www.caefs.ca /wp-content/uploads/2013/04/CorrectingCorrections_Mar3-09.pdf

Canadian Bar Association. (2011). Submission on Bill-C10: Safe Streets and Communities Act. Ottawa, ON: Author.

Canadian Psychiatric Association. (2013, October 1). Psychiatrists support Correctional Investigator: Corrections needs a new approach to federally sentenced women who self-injure. GlobeNewswire. Retrieved from http://globenewswire.com/newsrelease/2013/ 10/01/577224/10050690/en/Psychiatrists-Support-CorrectionalInvestigator.html

Canadian Psychological Association. (2012). Canadian Psychological Association submission to the senate standing senate committee on legal and constitutional affairs. Ottawa, ON: Author.

Cardoso, F.L. (2010). Political and sexual attitudes concerning same-sex sexual behaviours. Sexuality \& Culture, 14(4), 306-326. 
Carlen, P. (1986). Psychiatry in prisons: Promises, premises, practices and politics. In P. Miller \& N. Rose (Eds.), The power of psychiatry (pp. 241-266). Cambridge, UK: Polity Press.

Carlen, P., \& Worrall, A. (2004). Analysing women's imprisonment. Cullompton, UK: Willan Publishing.

Carlen, P. (2012). A criminological imagination: Essays on justice, punishment and discourse. London, England: Ashgate.

Carleton University. (2013). Field placement in criminology. Retrieved from http://carleton.ca/criminology/wp-content/uploads/Field-Placement-inCriminology-General-Info-2013.ppsx

Carrier, N. (2006). Academics' criminals: The discursive formations of criminalized deviance. Champ Penal/Penal Field, 3, 1-34.

Castel, R. (1991). From dangerousness to risk. In G. Burchell, C. Gordon, \& P. Miller (Eds.), The Foucault effect: Studies in governmentality (pp. 281-298). Chicago, IL: The University of Chicago Press.

CBC News. (2009, March 3). Jail death of N.B. teen 'entirely preventable': Report. $C B C$ News. Retrieved from http://www.cbc.ca/m/touch/canada/story/1.841541

CBC News. (2012, October 12) Self-harm rising among aboriginal women prisoners. CBC News. Retrieved from http://www.cbc.ca/news/canada/manitoba/self-harmrising-among-aboriginal-women-prisoners-1.1208556

Chandler, A., Myers, F., \& Platt, S. (2011). The construction of self-injury in the clinical literature: A sociological exploration. Suicide and Life-Threatening Behaviour, 41, 98-109.

Charney, D.S., \& Nestler, E.J. (2011). Neurobiology of mental illness ( $2^{\text {nd }}$ ed.). New York, NY: Oxford University Press.

Christie, N. (2010). Victim movements at a crossroad. Punishment \& Society, 12(2), 115122.

Cicourel, A.V. (1964). Method and measurement in sociology. New York, NY: The Free Press of Glencoe.

Claes, L., \& Vandereycken, W. (2007). Self-injurious behavior: Differential diagnosis and functional differentiation. Comprehensive Psychiatry, 48, 137-144.

Claes, L., Vandereycken, W., \& Vertommen, H. (2005). Self-care versus self-harm: Piercing, tattooing, and self injuring in eating disorders. European Eating Disorders Review, 13, 11-18. 
Claes, L., Vandereycken, W., \& Vertommen, H. (2007). Self-injury in female versus male psychiatric patients: A comparison of characteristics, psychopathology and aggression regulation. Personality and Individual Differences, 42, 611-621.

Claghorn, J.R., \& Beto, D.R. (1967). Self-mutilation in a prison mental hospital. Corrective Psychiatry \& Journal of Social Therapy, 13, 133-141.

Cohen, F. (2008). Penal isolation: Beyond the seriously mentally ill. Criminal Justice and Behaviour, 35(8), 1017-1047.

Cohen, O. (2005). How do we recover? An analysis of psychiatric survivor oral histories. Journal of Humanistic Psychology, 46(2), 333-354.

Cook, A.N., \& Roesch, R. (2012). "Tough on crime" reforms: What psychology has to say about the recent and proposed justice policy in Canada. Canadian Psychology, 53(3), 217-225.

Connell, R.W. (1995). Masculinities. Sydney, Australia: Allen \& Unwin.

Connell, R.W., \& Messerschmidt, J.W. (2005). Hegemonic masculinity: Rethinking the concept. Gender \& Society, 19(6), 829-859.

Conrad, P. (1992). Medicalization and social control. Annual Review of Sociology, 18, 209-232.

Conrad, P. (2005). The shifting engines of medicalization. Journal of Health and Social Behaviour, 46, 3-14.

Correctional Service of Canada. (1989). Role of the Research Branch. Retrieved from http://www.csc-scc.gc.ca/research/r05e-eng.shtml

Correctional Service of Canada. (2000). The closing of the prison for women in Kingston. Retrieved from http://www.csc-scc.gc.ca/text/pblct/brochurep4w/index-eng.shtml

Correctional Service of Canada. (2004). Commissioner's Directive 009: Research. In effect 2004-06-30. Ottawa, ON: Author.

Correctional Service of Canada. (2006). Strategic Plan for Aboriginal Corrections, 200607 to 2010-11. Ottawa, ON: Author, Aboriginal Initiatives Directorate.

Correctional Service of Canada. (2007). Commissioner's Directive 709: Administrative Segregation. In effect 2007-11-09. Ottawa, ON: Author.

Correctional Service of Canada. (2008). Speakers Binder, Section 2: The mandate, mission and priorities of the Correctional Service of Canada. Retrieved from http://www.csc-scc.gc.ca/text/pblct/sb-go/02-eng.shtml 
Correctional Service of Canada. (2009a). Correctional program descriptions:

Reintegration Programs Division. Retrieved from http://www.cscscc.gc.ca/text/prgrm/cor-pro-2009-eng.shtml

Correctional Service of Canada. (2009b). Evaluation report: Correctional Service Canada's correctional programs. Ottawa, ON: Author, Evaluation Branch.

Correctional Service of Canada. (2010a). Community strategy for women offenders. Ottawa, ON: Author, Women Offender Sector.

Correctional Service of Canada. (2010b). Evaluation report: Community maintenance program. Ottawa, ON: Author, Evaluation Branch.

Correctional Service of Canada. (2010c). Mental health strategy for corrections in Canada: A federal-provincial-territorial partnership. Ottawa, ON: Author.

Correctional Service of Canada. (2010d). Research plan 2010-11. Retrieved from http://www. csc-scc.gc.ca/ text/rsrch/crnt-rsrch/rpln-10-11/rpln-2010-11eng.shtml\#_Toc256777523

Correctional Service of Canada. (2010e). Response of the Correctional Service of Canada to the $37^{\text {th }}$ annual report of the Correctional Investigator 2009-2010. Retrieved from http://www.csc-scc.gc.ca/publications/ci09-10/index-eng.shtml

Correctional Service of Canada. (2010f, February 16). Combined IMHI/CMHI Mental Health Initiative Steering Committee Meeting. Document retrieved under the Access to Information and Privacy Act on February 14, 2013.

Correctional Service of Canada. (2011a). Audit of Regional Treatment Centres and the Regional Psychiatric Centre. Ottawa, ON: Author, Internal Audit Committee.

Correctional Service of Canada. (2011b). Bulletin-OMS: Alerts, flags and needs in $O M S$. Document retrieved under the Access to Information and Privacy Act on February 11, 2013.

Correctional Service of Canada. (2011c). Commissioner's Directive 726-1: National Standards for Correctional Programs. In effect 2011-06-03. Ottawa, ON: Author.

Correctional Service of Canada. (2011d). Evaluation report: Strategic plan for Aboriginal corrections - Chapter one: Aboriginal healing lodges. Ottawa, ON: Author.

Correctional Service of Canada. (2011e). National consultation: Revised program strategy for women offenders, roll-up of comments. Document retrieved under the Access to Information and Privacy Act on February 1, 2013. 
Correctional Service of Canada. (2011f). Report of the evaluation of CSC's community corrections Chapter 1: Correctional interventions. Ottawa, ON: Author, Evaluation Branch.

Correctional Service of Canada. (2011g). Report on plans and priorities 2011-12. Ottawa, ON: Author.

Correctional Service of Canada. (2011h). Response of the Correctional Service of Canada to the $38^{\text {th }}$ annual report of the Correctional Investigator 2010-2011. Retrieved from http://www.csc-scc.gc.ca/publications/ci10-11/index-eng.shtml

Correctional Service of Canada. (2011i, March). National action plan to address the needs of offenders who engage in self-injury: Fiscal year 2011-12. Document retrieved under the Access to Information and Privacy Act on February 11, 2013.

Correctional Service of Canada. (2011j, March). National strategy to address the needs of offenders who engage in self-injury. Ottawa, ON: Author.

Correctional Service of Canada. (2012a). Commissioner's Directive 705-6: Correctional Planning and Criminal Profile. In effect 2012-06-13. Ottawa, ON: Author.

Correctional Service of Canada. (2012b). Departmental performance report 2011-12. Ottawa, ON: Author.

Correctional Service of Canada. (2012c). Program strategy for women offenders (revised). Document retrieved under the Access to Information and Privacy Act on February 1, 2013.

Correctional Service of Canada. (2012d). Response of the Correctional Service of Canada to the 39 $9^{\text {th }}$ annual report of the Correctional Investigator 2011-2012. Retrieved from http://www.csc-scc.gc.ca/publications/005007-2801-eng.shtml

Correctional Service of Canada. (2012e). Review of practices in place to prevent/respond to death in custody. Ottawa, ON: Author, Internal Audit Committee.

Correctional Service of Canada. (2012f). Towards a continuum of care: Correctional Service Canada mental health strategy. Retrieved from http://www.cscscc.gc.ca/text/pblct/ health/tcc-eng.shtml\#_Toc267041273

Correctional Service of Canada. (2012g). Transformation: CSC transformation agenda. Retrieved from http://www.csc-scc.gc.ca/about-us/006-0009-eng.shtml

Correctional Service of Canada. (2013a). Addressing the issue of offender self-injury: Summary of expert roundtable. Retrieved from http://www.cscscc.gc.ca/publications/005007-9001-eng.shtml 
Correctional Service of Canada. (2013b). Commissioner's Directive 001: Mission, Values and Ethics Framework of the Correctional Service of Canada. In effect 2013-0729. Ottawa, ON: Author.

Correctional Service of Canada. (2013c). Commissioner's Directive 567-1: Use of Force. In effect 2013-11-18. Ottawa, ON: Author.

Correctional Service of Canada. (2013d). Commissioner's Directive 567-3: Use of Restraint Equipment for Security Purposes. In effect 2013-11-18. Ottawa, ON: Author.

Correctional Service of Canada. (2013e). Commissioner's Directive 567-4: Use of Chemical and Inflammatory Agents. In effect 2013-11-18. Ottawa, ON: Author.

Correctional Service of Canada. (2013f). Commissioner's Directive 568-1: Recording and Reporting of Security Incidents. In effect 2013-11-18. Ottawa, ON: Author.

Correctional Service of Canada. (2013g). Commissioner's Directive 702: Aboriginal Offenders. In effect 2013-11-12. Ottawa, ON: Author.

Correctional Service of Canada. (2013h). Commissioner's Directive 705-7: Security Classification and Penitentiary Placement. In effect 2013-06-13. Ottawa, ON: Author.

Correctional Service of Canada. (2013i). Commissioner's Directive 800-2: Physical Restraints for Medical Purposes. In effect 2013-11-18. Ottawa, ON: Author.

Correctional Service of Canada. (2013j). Commissioner's Directive 803: Consent to Health Service Assessment, Treatment and Release of Information. In effect 201301-09. Ottawa, ON: Author.

Correctional Service of Canada. (2013k). Commissioner's Directive 843: Management of Inmate Self-Injurious and Suicidal Behaviour. In effect 2013-09-23. Ottawa, ON: Author.

Correctional Service of Canada. (20131). Departmental performance report 2012-13. Ottawa, ON: Author.

Correctional Service of Canada. (2013m). Institutional profiles. Retrieved from http://www.csc-scc.gc.ca/institutions/index-eng.shtml

Correctional Service of Canada. (2013n). Memorandum of understanding concerning intern placement and CSC collaboration in the delivery of clinical criminology training. Document retrieved under the Access to Information and Privacy Act on January 16, 2014. 
Correctional Service of Canada. (2013o). Report on plans and priorities 2013-14. Ottawa, ON: Author.

Correctional Service of Canada. (2013p). Research at CSC. Retrieved from http://www.csc-scc.gc.ca/research/index-eng.shtml

Correctional Service of Canada. (2013q). Research topics. Retrieved from http://www.csc-scc.gc.ca/research/005008-2000-eng.shtml

Correctional Service of Canada. (2013r).Thisweek@ CSC article-MoU with University of Quebec en Outaouais. Document retrieved under the Access to Information and Privacy Act on January 17, 2014.

Correctional Service of Canada Review Panel. (2007). A roadmap to strengthening public safety. Ottawa, ON: Minister of Public Works and Government Services Canada.

Corrections and Conditional Release Act. (1992, c. 20). Retrieved from the Department of Justice Canada's website http://laws-lois.justice.gc.ca/eng/acts/C-44.6/

Corrigan, P.W. (2004a). Beat the stigma and discrimination! Four lessons for mental health advocates. Retrieved from http://www.dmh.ca.gov/peistatewideprojects/ docs/ CorriganBeattheStigmaandDiscrimination.pdf

Corrigan, P.W. (2004b). Don't call me nuts: An international perspective on the stigma of mental illness. Acta Psychiatrica Scandinavica, 109, 403-404.

Corrigan, P.W. (2004c) Target-specific stigma change: A strategy for impacting mental illness stigma. Psychiatric Rehabilitation Journal, 28, 113-121.

Corrigan, P.W., Edwards, A.B., Green, A., Diwan, S.L., \& Penn, D.L. (2001). Prejudice, social distance, and familiarity with mental illness. Schizophrenia Bulletin, 27(2), 219-225.

Corrigan, P.W., Kerr, A., \& Knudsen, L. (2005). On the stigma of mental illness: Explanatory models and methods for change. Applied and Preventive Psychology, $11,179-190$.

Cortoni, F., \& Nunes, K.L. (2008). Assessing the effectiveness of the national sexual offender program (R-183). Ottawa, ON: Correctional Service of Canada, Research Branch.

Coy, M. (2009). This body which is not mine: The notion of the habit body, prostitution and (dis)embodiment. Feminist Theory, 10, 61-75. 
Coyle, A. (2013, October 23). Who guards the guards: Prisons and public accountability. Public lecture at Ryerson University, Toronto, Ontario. Retrieved from http://ccla.org/wordpress/wp-content/uploads/2013/11/2013-11-14-Who-Guardsthe-Guards-Summary-of-Andrew-Coyles-talk.pdf

Cresswell, M. (2005). Psychiatric "survivors" and testimonies of self-harm. Social Science \& Medicine, 61, 1668-1677.

Crete, J.P. (2013). A disciplined healing: The new language of Indigenous imprisonment in Canada. Carleton University. Master's thesis. Retrieved from http://curve.carleton.ca/system/files/theses/27508_0.pdf

Crewe, B. (2011). Depth, weight, tightness: Revisiting the pains of imprisonment. Punishment \& Society, 13(5), 509-529.

Crick, N.R., \& Zahn-Waxler, C. (2003). The development of psychopathology in females and males: Current progress and future challenges. Development and Psychopathology, 15(3), 719-742.

Cronin, A.M. (2000). Consumerism and 'compulsory individuality': Women, will and potential. In S. Ahmed, J. Kirby, C. Lury, M. McNeil, \& B. Skeggs (Eds.), Transformations: Thinking through feminism (pp. 273-287). New York, NY: Routledge.

Crossley, N. (2004). Not being mentally ill: Social movements, system survivors and the oppositional habitus. Anthropology \& Medicine, 11(2), 161-180.

Cullen, E.J. (1985). Prediction and treatment of self-injury by female young offenders. In D.P. Farrington \& R. Tarling, Prediction in criminology (pp. 135-148). Albany, NY: State University of New York.

Cullen, F.T., \& Gendreau, P. (2000). Assessing correctional rehabilitation: Policy, practice, and prospects. Policies, Processes, and Decisions of the Criminal Justice System, 3, 109-175.

Cullen, K.R., Westlund, M.K., LaRivere, K.L., \& Klimes-Dougan, B. (2013). An adolescent with nonsuicidal self-injury: A case and discussion of neurobiological research on emotion regulation. American Journal of Psychiatry, 170(8), 821-831.

Currie, J. (2005). The marketization of depression: The prescribing of SSRI antidepressants to women. Retrieved from Women and Health Protection, http://www.whp-apsf.ca/pdf/SSRIs.pdf

Dabrowski, C. (1937). Psychological bases of self-mutilation. Genetic Psychology Monographs, 19, 1-104. 
Dalton, M. (2008). Guards' union calls for inquiry: Report into death of inmate Ashley Smith calls for testimony from prison managers. Retrieved from http://www.uccosacc.csn.qc.ca/Documents/UCCO-SACC/Ontario/documents/Archives/What_s_ new_Archive/2008/Media\%20Coverage.pdf

Davis, C., \& Karvinen, K. (2002). Personality characteristics and intention to self-harm: A study of eating disordered patients. Eating Disorders: The Journal of Treatment \& Prevention, 10, 245-255.

De Leo, D. (2011). DSM-V and the future of suicidology (Editorial). Crisis, 32(5), 233239.

De Leo, D., \& Heller, S.T. (2004). Who are the kids who self-harm? An Australian selfreport school survey. Medical Journal of Australia, 181, 140-144.

De Leo, D., Burgis, S., Bertolote, J.M., Kerkhof, A.J F.M., \& Bille-Brahe, U. (2006). Definitions of suicidal behavior: Lessons learned from the WHO/EURO Multicentre study. Crisis, 27(1), 4-15.

Dear, G.E. (2006). Preventing suicide and other self-harm in prison. New York, NY: Palgrave Macmillan.

Dear, G.E., Thomson, D.M., \& Hills, A.M. (2000). Self-harm in prison: Manipulators can also be suicide attempters. Criminal Justice and Behaviour, 27(2), 160-175.

DeHart, D.D., Smith, H.P., \& Kaminski, R. (2009). Institutional responses to selfinjurious behavior among inmates. Journal of Correctional Health Care, 15(2), 129-141.

Deliberto, T., \& Nock, M. (2008). An exploratory study of correlates, onset, and offset of non-suicidal self-injury. Archives of Suicide Research, 12, 219-231.

Dell, C.A., \& Boe, R. (2000). An examination of Aboriginal and Caucasian women offender risk and needs factors (R-94). Ottawa, ON: Correctional Service of Canada, Research Branch.

Derkzen, D., Booth, L., Taylor, K., \& McConnell, A. (2012). Mental health needs of federal female offenders. Psychological Services, 10(1), 24-36.

Derouin, A., \& Bravender, T. (2004). Living on the edge: The current phenomenon of self-mutilation in adolescents. American Journal of Maternal/Child Nursing, 29, 12-18.

Desjardins, L. (2013, September 30). Get self-harming women out of prison: Watchdog. Radio Canada International. Retrieved from http://www.rcinet.ca/en/2013/09/30/ get-self-harming-women-out-of-prison-watchdog/ 
Deutsch, J. (November 8, 2013). Trustees call for mental-health services. The Now News. Retrieved from http://www.thenownews.com/news/trustees-call-for-mentalhealth-services-1.689244\#

DeVellis, L. (2012, May 5). A wolf in sheep's clothing: The role of rehabilitative discourse in concealing penal punitiveness. Unpublished paper presented at the Second National Critical Perspectives: Criminology and Social Justice conference, Ottawa, Ontario, Carleton University.

Dixon-Gordon, K., Harrison, N., \& Roesch, R. (2012). Non-suicidal self-injury within offender populations: A systematic review. International Journal of Forensic Mental Health, 11, 33-50.

Dowden, C., \& Blanchette, K. (1999). An investigation into the characteristics of substance-abusing women offenders: Risk, need and post-release outcome (R-81). Ottawa, ON: Correctional Service of Canada, Research Branch.

Doyle, A., \& Moore, D. (Eds.). (2011). Introduction: Questions for a new generation of criminologists. In Critical criminology in Canada: New voices, new directions (pp. 1-24). Vancouver, BC: UBC Press.

Eaton, W.W, Muntaner. C., Smith, C., Tien, A., \& Ybarra, M. (2004). Center for Epidemiologic Studies Depression Scale: Review and revision (CESD and CESDR). In M.E. Maruish (Ed.), The use of psychological testing for treatment planning and outcomes assessment ( $3^{\text {rd }}$ ed.) (pp. 363-377). Mahwah, NJ: Lawrence Erlbaum.

Eisenkraft, M. (2006). Self injury: Is it a syndrome? The New School Psychology Bulletin, 4(1), 115-126.

Fagan, T.J., Cox, J., Helfand, S.J., \& Aufderheide, D. (2010). Self-injurious behavior in correctional settings. Journal of Correctional Health Care, 16(1), 48-66.

Faith, K. (1993). Unruly women. Vancouver, BC: Press Gang Publishers.

Farber, S. (2002). When the body is the target. Northvale, NJ: Aronson.

Favazza, A.R. (1992). Repetitive self-mutilation. Psychiatric Annals, 22, 60-63.

Favazza, A.R. (1996). Bodies under siege: Self-mutilation and body modification in culture and psychiatry ( $2^{\text {nd }}$ ed.). London, UK: Johns Hopkins University Press.

Favazza, A.R. (1998). The coming of age of self-mutilation. Journal of Nervous and Mental Disease, 186, 259-268.

Favazza, A.R., \& Conterio, K. (1988). The plight of chronic self-mutilators. Community Mental Health Journal, 24, 22-30. 
Favazza, A.R., \& Conterio, K. (1989). Female habitual self-mutilators. Acta Psychiatrica Scandinavica, 79, 283-289.

Favazza, A.R., DeRosear, L., \& Conterio, K. (1989). Self-mutilation and eating disorders. Suicide and Life-Threatening Behavior, 19(2), 352-361.

Fazel, S., \& Danesh, J. (2002). Serious mental disorder in 23000 prisoners: A systematic review of 62 surveys. Lancet, 359, 545-550.

Fazel, S., \& Seewald, K. (2012). Severe mental illness in 33588 prisoners worldwide: Systemtic review and meta-regression analysis. British Journal of Psychiatry 200, 364-373.

Featherstone, M. (1999). Body modification: An introduction. Body \& Society, 5(2-3), 1 13.

Fee, D. (Ed.). (2000). Pathology and the postmodern: Mental illness as discourse and experience. London, UK: Sage.

Feeley, M., \& Simon, J. (1992). The new penology: Notes on the emerging strategy of corrections and its implications. Criminology, 30(4), 449-474.

Feeley, M., \& Simon, J. (1994). Actuarial justice: The emerging new criminal law. In D. Nelken (Ed.), The futures of criminology (pp. 173-201). London, UK: Sage.

Fekete, S., Voros, V., \& Osvath, P. (2004). Suicidal behaviour and psychopathology in adolescents: results of a self-report survey among 15 and 16 year old adolescent people in Hungary. Journal of the European College of Neuropsychopharmacology, 14, S365.

Ferrari, J. (2011). Federal female incarceration in Canada: What happened to empowerment? Queen's University. Master's thesis. Retrieved from http://qspace.library.queensu.ca/ bitstream/1974/6352/3/Ferrari_Jacqueline_201104_MA.pdf

Fillmore, C.J, \& Dell, C.A. (2000). Prairie women, violence and self-harm. Winnipeg, MB: Elizabeth Fry Society of Manitoba.

Fillmore, C.J., \& Dell, C.A. (2005). Community mobilization for women and girls who self-harm: An environmental scan of Manitoba service providers. Winnipeg, MB: Elizabeth Fry Society of Manitoba.

Flynn, S.W., Land, D.J., Mackay, A.L., Goghari, V., Vavasour, I.M., Whittall, K.P.... Honer, W.G. (2003). Abnormalities of mylienation in schizophrenia detected in vivo with MRI, and post-mortem with analysis of oligodendrocyte proteins. Molecular Psychiatry, 8, 811-820. 
Fortin, D. (2004). Program strategy for women offenders. Ottawa, ON: Correctional Service of Canada, Women Offender Sector.

Fotiadou, M., Livaditis, M., Manou, I., Kaniotou, E., \& Xenitidis, K. (2006). Prevalence of mental disorders and deliberate self-harm in Greek male prisoners. International Journal of Law and Psychiatry, 29, 73.

Foucault, M. (1972a). Order of discourse. Social Science Information, 10, 7-30.

Foucault, M. (1972b). The archaeology of knowledge. New York, NY: Pantheon Books.

Foucault, M. (1977). Discipline \& punish: The birth of the prison. New York, NY: Vintage Books.

Foucault, M. (1978). Politics and the study of discourse. Ideology and Consciousness, 3, 7-26.

Foucault, M. (1980a). Power/knowledge: Selected interviews and other writings 19721977. New York, NY: Pantheon Books.

Foucault, M. (1980b). Prison talk. In C. Gordon (Ed.), Power/knowledge: Selected interviews and other writings 1972-1977 (pp. 37-54). New York, NY: Pantheon Books.

Foucault, M. (1980c). Truth and power. In C. Gordon (Ed.), Power/knowledge: Selected interviews and other writings 1972-1977 (pp. 109-133). New York, NY: Pantheon Books.

Foucault, M. (1984a). Nietzsche, genealogy, history (D.F Bouchard \& S. Simon, Trans.). In P. Rabinow (Ed.), The Foucault reader (pp. 76-100). New York, NY: Vintage Books.

Foucault, M. (1984b). On the genealogy of ethics: An overview of work in progress (R. Howard, Trans.). In P. Rabinow (Ed.), The Foucault reader (pp. 340-372). New York, NY: Vintage Books.

Foucault, M. (1984c). The birth of the asylum (R. Howard, Trans.). In P. Rabinow (Ed.), The Foucault reader (pp. 141-167). New York, NY: Vintage Books.

Foucault, M. (1986). The history of sexuality Vol. 3: The care of the self (R. Hurley, Trans.). New York, NY: Pantheon Books.

Foucault, M. (1987). Mental illness and psychology. Berkley, CA: University of California Press.

Foucault, M. (1988a). Madness and civilization: A history of insanity in the age of reason. New York, NY: Vintage Books. 
Foucault, M. (1988b). Technologies of the self. In L. H. Martin, H. Gutman, \& P. H. Hutton (Eds.), Technologies of the self: A seminar with Michel Foucault (pp. 1649). Amherst, MA: University of Massachusetts Press.

Foucault, M. (1991). Questions of method. In G. Burchell, C. Gordon, \& P. Miller (Eds.), The Foucault effect: Studies in governmentality (pp. 73-86). Chicago, IL: The University of Chicago Press.

Foucault, M. (1994). The birth of the clinic: An archaeology of medical perception. New York, NY: Vintage Books.

Foucault, M. (2003). Abnormal: Lectures at the Collège de France 1974-1975 (G. Burchell, Trans.). New York, NY: Picador.

Foucault, M. (2006a). History of madness. London, UK: Routledge.

Foucault, M. (2006b). Psychiatric power: Lectures at the Collège de France, 1973-1974 (G. Burchell, Trans.). London and New York: Palgrave Macmillan.

Foucault, M. (2010). Government of self and others: Lectures at the Collège de France, 1982-83 (G. Burchell, Trans.). New York, NY: Palgrave Macmillan.

Franklin, R.K. (1988). Deliberate self-harm: Self-injurious behavior within a correctional mental health population. Criminal Justice and Behaviour, 15(2), 210-218.

Freeman, D., \& Freeman, J. (2013a). The stressed sex: Uncovering the truth about men, women, and mental health. Oxford, UK: Oxford University Press.

Freeman, D., \& Freeman, J. (2013b, July 18). It's not just sexism, women do suffer more from mental illness: Why do mainstream mental health professionals give so little attention to the question of gender differences? Time Ideas. Retrieved from http://ideas.time.com /2013/07/18/its-not-just-sexism-women-do-suffer-morefrom-mental-illness/

Freeman, D., \& Freeman, J. (2013c, October 23). Women and mental illness: The silent struggle. Psychology Today. Retrieved from http://www.psychologytoday.com/blog/know-your-mind/201310/women-andmental-illness-the-silent-struggle

Friedel, R.O. (2004). Borderline personality disorder demystified. New York, NY: Marlowe \& Company.

Frigon, S. (2001). Femmes et emprisonnement: Le marquage du corps et l'automutilation. Criminologie, 34, 31-56.

Frost, M. (1995). Self-harm and the social work relationship. Norwich, UK: Social Work Monographs. 
Fulwiler, C., Forbes, C., Santangelo, S.L., \& Folstein, M. (1997). Self-mutilation and suicide attempt: Distinguishing features in prisoners. Journal of the American Academy of Psychiatry and the Law, 25(1), 69-77.

Gaes, G.G., Flanagan, T.J., Motiuk, L.L, \& Stewart, L. (1998). Adult correctional treatment. Federal Bureau of Prisons. Retrieved from www.bop.gov/resources/research_projects/ published_reports/gen_program_eval/oreprcopyoftr.pdf

Garland, D. (2000). The culture of high crime societies: Some preconditions of recent 'law and order' policies. British Journal of Criminology, 40, 347-375.

Garland, D. (2012). Criminology, culture, critique: A review of Jock Young, The criminological imagination (Cambridge: Polity, 2011). British Journal of Criminology, 52, 417-425.

Gee, J.P. (2011a). An introduction to discourse analysis: Theory and method ( $3^{\text {rd }}$ ed.). New York, NY: Routledge.

Gee, J.P. (2011b). How to do discourse analysis: A toolkit. New York, NY: Routledge.

Gendreau, P. (1996). Offender rehabilitation: What we know and what needs to be done. Criminal Justice and Behaviour, 23(1), 144-161.

Gendreau, P., \& Andrews, D.A. (1990). Tertiary prevention: What the meta-analyses of the offender treatment literature tell us about "what works". Canadian Journal of Criminology, 32, 173-184.

Gendreau, P., Little, T., \& Goggin, C. (1996). A meta-analysis of the predictors of adult offender recidivism: What works! Criminology, 34(4), 575-608.

Gergin, M. (2013, October 29). Highlights and lessons from the Pepler and Milton review of the Halifax regional school board's support of Rehtaeh Parsons. Borden Ladner Gervais. Retrieved from http://www.mondaq.com/canada/x/271844/Data+ Protection+Privacy/Highlights + And + Lessons + From + The + Pepler+And + Milton + External+Review + Of + The + Halifax + Regional + School + Boards + Support + Of + Reh taeh+Parsons

Gerrig, R.J., \& Zimbardo, P.G. (2002). Psychology and life (16 ${ }^{\text {th }}$ ed). Boston, MA: Allyn and Bacon.

Ghaemi, N. (2013, May 5). NIMH: A Requiem for DSM - and its critics. Psychology Today. Retrieved from http://www.psychologytoday.com/blog/moodswings/201305/nimh-requiem-dsm-and-its-critics 
Global News. (2013, November 6). What addiction experts are saying about Rob Ford's crack cocaine admission. Global News. Retrieved from http:/globalnews.ca/news/ 950097/what-addiction-experts-are-saying-about-rob-fords-crack-cocaineadmission/

Gobeil, R. (2007). Revalidation of the Security Reclassification Scale for Women (SRSW) (R-191). Ottawa, ON: Correctional Service of Canada, Research Branch.

Goldman, A. (2013, November 5). Rob Ford's "complicated mental health issue" and the stigma of crack. iVillage. Retrieved from http://www.ivillage.ca/health/rob-fordscomplicated-mental-health-issue-and-the-stigma-of-crack

Goldstein, A.L., Flett, G.L., Wekerle, C., \& Wall, A.M. (2009). Personality, child maltreatment, and substance use: Examining correlates of deliberate self-harm among university students. Canadian Journal of Behavioural Science, 41, 241251.

Gollust, S.E., Eisenberg, D., \& Golberstein, E. (2008). Prevalence and correlates of selfinjury among university students. Journal of American College Health, 56, 91-98.

Gordon, A. (2010, December). Research at a glance: Self-injury incidents in CSC institutions over a thirty-month period (R-233). Ottawa, ON: Correctional Service of Canada, Research Branch.

Gordon, A. (2010). Self-injury incidents in CSC institutions over a thirty-month period (R-233). Ottawa, ON: Correctional Service of Canada, Research Branch.

Government of Canada. (2006). The human face of mental health and mental illness in Canada. Ottawa, ON: Minister of Public Works and Government Services Canada.

Grant, B.A., Furlong, A., Hume, L., White, T., \& Doherty, S. (2008). The women offender substance abuse programming: Interim research report (R-171). Ottawa, ON: Correctional Service of Canada, Research Branch.

Gratz, K.L. (2001). Measurement of deliberate self-harm: Preliminary data on the deliberate self harm inventory. Journal of Psychopathology and Behavioral Assessment, 23, 253-263.

Gratz, K.L., \& Gunderson, J.G. (2006). Preliminary data on an acceptance-based emotion regulation group intervention for deliberate self-harm among women with borderline personality disorder. Behavior Therapy, 37, 25-35.

Gratz, K.L., Conrad, S.D., \& Roemer, L. (2002). Risk factors for deliberate self-harm among university students. American Journal of Orthopsychiatry, 72, 128-140. 
Gray, N.S., Hill, C.M.A., Timmons, D., MacCulloch, M.J., \& Snowden, R.J. (2003). Prediction of violence and self-harm in mentally disordered offenders: A prospective study of the efficacy of HCR-20, PCL-R, and psychiatric symptomatology. Journal of Consulting and Clinical Psychology, 71, 443-451.

Graycar, R., \& Wangmann, J. (2007). Redress packages for institutional child abuse: Exploring the Grandview agreement as a case study in 'alternative' dispute resolution. Sydney Law School Legal Studies Research Paper No. 07/05.

Great Britain Parliament Joint Committee on Human Rights. (2004). Deaths in custody: Third report of session 2004-05. Retrieved from http://www.publications. parliament.uk/pa/jt200405/jtselect/jtrights/15/1502.htm

Green, A.H. (1978). Psychiatric treatment of abused children. Journal of American Academy of Child Psychiatry, 17(1978), 356-371.

Groholt, B., Ekeberg, O., Wichstrom, L., \& Haldorsen, T. (2000). Young suicide attempters: A comparison between a clinical and an epidemiological sample. Journal of the American Academy of Child and Adolescent Psychiatry, 39, 868875.

Groves, A. (2004). Blood on the walls: Self-mutilation in prisons. The Australian and New Zealand Journal of Criminology, 37(1), 49-64.

Hacking, I. (1990). The taming of chance. Cambridge, MA: Cambridge University Press.

Hacking, I. (1991). How should we do the history of statistics? In G. Burchell, C. Gordon, \& P. Miller (Eds.), The Foucault effect: Studies in governmentality (pp. 181-195). Chicago, IL: The University of Chicago Press.

Haggerty, K.D. (2001). Making crime count. Toronto, ON: University of Toronto Press.

Haines, J., \& Williams, C.L. (1997). Coping and problem solving of self-mutilators. Journal of Clinical Psychology, 53(2), 177-186.

Haines, J., Williams, C.L., Brain, K.L., \& Wilson, G. (1995). The psychophysiology of self-mutilation. Journal of Abnormal Psychology, 104(3), 471-489.

Hales, H., Davison, S., Misch, P., \& Taylor, P.J. (2003). Young male prisoners in a young offenders' institution: Their contact with suicidal behaviour by others. Journal of Adolescence, 26, 667-685.

Hamilton, J.A., Grant, M., \& Jensvold, M.F. (1996). Sex and treatment of depressions: When does it matter?. In J.A. Hamilton, M. Jensvold, E. Rothblum, \& E. Cole (Eds.), Psychopharmacology of women: Sex, gender and hormonal considerations (pp. 241-260). Washington, DC: American Psychiatric Press. 
Haney, C. (2006a). Mental health issues in long-term solitary and "supermax" confinement. Crime \& Delinquency, 49(1), 124-156.

Haney, C. (2006b). Reforming punishment: Psychological limits to the pains of imprisonment. Washington, DC: American Psychological Association Books.

Haney, C. (2006c). The wages of prison overcrowding: Harmful psychological consequences and dysfunctional correctional reactions. Journal of Law \& Policy, $22,265-293$.

Haney, C. (2012). Prison effects of in the age of mass incarceration. The Prison Journal, $X X(\mathrm{X}), 1-24$.

Hanisch, C. (2000). The personal is political. In B. A. Crow (Ed.), Radical feminism: A documentary reader (pp. 113-116). New York, NY: University Press.

Hannah-Moffat, K. (1995). Feminine fortresses: Woman-centered prisons? The Prison Journal, 75(2), 135-164.

Hannah-Moffat, K. (1999). Moral agent or actuarial subject: Risk and Canadian women's imprisonment. Theoretical Criminology, 3(1), 71-94.

Hannah-Moffat, K. (2000). Re-forming the prisons: Rethinking our ideals. In K. HannahMoffat \& M. Shaw (Eds.), An ideal prison? Critical essays on women's imprisonment in Canada (pp. 30-40). Halifax, NS: Fernwood Publishing.

Hannah-Moffat, K. (2001). Punishment in disguise: Penal governance in Canadian women's prisons. Toronto, ON: University of Toronto Press.

Hannah-Moffat, K. (2004a). Criminogenic need and the transformative risk subject: Hybridizations of risk/need in penality. Punishment and Society, 7, 29-51.

Hannah-Moffat, K. (2004b). Feminine fortresses: Woman-centered prisons? In P. Schram \& B. Koons-Witt (Eds.), Gendered (in)justice: Theory and practice in feminist criminology (pp. 290-317). Long Grove, IL: Waveland Press.

Hannah-Moffat, K. (2004c). Losing ground: Gender, responsibility and parole risk. Social Politics, 11, 363-385.

Hannah-Moffat, K. (2006). Pandora's box: Risk/need and gender-responsive corrections. Criminology \& Public Policy, 5, 183-192.

Hannah-Moffat, K. (2009). Gridlock or mutability: Reconsidering 'gender' and risk assessment. Criminology and Public Policy, 8(1), 221-229.

Hannah-Moffat, K., \& O’Malley, P. (2007). Gendered risks. London, UK: Cavendish Publishing. 
Hannah-Moffat, K., \& Shaw, M. (2001). Taking risks: Incorporating gender and culture into the classification and assessment of federally sentenced women in Canada. Ottawa, ON: Status of Women Canada.

Harris, K. (2012, October 11). Prisoner self-injury on the rise in Canada: Biggest spike among aboriginal women offenders, documents show. $C B C$ News. Retrieved from http://www.cbc.ca/news/politics/prisoner-self-injury-on-the-rise-in-canada1.1208557

Harris, K. (2013, October 23). Suicide attempts, self-harm rising in Canada's prisons: Aboriginal offenders accounts for $45 \%$ of all incidents, ombudsman's report finds. $C B C N e w s$. Retrieved from http://www.cbc.ca/news/politics/suicideattempts-self-harm-rising-in-canada-s-prisons-1.1163978

Hartung, C.M., \& Widiger, T.A. (1998). Gender differences in the diagnosis of mental disorders: Conclusions and controversies of the DSM-IV. Psychological Bulletin, 123(3), 260-278.

Hawkesworth, M. (Ed.) (2006). Reconceptualizing objectivity. In Feminist inquiry From political conviction to methodological innovation (pp. 76-97). Piscataway, NJ: Rutgers University Press.

Hawton, K., Fagg, J., Simkin, S., Bale, E., \& Bond, A. (2000). Deliberate self-harm in adolescents in Oxford, 1985-1995. Journal of Adolescence, 23, 47-55.

Hawton, K., Hall, S., Simkin, S., Bale, L., Bond, A., Codd, S., \& Stewart, A. (2003). Deliberate self-harm in adolescents: A study of characteristics and trends in Oxford, 1990-2000. Journal of Child Psychology and Psychiatry, 44, 1191-1198.

Hawton, K., Rodham, K., Evans, E., \& Weatherall, R. (2002). Deliberate self harm in adolescents: self report survey in schools in England. British Medical Journal, $325,1207-1211$.

Haycock, J. (1989). Manipulation and suicide attempts in jails and prisons. Psychiatric Quarterly, 60(1), 85-98

Hayes, L. M. (1993). Suicidal or manipulative? Does it really matter? Crisis: The Journal of Crisis Intervention and Suicide Prevention, 14, 154-156.

Hayman, S. (2006). Imprisoning our sisters: The new federal women's prisons in Canada. Montreal, QC: McGill Queens University Press.

Heath, N.L., Toste, J. R., Nedecheva, T., \& Charlebois, A. (2008). An examination of nonsuicidal self-injury among college students. Journal of Mental Health Counseling, 30(2), 137-156. 
Heeren, K. (2010). From badness to madness: Penal and medical knowledge in federal women's prison policy. Concordia University. Unpublished master's thesis.

Hekma, G. (2007). Legs apart, voices low: Attitudes toward 'nonmasculine' behaviour among homosexual Men. Sociologie, 3(1), 81-94.

Heney, J. (1990). Report on self-injurious behaviour in Kingston prison for women. Ottawa, ON: Prepared for the Correctional Service of Canada.

Heney, J. (1996). Dying on the inside: Suicide and suicidal feelings among federally incarcerated women. Carleton University. Doctoral dissertation. Retrieved from http://curve.carleton.ca/system/files/theses/24574.pdf

Herpetz, S.C., Dietrich, T.M., Wenning, B., Krings, T., Erberich, S.G., Willmes, K., ... Sass, H. (2001). Evidence of abnormal amygdala functioning in borderline personality disorder: A functional MRI study. Biological Psychiatry, 50(4), 292298.

Hewitt, K. (1997). Mutilating the body: Identity in blood and ink. Bowling Green, OH: Bowling Green State University Popular Press.

Hillbrand, M. (1993). Self-injurious behavior in correctional and noncorrectional psychiatric patients: Prevalence and correlates. Journal of Offender Rehabilitation, 19(3-4), 95-102.

Hillbrand, M., Krystal, J.H., Sharpe, K.S., \& Foster, H.G. (1994). Clinical predictors of self mutilation in hospitalized forensic patients. Journal of Nervous and Mental Disease, 182, 9-13.

Hodgins, S., \& Cote, G. (1990). The prevalence of mental disorders among penitentiary inmates. Canada's Mental Health, 38, 1-5.

Hodgson, S. (2004). Cutting through the silence: A sociological construction of selfinjury. Sociological Inquiry, 74, 162-179.

Hogeveen, B. (2005). 'If we are tough on crime, if we punish crime, then people get the message': Constructing and governing the punishable young offender in Canada during the late 1990s. Punishment and Society, 7(1), 73-89.

Holley, H., \& Arboleda-Florez, J. (1988). Hypernomia and self-destructiveness in penal settings. International Journal of Law and Psychiatry, 11, 167-178.

Holly, S. (2007). Social influence and functions of non-suicidal self-injury in university students. McGill University. Master's thesis. Retrieved from http://digitool.library .mcgill.ca/web client/StreamGate?folder_id=0\&dvs=1387050454778 363 
Howard League for Penal Reform. (1999). Scratching the surface: The hidden problem of self harm in prisons. London, UK: Author.

Howell, E.F., \& Blizard, R.A. (2009). Chronic relational trauma disorder: A new diagnostic scheme for borderline personality and the spectrum of dissociative disorders. In P.F. Dell \& J.A. O’Neil (Eds.), Dissociation and the dissociative disorders: DSM-V and beyond (pp. 495-509). New York, NY: Routledge/Taylor \& Francis Group.

Humber, N., Hayes, A., Senior, J., Fahy, T., \& Shaw, J. (2011). Identifying, monitoring and managing prisoners at risk of self-harm/suicide in England and Wales. Journal of Forensic Psychiatry \& Psychology, 22(1), 22-51.

Hyman, S.E. (2007). Can neuroscience be integrated into the DSM-V? Perspectives, 8 , 725-732.

In-Albon, T., Ruf, C., \& Schmid, M. (2013). Proposed diagnostic criteria for the DSM-5 of Nonsuicidal Self-Injury in female adolescents: Diagnostic and clinical correlates. Psychiatry Journal. Retrieved from http://psycho.unibas.ch/index.php? $\mathrm{eID}=\mathrm{tx} \_$nawsecuredl $\& \mathrm{u}=0 \&$ file $=$ uploads $/ \mathrm{x} 4$ epublication $/ 48157 /$ FINAL.pdf $\& \mathrm{t}=13$ 85833652 \&hash $=17 \mathrm{~d} 4 \mathrm{e} 82 \mathrm{c} 80 \mathrm{fdb} 957515473817 \mathrm{ac} 9 \mathrm{bcd} 8$

Inckle, K. (2007). Writing on the body? Thinking through gendered embodiment and marked flesh. Newcastle, UK: Cambridge Scholars Publishing.

International Society for the Study of Self-injury. (2007). Definitional issues surrounding our understanding of self-injury. Conference proceedings from the annual meeting.

Ireland, J.L., \& Quinn, K. (2007). Officer attitudes towards adult male prisoners who self-harm: Development of an attitudinal measure and investigation of sex differences. Aggressive Behavior, 33(1), 63-72.

Jackson, M., \& Stewart, G. (2009). A flawed compass: A human rights analysis of the roadmap to strengthening public safety. Retrieved from http://www.elizabethfry. $\mathrm{ca} / \mathrm{mwginternal} / \mathrm{de} 5 \mathrm{fs} 23 \mathrm{hu} 73 \mathrm{ds} /$ progress? $\mathrm{id}=\mathrm{VUDxEURmYv}$

Jacobson, C.M., Muehlenkamp, J.J., Miller A.L., \& Turner, B.J. (2008). Psychiatric impairment among adolescents engaging in different types of deliberate selfharm. Journal of Clinical Child \& Adolescent Psychology, 37(2), 363-375.

Jaworski, K. (2003). Suicide and gender: Reading suicide through Butler's notion of performativity. Journal of Australian Studies, 73, 137-146.

Jeglic, E.L., Vanderhoff, H.A., Donovick, P.J. (2005). The function of self-harm behavior in a forensic population. International Journal of Offender Therapy and Comparative Criminology, 49(2), 131-142. 
Jimenez, M.A. (1997). Gender and psychiatry: Psychiatric conceptions of men disorders in women. Affilia, 12(2), 154-175.

Johnstone, L. (1997). Self-injury and the psychiatric response. Feminism \& Psychology, $7(3), 421-426$.

Jolliffe, D., \& Farrington, D.P. (2007). A systematic review of the national and international evidence on the effectiveness of interventions with violent offenders. Ministry of Justice (UK). Retrieved from http://www.crim.cam.ac.uk/people/ academic_research/david_farrington/violmoj.pdf

Justice for Children and Youth. (2011). Submissions on Bill-C10: Youth Criminal Justice Act Amendments. Submitted to the House of Commons Committee on Justice and Human Rights. Retrieved from www.jfcy.org/PDFs/BillC10_Nov2011.pdf

Kalapatapu, R.K., Patil, U., \& Goodman, M.S. (2010). Using the Internet to assess perceptions of patients with borderline personality disorder: what do patients want in the DSM-V? Cyberpsychology, Behavior, and Social Networking, 13(5), 483494.

Kapur, N., Cooper, J., O’Connor, R.C., \& Hawton, K. (2013). Non-suicidal self-injury v. attempted suicide: New diagnosis or false dichotomy? British Journal of Psychiatry, 202, 326-328.

Kaputsa, N.D. (2012). Non-suicidal self-injury and suicide risk assessment, quo vadis DSM-V? Suicidology Online, 2, 1-3.

Kaufman, F. (2002). Searching for justice: An independent review of Nova Scotia's response to reports of institutional abuse. Halifax, NS: Province of Nova Scotia. Retrieved from http://www.novascotia.ca/just/kaufmanreport/fullreport.pdf

Kay, J. (2013, May 21). A crackhead, if that's what he is, cannot be allowed to lead Toronto. The National Post. Retrieved from http:/fullcomment.nationalpost.com/ 2013/05/21/jonathan-kay-a-crackhead-if-thats-what-he-is-cannot-be-allowed-tolead-toronto/

Kaszor, D.H. (2013, December 19). Ashley Smith death ruled a homicide by inquest jury. National Post. http://news.nationalpost.com/2013/12/19/ashley-smith-deathruled-a-homicide-by-inquest-jury/

Kemshall, H. (2002). Effective practice in probation: An example of 'advanced liberal' responsibilization? The Howard Journal, 41(1), 41-58.

Kemshall, H. (2003). Understanding risk in criminal justice. England, UK: Open University Press. 
Kendall, G., \& Wickham, G. (1999). Using Foucault's methods. London, UK: Sage Publications.

Kendall, K. (1994). Therapy behind prison walls: A contradiction in terms? Prison Service Journal, 96, 2-11.

Kendall, K. (2000). Psy-ence fiction: Inventing the mentally-disordered female prisoner. In K. Hannah-Moffat \& M. Shaw (Eds.), An ideal prison? Critical essays on women's imprisonment in Canada (pp. 82-93). Halifax, NS: Fernwood Publishing.

Kendall, K. (2002). Time to think again about cognitive behavioural programmes. In P. Carlen (Ed.,) Women and punishment (pp. 182-198). Collumpton UK: Willan Publishing.

Keniston, J.M. (1913). Self mutilation by the insane. Boston Medical and Surgical Journal, 168, 571-573.

Kenning, A., Cooper, J., Short, V., Shaw, J., Abel, K., \& Chew-Graham, C. (2010). Prison staff and women prisoner's views on self-harm; their implications for service delivery and development: A qualitative study. Criminal Behaviour and Mental Health, 20, 274-284.

Kilby, J. (2001). Carved in skin: Bearing witness to self-harm. In S. Ahmed \& J. Stacey (Eds.), Thinking through the skin (pp. 124-142). New York, NY: Routledge.

Kilty, J.M. (2006). Under the barred umbrella: Is there room for a women-centered selfinjury policy in Canadian corrections? Criminology \& Public Policy, 5, 161-182.

Kilty, J.M. (2008a). Governance through psychiatrization: Seroquel and the new prison order. Radical Psychology, 2(7), 1-24.

Kilty, J.M. (2008b). Resisting confined identities: Women's strategies of coping in prison. Dissertation Abstracts International, A: The Humanities and Social Sciences, 70, 1041-1420.

Kilty, J.M. (2011). On self-injurious behaviour in prison. Journal of Prisoners on Prisons, 20(1), 102-107.

Kilty, J.M. (2012). 'It's like they don't want you to get better': Psy control of women in the carceral context. Feminism \& Psychology, 22(2), 162-182.

Kilty, J.M. (2013, January 14). Protesters hold vigil: Jennifer Kilty, assistant criminology professor at the University of Ottawa discusses the Ashley Smith case and what really happened behind those prison walls. CTV News. Retrieved from http://www.ctvnews.ca/ video?clipId=255275 
Kilty, J.M. (forthcoming). The evolution of feminist research in the criminological enterprise: The Canadian experience. In J.M. Kilty, M. Felices-Luna, \& S.C. Fabian (Eds.), Experiencing qualitative methods: Research practices in action (pp. 10-32). Vancouver, BC: UBC Press.

King, H. (1993). Once upon a text: Hysteria from Hippocrates. In S. Gilman, H. King, R. Porter, G. S. Rousseau, \& E. Showalter (Eds.), Hysteria beyond Freud (pp. 3-90). Berkeley, CA: University of California Press.

Kirchner, T., Forns, M., \& Mohíno, S. (2008). Identifying the risk of deliberate self-harm among young prisoners by means of coping typologies. Suicide and LifeThreatening Behavior, 38(4), 442-448.

Kirk, S., \& Kutchins, H. (1992). The selling of DSM: The rhetoric of science in psychiatry. New York, NY: Aldine de Gruyter.

Kitsuse, J.I., \& Cicourel, A.V. (1963). A note on the uses of official statistics. Social Problems, 11, 131-139.

Klonsky, E.D. (2007). The functions of deliberate self-injury: A review of the evidence. Clinical Psychology Review, 27, 226-239.

Klonsky, E.D., \& Muehlenkamp, J.J. (2007). Self-injury: A research review for the practitioner. Journal of Clinical Psychology: In Session, 63, 1045-1056.

Klonsky, E.D., Oltmanns, T.F., \& Turkheimer, E. (2003). Deliberate self-harm in a nonclinical population: Prevalence and psychological correlates. The American Journal of Psychiatry, 160, 1501-1508.

Kokaliari, E., \& Berzoff, J. (2008). Nonsuicidal self-injury among nonclinical women: Lessons from Foucault. Affilia, 23(2), 259-269.

Konrad, N., Daigle, M., Daniel, A., Dear, G., Frottier, P., Hayes, L., ... Sarchiapone, M. (2007). Preventing suicide in prisons, part I: Recommendations from the international association for suicide prevention task force on suicide in prisons. Journal of Crisis Intervention and Suicide Prevention, 28(3), 113-121.

Kupfer, D.J., Frank, E., \& Phillips, M.L (2012). Major depressive disorder: New clinical, neurobiological, and treatment perspectives. The Lancet, 379(9820), 1045-1055.

Kutchins, H., \& Kirk, S. (1997). Making us crazy: DSM: The psychiatric bible and the creation of mental disorders. New York, NY: Free Press.

Laishes, J. (2002). Mental health strategy for women offenders. Ottawa, ON: Correctional Service of Canada, Women Offender Sector. 
Lane, C. (May 4, 2013). The NIMH withdraws support for DSM-5. Psychology Today. Retrieved from http:/www.psychologytoday.com/blog/side-effects/201305/thenimh-withdraws-support-dsm-5

Lanes, E.C. (2009a). Identification of risk factors for self-injurious behavior in male prisoners. Journal of Forensic Science, 54(3), 692-698.

Lanes, E.C. (2009b). The association of administrative segregation placement and other risk factors with the self-injury-free time of male prisoners. Journal of Offender Rehabilitation, 48, 529-546.

Lanes, E.C. (2011). Are the "worst of the worst" self-injurious prisoners more likely to end up in long-term maximum-security administrative segregation? International Journal of Offender Therapy and Comparative Criminology, 55(7), 1034-1050.

Langer, S.K. (1942). Philosophy in a new keg: A study in the symbolism of reason, rite, and art. New York, NY: New American Library.

Langner, N., Barton, J., McDonough, D., Noël, C., \& Bouchard, F. (2002). Rates of prescribed medication use by women in prison. Forum on Corrections Research, $4(2), 10-13$.

Larner, W. (2000). Neo-liberalism: Policy, ideology, governmentality. Studies in Political Economy, 63, 5-25.

Latessa, E.J. (2004). The challenge of change: Correctional programs and evidence-based practices. Criminology \& Public Policy, 3(4), 547-560.

Latour, B.A. (1987). Science in action: How to follow scientists and engineers through society. Cambridge, MA: Harvard University Press.

Latour, B.A., \& Woolgar, S. (1979). Laboratory life: The social construction of scientific facts. Beverly Hills, CA: Sage.

Latzman, R.D., Gratz, K.L., Young, J., Heiden, L.J., Damon, J.D., \& Hight, T.L. (2010). Self-injurious thoughts and behaviors among youth in an underserved area of the Southern United States: Exploring the moderating roles of gender, racial/ethnic background, and school-level. Journal of Youth Adolescence, 39, 270-280.

Law, G.U., Rostill-Brookes, H., \& Goodman, D. (2009). Public stigma in health and non healthcare students: Attributions, emotions and willingness to help with adolescent self-harm. International Journal of Nursing Studies, 46, 107-118.

Laye-Gindhu, A., \& Schonert-Reichl, K. (2005). Nonsuicidal self-harm among community adolescents: Understanding the "whats" and "whys" of self-harm. Journal of Youth and Adolescence, 34(5), 447-457. 
Leadbeater, B.J., Blatt, S.J., \& Quinlan, D.M. (1995). Gender-linked vulnerabilities to depressive symptoms, stress, and problem behaviours in adolescents. Journal of Research on Adolescence, 5(1), 1-29.

LeBlanc, N. (2012). From 'deviant girl' to 'unempowerable woman': Reconstructing resistance in the case of Ashley Smith. University of Ottawa. Master's thesis. Retrieved from https://www.ruor.uottawa.ca/en/bitstream/handle/ 10393/23598/LeBlanc_Nicole_Marie_2012_thesis.pdf?sequence=1

LeBlanc, N., \& Kilty, J.M. (2012). Ashley Smith (1988-2007): A predictable death. Policy Options, 31-33. Retrieved from http://archive.irpp.org/po/archive/dec12/ leblanc\% 20kilty.pdf

Leibenluft, E., Gardner, D.L., \& Cowdry, R.W. (1987). The inner experience of the borderline self-mutilator. Journal of Personality Disorders, 1(4), 317-324.

Leighton, M.E. (2013, July 21). Facing the figures: Women are more prone to mental illness. Animadvert. Retrieved from http://www.animadvert.co.uk/2013/07/facingfigures-women-prone-mental-illness/

Lewis, M. (2011). Book review: James Paul Gee, An introduction to discourse Analysis: Theory and method. Discourse Studies, 13(6), 819-820.

Liebling, A. (1994). Suicide amongst women prisoners. Howard Journal, 33(1), 1-9.

Liebling, A. (1995). Vulnerability and prison suicide. British Journal of Criminology, 35(2), 173-187.

Linehan, M.M. (1993). Cognitive behavioural treatment of borderline personality disorder. New York, NY: Guilford Press.

Lingel, J. (2008). Delicate monsters: Stigmatized bodies and the rhizomatic promise. Licus, 4, 87-101.

Littlewood, R., \& Lipsedge, M. (1982). Aliens and alienists: Ethnic minorities and psychiatry. Harmondsworth, UK: Penguin.

Lloyd-Richardson, E.E., Perrine, N., Dierker, L., \& Kelley, M.L. (2007). Characteristics and functions of non-suicidal self-injury in a community sample of adolescents. Psychological Medicine, 27, 1183-1192.

Lohner, J., \& Konrad, N. (2007). Risk factors for self-injurious behaviour in custody: Problems of definition and prediction. International Journal of Prisoner Health, $3,135-161$.

Lord, E.A. (2008). The challenges of mentally ill female offenders in prison. Criminal Justice and Behavior, 35, 928-942. 
Luhmann, N. (1993). Deconstruction as second-order observing. New Literary History, 24(4), 763-782.

Lumos Labs Inc. (2013). Your brain is amazing: Learn just how much it can do. Retrieved from http://hcp.lumosity.com/research/neuroscience

MacSwain, M., \& Cheverie, M. (2012). Comparing the mental health treatment and abuse histories of Aboriginal and non-Aboriginal participants of the Methadone Maintenance Treatment Program (MMTP) (RS-12-08). Ottawa, ON: Correctional Service of Canada, Research Branch.

Maden, A., Chamberlain, S., \& Gunn, J. (2000). Deliberate self-harm in sentenced male prisoners in England and Wales: Some ethnic factors. Criminal Behaviour and Mental Health, 10, 199-204.

Mahoney, J. (2013, July 25). Canadian crime rate hits four-decade low, Toronto leads the trend. The Globe and Mail. Retrieved from http://www.theglobeandmail.com/ news/national/ canadas-crime-rate-drops-with-homicides-at-46-yearlow/article13416456/

Mallea, P. (2010). The fear factor: Stephen Harper's tough on crime agenda. Ottawa, ON: Canadian Centre for Policy Alternatives.

Martel, J. (1999). Solitude and cold storage: Women's journeys of endurance in segregation. Edmonton, AB: ACI Communication.

Martel, J. (2001). Telling the story: A study in the segregation of women prisoners. Social Justice, 28(1), 196-215.

Martel, J. (2004). Policing criminological knowledge: The hazards of qualitative research on women in prison. Theoretical Criminology, 8, 157-189.

Martel, J. (2006). To be, one has to be somewhere: Spatio-temporality in prison segregation. British Journal of Criminology, 46, 587-612.

Martinez, M.E. (1980). Manipulative self-injurious behavior in correctional settings: An environmental treatment approach. Journal of Offender Counseling, 4, 275-283.

Martinich, A.P., \& Battiste, B. (Eds.). (2011). Leviathan: Revised edition (Thomas Hobbes). Peterborough, ON: Broadview Press.

Marzano, L., Ciclitira, K., \& Adler, J. (2012). The impact of prison staff responses on self-harming behaviours: Prisoners' perspectives. British Journal of Clinical Psychology, 51(1), 1-15. 
Marzano, L., Fazel, S., Rivlin, A., \& Hawton, K. (2010). Psychiatric disorders in women prisoners who have engaged in near-lethal self-harm: Case-control study. British Journal of Psychiatry, 197, 219-226.

Matheson, F.I., Doherty, S., \& Grant, B.A. (2009). Women offender substance abuse programming \& community reintegration (R-202). Ottawa, ON: Correctional Service of Canada, Research Branch.

Maurutto, P., \& Hannah-Moffat, K. (2006). Assembling risk and the restructuring of penal control. British Journal of Criminology, 46, 438-454.

Maslow, A.H. (1943). A theory of human motivation. Psychological Review, 50, 370396.

McAllister, M. (2003). Multiple meanings of self-harm: A critical review. International Journal of Mental Health Nursing, 12, 177-185.

McAndrew, S., \& Warne, T. (2005). Cutting across boundaries: A case study using feminist praxis to understand the meanings of self-harm. International Journal of Mental Health Nursing, 14, 172-180.

McDonagh, D., Taylor, K., \& Blanchette, K. (2002). Correctional adaptation of Dialectical Behaviour Therapy (DBT) for federally sentenced women. Forum on Corrections Research, 14(2), 36-39.

McDonagh, D., Noël, C., \& Wichmann, C. (2002). Mental health needs of women offenders: Needs analysis for the development of the intensive Intervention Strategy. Forum on Correctional Research, 14, 32-35.

McLane, J. (1996). The voice on the skin: Self-mutilation and Merleau-Ponty's theory of language. Hypatia, 11(4), 107-118.

Medina, M. (2011). Physical and psychic imprisonment and the curative function of selfcutting. Psychoanalytic Psychology, 28(1), 2-12.

Menninger, K.A. (1935). A psychoanalytic study of the significance of self-mutilations. The Psychoanalytic Quarterly, 4, 408-466.

Menninger, K.A. (1938). Man against himself. New York, NY: Harcourt, Brace and Company.

Menzies, R. (2010, June). Navigating the grey zone: Advocacy for psychiatric citizenship in the academy. Paper presented at the Conference for Organizing Resistance Against Psychiatry, Toronto, Ontario. Retrieved from http://individual.utoronto.ca/psychout/panels/menzies_paper.pdf 
Merriam-Webster. (2013). Definition of 'hyster-'. Retrieved from http://www.merriamwebster.com/dictionary/hyster-

Micale, M.S. (1990). Hysteria and its historiography: The future perspective. History of Psychiatry, 1, 33-124.

Mientka, M. (2013, July 21). Why do women suffer from more mental illness? Medical Daily. Retrieved from http://www.medicaldaily.com/why-do-women-suffer-moremental-illness-247882

Miller, D. (2008). The nature, assessment, and treatment of adolescent self-injury. Psychology Quarterly, 23(1), 161-165.

Miller, P., \& Rose, N. (1990). Governing economic life. Economy and Society, 19(1), 131.

Ministry of Justice (UK). (2011). The correctional services accreditation panel report. National Offender Management Service. Retrieved from https:/www.gov.uk/ government/uploads/system/uploads/attachment_data/file/217276/correctionalservices-acc-panel-annual-report-2010-11.pdf

Ministry of Justice (UK). (2013). Safety in custody statistics: England and Wales update to December 2012. Retrieved from https://www.gov.uk/government/uploads/ system/uploads/attachment_data/file/192431/safety-custody-dec-2012.pdf

Moore, D., Burton, K.L., \& Hannah-Moffat, K. (2003). “Get tough” efficiency: Human rights, correctional restructuring and prison privatization in Ontario, Canada. In A. Coyle, A. Campbell, \& R. Neufeld (Eds.), Capitalist punishment: Prison privatization \& human rights (pp. 152-161). Ottawa, ON: Clarity Press.

Moore, D., \& Hannah-Moffat, K. (2005). The liberal veil: Revisiting Canadian penality. In J. Pratt, D. Brown, S. Hallsworth, \& W. Morrison (Eds.), The new punitiveness: Trends, theories and perspectives (pp. 85-100). Portland, OR: Willan Publishing.

Moore, J.P., \& Trevethan, S. (2002). Profiling federally incarcerated First Nations, Métis, and Inuit offenders. Forum on Corrections Research, 14(3), 25-27.

Morash, M. (2009). A great debate over using the Level of Service Inventory-Revised (LSI-R) with women offenders. Criminology \& Public Policy, 8(1), 173-181.

Morin, S. (1999). Federally sentenced Aboriginal women in maximum security: What happened to the promises of 'Creating Choices'? Ottawa, ON: Prepared for the Correctional Service of Canada. 
Motiuk, L.L., \& Serin, R.C. (Eds.) (2000). Compendium on effective correctional programming. Retrieved from http://www.csc-scc.gc.ca/005/008/ compendium/2000/index-eng.shtml

Muehlenkamp, J.J., \& Gutierrez, P.M. (2004). An investigation of differences between self-injurious behavior and suicide attempts in a sample of adolescents. Suicide and Life-Threatening Behavior, 34, 12-23.

Mulholland, A. (2013, December 19). After death deemed homicide, Ashley Smith family calls for new criminal investigation. CTV News. Retrieved from http://www.ctvnews.ca/canada/after-death-deemed-homicide-ashley-smithfamily-calls-for-new-criminal-investigation-1.1600083

Mullins-Sweatt, S.N., Lengel, G.J., \& Grant, D.M. (2012). Non-suicidal self-injury: The contribution of general personality functioning. Personality and Mental Health, $7(1), 56-68$.

Mullins, P., \& MacDonald, S.F. (2012). Offender substance use patterns - Aboriginal and non-Aboriginal offenders (RS-12-10). Ottawa, ON: Correctional Service of Canada, Research Branch.

Murphy, J.G. (2004). Two cheers for vindictiveness. Punishment \& Society, 2(2), 131143.

Nestler, E.J., \& Hyman, S.E. (2010). Animal models of neuropsychiatric disorders. Nature Neuroscience, 13, 1161-1169.

Newmeyer, F. (1998). Language form and language function. Cambridge, MA: MIT Press.

Nguyen, M.T. (2011). The biopower of beauty: Humanitarian imperialisms and global feminisms in an age of terror. Signs: Journal of Women in Culture and Society, 26(2), 359-383.

Nixon, M.K., Cloutier, P.F., \& Aggarwal, S. (2002). Affect regulation and addictive aspects of repetitive self-injury in hospitalized adolescents. Journal of the American Academy of Child and Adolescent Psychiatry, 41, 1333-1341.

Nixon, M.K., Cloutier, P., \& Jansson, S.M. (2008). Nonsuicidal self-harm in youth: A population based survey. Canadian Medical Association Journal, 178(3), 306-12.

Nock, M.K. (2010). Self-injury. Annual Review of Clinical Psychology, 6, 339-363.

Nock, M.K., \& Prinstein, M.J. (2004). A functional approach to the assessment of selfmutilative behaviour. Journal of Consulting and Clinical Psychology, 72, 885890. 
Nolan, A. (2012). Emerging research results: Outcomes for offender employment programs: The impact of CORCAN participation (ERR-12-5). Ottawa, ON: Correctional Service of Canada, Research Branch.

O’Keefe, M.L. (2008). Administration segregation from within: A corrections perspective. The Prison Journal, 88(1), 123-143.

O'Keefe, M.L., \& Schnell, M.J. (2007). Offenders with mental illness in the correctional system. Mental Health Issues in the Criminal Justice System, 45(1-2), 81-104.

O'Malley, P. (1996). Risk and responsibility. In A. Osborne, T. Barry, \& N. Rose (Eds.), Foucault and political reason (pp. 189-208). London UK: UCL Press.

O’Malley, P. (1999). Volatile and contradictory punishment. Theoretical Criminology, $3(2), 175-196$.

O’Malley, P. (2009). Risk, crime and prudentialism revisited. Legal Studies Research Paper, Sydney Law School. Retrieved from http://ssrn.com/abstract=1492477

Odelius, C.B., \& Ramklint, M. (2013). Clinical utility of proposed non-suicidal selfinjury diagnosis - A pilot study. Nordic Journal of Psychiatry, 1-6.

Office of the Correctional Investigator. (2006). Annual report of the Office of the Correctional Investigator, 2005-2006. Ottawa, ON: Author.

Office of the Correctional Investigator. (2008a). A preventable death. Ottawa, ON: Author.

Office of the Correctional Investigator. (2008b). Annual report of the Office of the Correctional Investigator, 2007-2008. Ottawa, ON: Author.

Office of the Correctional Investigator. (2009a). Annual report of the Office of the Correctional Investigator, 2008-2009. Ottawa, ON: Author.

Office of the Correctional Investigator. (2009b). Initial assessment of the Correctional Service of Canada's (CSC) response to the OCI's deaths in custody study, a preventable death. Ottawa, ON: Author.

Office of the Correctional Investigator. (2010a). Annual report of the Office of the Correctional Investigator, 2009-2010. Ottawa, ON: Author.

Office of the Correctional Investigator. (2010b). Final assessment: Correctional Service of Canada's response to deaths in custody. Ottawa, ON: Author.

Office of the Correctional Investigator. (2011). Annual report of the Office of the Correctional Investigator, 2010-2011. Ottawa, ON: Author. 
Office of the Correctional Investigator. (2012a). Annual report of the Office of the Correctional Investigator, 2011-2012. Ottawa, ON: Author.

Office of the Correctional Investigator. (2012b). Spirit matters: Aboriginal people and the Corrections and Conditional Release Act. Ottawa, ON: Author.

Office of the Correctional Investigator. (2013a, September 16). 39 ${ }^{\text {th }}$ Report to Parliament: Summary of issues and challenges in the management of prison selfinjury. Retrieved from http://www.oci-bec.gc.ca/cnt/comm/presentations/ presentationsAR-RA1112Info-eng.aspx

Office of the Correctional Investigator. (2013b). Risky business: An investigation of the treatment and management of chronic self-injury among federally sentenced women. Ottawa, ON: Author.

Office of the Correctional Investigator. (2013c). Annual report of the Office of the Correctional Investigator, 2012-2013. Ottawa, ON: Author.

Ogloff, J.R.P., Davis, M.R., Rivers, G., \& Ross, S. (2007). The identification of mental disorders in the criminal justice system. Criminal Research Council Consultancy. Victorian Institute of Forensic Mental Health, Monash University.

Ogloff, J.R.P., Roesch, R., \& Hart, S.D. (1994). Mental health services in jails and prisons: Legal, clinical, and policy issues. Law \& Psychology, 18, 109-136.

Ogrodnik, I. (2013, October 8). Artist aims to raise awareness by depicting mental health illnesses as monsters. Global News. Retrieved from http://globalnews.ca/news/ 889201/artist-aims-to-raise-awareness-by-depicting-mental-health-illnesses-asmonsters/

Ombudsman and Child and Youth Advocate. (2008). The Ashley Smith Report. Retrieved from http://www.gnb.ca/0073/PDF/AshleySmith-e.pdf

Onwuegbuzie, A.J., \& Leech, N.L. (2005). On becoming a pragmatic researcher: The importance of combining quantitative and qualitative research methodologies. International Journal of Social Research Methodology, 8(5), 375-387.

Osberg, D. (2010). Knowledge is not made for understanding; It is made for cutting. An International Journal of Complexity and Education, 7(2), pp. iii-viii.

Palmer, E.J., \& Connelly, R. (2005). Depression, hopelessness and suicide ideation among vulnerable prisoners. Criminal Behaviour and Mental Health, 15(3), 164170 .

Paris, J., Silk, K.R., Gunderson, J., Links, P.S., \& Zanarini, M. (2009). Formal rebuttal: The case for retaining borderline personality disorder as a psychiatric diagnosis. Personality and Mental Health, 3, 96-100. 
Parole Board of Canada. (2013). Policy manual: Volume 1 no. 29. Retrieved from http://www.pbc-clcc.gc.ca/infocntr/policym/polman-eng.shtml

Pate, K. (2013, November 3). The death of Ashley Smith: Prisons can't handle the mentally ill. The Globe and Mail. Retrieved from http://www.theglobeandmail. com/globe-debate/the-death-of-ashley-smith-prisons-cant-handle-the-mentallyill/article1216011/

Pavlich, G. (2000). Critique and radical discourses on crime. Aldershot, UK: Ashgate

Pembroke, L.R. (Ed.). (1994). Self-harm: Perspectives from personal experience. London, UK: Survivors Speak Out.

Penfold, S., \& Walker, G. (1984). Women and the psychiatric paradox. Milton Keynes, England: Open University Press.

Perkel, C. (2013a, October 16). Ashley Smith inquest: Gaps persist in managing mentally ill prisoner. CTV News. Retrieved from http://www.ctvnews.ca/canada/ashleysmith-inquest-gaps-persist-in-managing-mentally-ill-prisoners-1.1499019

Perkel, C. (2013b, October 16). Don't bother with costly recommendations, prison official tells Ashley Smith inquest jurors. The Globe and Mail. Retrieved from http://www.theglobeandmail.com/news/national/dont-bother-with-costlyrecommendations-prison-official-tells-ashley-smith-inquestjurors/article14895815/

Perry, A., \& Gilbody, S. (2009). Detecting and predicting self-harm behaviour in prisoners: a prospective psychometric analysis of three instruments. Social Psychiatry and Psychiatric Epidemiology, 44(1), 853-861.

Peters, Y. (2003). Federally sentenced women with mental disabilities: A dark corner in Canadian human rights. Toronto, ON: DisAbled Women's Action Network.

Piché, J. (2011). “Going public": Accessing data, contesting information blockades. Canadian Journal of Law and Society, 26(3), 635-643.

Piché, J. (2012). Accessing the state of imprisonment in Canada: Information barriers and negotiation strategies. In M. Larsen \& K. Walby (Eds.), Brokering access:

Politics, power, and freedom of information in Canada (pp. 234-260). Vancouver, BC: UBC Press.

Pickering, W.S.F., \& Walford, G. (2000). Durkheim's suicide: A century of research and debate. New York, NY: Routledge.

Pitts, V.L. (1998). 'Reclaiming' the female body: Embodied identity work, resistance and the grotesque. Body \& Society, 4(3), 67-84. 
Pitts, V.L. (1999). Body modification, self-mutilation and agency in media accounts of a subculture. Body \& Society, 5(2-3), 291-303.

Plener, P.L., \& Fegert, J.M. (2012). Non-suicidal self-injury: State of the art perspective of a proposed new syndrome for DSM V. Child and Adolescent Psychiatry and Mental Health, 6(9), 1-2.

Podovoll, E.M. (1969). Self-mutilation within a hospital setting: A study of identity and social compliance. British Journal of Medical Psychology, 42, 213-221.

Pollack, S. (2000a). Dependency discourse as social control. In K. Hannah-Moffat \& M. Shaw (Eds.), An ideal prison? Critical essays on women's imprisonment in Canada (pp. 72-81). Halifax, NS: Fernwood Publishing.

Pollack, S. (2000b). Reconceptualizing women's agency and empowerment: Challenges to self esteem discourse and women's lawbreaking. Women and Criminal Justice, 12(1), 75-89.

Pollack, S. (2005). Taming the shrew: Regulating prisoners through women-centered mental health programming. Critical Criminology, 13, 71-87.

Pollack, S. (2006). Therapeutic programming as a regulatory practice in women's prisons. In E. Comack \& G. Balfour (Eds.), Criminalizing women (pp. 236-249). Halifax, NS: Fernwood Publishing.

Pollack, S. (2008). Locked in, locked out: Imprisoning women in the shrinking and punitive welfare state. Retrieved from http://www.efryottawa.com/ documents/Lockedin Lockedout-SPollockresearchreport.pdf

Pollack, S. (2012). An imprisoning gaze: Practices of gendered, racialized and epistemic violence. International Review of Victimology, 1-12.

Porter, T.M. (1995). Trust in numbers: The pursuit of objectivity in science and public life. Princeton, NJ: Princeton University Press.

Potgieter, C. (2006). Masculine bodies, feminine symbols: Challenging gendered identities or compulsory femininity? Agenda, 67, 116-127.

Power, J. (2010, February). Research at a glance: Self-injurious behaviour: A review of the literature and implications for corrections (R-216). Ottawa, ON: Correctional Service of Canada, Research Branch.

Power, J. (2010, March). Research at a glance: Assessment, intervention and prevention of self-injurious behaviour in correctional environments (R-220). Ottawa, ON: Correctional Service of Canada, Research Branch. 
Power, J. (2010, May). Research at a glance: A comparative review of the suicide and self-injury investigative reports in a Canadian federal correctional population (R221). Ottawa, ON: Correctional Service of Canada, Research Branch.

Power, J. (2010a, July). Emerging research results: Preliminary results from the women's self-injurious behavior study (ERR-10-1). Ottawa, ON: Correctional Service of Canada, Research Branch.

Power, J. (2010b, July). Research at a glance: A qualitative study of self-injurious behaviour in women offenders (R-225). Ottawa, ON: Correctional Service of Canada, Research Branch.

Power, J. (2011). Non-suicidal self-Injury in federally sentenced women: Prevalence, nature, motivations, and pathways. Carleton University. Unpublished doctoral dissertation.

Power, J. (2011, June). Research at a glance: Correlates and trajectories to self-injurious behaviour in federally sentenced women (R-245). Ottawa, ON: Correctional Service of Canada, Research Branch.

Power, J. (2011, August). Research at a glance: Correlates and trajectories to selfinjurious behaviour in federally sentenced men (R-250). Ottawa, ON: Correctional Service of Canada, Research Branch.

Power, J. (2012, May). Research at a glance: A qualitative study of self-injurious behaviour in male offenders (R-269). Ottawa, ON: Correctional Service of Canada, Research Branch.

Power, J. (2012a, November). Research at a glance: A replication study of self-injury incidents in CSC institutions over a thirty-month period (R-293). Ottawa, ON: Correctional Service of Canada.

Power, J. (2012b, November). Research at a glance: Self-injurious behaviour in male offenders: A multi-method investigation (R-270). Ottawa, ON: Correctional Service of Canada.

Power, J., Beaudette, J., Usher, A. (2012). A qualitative study of self-injurious behaviour in male offenders (R-269). Ottawa, ON: Correctional Service of Canada, Research Branch.

Power, J., \& Brown, S. (2010). Self-injurious behaviour: A review of the literature and implications for corrections (R-216). Ottawa, ON: Correctional Service of Canada, Research Branch.

Power, J., Brown, S., \& Usher, A. (2013a). Non-suicidal self-injury in women offenders: Motivations, emotions, and precipitating events. International Journal of Forensic Mental Health, 12, 192-204. 
Power, J., Brown, S., \& Usher, A. (2013b). Prevalence and incidence of nonsuicidal selfinjury among federally sentenced women in Canada. Criminal Justice and Behaviour, 40(3), 302-320.

Power, J., Gordon, A., Sapers, J., \& Beaudette, J. (2012). A replication study of selfinjury incidents in CSC institutions over a thirty-month period (R-293). Ottawa, ON: Correctional Service of Canada.

Power, J., \& Riley, D. (2010). A comparative review of suicide and self-injury investigative reports in a Canadian federal correctional population (R-221). Ottawa, ON: Correctional Service of Canada, Research Branch.

Power, J., \& Smith, H.P. (forthcoming). Gendered-pathways to prisoner self-injurious behavior: Themes of convergence and divergence. Submitted to Journal of Offender Rehabilitation.

Power, J., \& Usher, A. (2010). A qualitative study of self-injurious behaviour in women offenders (R-225). Ottawa, ON: Correctional Service of Canada, Research Branch.

Power, J., \& Usher, A. (2010, October). Research review: The difference between suicide attempts and non-suicidal self-injury (RR-10-02). Ottawa, ON: Correctional Service of Canada, Research Branch.

Power, J., \& Usher, A. (2011a). A descriptive analysis of self-injurious behaviour in federally sentenced women (R-251). Ottawa, ON: Correctional Service of Canada, Research Branch.

Power, J., \& Usher, A. (2011b). Correlates and trajectories to self-injurious behaviour in federally sentenced men (R-250). Ottawa, ON: Correctional Service of Canada, Research Branch.

Power, J., \& Usher, A. (2011c). Correlates and trajectories to self-injurious behaviour in federally sentenced women (R-245). Ottawa, ON: Correctional Service of Canada, Research Branch.

Power, J., \& Usher, A. (2011d). Self-injurious behaviour in federally sentenced women: An archival study (R-249). Ottawa, ON: Correctional Service of Canada, Research Branch.

Power, J., \& Usher, A. (2011, July). Emerging research results: Preliminary results from the men's self-injurious behaviour study (ERR-11-1). Ottawa, ON: Correctional Service of Canada, Research Branch.

Power, J., Usher, A., \& Beaudette, J. (2012). Self-injurious behaviour in male offenders: A multi-method investigation (R-270). Ottawa, ON: Correctional Service of Canada. 
Pratt, J. (2000). Emotive and ostentatious punishment: Its decline and resurgence in modern society. Punishment \& Society, 2(4), 417-439.

Prison Justice. (2008, September 7). Criminalizing mental illness: The new disaster in the prison system. Retrieved from http:/www.prisonjustice.ca/downloads/ MentalHealthBehindBars.pdf

Public Health Agency of Canada. (2012, January 12). Mental health promotion. Retrieved from http://www.phac-aspc.gc.ca/mh-sm/mhp-psm/

Public Safety Canada. (2009). Corrections and conditional release statistical overview. Ottawa, ON: Public Works and Government Services Canada.

Public Safety Canada. (2012). Corrections and conditional release statistical overview. Ottawa, ON: Public Works and Government Services Canada.

Public Safety Canada. (2013, August 19). Safe Streets and Communities Act: Increasing offender accountability. Retrieved from http://www.publicsafety.gc.ca/ cnt/nws/nws-rlss/2012/20120613-1-eng.aspx

Purvis, T., \& Hunt, A. (1993). Discourse, ideology, discourse, ideology, discourse, ideology... British Journal of Sociology, 44(3), 473-499.

Radloff, L.S. (1977). The CES-D scale: A self-report depression scale for research in the general population. Applied Psychological Measurement, 1, 385-401.

Raimundo, A. (2013, November 20). Rob Ford and I? Mental Health x Design. Retrieved from http://mentalhealthxdesign.com/headlines/rob-ford-and-i.html

Rettinger, J. (1998). A recidivism follow-up study to investigate risk and need within a sample of provincially sentenced women. Carleton University. Doctoral dissertation. Retrieved from http://curve.carleton.ca/system/files/theses/25234.pdf

Rhodes, L. (1998). Panoptical intimacies. Public Culture, 10(2), 285-311.

Rhodes, L. (2010). Dreaming of psychiatric citizenship: A case study of supermax confinement. In B. Good, M. Fischer, S. Willen, \& M. DelVecchio (Eds.), $A$ reader in medical anthropology: Theoretical trajectories, emergent realities (pp. 181-198). Malden, MA: Wiley-Blackwell.

Richard, B. (2008). A report of the New Brunswick Ombudsman and Child and Youth Advocate on the services provided to a youth involved in the youth criminal justice system. Fredericton, NB: Office of the Ombudsman and Child and Youth Advocate. Retrieved from http://www.gnb.ca/0073/PDF/AshleySmith-e.pdf 
Ring, J. (2013). Incorrigible while incarcerated: Topic modeling mainstream Canadian news depictions of Ashley Smith. Carleton University. Unpublished master's thesis.

Rivera, M. (2010). Segregation is our prison within the prison: Operational examination of long-term segregation and segregation placements of inmates with mental health concerns in the Correctional Service of Canada. Ottawa, ON: Prepared for the Correctional Service of Canada.

Robert, D., Frigon, S., \& Belzile, R. (2007). Women, the embodiment of health and carceral space. International Journal of Prisoner Health, 3(3), 176-188.

Robertson, M., \& Walter, G. (2013). Ethics and mental health: The patient, profession and community. Boca Raton, FL: Taylor \& Francis Group.

Rodham, K., Hawton, K., \& Evans, E. (2004). Reasons for deliberate self-harm: Comparison of self-poisoners and self-cutters in a community sample of adolescents. Journal of the American Academy of Child and Adolescent Psychiatry, 43, 80-87.

Roland, M.J., Van den Bree, M., Ferriter, M., \& Taylor, P.J. (2010). Childhood risk factors for offending before first psychiatric admission for people with schizophrenia: A case-control Study of high security hospital admissions. Behavioural Sciences \& the Law, 28, 351-365.

Rose, N. (1985). Psychological complex: Psychology, politics and society in England. London, UK: Routledge and Kegan Paul.

Rose, N. (1990). Governing the soul: The shaping of the private self. New York, NY: Routledge.

Rose, N. (1991). Governing by numbers: Figuring out democracy. Accounting, Organizations and Society, 16(7), 673-692.

Rose, N. (1992). Of madness itself: Histoire de la folie and the object of psychiatric history. In A. Still \& I. Velody (Eds.), Rewriting the history of madness: Studies in Foucault's histoire de la folie (pp. 142-149). New York, NY: Routledge.

Rose, N. (1996a). Governing 'advanced' liberal democracies. In A. Barry, T. Osbourne, $\&$ N. Rose (Eds.), Foucault and political reason: Liberalism, neo-liberalism and rationalities of government (pp. 37-63). London, UK: UCL Press.

Rose, N. (1996b). Inventing our selves: Psychology, power and personhood. New York, NY: Cambridge University Press.

Rose, N. (1998). Governing risky individuals: The role of psychiatry in new regimes of control. Psychiatry, Psychology and Law, 5(2), 177-195. 
Rose, N. (1999). Powers of freedom: Reframing political thought. Cambridge, MA: Cambridge University Press.

Rose, N. (2000a). Government and control. British Journal of Criminology, 40, 321-339.

Rose, N. (2000b). The biology of culpability: Pathological identity and crime control in a biological culture. Theoretical Criminology 4(1), 5-34.

Rose, N. (2001). Normality and pathology in a biological age. Outlines, 1, 19-33.

Rose, N. (2003). Neurochemical selves. Society, 41(1), 46-59.

Rose, N. (2005). In search of certainty: Risk management in a biological age. Journal of Public Mental Health, 4(3), 14-22.

Rose, N. (2006). Disorders without borders? The expanding scope of psychiatric practice. BioSocieties, 1(4), 465-484.

Rose, N. (2007a). Beyond medicalization. The Lancet, 369(9562), 700-702.

Rose, N. (2007b). Molecular biopolitics, somatic ethics and the spirit of biocapital. Social Theory and Health, 5(1), 3-29.

Rose, N. (2007c). Pharmacogenomics in psychiatry: Social and ethical aspects. Psychiatry, 6(2), 80-82.

Rose, N. (2008a). Psychology as a social science. Subjectivity, 25, 446-462.

Rose, N. (2008b). Race, risk and medicine in the age of "your own personal genome". BioSocieties, 3(4), 425-441.

Rose, N. (2010). Screen and intervene: Governing risky brains. History of the Human Sciences, 23(1), 79-105.

Rose, N. (2013). The human sciences in a biological age. Theory, Culture and Society, $30(1), 3-34$.

Rosen, L.W., \& Thomas, M.A. (1984). Treatment technique for chronic wrist cutters. Journal of Behavior Therapy and Experimental Psychiatry, 15(1), 33-36.

Rosen, P.M., \& Walsh, B.W. (1989). Patterns of contagion in self-mutilation epidemics. American Journal of Psychiatry, 146, 656-658.

Rosenthal, R.J., Rinzler, C., Wallsh, R., \& Klauser, E. (1972). Wrist-cutting syndrome: The meaning of a gesture. American Journal of Psychiatry, 128(11), 1363-1368. 
Ross, R.R., \& McKay, H.B. (1976). A study of institutional treatment programs. International Journal of Offender Therapy and Comparative Criminology, 20, 165-173.

Ross, R.R., \& McKay, H.B. (1979). Self-mutilation. Lexington, MA: Lexington Books.

Ross, R.R., McKay, H.B., Palmer, W., \& Kenny, C. (1978). Self-mutilation in adolescent female offenders. Canadian Journal of Criminology, 20, 375-392.

Ross, S., \& Heath, N. (2002). A study of the frequency of self-mutilation in a community sample of adolescents. Journal of Youth and Adolescence, 31(1), 67-77.

Rotenberg, C.R. (2012a, May 5). Different words, same punishment: Unpacking the linguistic strategies of correctional policies that respond to self-injury in federal women's prisons. Unpublished paper presented at the second National Critical Perspectives: Criminology and Social Justice conference, Ottawa, Ontario, Carleton University.

Rotenberg, C.R. (2012b, May 30). Euphemisms for punishment: Terminology choices for solitary confinement practices in Canadian federal women's prisons. Unpublished paper presented at the Canadian Sociological Association annual conference, Congress of the Humanities and Social Sciences, Waterloo, Ontario, Wilfrid Laurier University.

Rotenberg, C.R. (forthcoming). On 'self-injury' and its inherent connection to gender. In J. Siltanen \& A. Doucet (Eds.), Gender relations in Canada ( $2^{\text {nd }}$ ed.).

Royal College of Psychiatrists. (2010). Self-harm, suicide and risk: Helping people who self harm. Retrieved from http://www.rcpsych.ac.uk/files/pdfversion/CR158.pdf.

Rusch, N., Angermeyer, M.C., \& Corrigan, P.W. (2005). Mental illness stigma: Concepts, consequences, and initiatives to reduce stigma. European Psychiatry, 20, 529-539.

Russ, M.J., Roth, S.D., Kakuma, T., Harrison, K., \& Hull, J.W. (1994). Pain perception in self-injurious borderline patients: Naloxone effects. Biological Psychiatry, 35, 207-209.

Ryan, E.G. (2013, July 18). Women definitely less sane than men, claim men. Jezebel. Retrieved from http://jezebel.com/women-definitely-less-sane-than-men-claimmen-825000458

Ryan, K., Heath, M.A., Fischer, L., \& Young, E.L. (2008). Superficial self-harm: Perceptions of young women who hurt themselves. Journal of Mental Health Counseling, 30, 237-254. 
Sapouna, M., Bisset, C., \& Conlong, A.M. (2011). What works to reduce reoffending: A summary of the evidence. Scottish Government, Justice Analytical Services. Retrieved from www.scotland.gov.uk/Resource/0038/00385880.pdf

Sedgewick, P. (1987). Psychopolitics. London, UK: Pluto.

Selby, E.A., Bender, T.W., Gordon, K.H., Nock, M.K., Joiner, T E. (2011). Non-suicidal self-injury (NSSI) disorder: A preliminary study. Personality Disorders: Theory, Research, and Treatment, 3(2), 167-175.

Senior, J., Hayes, A.J., Pratt, D., Thomas, S.D., Fahy, T., Leese, M. ... Shaw, J.J. (2007). The identification and management of suicide risk in local prisons. Journal of Forensic Psychiatry \& Psychology, 18(3), 368-380.

Serras, A., Saules, K.K., Cranford, J.A., \& Eisenberg, D. (2010). Self-injury, substance use, and associated risk factors in a multi-campus probability of college students. Psychology of Addictive Behaviors, 24(1), 119-128.

Shaffer, D., \& Jacobson, C. (2009). Proposal to the DSM-V childhood disorder and mood disorder work groups to include non-suicidal self-injury (NSSI) as a DSM-V disorder. Retrieved from http://www.dsm5.org/Proposed\%20Revision \%20Attachments/ APA\%20DSM-5\%20NSSI\%20Proposal.pdf

Shalev, S. (2011). Solitary confinement and supermax prisons: A human rights and ethical analysis. Journal of Forensic Psychology Practice, 11, 151-183.

Shantz, L., Kilty, J.M., \& Frigon, S. (2009). Echoes of imprisonment: Women's experiences of 'successful (re)integration'. Canadian Journal of Law and Society, 24(1), 85-106.

Sharkey, L. (2010). Does overcrowding in prisons exacerbate the risk of suicide among women prisoners? Howard Journal of Criminal Justice, 49(2), 111-124.

Shaw, C., \& Proctor, G. (2005). Women at the margins: A critique of the diagnosis of borderline personality disorder. Feminism \& Psychology, 15(4), 483-490.

Shaw, M., \& Hannah-Moffat, K. (2004). How cognitive skills forgot about gender and diversity. In G. Mair (Ed.), What matters in probation (pp. 90-121). Cullompton, UK: Willan Publishing.

Shaw, S. (2002). Shifting conversations on girls' and women's self-injury: An analysis of the clinical literature in historical context. Feminism \& Psychology, 5, 191-219.

Shea, G. (1999). Redress programs relating to institutional child abuse in Canada. Ottawa, ON: Law Commission of Canada. 
Shea, S. (1993). Personality characteristics of self-mutilating male prisoners. Journal of Clinical Psychology, 49(4), 576-585.

Short, V., Cooper, J., Shaw, J., Kenning, C., Abel, K., \& Chew-Graham, C. (2009). Custody vs care: Attitudes of prison staff to self-harm in women prisoners - a qualitative study. Journal of Forensic Psychiatry \& Psychology, 20, 408-426.

Showalter, E. (1985) The female malady: Women, madness and English culture, 18301890. London, UK: Virago.

Silliker, A. (2009, March 20). More resources needed for mentally ill offenders. Capital News. Retrieved from http://www4.carleton.ca/jmc/cnews/20032009/n2.shtml

Simeon, D., Stanley, B., Frances, A., Mann, J.J., Winchel, R., \& Stanley, M. (1992). Selfmutilation in personality disorders: Psychological and biological correlates. American Journal of Psychiatry, 149(2), 221-226.

Simon, J. (1988). The ideological effects of actuarial practices. Law \& Society Review, 22(4), 771-799.

Simon, J. (2000). The 'society of captives' in the era of hyper-incarceration. Theoretical Criminology, 4(3), 285-308.

Singh, I., \& Rose, N. (2009). Biomarkers in Psychiatry. Nature, 406, 202-207.

Sirdifield, C., Gojkovic, D., Brooker, C., \& Ferriter, M. (2009). A systematic review of research on the epidemiology of mental health disorder in prison populations: A summary of findings. Journal of Forensic Psychiatry \& Psychology, 20(S1), 78101.

Skegg, K., Nada-Raja, S., Dickson, N., Paul, C., \& Williams, S. (2003). Sexual orientation and self-harm in men and women. American Journal of Psychiatry, 160(3), 541-546.

Sloane, B. (1973). Suicide attempts in the District of Columbia prison system. Omega: Journal of Death and Dying, 4(1), 37-50.

Sly, A., \& Taylor, K. (2003). Preliminary evaluation of dialectical behaviour therapy within a women's structured living environment (R-145). Ottawa, ON: Correctional Service of Canada, Research Branch.

Sly, A., \& Taylor, K. (2005). Evaluation of psychosocial rehabilitation within the women's structured living environments (R-163). Ottawa, ON: Correctional Service of Canada, Research Branch. 
Smith, H.P. \& Kaminski, R.J. (2010). Inmate self-injurious behaviours: Distinguishing characteristics within a retrospective study. Criminal Justice and Behaviour, 37, 81-96.

Smith, H.P., \& Kaminski, R.J. (2011). Self-injurious behaviors in state prisons: Findings from a national survey. Criminal Justice and Behaviour, 38(1), 26-41.

Smith, P.S. (2006). The effects of solitary confinement on prison inmates: A brief history and review of the literature. Crime and Justice, 34(1), 441-528.

Smith, P., Cullen, F.T., \& Latessa, E.J. (2009). Can 14,737 women be wrong? A metaanalysis of the LSI-R and recidivism for female offenders. Criminology \& Public Policy, 8(1), 183-208.

Solano, R., Fernandez-Aranda, F., Aitken, A., López, C., \& Vallejo, J. (2005). Selfinjurious behaviour in people with eating disorders. European Eating Disorders Review, 13, 3-10.

Statistics Canada. (2011). National Household Survey: Aboriginal peoples in Canada: First Nations people, Métis and Inuit. Retrieved from http://www12.statcan.gc.ca/ nhs-enm/2011/as-sa/99-011-x/99-011-x2011001-eng.cfm

Statistics Canada. (2013). Executive summary. Retrieved from http://www.statcan.gc.ca/ pub/87-542-x/2011001/section/summary-resume-eng.htm

Stein, D.J., Phillips, K.A., Bolton, D., Fulford, K.W.M., Sadler, J.Z., \& Kendler, K.S. (2010). What is a mental/psychiatric disorder? From DSM-IV to DSM-V. Psychological Medicine, 40(11), 1759-1765.

Stewart, L., \& Wilton, G., (2011). Validation of the Computerised Mental Health Intake Screening System (CoMHISS) in a federal male offender population (R-244). Ottawa, ON: Correctional Service of Canada, Research Branch.

Stewart, L., Hamilton, E., Wilton, G., Cousineau, C., \& Varette, S. (2009). An examination of the effectiveness of Tupiq: A culturally specific program for Inuit sex offenders (R-213). Ottawa, ON: Correctional Service of Canada, Research Branch.

Stewart, L., Harris, A., Wilton, A., Archambault, K., Cousineau, C., Varette, S., \& Power, J. (2010). An initial report on the results of the pilot of the Computerized Mental Health Intake Screening System (CoMHISS) (R-218). Ottawa, ON: Correctional Service of Canada, Research Branch.

Stewart, L., Wilton, G., \& Cousineau, C. (2012) Federally sentenced offenders with mental disorders: Correctional outcomes and correctional response. (R-268). Ottawa, ON: Correctional Service of Canada, Research Branch. 
Stone, L. (2013, February 7). CSC closing country's only prison program for inmates who self-harm. iPolitics. Retrieved from http://www.ipolitics.ca/2013/02/07/cscclosing-countrys-only-prison-program-for-inmates-who-self-harm/

Straker, G. (2006). Signing with a scar: Understanding self-harm. Psychoanalytic Dialogues: The International Journal of Relational Perspectives, 16(2), 93-112.

Stys, Y., Dunbar, L., Axford, M., \& Grant, B.A. (2012). Federal offenders with a high Reintegration Potential (RP): Characteristics and community outcomes (R-260). Ottawa, ON: Correctional Service of Canada, Research Branch.

Sue, D., Sue, D.W., Sue, D., \& Sue, S. (2011). Understanding abnormal behavior $\left(10^{\text {th }}\right.$ ed.). Belmont, CA: Wadsworth.

Sussman, J.E., Lymer, G.K, McKirdy, J., Moorhead, T.W., Maniega, S.M., Job, D. ... McIntosh, A.M. (2009). White matter abnormalities in bipolar disorder and schizophrenia detected using diffusion tensor magnetic resonance imaging. Bipolar Disorders, 11, 11-18.

Suyemoto, K. L. (1998). The functions of self-mutilation. Clinical Psychology Review, 18(5), 531-554.

Suyemoto, K.L., \& MacDonald, M.L. (1995). Self-cutting in female adolescents. Psychotherapy, 32(1), 162-171.

Sykes, G. (1958a [2007]). The defects of total power. In The society of captives: A study of maximum security prison (pp. 40-62). Princeton, NJ: Princeton University Press.

Sykes, G. (1958b[2007]). The pains of imprisonment. In The society of captives: A study of maximum security prison (pp. 63-83). Princeton, NJ: Princeton University Press.

Szasz, T. (1961). The myth of mental illness. New York, NY: Harper \& Row.

Taiminen, T.J., Kallio-Soukainen, K., Nokso-Koivisto, H., Kaljonen, A., \& Helenius, H. (1998). Contagion of deliberate self-harm among adolescent inpatients. Journal of the American Academy of Child and Adolescent Psychiatry, 37, 211-217.

Taylor, B. (2003). Exploring the perspectives of men who self-harm. Learning in Health and Social Care, 2, 83-91.

Taylor, K.N., \& Blanchette, K. (2009). The women are not wrong: It is the approach that is debatable. Criminology \& Public Policy, 8(1), 221-229. 
The Associated Press. (2012, September 25). Isolation, mental health probed in Ashley Smith jail death. CBC News. Retrieved from http://www.cbc.ca/news/canada/ toronto/isolation-mental-health-probed-in-ashley-smith-jail-death-1.1194367

The Canadian Press. (2013, July 25). Canada's crime rate lowest since 1972. CBC News. Retrieved from http://www.cbc.ca/news/canada/canada-s-crime-rate-lowest-since1972-1.1334090

The Guardian. (2013, November 15). Nadezhda Tolokonnikova of Pussy Riot's prison letters to Slavoj Žižek. Retrieved from http://www.theguardian.com/music/ 2013/nov/15/pussy-riot-nadezhda-tolokonnikova-slavoj-zizek

Thomas, J., Leaf, M., Kazmierczak, S., \& Stone, J. (2006). Self-injury in correctional settings: 'Pathology' of prisons or of prisoners? Reaction essay. Criminology \& Public Policy, 5, 193-202.

Thompson, J., McConnell, A., \& Paquin-Marseille, L. (2011). The Security Reclassification Scale (SRSW) for shorter review periods among federal women offenders (RS-12-05). Ottawa, ON: Correctional Service Canada, Research Branch.

Timmermans, S., \& Gabe, J. (2002). Introduction: Connecting criminology and sociology of health and illness. Sociology of Health and Illness, 24(5), 501-516.

Toch, H. (1975). Men in crisis: Human breakdowns in prison. Chicago, IL: Aldine.

Toch, H. (2008). Punitiveness as "behavior management”. Criminal Justice and Behavior, 35(3), 388-397.

Tonks, C.M., Rack, P.H., \& Rose, M.J. (1968). Attempted suicide and the menstrual cycle. Journal of Psychosomatic Research, 11, 319-323.

Treasury Board of Canada Secretariat. (2011a). Managing for wellness - Disability Management handbook for managers in the federal public service. Retrieved from http://www.tbs-sct.gc.ca/hrh/dmi-igi/wds-mst/disability-incapacite10eng.asp

Treasury Board of Canada Secretariat. (2011b). Part IV: Leave provisions. Retrieved from http://www.tbs-sct.gc.ca/pubs_pol/hrpubs/coll_agre/pa/pa04eng.asp\#toc288724986

Treasury Board of Canada Secretariat (2012). Guide to integrated risk management. Retrieved from http://www.tbs-sct.gc.ca/tbs-sct/rm-gr/guides/girm-ggirtb-eng.asp

Trevethan, S. Crutcher, N., Moore, J.P., \& Mileto, J. (2007). Pê Sâkâstêw centre: An indepth examination of a healing lodge for federally incarcerated offenders (R170). Ottawa, ON: Correctional Service of Canada, Research Branch. 
Tyrer, P. (2009). Why borderline personality disorder is neither borderline nor a personality disorder. Personality and Mental Health, 3/2, 86-95.

Union of Canadian Correctional Officers. (2008a). A rush to judgment: A report on the death in custody of Ashley Smith, an inmate at Grand Valley Institution for Women. Retrieved from http://www.ucco-sacc.csn.qc.ca/Documents/UCCOSACC/National/documents/ Issues/GVI/Full\%20Report $\% 20$ $\% 20 \mathrm{~A} \% 20 \mathrm{Rush} \% 20$ to\%20Judgment.pdf

Union of Canadian Correctional Officers. (2008b, October 23). A rush to judgment: union releases report into death of federal inmate Ashley Smith. Retrieved from http://www.ucco-sacc.csn.qc.ca/Documents/UCCO-SACC/Ontario/documents/ ARushToJudgment/UCCO_SACC_CSN_PressRelease_oct23_2008.pdf

University of Ottawa. (n.d.). Co-operative programs: Anthropology and sociology. Retrieved from http://www.coop.uottawa.ca/en/en-prospective-students/enprogram-spec. asp? $\mathrm{ID}=48$

University of Ottawa. (2013b). Field placement directory, Criminology Department 2013-2014. Retrieved from http://socialsciences.uottawa.ca/sites/default/files/ public/ crm/eng/documents/placement-directory.pdf

University of Quebec en Outaouais. (2013a, September 4). Criminologie clinique à l'UQO: Des stages avec les Services correctionnels canadiens. Retrieved from http://uqo.ca/nouvelles/5422

University of Quebec en Outaouais. (2013b, September). Nouveau à l'UQO: Un programme en criminologie clinique dès septembre 2013. Retrieved from http://www4.uqo.ca/savoir/articles/a0213.html

Usher, A. (2011, August). Research at a glance: A descriptive analysis of self-injurious behaviour in federally sentenced women (R-251). Ottawa, ON: Correctional Service of Canada, Research Branch.

Usher, A., \& Power, J. (2011, August). Research at a glance: Self-injurious behaviour in federally sentenced women: An archival study (R-249). Ottawa, ON: Correctional Service of Canada, Research Branch.

Usher, A., \& Stewart, L. (2011). The effectiveness of correctional programs with diverse offenders: A meta-analytic study (R-246). Ottawa, ON: Correctional Service of Canada, Research Branch.

Usher, A., Power, J., \& Wilton, G. (2010). Assessment, intervention, and prevention of self-injurious behaviour in correctional environments (R-220). Ottawa, ON:

Correctional Service of Canada, Research Branch. 
Ussher, J.M. (1991). Women's madness: Misogyny or mental illness? Hempstead, NY: Harvester Wheatsheaf.

Ussher, J.M. (2004). Premenstrual syndrome and self-policing: Ruptures in self-silencing leading to increased self-surveillance and blaming of the body. Social Theory \& Health, 2, 254-272.

Ussher, J.M. (2006). Managing the monstrous feminine: Regulating the reproductive body. London, UK: Routledge.

Ussher, J.M. (2008). Challenging the positioning of premenstrual change as PMS: The impact of a psychological intervention on women's self-policing. Qualitative Research in Psychology, 5(1), 33-44.

Ussher, J.M. (2010). Are we medicalizing women's misery? A Critical review of women's higher rates of reported depression. Feminism \& Psychology, 20(1), 935.

Ussher, J.M. (2011). The madness of women: Myth and experience. London, UK: Routledge.

Ussher, J.M. (2013a). Diagnosing difficult women and pathologizing femininity: Gender bias in psychiatric nosology. Feminism \& Psychology, 23(1), 63-69.

Ussher, J.M. (2013b). DSM-5 helps perpetuate the myth of women's madness. The Conversation. Retrieved from http://theconversation.com/dsm-5-helps-perpetuatethe-myth-of-womens-madness- 14508

Valverde, M. (2008). Beyond Discipline and Punish: Foucault's challenge to criminology. Carceral Notebooks, 4, 201-223.

van der Kolk, B. (1996). Complexity of adaptation to trauma. In A. van der Kolk, A.McFarlane, \& L. Weisaeth (Eds.), Traumatic stress: The effects of overwhelming experience on mind, body and society. New York, NY: Guilford Press.

van Dijk, T.A. (2009). Discourse studies: A multidisciplinary introduction. Thousand Oaks, CA: Sage Publications.

Verbrugge, P., \& Blanchette, K. (2002). The validity of the Custody Rating Scale for the initial security classification of Aboriginal women. Forum on Corrections Research, 14(3), 10-12.

Völlm, B.A., \& Dolan, M. C. (2001). Self-harm among UK female prisoners: A crosssectional study. Journal of Forensic Psychiatry \& Psychology, 20(5), 741-751. 
von Hirsch, A. (1990). Proportionality in the philosophy of punishment: From "why punish?" to "how much?" Criminal Law Forum, 1(2), 259-290.

Walklate, S. (2007). Understanding criminology: Current theoretical debates $\left(3^{\text {rd }}\right.$ ed.). New York, NY: Open University Press.

Walsh, B.W., \& Rosen, P. (1985). Self-mutilation and contagion: An empirical test. American Journal of Psychiatry, 142, 119-120.

Walsh, B.W., \& Rosen, P. (1988). Self-mutilation: Theory, research and treatment. New York, NY: Guilford Press.

Warm, A., Murray, C., \& Fox, J. (2003). Why do people self-harm? Psychology, Health \& Medicine, $8(1), 71-79$.

Warner, A. (1998). Implementing choices at regional facilities: Program proposals for women offenders with special needs. Ottawa, ON: Prepared for the Correctional Service of Canada, Women Offender Sector.

Wasserman, J. (2013). The press and Ashley Smith: Power, knowledge, and the production of truth about a death in custody. Saint Mary's University. Master's thesis. Retrieved from http://library2.smu.ca/bitstream/handle/01/25058/ wasserman_jody_masters_2013.pdf?sequence $=1$

Webley, P., \& Lea, S. (1997). Topic 3: Path analysis. University of Exeter. Retrieved from http://people.exeter.ac.uk/SEGLea/multvar2/pathanal.html

Webster, C.M., \& Doob, A.N. (2004a). Classification without validity or equity: An empirical examination of the Custody Rating Scale for federally sentenced women offenders in Canada. Canadian Journal of Criminology and Criminal Justice, 46, 395-421.

Webster, C.M., \& Doob, A.N. (2004b). 'Taking down the straw man' or building a house of straw? Validity, equity, and the Custody Rating Scale. Canadian Journal of Criminology and Criminal Justice, 46, 631-638.

Wesley, M. (2012). Marginalized: The Aboriginal women's experience in federal corrections (APC 33 CA). Ottawa, ON: Prepared for Public Safety Canada, Aboriginal Corrections.

Western Australia Department of Justice. (2002). Report of performance. Perth, WA: Author.

Weston, G. (2012, June 20). Public sector sick days cost $\$ 1 \mathrm{~B}$ a year. CBC News. http://www.cbc.ca/news/politics/public-sector-sick-days-cost-1b-a-year1.1170309 
Whitlock, J., Eckenrode, J., \& Silverman, D. (2006). Self-injurious behaviors in a college population. Pediatrics, 117(6), 1939-1948.

Wichmann, C., \& Nafekh, M. (2001). Moderating segregation as a means to reintegration. Forum on Corrections Research, 13, 31-33.

Wichmann, C., \& Taylor, K. (2004). Federally sentenced women in administrative segregation: A descriptive analysis (R-158). Ottawa, ON: Correctional Service of Canada, Research Branch.

Wichmann, C., Serin, R.C., \& Abracen, J. (2002). Women offenders who engage in selfharm: A comparative investigation (R-123). Ottawa, ON: Correctional Service of Canada, Research Branch.

Wicks, R.J. (1974). Suicidal manipulators in the penal setting. Chittv's Law Journal, 22, 249-250.

Widiger, T., \& Weissman, M. (1991). Epidemiology of borderline personality disorder. Hospital and Community Psychiatry, 42, 1015-1019.

Wilkinson, P., \& Goodyer, I. (2010). Non-suicidal self-injury. European Child and Adolescent Psychiatry, 20(2), 103-108.

Wilson, H. (1942). Suicidal compromises: Psychopathy and rehabilitation. British Medical Journal, 1, 9-12.

Wilton, G. (2010, October). Emerging research results: Validating the computerized mental health intake screening system (ERR-10-1). Ottawa, ON: Correctional Service of Canada, Research Branch.

Wilton, G., \& Stewart, L. (2012). Outcomes for offenders with concurrent substance abuse and mental health disorders. (R-277). Ottawa ON: Correctional Service of Canada, Research Branch.

Wodak, R., \& Meyer, M. (Eds). (2009). Critical discourse analysis: History, agenda, theory, and methodology. In Methods for critical discourse analysis (pp. 1-33). Thousand Oaks, CA: Sage Publications.

World Congress on Probation. (2013, May 29). Mr. Frank Porporino offers his perspective as keynote speaker. Directorate General Justice of the European Commission. Retrieved from http://www.worldcongressonprobation.org/news/ $381 / 987$

Yeager, M. (2008). Getting the usual treatment: Censorship and the marginalization of convict criminology. Contemporary Justice Review, 11, 413-425. 
Yeomans, F.E., Levy, K.N., \& Clarkin, J.F. (2009). The case for borderline personality disorder: Commenting on Tyrer and Paris et al. Personality and Mental Health, 3, $110-115$

Young, J. (1986). The failure of criminology: The need for a radical realism. In R. Matthews, \& J. Young (Eds.), Confronting crime. London, UK: Sage.

Young, J. (2011). The criminological imagination. Cambridge, UK: Polity Press.

Young, M.H., Justice, J.V., \& Erdberg, P. (2006). Risk of harm: Inmates who harm themselves while in prison psychiatric treatment. Journal of Forensic Sciences, 51(1), 156-162.

Zetterqvist, M., Lundh, L.G., Dahlström, Ö., \& Svedin, C.G. (2013). Prevalence and function of non-suicidal self-injury in a community sample of adolescents, using suggested DSM-5 criteria for a potential NSSI disorder. Journal of Abnormal Child Psychology, 41, 759-773.

Zinger, I. (2004). Actuarial risk assessment and human rights: A commentary. Canadian Journal of Criminology and Criminal Justice, 46(5), 607-620.

Zinger, I. (2012a, October). Correctional Investigator finds measures to manage prison self-injury inadequate. Government of Canada News Release. Retrieved from www.theioi.org/downloads/4gi08/

Zinger, I. (2012b, June 18). Mental health in federal corrections. Presentation presented at the CASHRA Annual Conference, Winnipeg, Manitoba. Retrieved from http://www.oci-bec.gc.ca/cnt/comm/pdf/presentations/presentations20120618eng.pdf

Zlomislic, D. (2010, November 12). Ashley Smith's requests for help ignored. The Star. Retrieved from http://www.falconers.ca/documents/TheStar. AshleySmithsrequestsfor helpignored.Nov122010.pdf

Zuk, G. H. (1960). Psychodynamic implications of self-injury in defective children and adults. Journal of Clinical Psychology, 16, 58-60. 


\section{Appendix A}

Email exchange between myself and a representative of the $\mathrm{RB}$ indicating status of textual material as public knowledge.

\section{From: (NHQ-AC) Sent: Monday, August 27, 2012 9:29 AM}

To: Rotenberg Cristine

Subject: RE: Newly Available CSC Research Summaries/ Sommaires de recherche du SCC nouvellement disponibles

Good morning,

There are issues around accessibility standards on the web and also the cleaning up of all gov't sites.

From: Rotenberg Cristine

Sent: Monday, August 27, 2012 8:02 AM

To: (NHQ-AC)

Subject: RE: Newly Available CSC Research Summaries/ Sommaires de recherche du SCC nouvellement disponibles

$\mathrm{Hi}$

Oh alright, makes sense. Is there a reason why the full reports aren't being published on the Research website?

\section{Cristine}

From: (NHQ-AC) Sent: Friday, August 24, 2012 3:38 PM

To: Rotenberg Cristine

Subject: RE: Newly Available CSC Research Summaries/ Sommaires de recherche du SCC nouvellement disponibles

Hi Cristine,

I can see how this gets a little confusing when we are distributing the Research at a Glance but not having the reports posted on the web. However, you are able to cite the findings from the reports as they are in 
fact publicly available by contacting the Research Branch at the address referred to on the Research at a Glance - as you have done.

Please let me know if you have any other questions concerning this.

Thank you,

Knowledge Mobilization Unit | Unité de mobilisation des connaissances

Research Branch | Direction de la recherche

Correctional Service of Canada | Service correctionel du Canada

340 Laurier Avenue West, Ottawa, ON K1A OP9

Telephone | Téléphone

Email | Courriel:

Facsimile | Télécopieur

Government of Canada | Gouvernement du Canada

From: Rotenberg Cristine $\quad$ Sent: Thursday, August 23, 2012 8:38 AM

To: (NHQ-AC)

Subject: RE: Newly Available CSC Research Summaries/ Sommaires de recherche du SCC nouvellement disponibles

Good morning

I was wondering if you could tell me whether any recent publications published by the Research Branch are safe to cite (i.e., the ones you have sent me over the past month). Given that they are not published on the public website as of now (or are there plans to do so in the near future?), is it safe to cite research findings in documents that may be communicated to the regions or otherwise become public?

No research would be 'reproduced' or copied.

Thank you in advance for your assistance,

\section{Cristine Rotenberg}




\section{Appendix B}

Comprehensive roll-up of textual material.

\begin{tabular}{|c|c|c|c|}
\hline $\begin{array}{c}\text { Report } \\
\text { \# }\end{array}$ & Author, year & Title, Other document indicators & $\begin{array}{c}\text { \# of } \\
\text { pages }\end{array}$ \\
\hline 1 & $\begin{array}{l}\text { Power, J., Beaudette, J., \& } \\
\text { Usher, A. (2012) } \\
\text { Power, J. (2012, May) }\end{array}$ & $\begin{array}{l}\text { A Qualitative Study of Self-Injurious Behaviour } \\
\left.\text { in Male Offenders (N } \mathrm{N}^{\circ} \mathrm{R}-269\right) \\
\text { Research Branch (RB) Publication } \\
\text { [Acquired directly from RB] } \\
\text { Research at a glance: A Qualitative Study of } \\
\text { Self-Injurious Behaviour in Male Offenders (N } \\
\text { R-269) } \\
\text { http://www.csc-scc.gc.ca/005/008/092/005008- } \\
\text { 0269-eng.pdf }\end{array}$ & 55 \\
\hline 2 & $\begin{array}{l}\text { Power, J., Gordon, A., } \\
\text { Sapers, J., \& Beaudette, J. } \\
\text { (2012) } \\
\text { Power, J. (November 2012) }\end{array}$ & $\begin{array}{l}\text { A Replication Study of Self-injury Incidents in } \\
\text { CSC Institutions Over a Thirty-month Period } \\
\left(N^{\circ} \mathrm{R}-293\right) \\
\text { Research Branch (RB) Publication } \\
\text { [Acquired directly from RB] } \\
\text { Research at a glance: A Replication Study of } \\
\text { Self-injury Incidents in CSC Institutions Over a } \\
\left.\text { Thirty-month Period (N }{ }^{\circ} \mathrm{R}-293\right) \\
\text { http://www.csc-scc.gc.ca/005/008/092/005008- } \\
\text { 0293-eng.pdf }\end{array}$ & 50 \\
\hline 3 & $\begin{array}{l}\text { Power, J., Usher, A., \& } \\
\text { Beaudette, J. (2012) } \\
\text { Power, J. (November 2012) }\end{array}$ & $\begin{array}{l}\text { Self-injurious Behaviour in Male Offenders: A } \\
\left.\text { Multi-method Investigation ( }{ }^{\circ} \mathrm{R}-270\right) \\
\text { Research Branch (RB) Publication } \\
\text { [Acquired directly from RB] } \\
\text { Research at a glance: Self-injurious } \\
\text { Behaviour in Male Offenders: A Multi-method } \\
\left.\text { Investigation (N }{ }^{\circ} \mathrm{R}-270\right) \\
\text { http://www.csc-scc.gc.ca/research/005008- } \\
\text { 0270-eng.shtml }\end{array}$ & 63 \\
\hline 4 & $\begin{array}{l}\text { Power, J., \& Usher, A. } \\
\text { (2011) }\end{array}$ & $\begin{array}{l}\text { A Descriptive Analysis of Self-injurious } \\
\text { Behaviour in Federally Sentenced Women }\left(\mathrm{N}^{\circ}\right. \\
\text { R-251) } \\
\text { RB Publication } \\
\text { [Acquired directly from RB] } \\
\text { Research at a glance: A Descriptive Analysis } \\
\text { of Self-injurious Behaviour in Federally } \\
\text { Sentenced Women }\left(\mathrm{N}^{\circ} \mathrm{R}-251\right) \\
\text { http://www.csc-scc.gc.ca/005/008/092/005008- } \\
\text { 0251-eng.pdf }\end{array}$ & 54 \\
\hline 5 & $\begin{array}{l}\text { Power, J., \& Usher, A. } \\
\text { (2011) }\end{array}$ & $\begin{array}{l}\text { Correlates and Trajectories to Self-Injurious } \\
\text { Behaviour in Federally Sentenced Men (N }{ }^{\circ} \text { - } \\
250) \\
\text { RB Publication } \\
\text { [Acquired directly from RB] }\end{array}$ & 80 \\
\hline
\end{tabular}


Cutting Knowledge

\begin{tabular}{|c|c|c|c|}
\hline & $\begin{array}{r}\text { Power, J. (2011, } \\
\text { August) } \\
\text { Power, J., \& Usher, } \\
\text { A. (2011, July) }\end{array}$ & $\begin{array}{l}\text { Research at a glance: Correlates and } \\
\text { Trajectories to Self-Injurious Behaviour in } \\
\left.\text { Federally Sentenced Men (N } \mathrm{N}^{\circ}-250\right) \\
\text { http://www.csc-scc.gc.ca/005/008/092/005008- } \\
\text { 0250-eng.pdf } \\
\text { Emerging research results: Preliminary } \\
\text { Results from the Men's Self-Injurious } \\
\text { Behaviour Study (N }{ }^{\circ} \text { ERR-11-1) } \\
\text { http://www.csc-scc.gc.ca/005/008/092/err11-1- } \\
\text { eng.pdf }\end{array}$ & 1 \\
\hline 6 & $\begin{array}{l}\begin{array}{l}\text { Power, J., \& Usher, A. } \\
\text { (2011) } \\
\text { Power, J. (2011, } \\
\text { June) }\end{array} \\
\text { Power, J. (2010, } \\
\text { July) }\end{array}$ & $\begin{array}{l}\text { Correlates and Trajectories to Self-Injurious } \\
\text { Behaviour in Federally Sentenced Women }\left(\mathrm{N}^{\circ}\right. \\
\text { R-245) } \\
\text { RB Publication } \\
\text { [Acquired directly from RB] } \\
\text { Research at a glance: Correlates and } \\
\text { Trajectories to Self-Injurious Behaviour in } \\
\left.\text { Federally Sentenced Women ( } \mathrm{N}^{\circ} \mathrm{R}-245\right) \\
\text { http://www.csc-scc.gc.ca/005/008/092/005008- } \\
\text { 0245-eng.pdf } \\
\text { Emerging research results: Preliminary } \\
\text { Results from the Women's Self-injurious } \\
\text { Behaviour Study (N } \mathrm{N}^{\circ} \text { ERR-10-1) } \\
\text { http://www.csc-scc.gc.ca/005/008/092/005008- } \\
\text { err10-1-eng.pdf }\end{array}$ & 65 \\
\hline 7 & $\begin{array}{l}\text { Power, J., \& Usher, A. } \\
\text { (2011) } \\
\text { Usher, A., \& Power, } \\
\text { J. (2011, August) }\end{array}$ & $\begin{array}{l}\text { Self-Injurious Behaviour in Federally } \\
\text { Sentenced Women: An Archival Study ( } \mathrm{N}^{\circ} \mathrm{R}- \\
\text { 249) } \\
\text { RB Publication } \\
\text { [Acquired directly from RB] } \\
\text { Research at a glance: Self-Injurious } \\
\text { Behaviour in Federally Sentenced Women: An } \\
\text { Archival Study (N }{ }^{\circ} \text { R-249) } \\
\text { http://www.csc-scc.gc.ca/005/008/092/005008- } \\
\text { 0249-eng.pdf }\end{array}$ & 76 \\
\hline n/a & $\begin{array}{l}\text { Power, J., \& Usher, } \\
\text { A. (2010, October) }\end{array}$ & $\begin{array}{l}\text { Research review: The Difference Between } \\
\text { Suicide Attempts and Non-Suicidal Self-Injury } \\
\left(\mathrm{N}^{\circ} \mathrm{RR}-10-02\right) \\
\text { http://www.csc-scc.gc.ca/005/008/092/rr10-02- } \\
\text { eng.pdf }\end{array}$ & 1 \\
\hline 8 & $\begin{array}{r}\text { Gordon, A. (2010, } \\
\text { December) }\end{array}$ & $\begin{array}{l}\text { Self-Injury Incidents in CSC Institutions Over a } \\
\left.\text { Thirty-Month Period ( } \mathrm{N}^{\circ} \mathrm{R}-233\right) \\
\text { RB Publication } \\
\text { http://www.csc-scc.gc.ca/005/008/092/005008- } \\
\text { 0233-01-eng.pdf } \\
\text { Research at a glance: Self-Injury Incidents in } \\
\text { CSC Institutions Over a Thirty-Month Period } \\
\left(\mathrm{N}^{\circ} \mathrm{R}-233\right) \text { http://www.csc- } \\
\text { scc.gc.ca/005/008/092/005008-0233-eng.pdf }\end{array}$ & 52 \\
\hline
\end{tabular}




\begin{tabular}{|c|c|c|c|}
\hline 9 & $\begin{array}{l}\text { Power, J., \& Riley, D. } \\
\text { (2010) }\end{array}$ & $\begin{array}{l}\text { A Comparative Review of Suicide and Self- } \\
\text { Injury Investigative Reports in a Canadian } \\
\text { Federal Correctional Population (N R-221) } \\
\text { RB Publication } \\
\text { http://www.csc-scc.gc.ca/005/008/092/005008- } \\
\text { 0221-01-eng.pdf } \\
\\
\text { Research at a glance: A Comparative Review } \\
\text { of the Suicide and Self-Injury Investigative } \\
\text { Reports in a Canadian Federal Correctional } \\
\left.\text { Population (N } \mathrm{N}^{\circ} \mathrm{R}-221\right) \\
\text { http://www.csc-scc.gc.ca/005/008/092/005008- } \\
\text { 0221-eng.pdf }\end{array}$ & 56 \\
\hline 10 & $\begin{array}{l}\text { Power, J., \& Usher, A. } \\
\text { (2010) }\end{array}$ & $\begin{array}{l}\text { A Qualitative Study of Self-Injurious Behaviour } \\
\text { in Women Offenders (N }{ }^{\circ} \text { R-225) } \\
\text { RB Publication } \\
\text { http://www.csc-scc.gc.ca/005/008/092/r225- } \\
\text { eng.pdf } \\
\text { Research at a glance: A Qualitative Study of } \\
\text { Self-Injurious Behaviour in Women Offenders } \\
\left(\mathrm{N}^{\circ} \mathrm{R}-225\right) \\
\text { http://www.csc-scc.gc.ca/recherche/005008- } \\
\text { 0225-eng.shtml }\end{array}$ & 55 \\
\hline 11 & $\begin{array}{l}\text { Usher, A., Power, J., \& } \\
\text { Wilton, G. (2010) }\end{array}$ & $\begin{array}{l}\text { Assessment, Intervention and Prevention of } \\
\text { Self-Injurious Behaviour in Correctional } \\
\left.\text { Environments (N } \mathrm{N}^{\circ} \mathrm{R}-220\right) \\
\text { RB Publication } \\
\text { http://www.csc-scc.gc.ca/005/008/092/005008- } \\
\text { 0220-01-eng.pdf } \\
\\
\text { Research at a glance: Assessment, } \\
\text { Intervention and Prevention of Self-Injurious } \\
\text { Behaviour in Correctional Environments } \\
\left.\text { (N } \mathrm{N}^{\circ} \mathrm{R}-220\right) \\
\text { http://www.csc-scc.gc.ca/005/008/092/005008- } \\
\text { 0220-eng.pdf }\end{array}$ & 58 \\
\hline 12 & $\begin{array}{l}\text { Power, J., \& Brown, S. } \\
\text { (2010) }\end{array}$ & $\begin{array}{l}\text { Self-Injurious Behaviour: A Review of the } \\
\text { Literature and Implications for Corrections }\left(\mathrm{N}^{\circ}\right. \\
\text { R-216) } \\
\text { RB Publication } \\
\text { http://www.csc-scc.gc.ca/005/008/092/005008- } \\
\text { 0216-01-eng.pdf } \\
\\
\text { Research at a glance: Self-Injurious } \\
\text { Behaviour: A Review of the Literature and } \\
\left.\text { Implications for Corrections ( }{ }^{\circ} \mathrm{R}-216\right) \\
\text { http://www.csc-scc.gc.ca/005/008/092/005008- } \\
\text { 0216-eng.pdf }\end{array}$ & 67 \\
\hline
\end{tabular}


Cutting Knowledge

\begin{tabular}{|c|c|c|c|}
\hline 13 & $\begin{array}{l}\text { Wichmann, A., Serin, R.C., } \\
\text { \& Abracen, J. (2002) }\end{array}$ & $\begin{array}{l}\text { Women Offenders who Engage in Self-harm: } \\
\text { A Comparative Investigation (N }{ }^{\circ} \text { R-123) } \\
\text { RB Publication } \\
\text { http://www.csc- } \\
\text { scc.gc.ca/research/092/r123_e.pdf }\end{array}$ & 26 \\
\hline 14 & Heney, J. (1990) & $\begin{array}{l}\text { Report on Self-Injurious Behaviour in the } \\
\text { Kingston Prison for Women } \\
\text { Externally contracted report submitted and } \\
\text { published under Women's Corrections, Mental } \\
\text { Health and the Intensive Intervention Strategy } \\
\text { http://www.csc- } \\
\text { scc.gc.ca/text/prgrm/fsw/selfinjuries/toce- } \\
\text { eng.shtml }\end{array}$ & 40 \\
\hline
\end{tabular}

Textual Material Page Count

\begin{tabular}{|l|c|}
\hline Pre-2010 (2 full reports) & 66 \\
\hline Post-2010 (12 full reports) & 731 \\
\hline Post-2010 (15 one-pagers) & 15 \\
\hline \hline
\end{tabular}

Total pages published by the CSC with 'self-injury' or 'self-harm' in the title and 812 referenced on the CSC's public website 